\title{
Recovery from severe perinatal hypoxia;ischemia: studies of pathophysiology and treatment in the fetal sheep
}

Citation for published version (APA):

Roelfsema, V. (2006). Recovery from severe perinatal hypoxia;ischemia: studies of pathophysiology and treatment in the fetal sheep. [Doctoral Thesis, Maastricht University].

https://doi.org/10.26481/dis.20060420vr

Document status and date:

Published: 01/01/2006

DOI:

10.26481/dis.20060420vr

Document Version:

Publisher's PDF, also known as Version of record

\section{Please check the document version of this publication:}

- A submitted manuscript is the version of the article upon submission and before peer-review. There can be important differences between the submitted version and the official published version of record.

People interested in the research are advised to contact the author for the final version of the publication, or visit the DOI to the publisher's website.

- The final author version and the galley proof are versions of the publication after peer review.

- The final published version features the final layout of the paper including the volume, issue and page numbers.

Link to publication

\footnotetext{
General rights rights.

- You may freely distribute the URL identifying the publication in the public portal. please follow below link for the End User Agreement:

www.umlib.nl/taverne-license

Take down policy

If you believe that this document breaches copyright please contact us at:

repository@maastrichtuniversity.nl

providing details and we will investigate your claim.
}

Copyright and moral rights for the publications made accessible in the public portal are retained by the authors and/or other copyright owners and it is a condition of accessing publications that users recognise and abide by the legal requirements associated with these

- Users may download and print one copy of any publication from the public portal for the purpose of private study or research.

- You may not further distribute the material or use it for any profit-making activity or commercial gain

If the publication is distributed under the terms of Article $25 \mathrm{fa}$ of the Dutch Copyright Act, indicated by the "Taverne" license above, 


\section{RECOVERY FROM SEVERE PERINATAL HYPOXIA-ISCHAEMIA}

Studies of pathophysiology and treatment in the fetal sheep

Vincent Roelfsema 
(1) Vincent Roelfsema 2006

Design and Layout

D\&L graphics

www.dlgraphics.nl

Printed by

Schrijen-Lipperz-Huntjens

ISBN-10: $90-8590-011-5$

ISBN-13: 978-90-8590-011-5 


\title{
RECOVERY FROM SEVERE PERINATAL HYPOXIA-ISCHAEMIA Studies of pathophysiology and treatment in the fetal sheep
}

\author{
ter verkrijging van de graad van doctor \\ aan de Universiteit Maastricht, \\ op gezag van de Rector Magnificus, Prof. Mr. G.P.M.F Mols, \\ ingevolge het besluit van het College van Decanen, \\ in het openbaar te verdedigen op \\ donderdag 20 april 2006 om 14.00 uur \\ door
}

\section{Vincent Roelfsema}

Geboren op 9 september 1976

te Eindhowen 


\section{Promotores}

Professor Dr. E. Heineman, FRACS

Professor De. J. de Haan, FRCOG

\section{Co-promotores}

Assoclate professor A.J. Gunn, MBChB, PhD, University of Auckland, New Zealand Associate professon L. Bennet, PhD, University of Auckland, New Zealand

\section{Beoordelingscommissie:}

Prof. Dr. C.E. Blanco (voonzitter)

Prof. Dr. D.A. Giussani [University of Cambridge, UK)

Prot. Dr. J.G. Nijhuis

Prof. De. H.A.l. Struijker Boudier

Prof. Dr. J.S.H. Vles 


\section{CONTENTS}

Chapter 1. General introduction

Chapter 2. Cortisol and ACTH responses to severe asphyxia in preterm fetal sheep Experimental Physiology. 2005; 00(4): 545.55.

Chapter 3. Improved neural outcome with cerebral hypothermia after asphyxial injury is associated with suppression of EEG transients during recovery. Submitted.

Chapter 4. The effect of mild hypothermia on insulin-like growth factors after severe asphyxia in the preterm fetal sheep. Journal of the Society for Gynecologic Investigation 2005; (4) $232-237$.

Chapter 5. Window of opportunity of cerebral hypothermia for postischaemic white matter injury in the nearterm fetal sheep. Journal of Cerebral Blood Flow \& Metabolism 2004; 24: 877-886.

Chapter $6 . \quad$ The growth hormone and insulin-like growth factor axis: its manipulation for the benefit of growth disorders in renal failure. Journal of the American Society of Nephrology. 2001; 12(6): 1207-306.

Chapter 7. Summary and future perspectives

Samenvatting

List of publications

Abbreviations

Curriculum Vitae

Dankwoord 


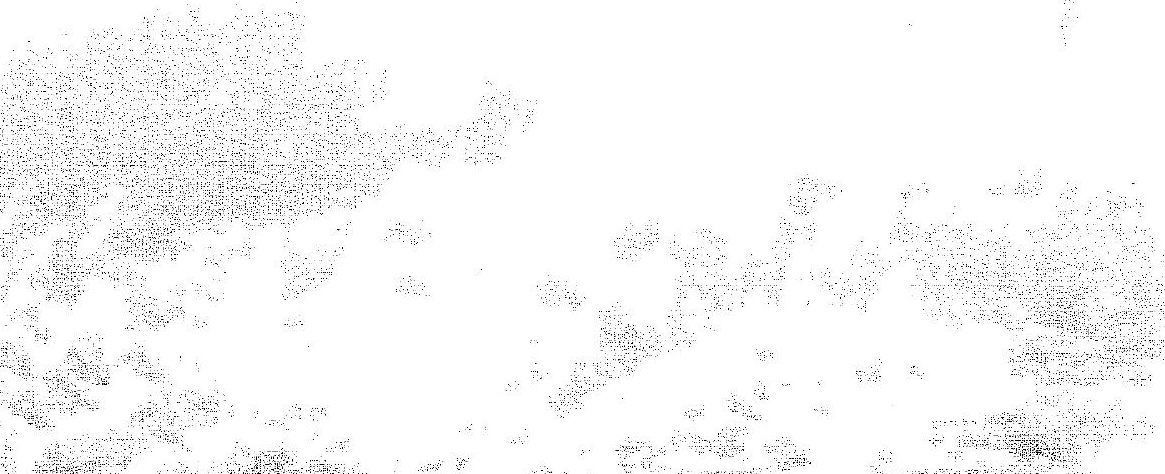

(1.

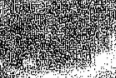

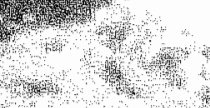

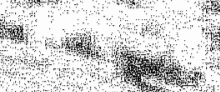
$-2 x^{3}$

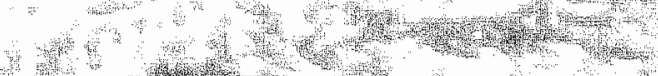

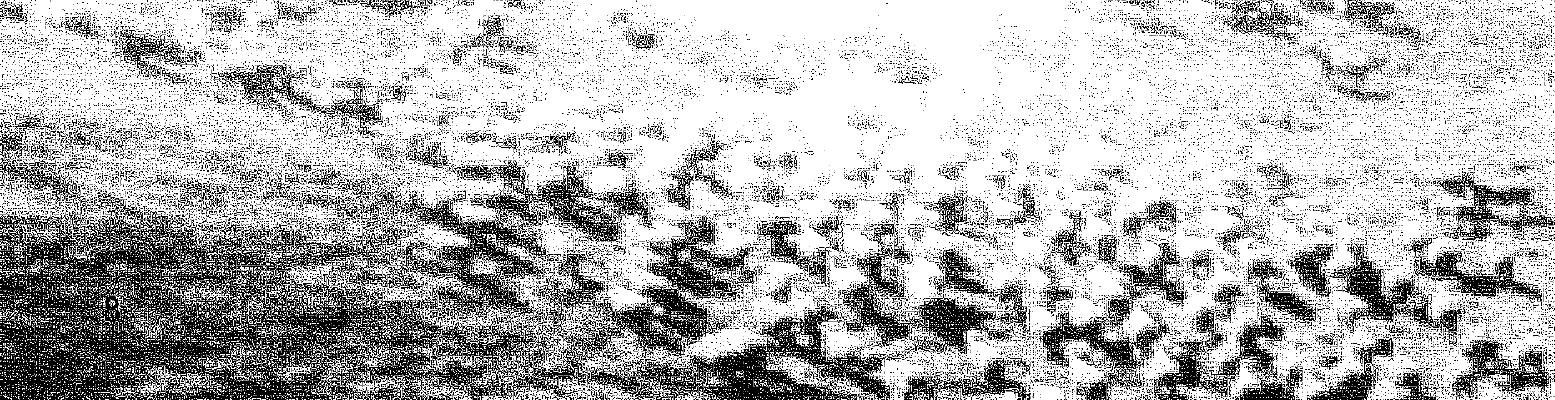

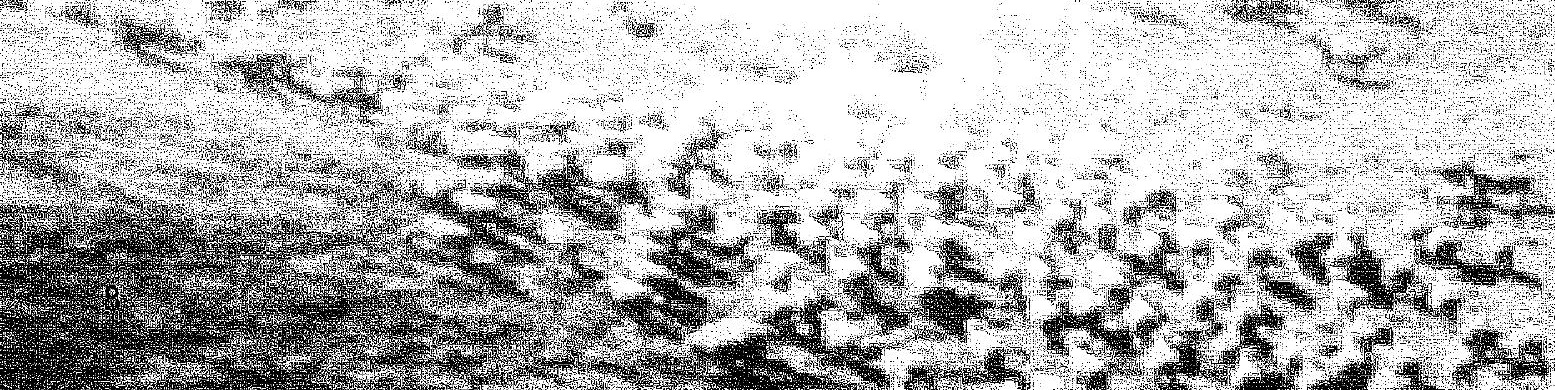

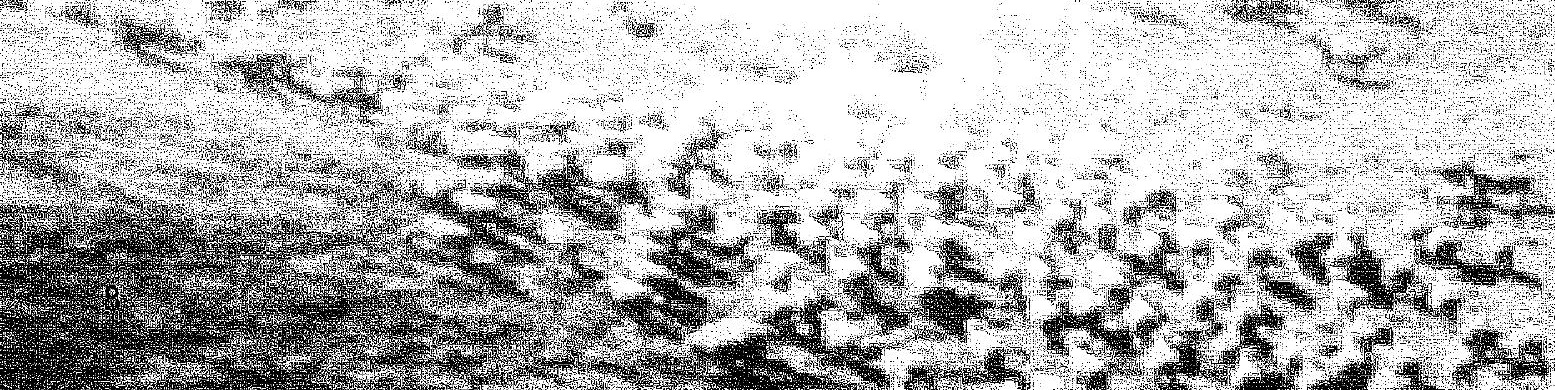




\section{HISTORY}

In 1861 William Jahn Little (1810-1894) defended his thesis before the Obstetric Society of London, where he argued his idea, based on 200 cases he accumulated in 20 years practice in orthopedics, that asphyxia (derived from a Greek word meaning pulseless) immediately before or during parturition could cause permanent damage to the central nervous system resulting in "spasmodic tetanus-like rigidity and distortion of the limbs' (Little 1801; Longo and Ashwal 1993). Little noted associations between the generalised spasticity and varying degrees of prematurity, difficult protracted labour requiring forceps delivery and severe asphyxia with convulsions (Longo and Ashwal 1993). Little postulated that the disabilities were secondary to "...interruption of the proper placental relation of the foetus to the mother and non-substitution of pulmonary respiration, [rather] than from direct mechanical injury' acting on the brains of 'too early and unripe-born foetuses' (Longo and Ashwa] 1993). The longterm disabilities and deformities associated with asphyxia (then termed "asphyxia neonatorum") were later termed "cerebral palsy" by William Osler (1849.1919) (Osler 1889). Besides motor handicaps, Osler also noted associations with impaired intellect, speech problems, epilepsy; of which, he found the latter to be the 'most common and distressing symptom' (Longo and Ashwal 1993).

Over time many different definitions for asphyxia have been used. In the 1930's Dr. Eastman defined asphyxia as "an inability of the child to breathe and apnea associated with oxygen deficiency during labour" and he demonstrated that asphyxia was associated with neonatal acidosis (Eastman 1932). Early experimental work studying the mechanisms of asphyxial brain injury was carried out in rhesus monkeys in the labouratory of Windle and Myers in the 1950's and 60's (Windle 1963; Myers 1967). In their studies asphyxiated newborn rhesus monkeys were resuscitated so that a number of them survived. Amongst the survivors, a certain number had neurologic deficits and a developmental pattern resembling cerebral palsy in human survivors of asphyxia. Brain histology showed a pattern of brain injury also observed in the asphyxiated human infant with parasagittal necrosis and "brain swelling" (Brann and Myers 1975).

\section{ASPHYXIA}

Asphyxia is now defined as an impaired maternal-fetal respiratory gas exchange resulting in hypoxemia, accompanied by the development of a combined respiratory and metabolic acidosis (Bennet et al. 2002). In practice, the key difference between 'hypoxia' and 'asphyxia' in experimental studies is simply severity: generally 'hypoxia' means moderate hypoxia with fetal $\mathrm{PaO} 2$ between 10 and $14 \mathrm{mmHg}$ with no, or trivial metabolic acidosis, in contrast with the severe hypoxia used in studies of asphyxia. Asphyxia may be caused by insufficient umbilical or insufficient uterine blood flow, as can occur following umbilical cord entanglement, uterine rupture, or placental abruption (Bennet et al. 2002). It is important to understand that asphyxia only leads to functional and structural organ damage when there is a long enough period of circulatory failure (hypoperfusion/ischaemia) (Parer 1994; Jensen et al. 1999; Bennet et al. 2002), as discussed in more detail under "Fetal responses to asphyxia", below. Although asphyxia is a global insult, affecting the whole fetus, it is the brain, heart and kidney that are particullarly at risk of damage from ischaemia-reperfusion injury associated with asphyxia (Jensen et al. 1999; Bennet et al. 2002).

Ischaemia-reperfusion injury in the brain and other organs of the fetus or neonate due to asphyxia remains a significant challenge for perinatal medicine. It continues to be associated with a high mortality in both premature and full-term infants, neonatal complications and permanent consequences in survivors including spastic motor deficits (cerebral palsy), mental retardation, language, hearing, vision, behavioural problems and epilepsy in later life (MacDonald et al. 1980; Mulligan et al. 1980; Vannucci 
2000; Volpe 200 $1 \mathrm{bl}$. This of course profoundly affects the child's future life and that of its family and therefore hypoxic-ischaemic injury has major social and health implications (Volpe $2001 \mathrm{~b}$ ).

\section{When does asphyxia lead to brain injury?}

The prevalence of biochemically defined fetal asphyxia (i.e. the presence of an oxgyen debt as shown by a metabolic aciclosis) in deliveries at term is estimated to be around 25 per 1000 live births (Low 2004). Besides acidosis determined from either fetal scalp sampling or umbilical artery blood, the diagnosis of asphyxia is usually inferred clinically from highly non-specific signs such as the presence of abnormal intrapartum fetal heart rate tracings, low Apgar scores (Nelson and Leviton 1991; Low et al. 1995b; Roland and Hill 1995). Approximately $15 \%$ of biochemically defined cases of asphyxia are considered to be moderate or severe asphyxia, i.e. associated with adverse short-term outcomes such as acute renal failure, newborn encephalopathy and other organ system complications (Low 1997; Low 2004).

There is now consensus that a $\mathrm{pH}$ of less than 7.00 with a base deficit $>10$ or $12 \mathrm{mmol} / 1$ on umbilical arterial cord blood represents an approximate threshold at which significant adverse neonatal sequelae, including subsequent neurological dysfunction and death begin to be seen (van den Berg et al. 1996; Hankins and Speer 2003). Even when this low pH threshold is used to define significant acidemia, most newborns in this category will be neurologically normal, with no apparent morbidity. For example, more than half of babies born with severe acidosis $(\mathrm{pH}<7.0$ and base deficit $>16 \mathrm{mmol} / \mathrm{l})$ do not develop even mild encephalopathy, while although at low frequency encephalopathy can still occur in association with relatively modest acidosis (Low 1997). The development of brain damage is associated most strongly with the severity and duration of fetal hypotension (Mallard et al. 1994). As it is not possible to directly measure fetal hypotension, but only other signs of stress such as $\mathrm{pH}$ and heart rate via CTG it will remain difficult to predict when asphyxia leads to brain injury.

\section{Fetal responses to asphyxia}

The absence of encephalopathy or other complications in many neonates exposed to 'significant' asphyxia must reflect in part the immense adaptive capacity of the fetus to prevent injury from asphyxia, and thus to delay or prevent the onset of hypotension (Low 1997; Bennet et al. 2002). Fetal defences have been studied primarily in animal models, such as the fetal sheep and llama and to a lesser extent the chick embryo (Bennet et al. 1998; Mulder et al. 1998; Llanos et al. 2003). Studies in fetal sheep and other models have clearly demonstrated that the fetus can initially compensate for an asphyxial insult and protect the vital organs such as the brain, heart and adrenals (Jensen and Berger 1991; Bennet et al. 1999; Bennet et al. 2000; Gunn et al. 20011. The most important initial defense is redistribution of combined ventricular output away from 'peripheral' organs such as the kidney, gut and limbs to maintain perfusion pressure to the critical organs (Peeters et al. 1979; Sheldon et al. 1979; Richardson 1989; Jensen and Berger 1991; Ball et al. 1994b; Mulder et al. 1998; Bennet et al. 1999). This is also termed circulatory centralization, a process mediated principally via the chemoreceptor and the sympathetic-adrenomedullary axis (Hanson 1997; Berger and Garnier 2000). Sympathetic activation and catecholamine release cause vasoconstriction in the 'peripheral' organs, resulting in a (relative) ischaemia of the organs affected, which via anaerobic metabolism leads to a buildup of lactate (Hanson 1997; Berger and Garnier 2000). Later, after restoration of oxygenation, the fetus can use lactate and ketone bodies directly as alternative energy substrates (Volpe 2001b).

Local defense mechanisms also have an important role in preventing injury from asphyxia. Critically, in the brain there is an actively mediated reduction in energy metabolism and oxygen consumption in an attempt to match blood flow to tissue requirement (Field et al. 1990; Richardson 1993; Parer 1994). Adenosine appears to play a key regulatory role in mediating the reduced cerebral metabolism 
during moderate hypoxia (Hunter et al. 2003a). Nitric oxide (NO) has been shown to play a role in mediating the local increase in cerebral blood flow (CBF) during hypoxia (Hunter et al. 2003b), although its role is less well studied during asphyxia (Hanson 1997).

If the asphyxial insult continues then fetal defense mechanisms will eventually faill. The fetus is then unable to maintain circulatory centralization, and cardiac output gradually falls as the myocardial glycogen stores and mitochondrial ATP concentrations become depleted. These two factors lead to progressive hypotension (Gunn et al. 2001). Fetal autoregulation of cerebral blood flow can maintain adequate cerebral perfusion during mild hypotension, however when blood pressure falls below the lower margin of autoregulation (Volpe 2001b; Muller et al. 2002), an adequate cerebral perfusion pressure to match blood flow and tissue demand can no longer be maintained (Berger and Garnier 2000). Thus during prolonged asphyxia (severe hypoxia), in contrast to moderate hypoxia, cerebral blood flow eventually falls leading to hypoperfusion (Bennet et al. 1998; Bennet et al. 1999). This combination of severe hypoxia with hypoperfusion is a classic combination of events, leading to 'hypoxic-ischaemic' injury to the brain, heart, kidney and other organs, and eventually death (Parer 1998; Gunn et al. 20011. The pathophysiology of this injury is discussed below. There is now considerable evidence that secondary damaging processes continue following reoxygenation and reperfusion after a period of significant hypoxia-ischaemia (Berger and Garnier 2000; Gunn 2000). Thus hypoxic-ischaemic injury may also be referred to as ischaemia-reperfusion injury.

\section{BRAIN INJURY}

\section{Causes of brain injury in infants born at term}

There has been much debate as to what proportion of cerebral palsy can be attributed to perinatal asphyxia. Estimates vary from $12-36 \%$ in term newborns (Nelson and Leviton 1991; Badawi et al. 1998b; Edwards and Nelson 1998; MacLennan 1999; Hagberg et al. 20011. Other causes of cerebral palsy in children born at term include infection, ischaemic stroke, cerebral malformation, genetic disorders, maternal thyroid disease and many other conditions (Badawi et al. 1998b; Badawi et at 1998a; MacLennan 1999; Felix et al. 2000; Cowan et al. 2003). Some of these underlying conditions may make the fetus more susceptible to hypoxia during labour and delivery or even be confounded with intrapartum asphyxia (Tuerlings et al. 2002; Cowan et al. 2003).

\section{Pattern of brain injury in infants born full-term}

Two major patterns of injury are typically identified in full-term neonates with hypoxic-ischaemic encephalopathy (Martin and Barkovich 1995). One pattern, commonly associated with prolonged partial asphyxia, is injury to the watershed regions of the parasagittal cortex and subcortical white matter, with relative sparing of the thalami and basal ganglia. The second pattern is a more central pattern of injury, whereby the basal ganglia, thalami, cerebellum, and brain stemare mostly affected, with relative preservation of the cerebral cortex (although rolandic/sensorimotor cortex and hippocampal injury may be present). This pattem is associated with profound, near terminal asphyxia such as can occur in placental abruption (Barkovich et al. 1995; Rutherford et al 1995; Yokochi and Fujimoto 1996; Campistol et al. 1999; Sie et al. 2000; Volpe 2001 b; Mercuri et al. 2002; Cowan et al. 2003; Sargent et al. 2004). Although brain injury in neonates at term was previously thought to be predominantly neuronal, there is increasing evidence from MRI studies that subcortical white matter injury is also a significant contributor to neurodevelopmental problems in infant born at full-term and may accompany both patterns described above (Barkovich et al. 1995; Yokochi and Fujimoto 1996; Okumura et al. 1997; Mercuri et al. 1999). 
True perinatal stroke is now also becoming increasingly recognised as a cause of neonatal brain injury, although its probably still underestimated because of variation in the presentation and evaluation (Lynch and Nelson 2001; Nelson and Lynch 2004). The incidence is approximately 1 in 4000 term births (Nelson and Lynch 2004). The middle cerebral artery is most commonly affected due to a thromboembolism from an intracranial or extracranial vessel, the heart, or the placenta (Nelson and Lynch 2004). Risk factors include cardiac disorders, coagulation abnormalities, and infection in the perinatal period (Lynch and Nelson 2001; Nelson and Lynch 2004).

\section{Causes of brain injury in prematurely born infants}

Compared to infants born at full-term, the incidence of brain injury is much higher in infants born preterm (Volpe 1998a). All births before 37 weeks of gestation are considered preterm (or premature) according to the World Health Organization (WHO) (11 \% of all births), however births before 32 weeks" gestation ( $2 \%$ of all births) account for the majority of neonatal deaths and neurological disorders (Robertson et al. 1992; Tucker and McGuire 2004). Broadly, outcomes improve with increasing gestational age; for any given length of gestation survival is reduced in growth retarded infants. Other factors, including ethnicity and gender also influence survival and the risk of neurological impairment (Stevenson et al. 2000; Tucker and McGuire 2004).

Technological, pharmacological and organization advances in perinatal medicine such as regionalization of specialist perinatal care have substantially improved survival, with survivors born as early as 23-24 weeks gestation (Allen et al. 1993; Goldenberg and Rouse 1998). These advances include antenatal corticosteroid administration, new mechanical ventilation techniques and exagenous-surfactant therapy. For example, survival of infants born at 25 weeks of gestation is now approximately $80 \%$ compared to just 5\% in the 1960's (Allen et al. 1993).

However, this improved survival has not been accompanied by a proportionate improvement in age specific morbidity and mortality. Neurodevelopmental complications such as cerebral palsy, blindness and/or deafness and mental retardation are common in these children (Hagberg et al. 1989; Pharoah et al. 1996; Clark and Hankins 2003). twelve to thirty-five percent of surviving infants born at 25 weeks' gestation have severe complications (Hack and Fanaroff 2000; Wood et al. 2000). The incidence of cerebral palsy in developed countries is around 2 per 1000 life births and has not changed significantly in the last 2 decades (Hagberg et al. 2001; Nelson 2003). Approwimately 10\% of children with cerebral palsy are born extremely preterm (under 28 weeks), $18 \%$ are very preterm (28-31 weeks), 15\% are moderately preterm $(32-36$ weeks), and $58 \%$ are born at term ( $>37$ weeks), according to a recent study by Hagberg et al. (Hagberg et al. 2001). More subtle disabilities, such as learning difficulties at school and behavioral difficulties occur in a majority of very premature infants (Hack et al. 2002). Thus, despite all advances and improved survival rates the percentage of prematurity-associated neurologic handicaps has not changed significantly over the years (Hack and Fanaroff 2000).

The question arises whether the adverse neurodevelopmental outcome associated with prematurity is primaitily due to the gestational age itself or whether outcome depends primarily on the presence of acquired brain lesions. Recent studies indicate that most cases of adverse neurodevelopmental outcome and symptoms of attention deficit hyperactivity disorder can be predicted on the type of the intracranial lesion rather than simply gestational age (Krageloh-Mann et al. 1999; Han et al. 2002; Vollmer et al. 2003; De Vries et al. 2004). However, a correlate for cognitive impairment in prematurely born children without mental retardation cannot be identified using conventional imaging techniques (Krageloh-Mann et al. 1999), although sophisticated MRI analyses shows this may be related to a reduced cerebral cortical surface development in very premature infants (Ajayj-Obe et al. 2000 ). 
The etiology of brain injury in premature infants is complex and multifactorial (Volpe 2001b). Both clinical and pathological data suggest that exposure to hypoxia-ischaemia and potentially infectioninflammation are important factors in the etiology of brain injury in preterm neonates (Volpe 200 lb; Jacobsson et al. 2002; Kumazaki et al. 2002; Salhab and Perlman 2005). Clinical studies using serial EEG (electro-encephalography) or ultrasound have shown that events leading to brain injury may start antenatally, but the majority of events occur during or shortly after birth (Bejar et al. 1988; de Vries et al. 1998; Hayakawa et al. 1999; Hagberg et al. 20011. Exposure to moderate or severe asphyxia is much more common in infants born prematurely than at full-term (MacDonald et al. 1980; Low et al. 1990; Low 2004; Salhab and Periman 2005) and may begin before labour (Low et al. 2003). Exposure to perinatal asphyxia is highly associated with worse mortality and adverse neurodevelopmental autcome (MacDonald et al. 1980; Weindling et al. 1985; Low et al. 1990; Mires et al. 1991; Low et al. 1992; Gibbs and Weindling 1994; Low et al 1995a; Spinillo et al. 1998; Han et al. 2002; Groenendaal et al. 2003; Victory et al. 2003; Salhab and Perman 2005). Haemodynamic disturbances in the neonatal period such as hypotension also can contribute to the development of brain injury (Volpe 2001b; Martens et al. 2003).

\section{Pattern of brain injury in prematurely born infants}

In the premature infant, periventricular leukomalacia (PVL) and periventricular/intraventricular haemorrhage (PVH/IVH) are the leading forms of brain injury. PVH/NH is most common before 28 weeks of gestation, and the severe forms with extension into the parenchyma are associated with adverse outcome (de Vries and Groenendaal 2002). PVL is the major pattern of injury associated with neurological morbidity in surviving premature inlants (Volpe 1998b; de Vries and Groenendaal 2002). The incidence of PVL is highest between 28 and 34 weeks (Volpe 1998b). PVL may either be focal necrotic lesions in periventricular white matter (cystic PVL) and/or more diffuse cerebral white matter injury. It is estimated that time of injury to the time of cavitation is $2-3$ weeks (de Vries et al. 1992). Deep focal periventricular lesions are associated with spastic diplegia and cerebral visual impairment, whereas diffuse PVL is hypothesised to be associated with cognitive and behavioral deficits /Volpe 2001a). The mechanism of this surprising association is still unclear, but is most likely mediated through subsequent impaired development of the grey matter regions, inciuding the cortex and deep nuclei (Inder et al. 1999; Volpe 2005). This impaired development may be in part due to the often unappreciated hypoxic-ischaemic injury to the subcortical regions, and partly due to chronic transformations secondary to initial injury (Barkovich and Sargent 1995; Yokochi 1997; Paneth 1999; Lin et al. 2001; Volpe 2001 b; Volpe 2005).

\section{EXPERIMENTAL ANIMAL STUDIES OF PERINATAL ISCHAEMIA-REPERFUSION INJURY}

In order to understand and potentially treat the pathophysiological processes after hypoxia-ischaemia that lead to tissue damage, a range of specialised models are required.

\section{Models of hypoxia-ischaemia}

The choice of experimental approach should be driven by the specific research question asked (Gunn et al 1997 aj. In general, experimental models of perinatal brain injury can be divided into pathophysiological and functional in nature. Pathophysiological models attempt to mimic potential systemic factors in the human that lead to brain injury, such as asphyxia (Hagberg et al. 2002). In contrast, functional models focus on the cerebral injury itself, for example by inducing cerebral ischaemia by carotid artery 
occlusion. Functional models therefore differ from clinical asphyxia with respect that they lack multiorgan injury, which is present in all the infants with severe asphyxial brain injury and which may influence outcome.

Use of nonhuman primates is very expensive and has ethical implications, and thus are seldom used in most countries. Small functional animal models are extensively used because they are cheap, but have considerable disadvantages, which include limited access for continuous physiological monitoring (blood pressure, bloodflow, temperature) or blood sampling (Hagberg et al. 1997). The widely used Vannucci-Rice model (unilateral carotid occlusion with inhalational hypoxia) produces a stroke like pattern with an essentially bimodal incidence of damage (Hagberg et al. 1997; Ashwal and Pearce 2001).

\section{Physiological models: the fetal sheep}

Fetal sheep are relatively precocial at birth, l.e. show more advanced development than human infants (Dobbing and Sands 1979), they share many developmental features with the human fetus, making the chronically instrumented fetal sheep preparation (figure 1) an excellent model to study fetal cardiovascular, neural and endocrine (patholphysiologic processes in detail. Many studies in fetal sheep have examined the fetall cardiovascular and cerebrovascular responses to (isocapnic) hypoxia (Sheldon et al. 1979; lwamoto et al. 1989; Jensen and Berger 1991; Giussani et al. 1997; Hanson 1997; Bennet et al. 1998; Hunter et al. 2003b]. These studies have gained important insights in the fetal responses and the mechanism controlling these responses to isolated fetal hypoxia, however, this insult is not typically associated with neurological or organ injury (Gunn et al. 1991). Therefore, severa] pathophysiological fetal sheep models of asphyxia have been developed whereby asphyxia is induced by inflation of an occluder around the umbilical cord, producing either continuous or intermittent occlusion. (ltskovitz

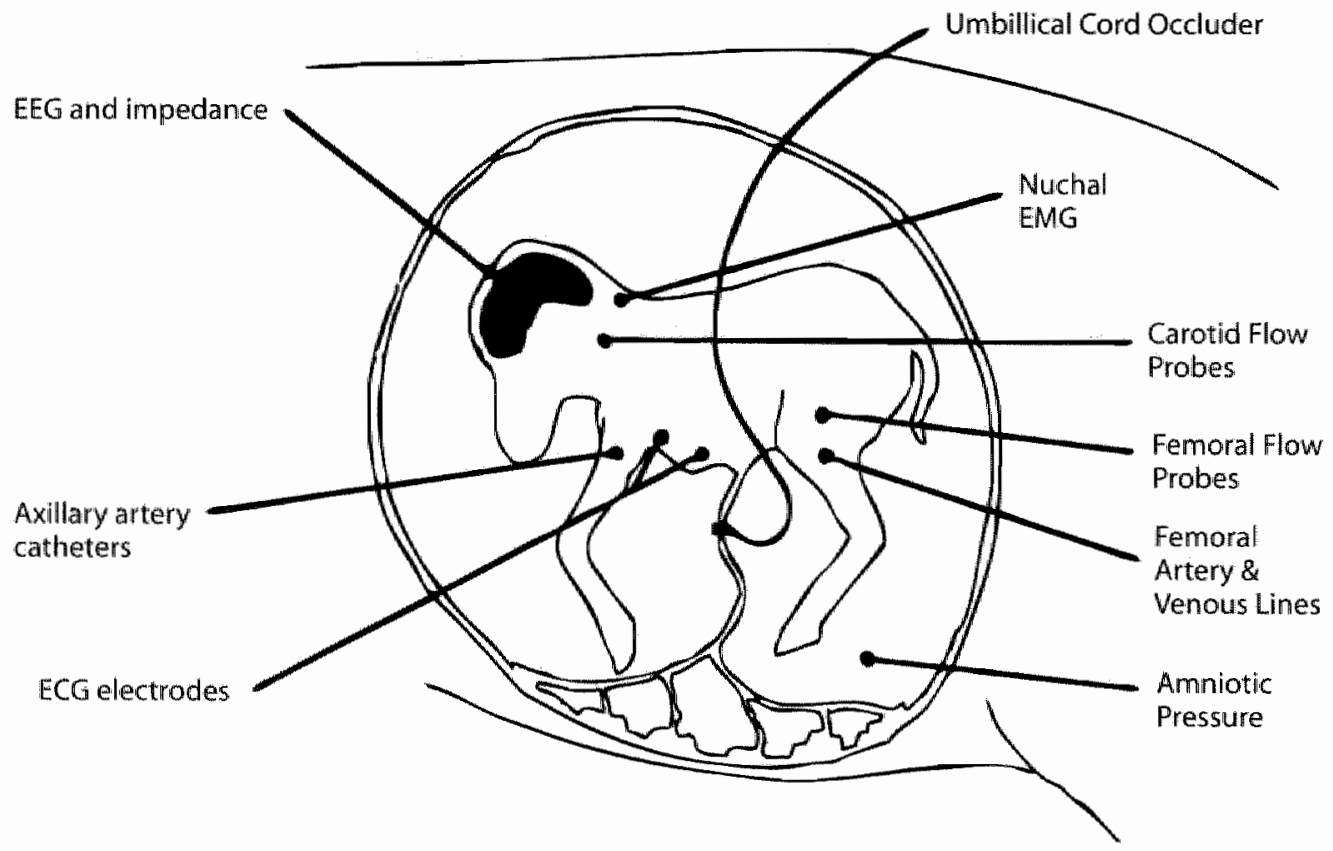

Figure 1: the chronicaly instrumented fetal sheep preparation. 
et al. 1983; Mallard et al. 1992; Mallard et al. 1994; Richardson et al. 1996; De Haan et al 1997; Keunen et al 1997; Bennet et al. 1999; Gardner et al. 2001). Other models have been developed, for example using an occluder around the maternal uterine or common internal iliac artery (Muijsers et al. 1990; Jensen et al. 1991; Bail et al. 1994a; Rees et al. 1997). These models differ in the pattern and severity of brain injury, depending on the fetal gestational age, duration of occlusion, and whether fetal hypotension was induced (Gunn et al. 1997a; Gunn et al. 2001).

An alternative but more functional ischaemia-reperfusion model in near term fetal sheep, is cerebral ischaemia induced by bilateral occlusion of the carotid arteries for 30 minutes (Williams et al 1990; Gunn et al. 1997b). This model induces predominantly parasagittal neuronal and white matter injury, but also neuronal. injury to the striatum and hippocampus (Williams et al. 1990; Gunn et al. 1997b; Guan et al. 2001; Petersson et al. 2002).

\section{PATHOPHYSIOLOGY OF ISCHAEMIA-REPERFUSION BRAIN INJURY}

Using such models of perinatal hypoxia-ischaemia, significant advances have been made in the understanding of the pathophysiological mechanisms leading to brain damage in the last few decades. The key concept that is now overwhelmingly established is that cerebral injury following a hypoxicischaemic insult is an evolving process, with cell death occurring well after the initial insult (Kirino 1982; Williams et al. 1993; du Plessis and Volpe 2002). This concept is critical as it suggests that treatment can still be effective for some time after the primary event has occurred.

\section{Phases of evolving of cerebral injury following hypoxia-ischemia}

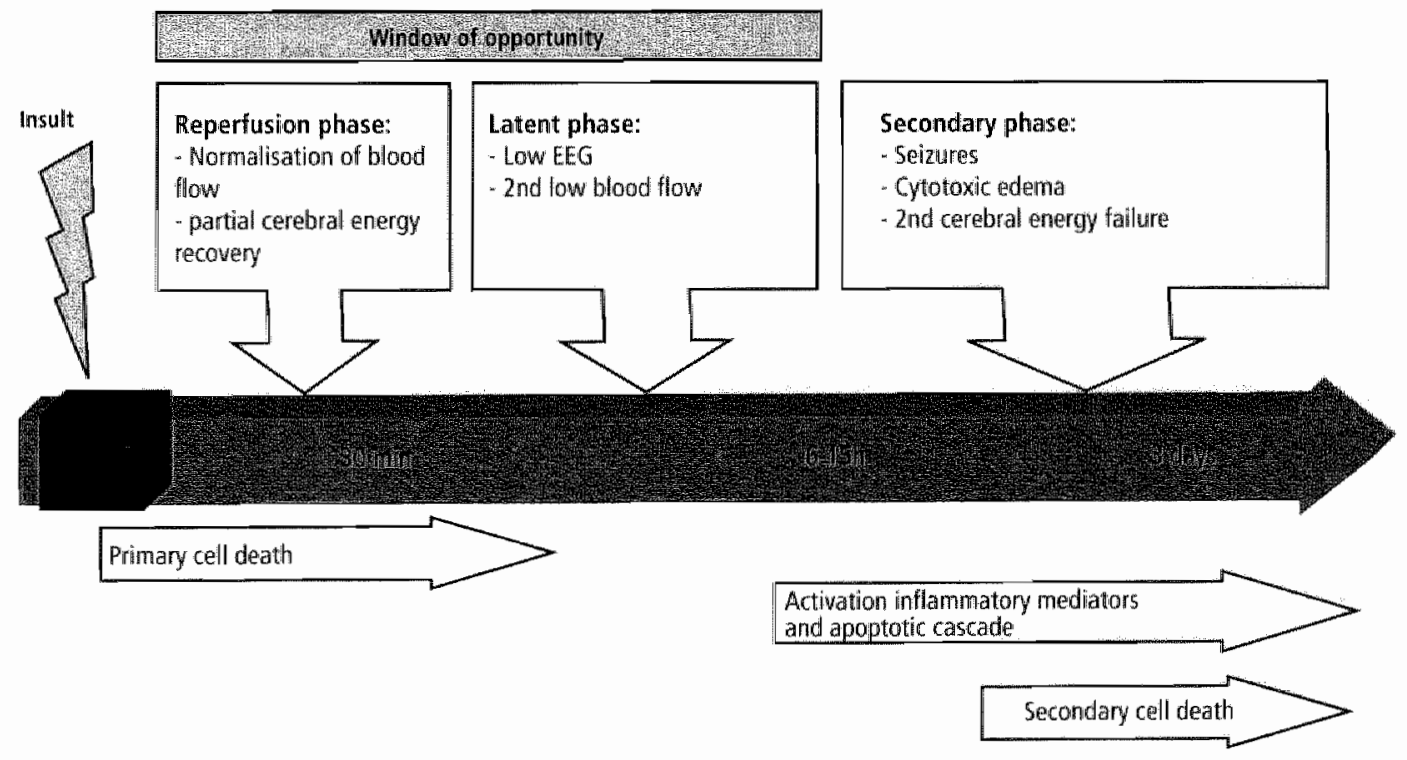

Figure 2: Phases of cerebral injury following a severe hypoxicischatemic ansult, adapted from (Cunn 2000). 


\section{Phases of evolving cerebral injury}

Studies in near term animals have delineated several important phases of evolving injury. These events are illustrated in figure 2. During the primary phase, i.e. the actual hypoxic-ischaemic event, cerebral energy failure develops as shown by magnetic resonance spectroscopy (MRS) (Lorek et al. 1994). There is depolarisation of cells, leading to severe cytotoxic edema, and initiation of a complex cascade of damaging processes including extracellular accumulation of excitatory amino acids ("excitotoxins"), such as glutamate (Williams et al. 1991; Abi Raad et al. 1999). The resulting "overstimulation" of neuronal glutamate receptors, particularly the $\mathrm{N}$-methyl-d-aspartate (NMDA) receptor leads to an increase in intracellular calcium through receptor-gated ion channels, resulting in metabolic derangements and generation of reactive oxygen species (ROS) and nitric oxide (NO) (Lee et al. 2000).

Following reperfusion, there is a rapid recovery of cellular oxidative and energy metabolism, with resolution of the acute cellular hypoxic-depolarization and cell swelling (Williams et al. 1991; Abi Raad et al. 1999). The initial cell death following reperfusion has a 'necrotic' appearance (Northington et al. $2001 \mathrm{~b}$ ). This may be followed by a latent phase, in which there is nearly complete normalization of oxidative cerebral energy metabolism, with similar recovery of cell swelling but depressed electroencephalogram (EEG) activity and a secondary fall in cerebral blood flow (Williams et al. 1991; Lorek et al. 1994; Abi Raad et al. 1999). During this latent phase there is activation of pro-inflammatory cytokines, such as IL-1 and TNF. (Silverstein et al. 1997; Bona et al. 1999j. It is highly likely that the processes active during the latent period involve activation of the intracytoplasmic phase of programmed cell death (Samejima et al. 1998; Earnshaw et al. 2000; Kaufmann et al. 2000; Susin et al. 2000).

The latent phase may be followed by secondary deterioration phase 6 to 15 hours after the acute asphyxial event (Gunn 2000). This phase is marked by the onset of seizures, secondary cytotoxic edema as measured by cerebral impedance (Williams et al. 1991; Abi Raad et al. 1999). Cerebral blood flow in the delayed phase is markedly increased (Abi Raad et al. 1999). Studies using NIRS also show a delayed increase in cerebral blood volume, indicating vasodilaton (Marks et al. 1996). At the cellular level there is an accumulation of toxic metabolites, such as the excitatory amino acid glutamate, impaired intracellular calcium turnover, activation of microglia, iron accumulation and overproduction of free-tadicals (Bana et al. 1999; Gunn 2000). Cytochrome c concentrations as shown by NIRS progressively fall, indicating impaired mitochondrial respiration (Marks et al. 1996; Chang et al. 1999), with a corresponding secondary impairment of oxidative metabolism (Lorek et al. 1994). In asphyxiated infants the degree of the delayed energy failure closely correlates with neurodevelopmental impairment at 1 and 4 years of age (Roth et al. 1997).

\section{Cell death}

Ultimately these events lead to delayed cell death. Critical processes in the programmed cell death are in progress from as early as $6 \mathrm{~h}$ post-insult, including elevation of the Fas death receptor protein, accumulation of cytosolic cytochrome c, caspase-8 activation, and perinuclear clustering of mitochondria (Northington et al. 2001 aj. Caspase 3 activation, showing the onset of the execution phase of apoptosis, occurs from $24 \mathrm{~h}$ post-insult (Nakajima et al. 2000). Histologically, delayed cell death may have either an apoptotic or necrotic appearance (Beillharz et al. 1995; Colbourne et al. 1999b; Northington et al. 200 I b). However, appearance is not a good guide to whether apoptotic processes are or are not involved, and indeed the distinction between necrosis and apoptosis in the delayed phase does not appear to be as clear as once thought. Instead, an 'apoptotic-necrotic continuum' has recently been described on electron microscopy studies (Martin 2001). Compared to the adult brain, apoptotic mechanisms appear to be more important after hypoxia-ischaemia in the immature brain. As caspase-3 is expressed until at least 7 days postinsult, apoptosis is likely to have a prolonged role in neonatal cerebral injury (Nakajima et al. 2000). 


\section{Temperature}

There is now strong experimental evidence that changes in cerebra! temperature either during hypoxia-ischaemia or in the latent phase critically modulate the extent of brain injury (Busto et al. 1987). Hyperthermia either during or following an hypoxic -ischaemic event is associated with worse outcome in both animals and humans, while hypothermia generally improves functional and structural outcome (Busto et al. 1987; Baena et al. 1997; Leberman et al. 2000; Suzuki et al. 2000; Tommatsu et al. 2003). An explanation for the epidemiological link between evidence of infection, which typically involves maternal pyrexia and adverse neonatal outcones may be that high cerebral temperature renders the fetal brain much more susceptible to even mild hypoxia-1schaemia (Tomimatsu et al. 2003), as can occur in nomal labour and delivery. For example, hyperthermia has been shown to prevent the protective metabolic and cerebral flow responses during hypoxia (Suzuki et al. 2000) and to induce earlier and stronger caspase-3 activation following ischaemia (Tominatsu et al. 2003). Alternatively of course elevated levels of cytokines, either as a result of ischaemia or infection/fever may represent a final common pathway leading to brain injury (Shalak and Periman 2002).

\section{Endocrine and auto/paracrine responses}

Apart from secondary damaging processes following ischaemia-reperfusion, systemic and auto/paracrine responses from neurotrophic factors such as insulin growth factor (IGF)-I and transforming growth factor B (TGF B) may play a role in reducing brain injury (Beilharz et al. 1998; Gluckman et al. 1998; Gluckman et al. 2001). Inhibition of apoptosis is one of the known important functions of IGF-I following ischaemia-reperfusion (Guan et al. 2003). The role of circulating IGF following ischaemiareperfusion is less clear. Local induction of insulin-like growth factor binding proteins appear to be involved in the transport of IGF-I to the site of injury (Guan et al. 1996). Activation of the hypothalamicpituitary-adrenal (HPA) axis may have an important cardiovascular role, but adverse effects of cortisol. on the development of brain injury has also been suggested (Fassbender et al. 1994).

\section{Maturational factors}

The initiating mechanisms of brain injury, principally ischaemia and reperfusion, and the final common pathways to cell death are similar in term and preterm infants (Inder and Volpe 2000). Thus the precise mechanisms of the much greater prevalence and unique patters of brain injury in prematurely bom infants are not fully understood. One likely explanation for the increased prevalence is that events that initiate injury, such as hypoxic-ischaemic events occur more frequent in prematurely born infants than infants born at term (MacDonald et al. 1980; Low et al. 1990; Low 2004). Nevertheless, is has also been postulated that the preterm fetus or infant is intrinsically more vulnerable to hypoxic-ischaemic events due to its immaturity (Volpe $200 \mathrm{lb}$ ). Several maturational factors influencing overall vulnerability and differences in the pattern of cellular injury have been suggested. These include anatomical, cellular and physiological factors.

Anatomical factors that may be involved in the maturation dependent vulnerability of the preterm fetus include the maturation of the cerebral vascular system (both arterial and venous), myelination, and changes in neurotransmitters and their receptors. The vascular supply to periventricular white matter is in an incomplete state of development in preterm infants, making it a vascular watershed zone, particularly vulnerable to cerebral hypoperfusion (Volpe 2001a). The regions of hypoxic-ischaemic brain injury in term infants correspond more to the mature intervascular watershed zones, including parasagittal cortex and the subcortical white matter (Barkovich and Truwit 1990; Volpe 2001b). Regional vulnerability of the brain may also be related to differences in metabolic rate, i.e. the oxygen 
and glucose requirement of certain areas and cell types, such that higher obligate rates of oxidative metabolism may be associated with increased vulnerability. Consistent with this hypothesis, in very premature infants (less than 32 weeks), the greatest blood flow and glucose uptake occurs in the thalami and posteriot fossa, with comparatively little cortical activity, whereas in the term infant blood flow and glucose uptake increases in the basal ganglia and perirolandic cortex (sensorimotor cortex) (Barkovich and Hallam 1997). There is some evidence that these metabolic differences may be associated with differences in the expression and function af receptors that contribute to ischaemiareperfusion injury, such as the NMDA receptors (Mishra et al 2001).

Before the onset of myelination, which in the human brain starts at around 32 weeks of gestation, the cerebral white matter predominantly consists of immature oligodendrocytes (Back et al. 2001). Back and colleagues have suggested that the late oligodendrocyte progenitors may be selectively vulnerable to hypoxia-ischaemia and free radicals (Volpe 2001a; Back et al. 2002). Nevertheless, it is important to accept that there is evidence from other studies that mature, myelinating oligodendrocytes are at least as vulnerable to hypoxia-ischaemia as neurons (Ikeda et al. 1998; Petersson et al. 2002).

\section{Physiological factors}

Several physiological factors have been proposed to play a role in the increased vulnerability of the preterm fetus to organ injury. It has been hypothesized that the "stress responses" of the preterm fetus are immature compared to the near-term fetus (Iwamoto et al. 1989). This is posited to compromise the ability of the preterm fetus to respond to severe hypoxia and to contribute to the high rate of hypotension in premature newborns (Bolt et al. 2002a; Bolt et al. 2002b; $\mathrm{Ng}$ et al. 2004). This supposedly immature stress response includes both the catecholamine (Cohen et al. 1982; Mulder et al. 2000) and the hypothalamus-pituitary-adrenal (HPA) axis response of ACTH and cortisol (Rose et al. 1981; Challis and Brooks 1989; Matsuda et al. 1992; Fraser et al. 2001). On the other hand, preterm newborns have been suggested to be able to mount a considerably more vigorous response to inflammatory stimuli than infants born at term (Dammann and Leviton 2000).

The original studies that suggested this immature stress response examined only moderate hypoxic insults. The preterm fetus has a much greater anaerobic reserve and relatively reduced aerobic requirements compared to the term fetus (Dawes et al. 1959; Mott 1961; Shelley 1964), making it more tolerant to hypoxia/asphyxia (Mallard et al. 1994). There have been no studies examining the HPA response of the preterm fetus to a severe hypoxic challenge sufficiently as to be expected to elicit a near-maximall HPA response. Further, studies in preterm fetal sheep have demonstrated that the preterm fetus has highly adaptive and relatively mature cardiovascular responses to severe asphyxia (Dawes et al. 1963; Mallard et al. 1994; Bennet et al. 1999; Quaedackers et al. 2004), and can survive much more prolonged periods of asphyxia than the nearterm fetus (Gunn et al. 2001).

Pretertro fetuses and infants have a smaller range of cerebral blood flow autoregulation compared to term infants (Papile et al. 1985; van de Bor and Walther 1991; Volpe 2001a; Muller et al. 2002). Especially in sick newborns the cerebral circulation has been proposed to be almost pressure-passive, meaning that each reduction in blood pressure leads to hypoperfusion and ischaemia in the arterial end zones and border zones in cerebral white matter (Gluckman et al. 2005), whereas 10 minutes of umbilical cord occlusion in late-gestation fetal sheep leads to hippocampal damage (Mallard et at. 1994) and in term monkeys damage is detected after only 7 minutes (Ranck and Windle 1959). Thus the ability to survive extra-ordinarily prolonged exposure of the brain to hypoxia-ischaemia may paradoxically allow the ultimate development of severe injury to the brain in the preterm fetus (Mallard et al. 1994; Gunn et al. 2001). 


\title{
TREATMENT OF HYPOXIC-ISCHAEMIC ENCEPHALOPATHY
}

\section{Potential treatments}

Currently, post-resuscitation treatment of preterm and term neonates at risk for brain injury is only supportive in nature, such as blood pressure support and seizure control (Niermeyer et al. 2001). There is a strong need for interventions to reduce brain injury from ischaemia-reperfusion following both term and premature birth. To date there are no approved specific treatments to improve the neurological outcome.

The first hours after asphyxia (the 'latent phase') appears to represent a key window of opportunity for intervention, prior to the final execution phase of delayed cell death (Gunn 2000). Many different treatment modalities have been or are currently under investigation (Vannucci and Perlman 1997; Dammann and Leviton 2000; Gluckman et al. 2001), as listed in table 1. Although drugs to ameliorate brain injury appear effective in animal models of perinatal brain injury, clinical trials have been unsuccessful to date (Gluckman et al. 2001).

Table 1: List of potential treatments for HIE under investigation

\author{
Hypothermia \\ Oxygen free radical scavengers, eg Allopurinol, vitamin K \\ NOr Nos inhibitors eg. Allopurinol, 2 Iminoblotin \\ Membrane stabilizing agents, eg. Monoganglioside GM-1 \\ Calcium dhannel blockers eg, flunarizine \\ Glutamate Antagonists: \\ - NMDA receptor antagonists, eg MK $801, \mathrm{MgSO} 4$ \\ AMPA kainate receptor antagonists, eg NBQX \\ - Metabotrobic glutamate receptor antagonists \\ Anti-inflammatory $\mathrm{eg} / \mathrm{l}-1 \mathrm{~B}$ receptor antagonist \\ Growth factors/anti-apoptotic factors eg. IGF-1, GPE, TGF-B, bFGF \\ Pro-plasticity
}

Adapted from. Vannucc and Perlmar 1997 ; Dammann and Leviton 2000; Gluckman et al 2001, Peterts and van Bel 2001)

Several factors may play a role in the fallure of many drugs trials to prevent permanent brain injury. Many previous agents have focussed on treating NMDA-receptor mediated glutamate excitotoxicity. However, clinical use of many NMDA receptor antagonists is limited by adverse effects (Lutsep and Clark 1999). Magnesium sulphate (MgSO4) is a safer (partial) NMDA receptor antagonist, however it has low potency in the neonatal brain (Chahal et al 1998). In a recent trial, magnesium sulfate given to women immediately before very preterm birth was not effective in reducing the primary end points, i.e. the risk of total pediatric mortality or cerebral palsy among survivors at 2 years of age (Crowther et al. 2003).

Another potential factor is that the role of white matter injury in neurodevelopmental outcome was previously under-recognised. Most treatments focussed on treatment of neuronal injury, and may have been less effective for the damaged white matter. For example, NMDA-receptor blockade does not seem to protect against axonal damage (Yam et al. 2000). Other neuroprotective agents are only effective during or immediately following ischaemia-reperfusion, limiting their clinical use.

Recently, hypothermia has been demonstrated to improve neurological outcome after circulatory arrest in adults (Bernard et al. 2002; Hypothermia After Cardiac Arrest Study Group 2002). 
Experimental studies in a number of different animal models have shown good efficacy following ischaemla-reperfusion, even if start of treatment was delayed by several hours after the insult (Gunn 2000). Therefore, hypothermia is now considered one of the most promising treatment modalities to improve neurodevelopmental outcome following neonatal HIE (Du Plessis 1998; Thoresen 1999; Gunn 2000).

\section{HYPOTHERMIA}

Hypothermia in neonates is typically defined as a body temperature below $36.5^{\circ} \mathrm{C}$. In the studies discussed below, mild hypothermia is defined as a rectal temperature of $34-35^{\circ} \mathrm{C}$ and moderate hypothermia as $30-33^{\circ} \mathrm{C}$.

\section{History of hypothermia}

The potential therapeutic benefits of cooling were reportedly recognized by Hippocrates for sprains, fractures, tetanus and febrile convulsions (Thoresen 2000). Sir John Floyer (1697) advocated the use of ice cold water to stimulate the onset of respiration in depressed newborn infants (Wyatt and Thoresen 1997). In 1949, Miller was the first to show that survival of newborn guinea pigs under anoxia was increased by hypothermia (Miller 1949). Following on from those observations, Miller and Westin were the first to study the use of hypothermia for "asphyxia neonatorum" (Miller et al 1964; Thoresen 2000). In 1958, they reported induced hypothermia by immersing the 10 severely depressed, term apnoeic infants in a specially constructed cold water bath and stopped when spontaneous respirations commenced or when the rectal temperature approached $27^{\circ} \mathrm{C}$. The infants were then dried and allowed to rewarm spontaneously. Only one of the 10 infants died, the remaining 9 infants survived, despite minimum core temperatures of between $23^{\circ} \mathrm{C}$ and $30^{\circ} \mathrm{C}$, and periods of apnoea ranging from 8 to 79 minutes. At follow-up 10 years later, none of the nine infants showed neuromotor impairment or cerebral palsy (Wyatt and Thoresen 1997). Subsequent uncontrolled studies had similar encouraging results. Mortality was the same in all studies, around $12-15 \%$, which was similar to standlard care at that time (Thoresen 2000). Russians doctors were the first to describe a more "selective" head cooling technique, using a shower to the head they cooled the head $1.5^{\circ} \mathrm{C}$ lower than rectal temperature $\left(30^{\circ} \mathrm{C}\right.$ rectal) (Kopchev 1985 ).

Despite these positive results, the use of hypothermia following fetal asphyxia fell out of favor because the studies were uncontrolled, and controlled studies in preterm infants reported increased mortality rates with even mild hypothermia (Silverman et al. 1958; Buetow and Klein 1964; Day et al. 1964).

\section{The mechanisms of action of hypothermia}

Scientific interest in the therapeutic properties of hypothermia resurfaced after it was recognised that the temperature of the brain has an important influence on the extent of brain injury following hypoxiaischaemia (Busto et al. 1987; Thoresen and Wyatt 1997; Gunn and Gunn 1998). Recent research in fetal and newborn animal models has focussed on the mechanisms of action of hypothermia and questions of post-ischaemic delay, depth, duration of hypothermia and method of cooling.

Hypothermia during hypoxia-ischaemia is likely to work via different mechanisms than delayed, postischaemic hypothermia. The protective effects of intra-ischaemic hypothermia is mostly due to a graded reduction in cerebral metabolism which slows cell depolarisation, reduces accumulation of excitotoxic neurotransmitters, and suppresses oxygen free radical release and lipid peroxidation of cell membranes [Gunn and Gunn 1998). The mechanisms of mild delayed hypothermia after severe transient hypoxia- 
ischaemia include suppression of post-ischaemic inflammation (Inamasu et al. 2000b), including nitric oxide synthesis and induction of microglia (Kumar and Evans 1997), and suppression of apoptosis (Edwards et al. 1995; Inamasu et al. 2000a). Reducing the duration of post-asphyxial seizures may be an other important mechanism of hypothermia (Thoresen and Whitelaw 2005).22

\section{Optimal timing of hypothermia}

Even though cooling during ischaemia or in the immediate resuscitation is effective, it would be almost impossible to test it in clinical practice. Therefore, the effect of delaying hypothermia has been tested at different time points after ischaemic insults in several models, including the fetal sheep and adult gerbil (Colbourne and Corbett 1994; Colboume and Corbett 1995; Gunn et al. 1997b; Gunn et al. 1998; Gunn et al. 1999a; Colbourne et al. 2000). In near term fetal sheep, cooling starting at 90 minutes after reperfusion resulted in dramatic neuroprotection (Gunn et al. 1997b). Hypothermia was still partially neuroprotective when started 5.5 hours after reperfusion (6h after start of ischaemia) (Gunn et al. 1998), but not neuroprotective when it was initiated at $8.5 \mathrm{~h}$ after reperfusion, during the phase of secondary deterioration, indicated by the onset of post-ischaemic seizures (Gunn et al. 1999 aj. It is not known if the window of opportunity for neuroprotection is the same for different areas or cell populations in the brain, such as oligodendrocytes in the white matter.

\section{Depth of hypothermia}

The optimal depth of hypothermia required for effective neuronal rescue seems to be between 32 and $34^{\circ} \mathrm{C}$ (Colbourne et al. 1997). Studies by Gunn et al. in fetal sheep cooled from 90 minutes after ischaemia show substantial neuroprotection only in fetuses who had a sustained decrease in the extradural temperature to less than $34^{\circ} \mathrm{C}$ (normal temperature in fetal sheep, $39.5^{\circ} \mathrm{C}$ ) (Gunn et al. $1997 \mathrm{~b}$ ). In adult gerbils, cooling to a rectal temperature of $32^{\circ} \mathrm{C}$ was associated with greater behavioural and histologic neuroprotection than cooling to $34^{\circ} \mathrm{C}$ (Colbourne and Corbett 1994; Colbourne and Corbett 1995; Colbourne et al. 2000). As the core temperature falls below $34^{\circ} \mathrm{C}$ the risk of complications increases markedly (Gunn and Gunn 1998). The effectiveness of hypothermia may also decrease. For example, in adult dogs, deep hypothermia $\left(15^{\circ} \mathrm{C}\right)$ following a cardiac arrest produced detrimental cerebral and cardiac outcomes, whereas mild $\left(34^{\circ} \mathrm{C}\right)$ hypothermia improved outcome compared to normothermia (Weinrauch et al. 1992). The adverse effects responsible for the impaired effectiveness of greater cooling levels are unknown but are likely to be related to impaired cardiac contractility leading to decreased cardiac output, arterial hypotension, and compromised perfusion (Gunn and Gunn 1998). Consistent with these experimental data, in adults after a cardiac arrest mild hypothermia $\left(34\right.$ to $36^{\circ} \mathrm{C}$ ) from 10 minutes until 12 hours after was beneficial (Bernard et al. 2002; Hypothermia after Cardiac Arrest Study Group 2002).

\section{Duration of hypothermia}

The optimum duration for hypoxic-ischaemic injury may depend on the severity of the injury and the delay before hypothermia is achieved (Colbourne et al. 1999a; Gunn 2000). A longer period of cooling may be necessary to compensate for severe injury or a longer delay. Studies in fetal sheep by Gunn et al. have used 72 hours of hypothermia, as pilot studies suggested that shorter duration was not effective (Gunn et al. $1997 \mathrm{~b}$ ). Nevertheless, shorter durations of hypothermia (even 3 hours) has also been effective in anesthetized neonatal piglets when cooling was started directly following reperfusion (Haaland et al. 1997). In gerbils, increasing the duration of hypothermia that started $1 \mathrm{~h}$ after ischaemia from 12 to 24 h produced much greater neuroprotection (Colbourne and Corbett 1994).

Rewarming after cooling treatment for severe hypoxic-ischaemic encephalopathy is potentially more 
complex than induction of cooling, because it might lead to destabilizing changes in neuronal activity [Battin et al. 2004|. There is evidence for example of rebound seizure activity during rapid rewarming from 272 -hour period of hypothermia in the fetal sheep (Gerrits et al 2005). The optimal rewarming strategy following cooling is unknown, but clinical studies of therapeutic hypothermia typically have rewarmed infants at no more than $0.5^{\circ} \mathrm{C}$ per hour (Gluckman et al. 2005).

\section{Method of cooling}

Brain hypothemia can be induced by either cooling the whole body (i.e. lowering core temperature) or by semi-selective cooling of the brain, using a cooling cap around the infant's head. The advantages of whole body cooling are simplicity and that the whole brain, including its deep structures is cooled (Van Leeuwen et al. 2000). Conversely, the key disadvantage of whole body cooling is that the risk of systemic complications of hypothermia is likely to be higher (Gunn and Gunn 1998).

Head cooling induces a marked temperature gradient across the brain, with very cool temperatures near the brain's surface and less cool temperatures more deeply in the brain. Mathematical modelling studies suggest that cooling of deep brain structures in humans may not be feasible with selective head cooling (Van Leeuwen et al. 2000). However, Tooley et al. have shown in the piglet that it is possible by means of a head-cooling cap to cool the basal ganglia substantially more than the body $\left(3\right.$ to $\left.5^{\circ} \mathrm{C}\right)$ for a 24-hour period while keeping the core temperature mildy hypothermic (Tooley et al. 2002) or even normothermic (Tooley et al. 2005).

\section{Physiological responses to hypothermia}

Induced hypothermia is associated with many cardiovascular and metabolic responses. These responses are important to understand as they may have implications for the therapeutic effects of hypothermia. Hypothermia leads to rapid peripheral vasoconstriction, also termed centralization of blood flow (Gunn and Gunn 1998; Gunn and Battin 2000). This vasoconstriction is mediated wia both central and skin thermoreceptors (Gordon and Heath 1986), whereby in man, skin temperatures only contribute $20 \%$ to the onset threshold for vasoconstriction during cooling (Cheng et al. 1995). Hypothermia also has well known cardiac effects, which include sinus bradycardia, prolonged PR interval, prolonged OT interval and Osborn or J waves visible on electrocardiography, and in some cases cardiac arrhythmias. All cardiac effects of hypothermia are reversible with rewarming (Gunn et at. 1990b).

The other major response to hypothermila is increased heat production. This response is typically seen at a similar but not identical temperature threshold to vasoconstriction (Gunn and Battin 2000 ). Unlike adults, infants preferentially use brown fat (nonshivering thermogenesis) rather than shivering to produce heat (Gunn and Gluckman 1995). Factors that inhibit nonshivering thermogenesis or muscle activity, such as hypoxia and many anesthetic or sedative agents, result in reduced endogenous heat production. Postasphyxial seizures may also be an important source of both cerebral and peripheral thermogenesis (Jordan 1904; Gonzalez et al. 2005).

Recently, a study examining the effects of hypothermia in unsedated piglets found that shivering was associated with elevated blood levels of cortisol, indicating that feeling cold induced a stress response that potentially interfered with the neuroprotective effects of hypothermia (Thoresen $e t$ al 2001 ). Although not conclusive, this study points to the need of studying the stress response in studies of lnypothermia, and to evaluate whether sedation might be necessary in infants treated with hypothermia. However, the effects of hypothermia are different in humans (and sheep) as compared to piglets. Human infants and sheep both predominantly use non-shivering thermogenesis and do not shiver" until brown fat stores have been depleted (Gunn and Gluckman 1995). Nevertheless, further 
studies are warranted to examine whether there is a stress response to hypothemia and whether this impairs the neuroprotective effects of hypothermia. Finally, the effects of hypothenmia on other endocrine systems such as IGF and its binding proteins are largely unknown currently. This is of interest as IGF has important functions in metabolic regulation, growth, and organ function and development.

\section{Clinical experience}

In the words of late William A. Silverman "The hoary intervention for total-body hypothermia was first mooted 300 years ago. A proper trial (with concurrent controls) of the latter intervention should have been carried out at least 35 years ago: the mills of the gods do, it seems, grind very slowly indeed." (Silverman 1998).

After this considerable delay, hypothermia has now been the subject of several large randomized controlled trials both in adults and newborns to evalluate its efficacy. Trials in adults demonstrated that hypothermia initiated immediately after cardiac arrest improved outcomes (Bernard et al. 2002; Hypothermia after Cardiac Arrest Study Group 2002). The first large RCT in term infants with hypoxicischaemic encephalopathy (HIE) was the CoolCap trial (Gluckman et aL 2005). Seventy-two hours of selective head cooling with mild systemic hypothermia (rectal temperature $34.5 \pm 0.5^{\circ} \mathrm{C}$ ) reduced death or disability in the infants with less severe electroencephalographic changes at entry of the trial, but there was no significant benefit in infants with the most severe electroencephalographic changes. Cooling was not associated with any adverse effects. Inder et al demonstrated that systemic hypothermia led to less cortical gray matter injury on magnetic resonance imaging [MRI] (Inder et al. 2004). Further randomized-controlled trials are underway (Jacobs et al. 2004).

\section{OBJECTIVES OF THE STUDIES IN THIS THESIS}

This review has highlighted many aspects of the pathogenesis and treatment of perinatal asphyxia. Many questions remain unanswered. For example, hypothermia is a promising treatment for hypoxicischaemic encephalopathy in term neonates (Gunn 2000): however, there is no information on whether it is effective in the preterm brain, and in particular whether delayed hypothermia can reduce white matter loss. Further, there is surprisingly little information on how it affects recovery from severe systemic hypoxia, and none in preterm models.

Thus, overall aim of this thesis was to better understand the endocrine and cardiovascular responses of the fetus to severe hypoxia (asphyxia) and to dissect the effects of rescue therapy with head cooling on neural and systemic recovery from such severe hypoxia. 
chapter 1 


\section{REFERENCES}

Abi Raad R, Tan WK, Bennet L, Gunn Al, Davis SL, Gluckman PD, Johnston BM, Wiliams CE. (1909) Role of the cerebrovascular and metabolic responses in the delayed phases of injury after transient cerebral ischema in fetal sheep. Stroke 30:2735-2741

Ajayi-Obe $M$, Saeed $N$, Cowan FM, Rutherford MA, Edwards AD. (2000) Reduced development of cerebral cortex in extremely preterm infants. Lancet $356: 1162-1163$

Allen MC, Donohue PK, Dusman AF. (1093) The limit of viability-neonatal outcome of infants bon at 22 to 25 weeks' gestation. N Engl/Med 329:1597-1601

Astwwal S, Pearce WJ. (2001) Animal models of neonatal stroke. Curr Opin Pediatr 13:506-516

Back SA, Han BH, Luo NL, Chricton CA, Xanthoudakis S. Tam J. Arwin KL, Holtzman DM. (2002) Selective wuherability of late oligodendrocyte progenitors to hypoxia-ischemia. J Neurosci $22: 455-463$

Back SA, Luo NL, Borenstein NS, Levine IM, Volpe J, Kinney HC. (2001) Late Oligodendrocyte Progenitors Coincide with the Developmental Window of Vunerability for Human Perinatal White Matter Injury $/$ Neurosci $21: 1302 \cdot 1312$

Badawi N, Kurinczuk II, Keogh JM, Alessandri LM, O'Sulliwan F, Burton PR, Pemberton PJ, Stanley I. (1998a) Antepartum risk factors for newbom encephalopathy: the Western Australian case-control study. BM $317: 1549-1553$

Badawi N, Kurinczuk JI, Keogh JM, Alessanäi LM, OSulliwan F; Burton PR, Pemberton PJ, Stanley Fl. (1998b) Intrapartum risk factors for newborn encephalopathy: the Western Australian case-control study. BM $317: 1554 \times 1558$

Baena RC, Busto R, Dietrich WD, Globus MY, Ginsberg MD. (1997) Hyperthermia delayed by 24 hours aggravates netronal damage in rat hippocampus following global ischemia. Neurology 48:768.773

Ball RH, Espinoza MI, Parer JT, Alon E, Vertommen ], Johnson ]. (1994a) Regional blood flow in asphyxiated letuses with seizures. Am I Obstet Gynecol 170:150.161

Bail RH, Parer JT, Caldwell LE, Johnson J. (1994b) Regional blood flow and metabolism in ovine fetuses during severe cord occlusion. Am J Obstet Gynecol 171:15:49-1555

Barkovich A], Hallam D. (1997) Neuroimaging in perinatal hypoxic ischemic injury. MRDD Research Reviens $3: 28-41$

Barkovich AJ, Sargent SK. (1995) Profound asphyxia in the premature infant: imaging findings. ANR Am ) Neuroradiol $10: 1837-1846$

Barkovich A, Truwit CL. (1990) Brain damage from perinatal asphywa: correlation of MR findings with gestational age. ANR Am / Newroradiol I 1:1087-1090

Barkovich AJ, Westmark K. Partridge C, Sola A, Ferriero DM. I 1995 I Perinatal asphyxia: MR Indings in the first 10 days. AJNR Am I Neuroradiol 10:427.438

Battin M, Bennet L, Gunn A. (2004) Rebound seizures duning rewarming Pediatrics 1 14:1369

Beilharz EJ, Russo VC, Buler G, Baker NL, Connor B, Sirimanne ES, Dragunow M, Werther GA, Guckman PD, Willams CE, Scheepens A. (1998) Co-ordinated and cellulal specific induction of the components of the IGF/IGFBP axis im the rat brain following hypoxicischemic injury. Brain Res Mol Brain Res 50:119.134

Beilharz EJ, Williams CE, Dragunow M, Sirmanne ES, Gluckman PD. (1995) Mechanisms of delayed cell death following hypoxic ischemic injury in the immature rat: evidence for apoptosis during selective neuronal loss. Brain Res Mol Brain Res 29:1-14

Bejar R, Wozniak P, Allard M, Benirschke K, Vaucher Y, Coen R, Berry C, Schragg P, Villegas I, Resnik R. (1988) Antenatal origin of neurologic damage in newbom infants. I. Preterm infants. Am J Obstet Gynecol 159:357-363

Benret L, Peebles DM, Edwards AD, Rios A, Hanson MA. (1998) The cerebral hemodynamic response to asphyxia and hypoxia in the neatem fetal sheep as measured by near infrared spectroscopy. Rediatr Res 44:951.057 
Bennet $L$, Ouaedackers $1 S_{3}$ Gunn Al, Rossenrode $\$$, Heineman E. (2000) The effect of asphyxia on superior mesenteric artery blood flow in the premature sheep fetus. I Pediat Surg 35.34-40

Bennet L, Rossenrode S, Gunning M, Guckman PD, Gumn AJ (1999) The cardiovascular and cerebrovascular responses of the immature fetal sheep to acute umbilical cord occlusion. I Prysiol (Lond) 517:247-257

Bennet I, Westgate IA, Cluckman PD, Gurn A. (2002) Pathophysiology of asphyxid. In: Fetal and Neonatal Neurology and Newrosurgery (Levene $M$, Whitule $M_{y}$ Chervenak F et al, eds)

Berger $R$, Gamier $Y .(2000)$ Pernatal brain injury. J Perinat.Med 28261-285

Bernard SA, Gray TW, Bust MD, Jones BM, Silvester $W$, Gutteridge $G_{1}$ Smith $K$. (2002) Treament of comatose survivors of out of hospital cardiac arrest with induced hypothermia. N Engl J Med 346:557-563

Bolt RI, van Weissenbruch MM, Lafeber HN, Delemarre-van de Waal HA. [2002a) Development of the hypothalamic pituitary adrenal axis in the fetus and preterm infant. J Pediatr Endocrinol Metab 15:759.769

Bolt R, Van Weissenbruch MM, Popp-5nijders C, Sweep FG, Lafeber HN, Delemarre van de Waal HA. (2002b) Maturity of the actrenal cortex in very preterm infants is related to gestational age. Pediatr Res 52:405-410

Bona E, Andersson AL, Blomgren K, Gilland F, Puka Sundwall M, Gustafson K, Hagberg H. (1999) Chemokine and inflammatory cell response to hypoxia-ischemia in immature rats. Pediatr Res 45:500-509

Brann AW, Ji., Myers RE. (1975) Central nervous system findings in the newborn monkey following severe in utero partial asphyxia. Newrology $25: 327 \cdot 338$

Buetow KC, Kein SW. (1964) Effect of Maintenance of "Normal" Skin Temperature on Sutvival of Infants of Low Binth Weight. Pediatrics 34:163-170

Busto R, Dietrich WD, Globus MY, Valdes I, Scheinberg P, Ginsberg MD. (1.987) Small differences in intraischemic brain temperature critically determine the extent of ischemic neuronal injury. J Cereb Blood Flow Metab 7:729-738

Campistol J, Poo P, Fernaridez AE, Carratala F. (1990) Parasagittal cerebral injury: magnetic resonance findings. I Child Neurol 14:683-685

Chatual $H$, D'Souza SW, Barson Al, Slater P. (1998) Modulation by magnesium of N-methyl-D-aspartate receptors in developing human brain. Arch Dis Child Fetal Neonatal Ed 78:F110-120

Challis JR, Brooks AN. (1989) Maturation and activation of hypothalamic-piwitary adrenal function in fetal sheep. Endocr.Rev. 10:182204

Chang YS, Park WS, Lee M, Kim KS, Shin SM, Choi JH. (1999) Near intrared spectroscopic montoring of secondary cerebral energy lailure after tansient global hypoxialschemia in the newborn piglet. Neurol Res $21: 210 \cdot 224$

Cheng C, Matsukawa T, Sessler Df, Ozaki M, Kurz A, Merrfield B, Lin H. Olofsson P. (1095) Increasing mean skin temperature linearly reduces the coretemperature thresholds for wasoconstriction and shivering in humans. Anesthesiology $82: 1160 \cdot 1168$

Clark SL, Hankins GD. (2003) Temporal and demographic trends in cerebral palsy-fact and fiction. Am.J. Obstet. Gynecot. 188:628-033

Cohen WR, Plasecki GI, Jackson BT. (1982) Plasma catecholamines during hypoxemia in fetal lamb. Am J Physiol 243:R520-R525

Colboume F, Corbett D. (1904) Delayed and prolonged post-ischemic hypothermia is neuroprotective in the gerbil. Brain Res $054265-272$

Colboume F, Corbett D. (1905) Delayed postischemic hpothermia: a six month survival study using behavioral and histological assessments of neuroprotection. f Neurosci 15:7250.7260

Colboume F, Corbett D, Zhao Z, Yang J, Buchan AM. (2000) Prolonged but delayed postischemic hypothermia: a longterm outcome study in the rat middle cerebral artery occlusion model. / Cereb Blood Flow Metab 20:1702-1708 
Colboume $\mathrm{FHH}$, Buchan AM. (1999a) Indefatgable CA I sector neuroprotecton with mild hypotherinta induced 6 hours after severe forebrain ischemia in was. / Cereb Blood Flow Metab 19.742749

Colboume F, Sutherland G, Corbet D. (1097) Postschemic hpothemia. A critical appraisal with implications for cinical treatment. Mol Newrobiol 14:171-201

Colboume F, Sutherland GR, Auer RN. (1999b) Electron microscopic evidence agatinst apoptosis as the mechanism of neuronal death in global ischemia. J Neurosci $19: 4200 \cdot 4210$

Cowan F, Rutherford M, Groenendaal F, Eken P, Mercuri E, Bydder GM, Meiners LC, Dubowitz LM, de Vies LS. (2003) Origin and thing of brain lesions in term infants with neonatal encephalopathy. Lancer $301: 730^{\circ}$ 742

Crowther CA, Hiler JE, Doyle LW, Hastam RR. [2003) Effect of magnesim sulate given for meuroprotection belore preterm birth: a randomized controlled trial. /AMA 200:2669-2676

Dammann O, Leviton A. (2000) Brain damage in preterm newborns: biological response modification as a strategy to reduce disabilities. I Pediatr $136: 433-438$

Dawes GS, Mott IC, Shelley HI. (1959) The importance of cardiac glycogen for the maintenance of life in foetal lambs and newborn animals during anoxia. / Physiol 146.516 .538

Dawes GS, Mott IC, Shelley HJ, Stafford A. (1963) The Prolongation of Survival Time in Asphyxiated Immature Foetal Lambs. J Physiol 168:43-64

Day RL, Caliguiri L, Kamenski C, Ehrich F. (1964) Body temperature and survival of premature infants. Pediatrics $34: 171-181$

De Haan HH, Gunn AJ, Williams CE, Gluckman PD. (1997) Brief repeated umbilical cord occlusions cause sustained cytotoxic cerebral edema and focal infarcts in nearterm felal lambs. Pedatr Res 41:90:104

de Vries LS, Eken P, Dubowitz LM. (1992) The spectrum of levkomalacia using cranial ultrasound. Behaw Brain Res $49: 1-6$

de Vries LS, Eken P, Grcenendaal F, Rademaker KJ, Hoogervorst B, Bruinse HW. (1998) Antenatal onset of haemorithagic and/or ischaemic lesions in preterm infants: prevalence and associated obstetric variables. Arch Dis Child Fetal Neonatal Ed 78:151-F56

de Vries LS, Groenendaal F. (2002) Neuroimaging in the preterm infant. Ment Retard Dev Disabil Res Rev 8:273. 280

De Vhies LS, Van Haastert IL, Rademaker KJ, Koopman C, Groenendaal F. (2004) Ultrasound abnormalities preceding cerebral palsy in higl risk preterm inants. / Pediatr 144:815-820

Dobbing J, Sands J. (1979) Comparative aspects of the brain growth spurt. Earty Hum Dev 3:70.83

Du Plessis AJ. (1998) Induced mild hypothemia: the spearhead strategy for effective neonatai neuroprotection? Pediatros 102:972974

du Plessis Al, Volpe J. (2002) Perinatal brain injury in the pretern and tern newbom. Cur Oph Neurol 15:151-157

Eamshaw WC, Samejima K, Durrieu F, Fortune J, Osheroff N. (2000) Biochemical mechanism of apoptotc execution. Ann Endocrinol (Paris) $61: 137$

Easman NJ. 1932) Foetal Blood Studies III: The Chemical Nature of Asphyxia Neonatorum and its Bearing on Certain Practical Problems. Bull \%. Hop. Hosp. 50:1:39

Edwards AD, Nelson KB. 1998 ) Neonatal encephalopathies. Time to reconsider the cause of ancephalopathies. BM $317: 1537-1538$

Edwards AD, Yue X, Squier MV, Thoresen M, Cady EB, Penrice J, Cooper CE, Wyat IS, Reynolds Eo, Mehmet H. (1995) Specific inhibition of apoptosis after cerebral hypoxia-ischaemia by moderate postinsult hypothermia. Biochem Biophys Res Commun 217:1193-1199

Fassbender K, Schmidt R, Mossner R, Daffertshofer M, Hennerici M. (1994) Pattern of activation of the hypothalamic-pituitaryadrenal axis in acute stroke. Relation to acute conlusional siate, extent of bram damage, and clinical outcome. Stroke 25:1105-1108 
Felix JF, Badawi N, Kurinczuk J, Bower $\mathrm{C}$, Keogh JM, Pemberton PJ. (2000) Birth defecis in children with newborn encephalopathy. Dev Med Child Neurol 42,803-808

Feld DR, Parer IT, Austender RA, Cheek DB, Baker W, Johnson J. (1990) Cerebral oxygen consumption during asplywia in fetal sheep. J Dev Physiof $14: 131-137$

Fraser $M$, Braems $G A$, Challs $)$ R. (2001) Developmental regulation of corticotrophin receptor gene expression in the adrenal gland of the owne fetus and newbom lamb. effects of hypoxia duning late pregnancy. J Endocrinol $169: 1-10$

Gardner DS, Fletcher Ad, Fowden AL, Gussani DA. (2001) A nowel method for controlled and reversible long term compression of the umbilical cond in fetal sheep. I Physiol 535:217-229

Gerrits LC, Battin Mh, Benzet L, Gonzalez H, Gunn AJ. (2005) Eplleptiform activity during rewarming from moderate cerebral hypothermia in the nearterm fetal sheep. Pediatr Res 57:342-346

Gibbs IM, Weindling AM. (1994) Neonatal intracranial lesions following placental abruption. Eur J Pediatr 153:195. 197

Gussani DA, Unno $N$, Jenkins SL, Wentworth RA, Derks JB, Collins JH, Nathanielsz PW. (1997) Dynamics of Cardovascular responses to repeated partial umbilical cord compression in late-gestation sheep fetus. Am I Physiol $273:-12351-12360$

Gluckman PD, Guan J, Willams C, Scheepens A, Zhang R, Bennet L, Gunn A. (1998) Asphyxial brain injurythe role of the IGF system. Mol Cell Endocinal 140:95.99

Gluckman PD, Pinal CS, Gunn AJ. (2001) Hypoxic-ischemic brain injury in the newborn: pathophysiology and potential strategies for intervention. Semin Neonatol 6:109-120

Gluckman PD, Wyatt JS, AzzopardI D, Ballard R, Edwards AD, Ferriero DM, Polin RA, Robertson CM, Thoresen M, Whitelaw A, Gunn AJ. (2005) Selective head cooling with mill systemic hypothermia after neonatal. encephalopathy: multicentre randomised trial. Lancet 305:603-670.

Goldenberg RL, Rouse D). (1998) Prevention of premature birth. N Ergl / Med 339:313-320

Gonzalez H, Hunter CI, Bennet L, Powet GG, Gunn A]. (2005) Cerebral axygenation during postasphyxial seizures in nearterm fetal sheep. J Cereb Blood Flow Metab 25:911.918

Gordon Cl, Heath JE. (1986) Integration and central processing in temperature regulation. Annu Rev Physiol 48:595-612

Groenendaal F, Lindemans C, Uiterwaal CS, de Vries LS. (2003) Early arterial lactate and prediction of outcome in preterm neonates admitted to a neonatal intensive care unit. Biol Neonate $83: 171-176$

Guan J, Bennet L, George S, Wu D, Waldvogel H, Gluckman PD, Faull RL, Crosier PS, Gunn A. (2001) Insulinlike growth factor 1 reduces postischemic white matter injury in fetal sheep. I Cereb Blood Flow Metab 21:403-502

Guan 1, Bennet L, Gluckman PD, Gunn A. (2003) Insulin-ike growth factor-1 and post ischemic brain injury. Prog Neurobiol $70: 443-462$

Guan J, Willams CE, Skinner SI, Mallard EC, Gluckman PD. (1996) The effects of insulin-like growth factor

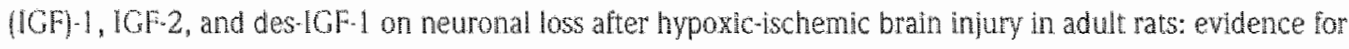
a role for 1CF binding proteins. Endocrinology 137:893-898

Gunn A. 120001 Cevebral hypothermia for prevention of brain injury following perinatal asplyxia. Curt Opin Pediatr 12:111-115

Gunn AJ, Battin M. (2000) Hypothermic centralization: new use for old knowledge? Pediatrics 106:133-134

Gunn A, Bennet L, Guning MI, Gluckman PD, Gunn TR. (1999a) Cerebral hypothemia is not neuroprotective When started after postischemic seizures in felal sheep. Pediatr Res 46:274280

Gunn A. Cook Cl, Williams CE, Johnston BM, Giuckman PD. (1991) Electrophysiological responses of the fetus to bypoxia and asphyxia. Dew Physiol 16:147.153 
Gun A, De Haan HH, Gluckman PD. (1997a) Experimenta models of penatal bran injury. In: Fetal o Neonatal Brain hiury Mechanisms, management and the risks of practice (Stevenson DK. Sundhine P, eds), Oxford: Oxford Medical Publications, pp 59.70

Gunn AJ, Gunn TR. (1998) The 'pharmacology' of neuronal rescue with cerebral hypothemia. Earty Hum Dev 53:19-35

Gunn A), Gunn TR, De Haan HH, Wiliams CE, Gluckman PD. (1997b) Dramatic neuronal rescue with prolonged selective head cooling after ischemia in fetal lambs / Chn /mwest 09:248.250

Gunn A, Gun TR, Guning Ml, Willams CE, Gluckman PD. (1998) Neuroprotection with prolonged head cooling started before postischemic seizures in fetal sheep. Pedatrics 102:1008-1106

Gunn AJ, Quaedackers IS, Guan J, Heineman E, Bennet L. 12001) The premature tetus: not as defenseless as we thought, but still paradoxically vulnerable? Dev Newrosci $23: 175-179$

Gunn TR, Gluckman PD. (1995) Perinatal themogenesis. Early Hum Dev 42:169-183

Gunn TR, Wison NJ, Aftimos S, Gunn Al. (19990) Brain hypothemia and OT interval. Pediatrics 103:1079

Hadand K, Loberg EM, Steen PA, Thoresen M. (1997) Posthypoxic hypothermia in newbon piglets. Pediatr Res $41.505 \cdot 512$

Hack M, Fanaroff AA. (2000) Outcomes of chidren of extremely low bithweight and gestational age in the 1990s. Semin Neonato $5: 89-100$

Hack M, Flannery D], Schluchter M, Cartar L, Borawski E, Klein N. (2002) Outcomes in young adulthood for

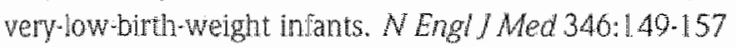

Hagberg $B$, Hagberg $O$, Beckung E, Uvebrant P. (2001) Changing panorama of cerebral palsy in Sweden. VII.. Prevalence and origin in the birth year period 1991-94. Acta Paedatr 90:27 1-277

Hagberg B, Hagherg $\mathrm{G}_{4}$ Zetterstrom R. 1989 ) Decreasing perinatal mortality-increase in cerebral palsy morbidity. Acta Paediatr Scand78:604-670

Hagberg H, Bona E, Gilland E, Puka-Sundvall M. (1997) Hypoxia-Aschaemia model in the 7-day-old rat: possibilities and shortcomings. Acta Paediatr Suppl 422:85-88

Hagberg H, Peebles D, Mallard C. (2002) Models of white matter injury: Comparison of infectious, hypoxicischemic, and excitotoxic insults. Ment Retard Dev Disabil Res Rev 8:30-38

Han TR, Bang MS, Lim JY, Yoon BH, Kim IW. (2002) Risk factors of cerebral palsy in preterm infants. Am J Phys Med Rehabil B1:297-303

Hankins GD, Speer M. (2003) Defining the pathogenesis and pathophysiology of neonatal encephalopathy and cerebral palsy. Obstet Gyneco 1 102:628.636

Hanson MA. (1907) Do we now understand the control of the fetal circulation? Eur / Obstet Gynecol Reprod Bol $75: 55-61$

Hayakawa $F$, Okumura A, Kato $T, K u n o ~ K$, Watanabe K. (1999) Determination of timing of bratn injury in pretem Iniants whith perivenucular leukomalacia with serial neonatal electroencephalography. Pediatrics $104: 10771081$

Hunter CJ, Bennet L, Power GG, Roelsema V, Blood AB, Ouaedackers JS, George S, Cuan J, Gunn A. (2003a) Key neuroprotective role for endogenous adenosine $A 1$ receptor activation during asphyxia in the fetal sheep. Stroke $34: 2240 \cdot 2245$

Hunter CJ, Blood AB, White CR, Pearce W], Power GC. 2003b) Role of nitric oxide in hypoxic cerebral wasodilatation in the ovine fetus. / Physiol 549:625 633

Hypothermia after Cardiac Arrest Study Group. (2002) Mild therapeutic hypothermia to improve the neurologic outcome after cardiac arrest. $N$ Engl / Med $340: 549-550$

Ikeda T, Murata Y, Quilligan EI, Choi BH, Parer IT, Dot S, Park SD. (1998) Physiologic and histologic changes in nearterm fetal lambs exposed to asphyxia by partial umbilical cord occlusion. An / Obstet cynecol 178:24-32

Inamasu J, Suga S, Sato S, Horiguchi T, Akaji K, Mayanagi K, Kawase T. 2000a) Postischemic hypothermia attenuates apoptotic cell death in transient focal ischemia in rats. Acta Neurochir Suppl 76:525.527 


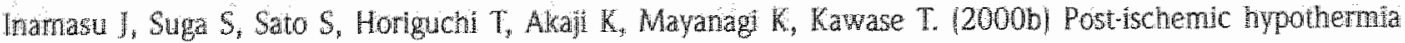
delayed neutrophl accumulation and microglal actwation following transient local ischemia in rats. $f$ Neurommunol. 109:60-74

Inder TE, Hunt RW, Monley CJ, Colenan L, Stewart M, Doyle LW, Jacobs SE. (2004) Randomized trial of systemic hypothermia selectively protecs the cortex on MRI in werm hypoxic-ischemic encephalopathy. $f$ pediatr $145,835 \times 837$

Inder TE, Huppi PS, Waffeld S, Kiwinis R, Zlentara GP, Banes PD, Jolesz F, Volpe J). (1099) Periventricular white matter infury in the prenature infant is followed by reduced cerebral cortical gray matter volune at term. Ann Neurol $46: 755760$

Inder TE, Volpe ]. (2000) Mechanisms of pernatal brain injury. Semin Neonatol 5:3-16

Itskovitz ], LaGamma EF, Rudolph AM. (1983) The effect of reducing umbilical blood flow on letal okygenation. An J Obstet Cynecol 145:813-818

Iwamoto HS, Kaufman T, Keil LC, Rudolph AM. (1989) Responses to acute hypoxemia in fetal sheep at 0.60 .7 gestation. Anu.Physiol 250:Ho13-Ho20

Jacobs S, Hunt R, Tamow Mordi $W$, Inder T, Davis P. 2004) Cooling for newboms with hypoxic ischaemic encephalopathy (Cochrane Review). The Cochrane Library

Jacobsson B, Hagberg $G_{3}$ Hagberg B, Ladtors L, Nklasson A, Hagberg H. (2002) Cerebral palsy in preterm infants: a population-based casecontrol study of antenatal and intrapartal risk factors. Acta Paediatr 91.946 .951

Jensen A, Berger R. (1991) Fetal circulatory responses to oxygen lack. J Dev Physiol 16:181-207

Jensen A, Garnier Y, Berger R. (1909) Dynamiss of fetal circulatory responses to hypoxia and asphyxia. Eur J Obstet Gyrecol Reprod Biol 84:155-172

Jensen A, Roman C, Rudalph AM. (1991) Effects of reducing uterine blood flow on fetal blood flow distribution and oxygen delwery. J Dev Physiol 15:309-323

Jordan KG. (1994) Staus epllepticus. A perspective from the neuroscience intensive care unit. Neurosurg Clin NAm 5:671-680

Kaulmann SH, Mesner PW, Ir., Samejima K, Tone S, Eamshaw WC. (2000) Detection of DNA cleavage in apoptotic cells. Methods Enzymal 322:3-15

Reunen H, Blanco CE, Van Reempts IL, Hasaart TH. (1997) Absence of neuronal damage after umbilical cord occlusion of 10,15, and 20 minutes in midgestation fetal sheep. Am J Obstet Gynecol 176.515 .520

Kirno T. (1982) Delayed neuronal death in the gerbil hippocampus following ischemia. Brain Res 239:57.69 Kopchev SN. (1985) Crano-cerebral hypothemia in obstertics. Moscow: Medicina: $1-112$.

Krageloh-Mann 1, Toft P, Lunding J, Andresen I, Pryds. O, Lou HC. (1999) Brain lesions in preterms: origin, consequences and compensation. Alcia Paediatr 88:897-908

Kumar K. Evans AT. 11997) Effect of hypothermia on microglial reaction in ischemic brain. Nouroreport $8: 947$ 950

Kumazaki K, Nakayama M, Sumida Y, Ozono K, Mushake S, Suehara N, Wada Y, Fulimura M. (2002) Placental features in preterm infants with periwentricuat leukomalacia. pediatrics 109:650-655

Lee JM, Grabb MC, Zipfel GI, Chot DW. 2000/ Brain tissue responses to ischemia. / Clin Invest 106:723-731

Lieberman E, Lang I, Richardson DK, Frigoletto FD, Heffner LJ, Cohen A. 2000 J Intrapartum matenal fever and neonatal outcome. Pediatrics 1.05:8-13

Lin X, Okumuma, Hayakawa F, Kato K, Kuno T, Watanabe K. (2001) Quantitative evaluation of thalami and basal ganglia in infants with periventricular leukomalacia. Dev Med Child Neurol 43:481.485

Litte WI. (1801) On the Influence of Abnormal Parturition, Difficult Labours, Premature Birth and Asphyxia Neonatorum on the Mental and Physical Condition of the Child, Especialy in Relation to Deformity. Trams. Obstet. Sac. London 3.293-344 
Llanos Al, Riquelme RA, Sanhueza EM, Hanson MA, Banco CE, Parer JT, Herrera EA, Pulgar WM, Reyes RV, Cabello G, Guussani DA. (2003) The fetal hama versus the letal sheep: different strategles to whinstand hypoxia. High Alt Med Biol 4.193202

Longo LD, Ashwal S. (1993) William Osler, Sigmund Freud and the evolution of deas concerning cerebral palsy. J Hist Neurosci 2.255282

Lorek A, Take Y, Cady EB, Wyat IS, Pentice J, Edwards AD, Peebles D, Wylezinska M, Owen-Reece H, Kirkbnde V. (1994) Delayed " "secondary") cerebral energy lailure after acute bypoxia-ischemia in the newbon piglet: contimuous 48-hour studies by phosphorus magnetic resonance spectroscopy. Pediatr Res 36.099 .700

Low IA. (1997) Intrapartum fetal asphyxia: definition, diagnosis, and classfication. Am J Obstet Gynecol176:957. 959

Low JA. $[2004)$ Determining the contribution of asphyxia to brain damage in the neonate. / Obstet Oynaecol Res $30: 276 \cdot 280$

Low IA, Gabraith RS, Muir DW, Killen HL, Pater EA, Karchmar El. (1992) Mortally and morbidity after intraparum asphyxia in the preterm fetus. Obstet Gynecol $80.57-61$

Low JA, Killen H, Derrick E. (2003) Antepartum fetal asphyxia in the preterm pregnancy. Am. . Obstet. Gynecol: $188: 461-465$

Low JA, Panagiotopoulos $\mathrm{C}$, Derrick El. (1995a) Newborn complications after intrapartum asphyxia with metabolic acidosis in the pretem fetus. Am J Obstet Gynecol 172:805-810

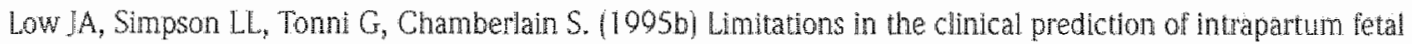
asphyxia. Am I Obstet Gynecol 172:801-804

Low JA, Wood SL, Killen HL, Pater EA, Karchmar EJ. (1900) Intrapartum asphyxia in the pretern letus less than $2000 \mathrm{gm}$. Am J Obstet Gynecol 162:378-382

Lutsep HL, Clark WM. (1999) Neuroprotection in acute ischaemic stroke. Current status and future potential. Drugs R D 138 Lynch \K, Nelson KB. (2001) Epidemiology of perinatal stroke. Cur Opin Pediatr 13:499-505

MacDonald HM, Mulligan JC, Allen AC, Taylor PM. (1980) Neonatal asphyxia. I. Relationship of obstetric and neonatal complications to neonatal mortality in 38,405 consecutive deliveries. J Pediatr $96: 898.902$

MacLennan A. (1999) A template for defining a causal relation between acute intrapartum events and cerebral palsy: international consensus statement. BM/319:1054-1059

Mallard EC, Gunn A., Willams CE, Johnston BM, Gluckman PD. (1992) Transient umbilical cord occlusion causes hippocampal damage in the fetal sheep. Am J Obstet Gynecol 167:1423-1430

Mallard EC, Wiliams CE, Johnston BM, Guckman PD. 11094] Increased wunerability to neuronal damage after umbilical cord occlusion in fetal sheep with advancing gestation. Am J Obsted Gynecol 170:200-21.4

Marks KA, Mallard EC, Roberts 1 , Williams CE, Simanne ES, Johnston B, Gluckman PD, IEdwards AD. (1996) Delayed vasodilation and altered oxygenation after cerebral ischemia in fetal sheep. Pediatr Res $39: 48.54$

Martens SE, Rijken M, Stoelhorst CM, van Zwieten PH, Zwinderman AH, WH MM, Hadders Agra M, Veen S. 12003) Is hypotension a major risk factor for neurological morbidity at term age in very preterm infants? Early Hum Dev $75: 79.89$

Marin E, Barkovich A]. (1005) Magnetic resonance jmaging in perinatal asphyxia. Arch Dis Child Fetal Neonatal Ed 72 FO2 F 70

Martin Ll. (2001) Neuronal cell death in nervous system development, disease, and injury (Review). Int I $\mathrm{Mol}$ Med 7:455-478

Matsuda Y, Patrick J, Cammichael L, Challis J, Richardson B. (1992) Effects of sustained hypoxemia on the sheep Tetus at midgestation: endocrine, cardiovascular, and biophysical responses. Am./.Obste Gynecol. 167:531.540

Meruri E, Guzzetta A, Haataja L, Cowan F, Rutherford M, Counsell S, Papadimitriou M, Cioni G, Dubowitz L. (1999) Neonatal neurological examination in infants with hypoxic ischaemic encephalopathy: cortelation with MRI findings. Neuropediatrics $30: 83.89$ 
Mercuri E, Rutherford M, Barnet A, Fogia C, Hataja L, Counsell S, Cowan F, Dubowiz L. (2002) MRI lesions. and infonts wih neonatal encephapothy. Is the Apgar score predictive? Neuropediatrics 33:150150

Miler JA. (1049) Factors in neonatal rewistance to anoxia. I. Temperature and survival of newborn guinea pigs under anoxia. Sclence $110: 113-114$

Miller JA, Miller FS, Westin B. (1964) Hypothermia in the treatment of asphyxia neonatorum. Biol Neonate $6: 148 \cdot 103$

Mires GJ, Agustsson P, Forsyth JS, Patel NB. (1091) Cerebral pathology in the very low birthweight infant: predictive walue of peripartum metabolic acidosis. Eur / Obstet Gynecol Reprod Biol 42:181-185

Mishra OP, Fitz KI, Delivoria-Papadopoulos M. (2001) NMDA receptor and neonatal hypoxic brain injury. Ment Retard Dew Disabll Res Rev 7:249.253

Mott JC. (1961) The ability of young mammals to withstand total oxygen lack. Br Med Bull 17:144-148

Muijsers Cf, Hasaart TH, Ruissen C], van Huisseling H, Peeters LL, de Haan I. (1990) The response of the umbilical and femoral artery pulsatliny indices in fetal sheep to progressively reduced uteroplacental blood flow. I Dev Physiol 13:215-221

Mulder AL, Golde JM, Goor AA, Giussani DA, Blanco CE. (2000) Developnental changes in plasma catecholamine concentrations during normoxia and acute hypoxia in the chick embryo. J.Physiol $527 \mathrm{Pt}$ $3.593 \cdot 9.593 .599$

Mulder AL, van Golde JC, Prinzen FW, Blanco CE. [1998] Cardiac output distribution in response to hypoxia in the chick embryo in the second half of the incubation time. J Physiol 508 (Pt 1):28|-287

Muller T, Lohle M, Schubert H, Bauer R, Wicher C, Antonow-Schlorke I, Sliwka U, Nathanielsz PW, Schwab M. (2002) Developmental changes in cerebual autoreguatory capacity in the fetal sheep parletal cortex. / Physiol $539: 957.067$

Mulligan IC, Painter MJ, O'Dorncghe PA, MacDonald HM, Allan AC, Taylor PM. (1980) Neonatal asphyxia. II. Neonatal mortality and long-term sequelae. J Pediatr 90:903-907

Myers RE. (1967) Experimental brain damage in the newborn monkey. J Neuropathol Exp Neuro $26: 172$

Nakalima W, Ishida A, Lange MS, Gabrielson KL, Wilson MA, Martin L, Blue ME, Johnston MV. (2000) Apoptosis has a prolonged role in the neurodegeneration after hypoxic ischemia in the newborn rat. $/$ Neurosc 20:7904.8004

Nelson KB. (2003) Can we prevent cerebral palsy? N Engl/ Med 349:1765-1769

Nelson KB, Leviton A. (1991) How much of neonatal encephalopathy is due to birth asphyxia? Am / Dis Child $145: 1325 \cdot 1331$

Nelson KB, Lynch IK. (2004) Stroke in mewbon infants. Lancet Newro 3:150-158

Ng PC, Lee CH, Lam CW, Ma KG, Fok TF, Chan IH, Wong E. (2004) Transient adrenocortical insufficiency of prematurity and systemic hypotension in very low birthweight infants. Arch Dis Child Fetal Neonatal Ed $89 . \% 110.120$

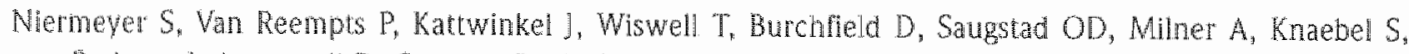
Perlman J, Azzopardi D, Cunn A, Boyle R, Toce S, Solimano A. (2001) Resuscitation of newborns. Ann Emerg Med $37 . \$ 110-125$

Northington F., Ferrtero DM, Flock DL, Martin LJ. (2001 a) Delayed meurodegeneration in neonatal rat thalamus after bypoxia ischemia is apoptosis. INeurosci $21: 1931 \cdot 1038$

Northington E. Ferriero DM, Graham EM, Traystman R, Martin LJ. (2001b) Early Neurodegeneration after Hypoxia- Ischemia in Neonatal Rat Is Necrosis while Delayed Neuronal Death Is Apoptosis. Neurobiol Dis 8:207-219

Okumura A, Hayakawa F, Kato T, Kuno K, Watanabe K. (1097) MRl findings in patients with spastic cerebral palsy. I: Correlation with gestational age at birth. Dev Med Child Neurol $39: 363368$

Oster W. 18894 The Cerebral Palsies of Children. Phiadelonia, Pa: Blakiston, Son \& Co 
Paned N. (1999) Classifying brain damage in preterm infants. J Pediat" 134527.529

Paple LA, Rudolph AM, Heymann MA. (1985) Autoregulation of cerebral blood flow in the preterm fetal lamb. Pedatr Res 19:159-161

Parer JT. (1094) Fetal cerebral metabolism: the infuence of asphyxia and other tactors. / Ferinato 14:376.385

Parer JT. (1998) Effects of fetal asphyxia on brain cell structure and Hunction: Himits of tolerance. Comp Biochem Physiol A Mol integr Physio 119:711.716

Peeters $C_{\text {s }}$ wan Bel F. (2001) Phamacotherapeutical reduction of posthypoxic-ischemic brain injury in the newborn. Biol Neonate 79:274.280

Peeters LL, Sheldon RE, Jones MD, Ir., Makowski EL, Meschia G. 11979 Blood flow to fetal organs as a function of arterial oxygen content. Am / Obstet Gyrecol 135:637-646

Petersson KH, Pinar H, Stopa EG, Fanis RA, Sadowska GB, Hanumara RG, Stonestreet BS. (2002) White matter injury after cerebral ischemia in ovine fetuses. Pediat Res 51:768.776

Pharoah PO, Plati MJ, Cooke T. (1996) The changing epidemiology of cerebral palsy. Arch Dis Child Fetal Neonatal Ed 75:F169-173

Quaedackers IS, Roelfsema V, Hunter CJ, Heineman E, Gunn AJ, Bennet L. (2004) Polyuria and impaired renal blood flow after asphyxia in preterm fetal sheep. Am J Physiol Regul integr Comp Physiol 286:R576-583

Ranck. JB, Jr. Winde WF. (1959) Brain damage in the monkey, macaca mulatta, by asphyxia neonatorum. Exp Netrol 1:130-154

Rees S, Stringer M, Just $Y$, Hoopel: SB, Harding R. (1997) The vulnerability of the fetal sheep brain to hypoxemia at mid-gestation. Brain Res Dev Brain Res 103:103-118

Richardson BS. (1989) Fetal adaptiwe responses to asphyxia. Clin Perimato 10.505 .611

Richardson BS. (1993) The fetal brain: metabolic and circulatory responses to asphyxia. Clin Invest Med 16:103. 114

Richardson BS, Carmichael L, Homan I, Johnston L, Gagnon R. (1996) Fetal cerebral, circulatory, and metabolic responses duning heart rate decelerations with umbilical cord compression. Am J Obstet Gynecol 175:929. 936

Robertson PA, Snideman SH, Lafos RK, Jr, Cowan R, Heilbron D, Goldenberg RL, Iams JD, Creasy RK. (1092) Neonatal morbidily according to gestational age and birth weight from five tertiary care centers in the United States, 1983 through 1986. Am / Obstet Gynecol 166:1629-1641; discussion 1641-1625

Roland EH, Hill A. (1995) Glincal aspects of perinatal hypoxic-ischemic brain injury. Semin Pediatr Neurol2:5771

Rose JC, Meis PI, Morris M. [1981) Ontogeny of endocrine (ACTH, vasopressin, cortisol] responses to hypotension in lamb fetuses. Am.J.Physiol 240:E650-E661

Roth SC, Baudin I, Cady E, Johal K, Townsend IP, Wyatt JS, Reynolds EO, Stewart AL. (1907) Relation of deranged neonatal cerebral oxidative metabolism with neurodevelopmental outcome and head circumference at 4 years. Dev Med Child Neurol 39:718-725

Rutherford MA, Pennock JM, Schwieso JE, Cowan FM, Dubowitz LM. (1995) Hypowic ischaemic encephalopathy: early magnetic resonance imaging findings and their evolution. Neuropediatics $26: 183$. 191

Salhab WA, Perman IM. (2005) Severe fetal acidemia and subsequent neonata encephalopathy in the larger premature infant. Pediatr Neurol $32: 2529$

Samejima K, Tone S, Kottke T], Enari M, Sakahira H, Cooke CA, Durreu F, Martins LM, Nagata S, Kaufmann SH, Earnshaw WG. (1998) Transition from caspase-dependent to caspase-independent mechanisms at the onset of apoptotic execution. / Cell Biol $1432225-239$

Sargent MA, Poskitt KJ, Roland EH, Hill A, Hendson G. (2004) Cerebellar vermian atrophy after neonatal hypoxicischemic encephalopathy. A/NR Am J Neuroradiol 25:1008.1015 
Shalak LF Perman IM. (2002) Infection markers and early signs of neonatal encephatopathy in the tern infant. Ment Retard Dev Disabll Res Rev 8:14 19

Sheldon RE, Peeters LL, Jones MD, J., Makowsk EL, Meschia G. 11979) Redistribution of cardiac output and oxygen delwery in the hypoxemic letal lamb. Am J Obstet Gnecol 135:1071-1078

Shelley HJ. (1964) Carbohydrate Reserves in the Newborn Infant. Br Med/5378.273.275

Sle LT, wan der Knaap MS, Oosting I, de Vries LS, Lafeber HN, Valk J. (2000) MR pattems of trypoxicischemic brain dantage after prenatal, periuatal or postnatal asphyxia. Neuropediatrics 31:128.136

Silwermar WA. (1998) Cooling the asplyxiated newborn-responsibly. Pediatrics 101:697-698

SHwerman WA, Fertig IW, Berger AP. (1958) The intluence of the thermal envimonment upon the survival of newly born premature infants. Pedatrics $22,876.886$

Siversten FS, Barks JD, Hagan P, LH XH, lvacko J, Saglarski I. (1997) Cytokines and perinatal brain injury. Neurochem Int 30:375-383

Spinillo A, Capuzzo E, Sronati M, Ometo A, De Santolo A, Acciano S. 119981 Obsteric risk factors for periwentricular leukomalacia among preterm intants. Br J Obstet Gynaecol 105:865871

Stevenson DK, Werter ], Fanaroff AA, On W, Enrenkranz RA, Shankaran S, Donovan EF, Wright LL, Lemons JA, "yson IE, Korones SB, Bauer CR, Stoll BJ, Papile LA. (2000) Sex differences in outcomes of wery low birthweight infants: the newborn male disadvantage. Arch Dis ChId Fetal Neonatal Ed 83:F182-185

Susin SA, Daugas E, Ravagnan L, Samejima K, Zamzami N, Loefler M. Costantini P, Feni KF, Irinopoulou T, Prevost MC, Brothers G, Mak TW, Penninger J, Earnshaw WC, Kroemer G. [2000) Two distinct pathways leading to nuclear apoptosis. / Exp Med 192:571.580

Suzuki S, Murata T, Jiang L, Power GG. (2000/ Hyperthermia prevents metabolic and cerebral flow responses to bypoxia in the fetal sheep. / Soc Gynecol Investig $7: 45.50$

Thoresen M. (1999) Cooling the asphyxiated brain - ready for clinical trials? Eur J Pediatr 158 Suppl I.S5-S8

Thoresen M. (2000) Cooling the newbon after asphyxia - physiological and experimental background and its clinical use. Semin Neonato/ $5: 01.73$

Thoresen M, Satas S, Loberg EM, Whitelaw A, Acolet D, Lindgren C, Penrice J, Robertson N, Haug E, Steen PA. 20011 Twenty-four hours of mild hypothermia in unsedated newborn pigs starting after a severe global hypoxic-ischernic insult is not neuroprotective. Pediatr Res 50:405-411

Thoresen M, Whitelaw A. (2005) Therapeutic hypothermia for hypoxic ischaemic encephalopathy in the newborn infant. Curr Opin Neurol 18:111-116

Thoresen M, Wyati 1. (1997) Keeping a cool head, post hypoxic hypothermia-an old idea revisited. Acta Paediatr 80:1029-1033

Tomimalsu T, Fukuda H, Kanagawa T, Mu I, Kanzaki T, Murata Y. 2003) Effects of byperthermia on hypoxic ischemic brain damage in the immature rat: its influence on caspase 3-ike protease. Am. Obstet. Gynecol. $188: 708-773$

Tooley 1, Satas S, Eagle R, Silve: IA, Thoresen M. 2002) Significant Selective Head Cooling Can be Maintained Long Term After Global Hypoxia Ischemia in Newbon Piglets. Pediatrics 109:643049

Tooley JR, Eagle RC, Satas S, Thoresen M. (2005) Significant head cooling can be achieved while maintaning normothermia in the newborn piglet. Arch Dis Child Fetal Neonatal Ed 90:2262-260

Tucker ], McGuire W. [2004) Epidenlology of preterm birth. BMJ329:075-678

Tuertings 1H. Smits AP, van den Berg PP. (2002) IPerinatal asphyxia as inconect explanation for mental retardation. Ned Tidsch Geneeskd 146:1705.1768

van de Bor M, Walther $\mathrm{H}$. (1991) Cenebral blood flow velocity regulation in preterm infants. Biol Neonate 59:32\%335

wan den Berg PP, Nelen WL, Jongsma HW, Nilland R, Kollee LA, Nijhuis JG, Eskes TK. (1996) Neonatal complications in newborns with an umbilical artery $\mathrm{pH}<7.00$. Am / Obstet Gmecol 175:1152-1157 
Wan Leewwen GM, Hand JW, Lagendik J, Azzopardi DV, Edwards AD. $[2000$ 1 Numerical modeling of temperature distributions within the neonatal head. Pedat Res $48.351-350$

Vannucci RC. (2000) Hypoxic ischemic encephatopathy. Am J Pernatol $17.113 \cdot 120$

Wannuci RC, Pertman JM. (1997) Interventions for perinatal hypoxiclschemic encephalopathy. Pedatrics 100:1004-1014

Victory R, Penawa D, da Siva O, Natale R, Richardson B. (2003) Umbilical cord pH and base excess values in relation to neonatal morbidity for infants delivered pretem. Am/.06stet.Gyecol. 189:803-807

Volmer B, Roth S, Baudin I, Stewart AL, Neville BG, Wyatt IS. (2003) Predictors of long-tenin outcome in very preterm infants: gestational age yersus neonatal cranial ultrasound. Pedatrics $112: 1108-1114$

Volpe J. (1998a) Brain injury in the premature infant: overview of clincal aspects, neuropathology, and pathogenesis. Semin Pediatr Neurol 5:135-151

Volpe 11. (1998b) Brain injury in the premature infant: overwew of cinical aspects, neuropathology, and pathogenesis. Semin Pediatr Neurol 5:135151

Volpe J. (2001a) Neurobiology of periventricular leukomalacia in the premature infant. Pediatr Res 50:553-562

Volpe IJ. (200 lb) Neurology of the Newborn. Boston, Massachusetts: WB. Saunders Company

Volpe JJ. (2005) Encephalopathy of prematurity includes neuronal abnormalities. Pediatrics 110.221 .225

Weindling AM, Wikinson AR, CookI, Calvert SA, Fok TF, Rochefort MI. (1985) Perinatal events which precede periventricular haemorrhage and leukomalacia in the newborn. Br. Obstet Gynaecol 92:1218-1223

Weinrauch V, Safar P, Tisheman S, Kuboyama K, Radovsky A. (1992) Beneficial effect of mild hypothermia and detrimental effect ot deep hypothermia after cardiac arrest in dogs. Stroke 23:1454-1462

Williams CE, Gumn $A_{1}$ Gluckman PD. (1991) Time course of intracellular edema and epileptiform activity following prenatal cerebral ischemia in sheep. Stroke $22: 516.521$

Wiliams CE, Gunn AI, Synek B, Gluckman PD. (1990) Delayed seizures occuring with hypoxic ischemic encephalopathy in the fetal sheep. Pediatr Res 27:561-565

Willams CE, Mallard C, Tan W, Gluckman PD. (1993) Pathophysiology of pernatal asphyxia. Cin Perinatol $20: 305-325$

Windle W. [1963] Selective vulnerability of the CNS of thesus monkeys to asphyxia during birth. In: Selective Vulnerabilty of the brain in hypoxemia (Schade J, McMenemy W, eds), Philadelphia: Davis, pp 251255

Wood NS, Marlow N, Costeloe K, Gibson AT, Wilkinson AR. (2000) Neurologic and developmental disability after extremely preterm bith. EPICure Study Group. N Engl J Med 343:378-384

Wyat J5, Thoresen M. (1997) Hypothemia treament and the newbom. Pedatrics 100:1028-1030

Yam PS, Dunn LT, Graham DI, Dewar D, McCuloch I. (2000) NMDA receptor blockade bails to alter axonal injury in focal cerebral ischemia. I Cereb Blood Flow Metab 20:772-779

Yokochi $\mathrm{K}$. (1997) Thalamic lesions revealed by MR associated with periventricular leukomalacia and clinical profiles of subjects. Acta Paediatt $86: 493-490$

Yokoch $K$, Fujmoto S. (1990) Magnetic resonance imaging in children with neonatal asphyziat correlation with developmental sequelae. Acta Paediat $85: 88.95$ 


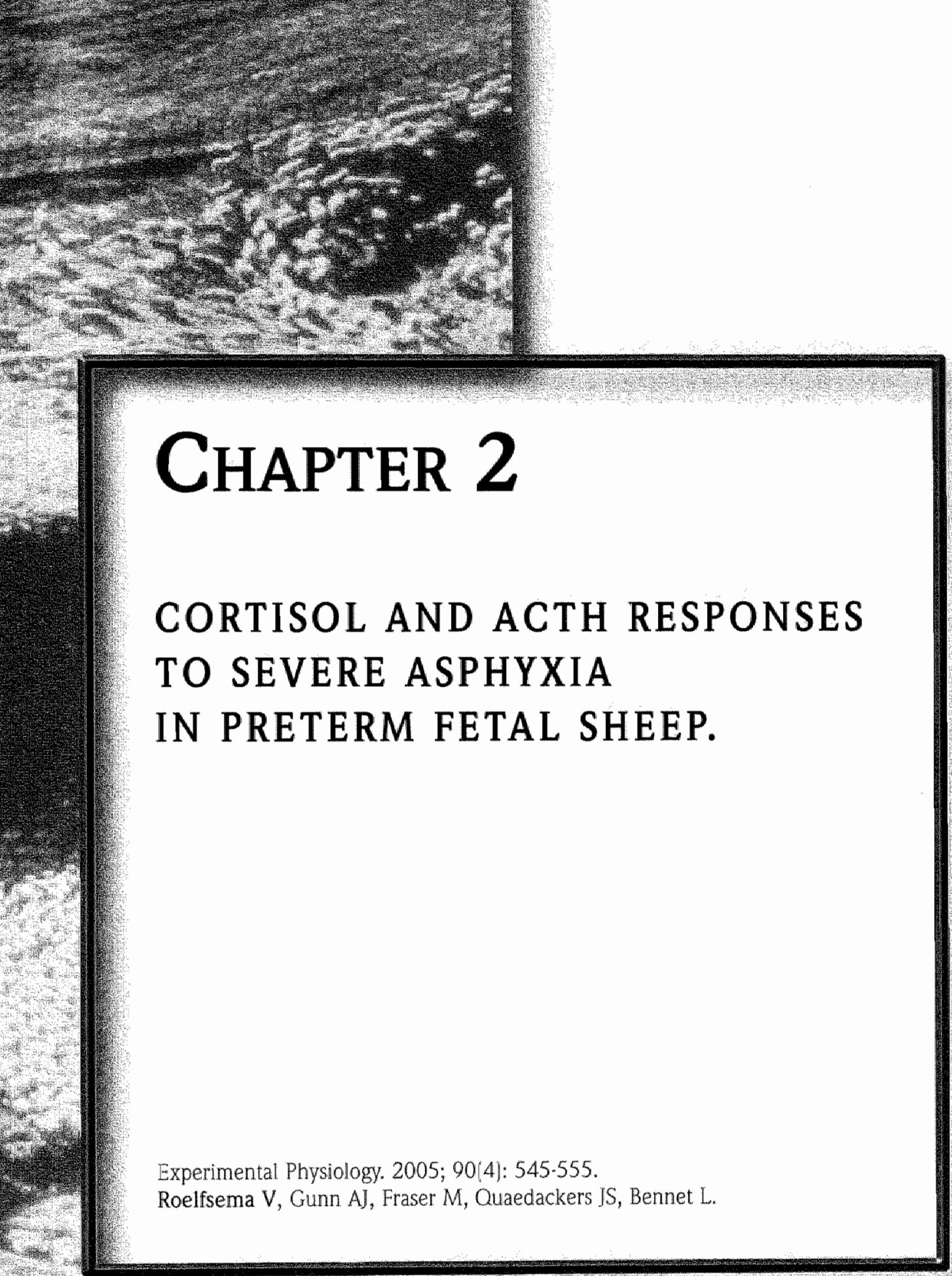

Experimental Physiology. 2005; 90:4]: 545-555.

Roelfsema V, Gunn A], Fraser M, Quaedackers IS, Bennet L. 


\section{ABSTRACT}

It has been hypothesized that the hypothalamic pituitary-adrenal (HPA) axis is immature in the preterm fetus and that this compromises their ability to adapt to hypoxic stress; however, there are few direct data. We therefore examined the effects of asphyxia on HPA responses in chronically instrumented preterm fetal sheep (104 days of gestation; term is 147 days), allocated to a sham control group $(n=7)$ or 25 min of complete umbilical cord occlusion $(n=8)$, followed by recovery for $72 \mathrm{~h}$. During umbilical cord occlusion there was a rapid rise in ACTH levels $\left(230.4 \pm 63.5\right.$ versus $14.1 \pm 1.8 \mathrm{ng} \mathrm{ml}^{-1}$ in sham controls, 16 -fold $)$ and cortisol levels $\left(7.4 \pm 4.9\right.$ versus $0.2 \pm 0.1 \mathrm{ng} \mathrm{m}^{-1}, 31$-fold), with further increases after release of cord occlusion. ACTH levels were normalized by $24 \mathrm{~h}$, while plasma cortisol levels returned to sham control values $72 \mathrm{~h}$ after asphyxia. Fetal arterial blood pressure was elevated in the first $36 \mathrm{~h}$, with a marked increase in femoral vascular resistance, and correlated positively with cortisol levels after asphyxia $(P=0.05)$. In conclusion, the preterm fetus shows a brisk, substantial HPA response to severe hypoxia.

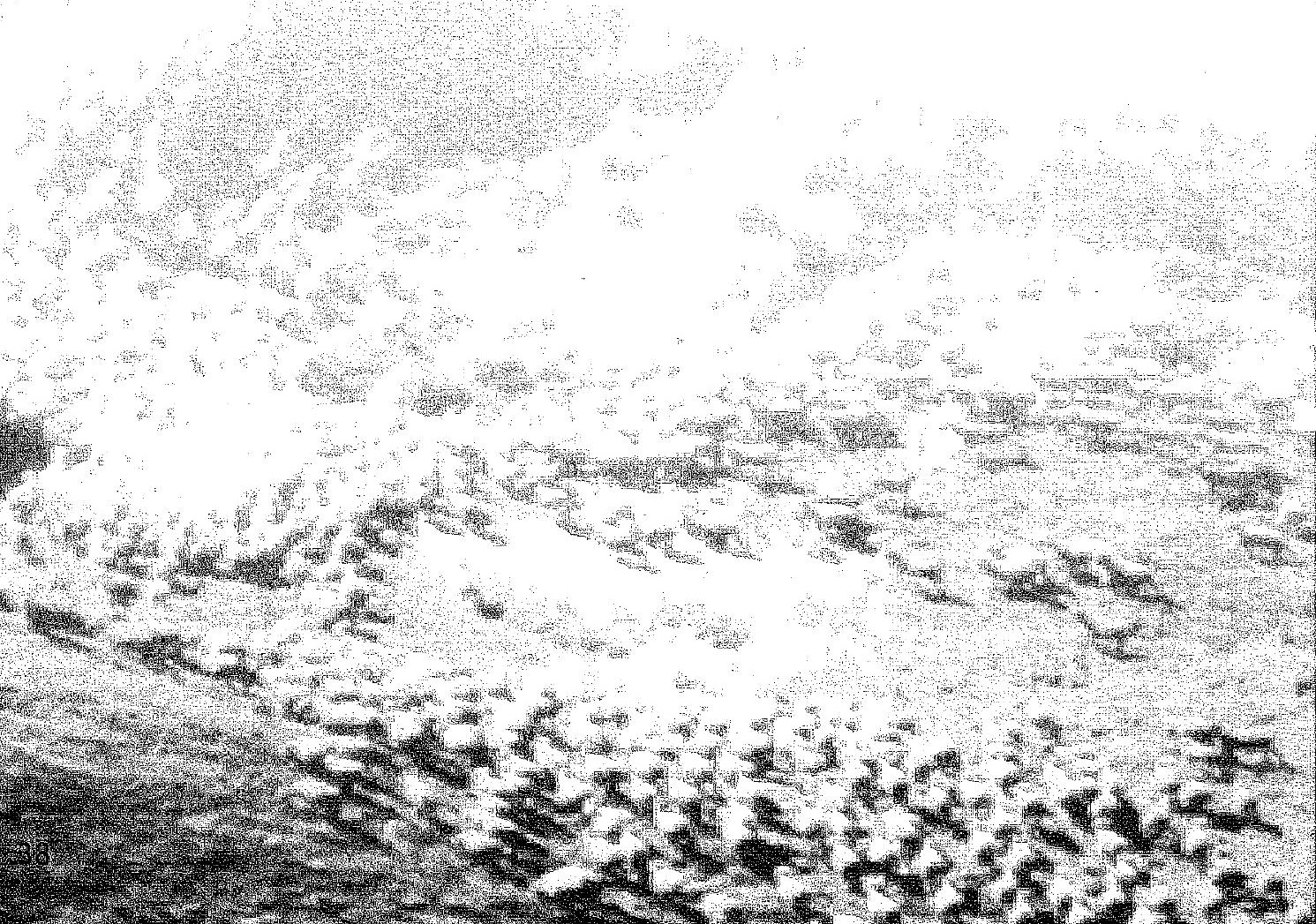




\section{INTRODUCTION}

Both human and ovine fetuses show activation of the hypothalamic-pituitary-adrenal (HPA) axis in late gestation (in the ovine fetus from 120 days gestation onwards), which contributes to organ maturation (Challis \& Brooks, 1989). Activation of the fetal HPA axis also occurs in response to hypoxic stress, as shown by increased plasma concentrations of ACTH and cortisol, which in turn support acute cardiovascular and metabolic adaptations (Giussani et al. 1994C). It has been proposed that these two phenomena are linked, i.e. that the rise in basal cortisol levels (Whittle et al. 2001) and increased levels of mRNA for the adrenal A.CTH receptor near term (Fraser et at. 2001) predict a maturational increase in the responsiveness of the fetal adrenal gland to hypoxic stress and ACTH (Challis \& Brooks, 1989).

Consistent with this proposal, the ACTH and cortisol responses of preterm fetuses (before 120 days gestation) to moderate hypoxia (Akagi \& Challis, 1990b; Matsuda et al. 1992), brief umbilical cord occlusion (Green et al. 2000) or hypotension (Rose et al. 1978, 1981) were markedly less than those reported in the late gestation fetus (Rose et al. 1978, 1981; Jackson et al. 1989; Akagi \& Challis, 1990 b; Richardson et al. 1996; Carmichael et al. 1997; Unno et al. 1997; Fraser et al. 2001; Gardner et al. 2001). Strikingly, although some studies in preterm fetuses have reported a rise in ACTH, albeit to lower peak levels than in late gestation, they found no rise in cortisol levels (Rose et al. 1981; Akagi \& Challis, 1990b; Green et al. 2000). For example, at 112-116 days gestation, Green et at. (2000) found a significant rise in ACTH levels, but no increase in cortisol levels after either the first or seventh episode of a series of $90 \mathrm{~s}$ umbilical cord occlusions repeated at an interval of $30 \mathrm{~min}$. These data suggested that it is the adrenocortical response to ACTH that is immature in the preterm fetus (Rose et al. 1982; Green et al. 2000), possibly due to reduced expression of the adrenal ACTH receptor [Fraser et al. 2001]. It is hypothesized that this apparent profound adrenocortical immaturity compromises the ability of the pretermfetus to maintain homeostasis during hypoxic stress, contributing to hypotension and other morbidity after birth (Bolt et al. 2002; $\mathrm{Ng}$ et al. 2004). This has important implications, since severe hypoxia is more common in infants born prematurely than at term (Low, 2004), and frequently occurs before the onset of labour (Low et al. 2003).

However, an important methodological issue for studies of hypoxic stress is that preterm fetuses have a much greater anaerobjc capacity and lower aerobic requirements than at term (Dawes et al. 1959; Mott, 1961; Shelley, 1964). These considerations led us to hypothesize that previous experiments in the preterm fetus using mild or brief hypoxic insults may not have been sufficient to elicit a near maximal HPA response, and that responses comparable with that seen at term could be elicited by a severe insult. We therefore examined the time course of changes in the HPA axis after severe asphyxia in the preterm fetus at $70 \%$ of gestation (term is $₫ 47$ days gestation), equivalent to the human fetus of 30-32 weeks of gestation (McIntosh et al. 1979).

\section{METHODS}

\section{Experimental preparation}

All procedures were approved by the Animal Ethics Committee of The University of Auckland. Groups of Suffolk ewes were time mated (three days) with Romney rams in a ratio of $5: 1$ at fortnightly intervals. The ewes were individually identified by ear tags. Ewes who did not conceive after $48 \mathrm{~h}$ with the ram were not re-bred. Pregnancy was confirmed by ultrasound at 40 days. Fifteen singleton fetal sheep were instrumented at 97-99 days of gestation (term is 147 days) as previously described (Bennet et al. 1999). Food, but not water was withdrawn $18 \mathrm{~h}$ before surgery. Ewes were given $5 \mathrm{ml}$ of Streptocin (procaine 
penicillin, 250000 [U) and dihydrostreptomycin (250 mg ml-1; Stockguard Laboratories Ltd, Hamilton, New Zealand) intramuscularly for prophylaxis 30 min prior to the start of surgery. Anaesthesia was induced by i.v. injection of Alfaxan (alphaxalone, $3 \mathrm{mg} \mathrm{kg}^{-1}$; Jurox, Rutherford,NSW, Australia), and general anaesthesia maintained using $2-3 \%$ halothane in $\mathrm{O}_{2}$. Ewes were intubated, and the depth of anaesthesia, matemal heart rate and respiration were constantly monitored by trained anaesthetic staff.

Using sterile techniques, catheters were placed in the left fetal femoral artery and vein, right brachial artery, and the amniotic sac. An ultrasound blood flow probe (size 2R; Transonic Systems Inc., Ithaca, NY, USA) was placed around the right femoral artery to measure femoral bloodflow(FBF). Astainlesssteel electrode (CoonerWire, Chatsworth, CA, USA) was placed across the fetal chest to measure the fetal electrocardiogram (ECG). An inflatable silicone occluder was placed around the umbilical cord of all fetuses (In Vivo Metric, Healdsburg, CA, USA; Bennet et al. 2000; Cuaedackers et al. 2004a). All fetal leads were exteriorized through the maternal flank and a maternal long saphenous vein was catheterized to provide access for postoperative care. After surgery, all exteriorized catheters and leads were kept in an enclosed Perspex box suspended from the side of the Ewe's metabolic cage. Antibiotics (gentamicin, $80 \mathrm{mg}$; Pharmacia and Upjohn, Rydalmere, NSW, Australia) were administered into the amniotic sac prior to closure of the uterus.

Postoperatively all sheep were housed in separate metabolic cages with access to water and food ad libitum, together in a temperature-controlled room $\left(16 \pm 1^{\circ} \mathrm{C}\right.$, humidity $50 \pm 10 \%$ with a $12 \mathrm{~h}: 12 \mathrm{~h}$ light:dark cycle. A period of 4-6 days postoperative recovery was allowed before experiments commenced, during which time antibiotics were administered to the ewe daily for four days i.v. (benzylpenicillin sodium, $600 \mathrm{mg}$; Novartis Ltd, Auckland, New Zealand, and gentamicin, $80 \mathrm{mg}$ ). Fetal catheters were maintained patent by continuous infusion of heparinized saline $\left(20 \mathrm{Um}^{-1}\right.$ at 0.15 $\mathrm{ml} \mathrm{h}^{-1} \mathrm{~J}$ and the maternal catheter maintained by daily flushing.

\section{Experimental design}

Experiments were conducted at 103-104 days gestation (70\% of gestation). Fetal arterial and venous pressures, corrected for maternal movement by subtraction of amniotic fluid pressure, FBF and fetal heart rate (FHR) derived from the fetal ECG were recorded continuously from $12 \mathrm{~h}$ before occlusion to $72 \mathrm{~h}$ after occlusion. Data were stored to disk by custom software for off-line analysis (Labview forWindows; National Instruments Ltd, Austin, TX, USA). Fetuses were randomly assigned to the sham control $(n=7)$ or the asphyxia group $(n=8)$. Fetal asphyxia was induced by rapid inflation of the umbilical cord occluder for 25 min with sterile saline of a defined volume known to completely inflate the occluder and totally compress the umbilical cord, as determined in pilot experiments with a Transonic flow probe placed around an umbilical vein (Bennet et al. 1999). The duration of occlusion was chosen as one that we have previously reported to represent an acute, severe, near-terminal insult but which could be survived without postasphyxial cardiac support (Bennet et al. 2000; Quaedackers et al. $2004 a, b$. Successful occlusion was confirmed by observation of a rapid onset of bradycardia with a rise in mean arterial pressure (MAP), and by $\mathrm{pH}$ and blood gas measurements.

Fetal arterial biood samples were taken from the brachial catheter at $15 \mathrm{~min}$ prior to umbilical cord occlusion or sham occlusion, 5 and 20 min during occlusion or sham occlusion and $2,4,6,10,24$, 48 and $72 \mathrm{~h}$ after occlusion or sham occlusion for determination of blood gases, acid-base balance (Ciba-Corning Diagnostics 845 blood gas analyser and co-oximeter; EastWalpole, MA, USA) and for glucose and lactate determination (YSImodel 2300; Yellow Springs Instruments, Yellow Springs, $\mathrm{OH}$, USA). Blood samples $(1 \mathrm{ml})$ were collected at the same times (except for $5 \mathrm{~min}$ of occlusion), transferred immediately to chilled test tubes and centrifuged at $4^{\circ} \mathrm{C}$ for $15 \mathrm{~min}(1811 \mathrm{~g})$. Plasma was stored at $20^{\circ} \mathrm{C}$ for subsequent adrenocorticotrophic hormone (ACTH) and cortisol assay. After the last 
blood sample, ewes and fetuses were killed by an intravenous orerdose of pentobarbitone sodium $19 \mathrm{~g}$ ) to the ewe (Pentobarb 300; Chemstock International, Christchurch. New Zealand).

\section{Hormone analysis}

Fetal plasma ACTH and cortisol levels were measured using specific radioimmunoassays [RLA] established and validated for ovine plasma (Fraser et al. 1997). Total immunoreactive cortisol concentrations were determined in triplicate after extraction with diethyl ether by an in-house RIA validated for" use with maternal and fetal ovine plasma. The antiserum to cortisol was raised in rabbits against Cortisol-3-O. carboxymethy]-oximebovine serum albumin (Cortisol 3-CMO: BSA) and was used at a final dilution of $1: 19200$. The cross-reactivity of the antiserumat $50 \%$ binding with ather relevant sterold related compounds was $3.3 \% 11$-deoxycortisol, $0.18 \%$ cortisone, $0.5 \%$ corticosterone, $0.015 \%$ progesterone and $0.002 \% 11 \alpha$-hydroxyprogesterone. No detectable crossreactivity was observed for $17 \alpha$ hydroxypregnenolone, pregnanediol, 21 deoxycortisone, aldosterone, cholesterol or dexamethasone. The lower limit of detection was 10 pg per tube $10.13 \mathrm{ng} \mathrm{ml}^{-1}$; samples containing $<0.13 \mathrm{ng} \mathrm{ml}^{-1}$ were given this value for the purposes of analysis. The intra- and interassay coefficients of variations were 3.68 and $3.97 \%$, respectively, at the cortisol concentrations determined in plasma.

Immunoreactive concentrations of ACTH were measured in duplicate using a commercially available 125I RIA kit (24130, DiaSorin, Stillwater, MN, USA) previously validated for use with both tetal and maternal ovine plasma. The intra-assay and interassay coefficients of variation were 9.7 and $12.8 \%$, respectively. The mean sensitivity of the ACTH assay was $9.7 \mathrm{pg} \mathrm{m} \mathrm{ml}^{-1}$; samples containing $<9.7 \mathrm{pg} \mathrm{ml}{ }^{-1}$ were given this value for analysis.

\section{Data analysis and statistics}

Off-line analysis of the physiological data was performed using customized Labview programs (Labview, National Instruments, Austin, TX, USA). The effect of asphyxia was evaluated by analysis of variance (ANOVA; SPSS v10, SPSS Inc., Chicago, IL, USA). Femoral vascular resistance (FVR) was calculated using the formula (mean arterial pressure - mean venous pressure)/absolute femoral artery blood flow ( $\mathrm{mmHg}$ min $\mathrm{ml}^{-1}$ ). The baseline period was taken as the mean of the 12 h before occlusion. Differences between groups were determined by analysis of variance, adjusted using baseline levels as a covariate (ANCOVA). Where a signilicant effect of treatment group or an interaction between time and group was found, post hoc comparisons were undertaken using the least significant difference test. The within-subjects relationship between fetal mean arterial blood pressure and cortisol levels after asphyxia was examined using the method of Bland\&Atman(1995). Statistical significance was accepted at $P<0.05$. Data are presented as means \pm S.E.M.

\section{RESULTS}

\section{Blood composition measurements}

Twenty-five minutes of umbilical cord occlusion was associated with marked fetal hypoxia, hypercapnia and mixed respiratory and metabolic acidosis (Table 1), which resolved after release of occlusion.

\section{Fetal cardiovascular responses during and immediately after umbilical cord occlusion}

There were no significant baseline differences between the sham and asphyxia groups in any parameter measured. At the onset of cord occlusion there was a rapid fall in FHR, with a sustained bradycardia throughout the period of occlusion (nadir at the end of occlusion $57.4 \pm 3.8$ beats $\mathrm{min}^{-1}$ versus sham 
Table 1. Thetal arterial pH, blood gas, glucose and lactate values for sham control (S) and asphyxia (A) groups betore uniblical coid occluston (haseline), after 20 min of occlusion or sham occlusion, and $2,4,6,24,48$ and $72 \mathrm{~h}$ postocclusion

\begin{tabular}{|c|c|c|c|c|c|c|c|c|}
\hline & Baseline & Asphyxia & $2 h$ & $4 \mathrm{~h}$ & $6 \mathrm{ht}$ & $24 h$ & $48 h$ & $72 \mathrm{~h}$ \\
\hline \multicolumn{9}{|c|}{$\mathrm{pH}$} \\
\hline 3 & $7,39+0,00$ & $138+0,00$ & $739,0.00$ & $739+0: 00$ & $7,38+0,00$ & $738+0,00$ & $737=0.00$ & $737 \pm 001$ \\
\hline A & $737=0,00$ & $682 \pm 0.03$ & 734000 & $740+0,00$ & $741+0.00$ & $737 \pm 0.00$ & $738 \pm 0.00$ & $738+0.00$ \\
\hline \multicolumn{9}{|c|}{ Paco, (mmig) } \\
\hline 5 & $48,8+13$ & $483 \pm 15$ & $46.8 \pm 10$ & $473+08$ & $478+12$ & $450+17$ & $480+11$ & $463=16$ \\
\hline A & $782+10$ & $1422 \pm 6,0$ & $46.8 \pm 10$ & $478+12$ & $456 \pm 1.4$ & $474 \pm 11$ & $472=0,9$ & $46.5 \pm 12$ \\
\hline \multicolumn{9}{|c|}{$P_{\text {ag }}(\mathrm{mmilg})$} \\
\hline 5 & $22.5+0.9$ & $227+0.9$ & $221+10$ & $226 \pm 10$ & $223 \pm 10$ & $222+21$ & $23.4+15$ & $235+14$ \\
\hline & $230+0,9$ & $87+0.8^{2}$ & $262 \pm 13$ & $24.8+10$ & $24.8+09$ & $266 \pm 13$ & $280.13^{*}$ & $283+36^{*}$ \\
\hline \multicolumn{9}{|c|}{ Glucose (mmol ] 1$)$} \\
\hline 9 & $1,03=0,10$ & $103+011$ & $101+0,12$ & $1,10 \pm 0,06$ & $1.11 \pm 0.10$ & $120=0.12$ & $120=010$ & $120 \div 010$ \\
\hline A & $102 \pm 0,10$ & $0,67+0,10^{\circ}$ & $124+0,10$ & $1,30 \pm 0.10^{*}$ & $140+010^{*}$ & $150 \pm 014^{*}$ & $130+0.10$ & $123 \pm 010$ \\
\hline \multicolumn{9}{|c|}{ Lactate (mmol l 1 ) } \\
\hline 5 & $0,73+0: 10$ & $0.73 \pm 0.11$ & $0,66 \pm 012$ & $075+0,04$ & $0.75 \pm 0.15$ & $0.64=010$ & $0.83 \pm 0.11$ & $0.90+012$ \\
\hline A & $072+0.03$ & $645+0,17$ & $3.6+0.52$ & $2,48+0,44^{*}$ & $186 \pm 0.24 \%$ & $1.00 \pm 012^{*}$ & $0.78=0.10$ & $088+010$ \\
\hline
\end{tabular}

Walus are expressed as means $\mathrm{s} \mathrm{EM} \mathrm{PaCa}_{2}$ fetal anterial partial pressure of $\mathrm{CO}_{2}: \mathrm{PaO}_{2}$ : fetal arterial partial pressure of $\mathrm{CO}_{2} * \mathrm{P}<0.05$ compared to sham control.

$188.9 \pm 3.3$ beats $\mathrm{min}^{-1}, P<0.05$; Fig. 1). Following the end of occlusion FHR rapidly increased to a peak of $235.4 \pm 5.4$ beats $\mathrm{min}^{-1}$ at $8 \mathrm{~min}$ postocclusion $(P<0.001)$ before returning to baseline values by $1 \mathrm{~h}$. MAP was initially elevated at the onset of occlusion (peaking at 4 min of occlusion at $57.0 \pm$ $1.0 \mathrm{mmHg}$ versus $37.3 \pm 0.2 \mathrm{mmHg}$ in sham controls, $P<0.001$, Fig. 1). MAP then fell, to a nadir of $10.3 \pm 0.6 \mathrm{mmHg}, P<0.05$ [Fig. 1]. Following the end of occlusion MAP rapidly recovered, with an initial transient period of hypertension (peaking at $8 \mathrm{~min}$ at $49.9 \pm 2.7 \mathrm{mmHg}, \mathrm{P}<0.05$ ) before falling slightly, but remaining elevated through the first hour $(P<0.05$ ).

At the onset of occlusion FBF fell rapidly to a nadir of $0.6 \pm 0.6 \mathrm{ml} \mathrm{min.1}$ versus $10.8 \pm 0.2 \mathrm{ml}$ min $'$ by 4 min of occlusion ( $P<0.05$, Fig. 1). FBF then transiently rose to approximately $50 \%$ of baseline, before falling again to a final nadir of $2.1 \pm 0.5 \mathrm{ml} \mathrm{min}^{-1}$ at the end of occlusion. Following the end of occlusion there was an initial increase in FBF back to baseline values by $5 \mathrm{~min}$, followed by a secondary fall (nadir at the end of the first hour postocclusion $3.8 \pm 0.7 \mathrm{ml} \mathrm{min}^{-1}, P<0.05$, Fig. 1). FVR was significantly elevatedat the onsetofocclusion (peaking at 4 min of occlusion at $207.4 \pm 70.2$

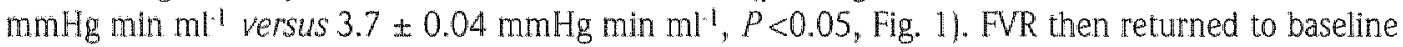
values, with a secondary more modest increase in resistance observed during the last $7 \mathrm{~min}$ of occlusion ( $7.4 \pm 2.3 \mathrm{mmHg} \mathrm{min} \mathrm{ml}^{-1}$ at $25 \mathrm{~min}$ of occlusion, $\left.P<0.05\right)$. Following occlusion, a transient fall in FVR to baseline values during the first $5 \mathrm{~min}$ was followed by a significant increase, peaking at

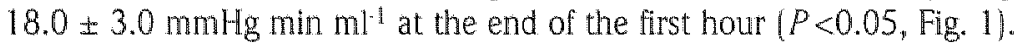

\section{Fetal cardiovascular responses after release of cord occllusion}

Following reperfusion, there was an initial. rapid recovery of FHR with a brief overshoot tachycardia followed by a return to baseline values, although there was a trend for FHR to be elevated initially. 
Figure 1. Time sequence of changes in fetal heart rate (FHR), mean arterial blood pressure (MAP), femoral blood flow (FBF) and femoral vascular resistance (FVR) in the asphyxia group from $60 \mathrm{~min}$ before occlusion of the umbilical cord until 60 min after release of occlusion

Sham conirol data are not showm for clarity. The 25 min period of umbilical cord occlusion is shown by the shaded area. Note the initial increase in fetal MAP, assaciated with a rapid increase in FVR and reduction in FBE. These changes were not sustained. From approximately $6 \mathrm{~min}$ of occlusion the increase in FVR was lost, with a relative increase in FBF and a progressive fall in MAP. Profound hypotension was present at the end of the insult. Data are 1 min awerages, shown as means $t$ S.E.M.; $* P<0.05,+P<0.01, * P<$ 0.001 compared to sham controls.

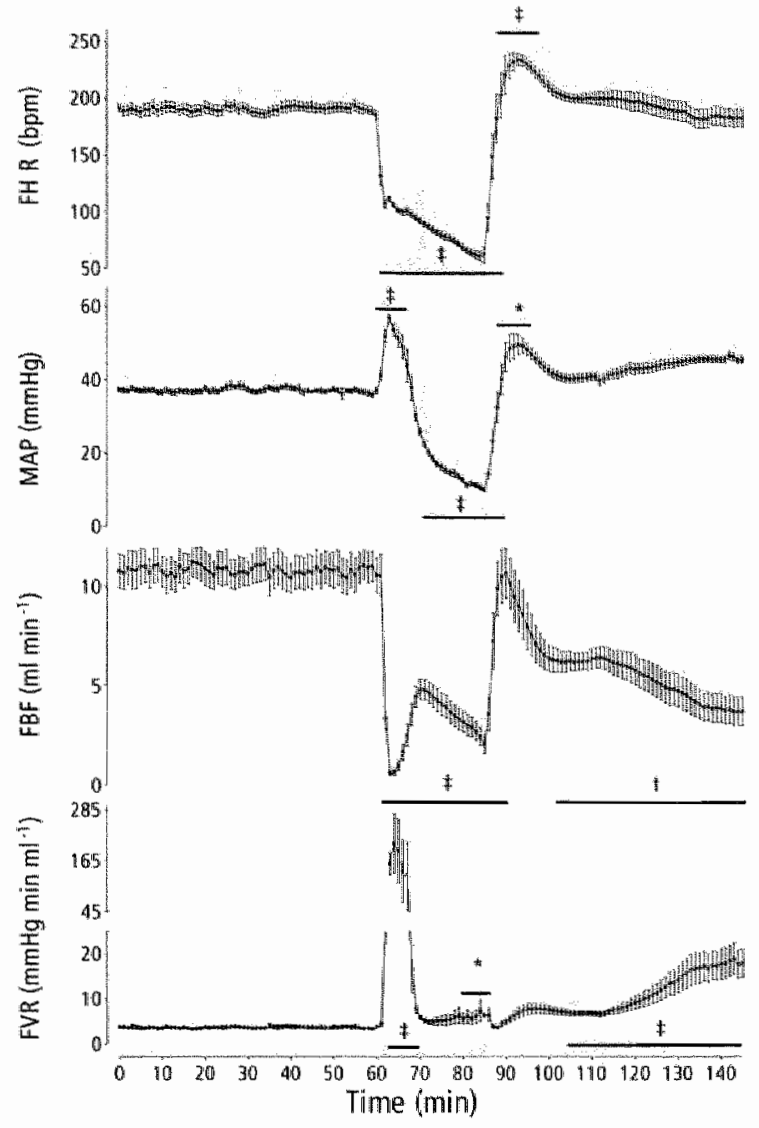

FHR then fell and was significantly suppressed compared with the sham group between 42 and $66 \mathrm{~h}$ after occlusion (Fig. 2). In contrast, MAP was significantly elevated overall during the first $36 \mathrm{~h}$ after occlusion ( $P<0.05$, ANOVA; Fig. 2 ), maximal in the first $3 \mathrm{~h}$. FBF was profoundly reduced throughout the entire recovery period compared with the sham group $(P<0.05$; Fig. 2$)$, while FVR was increased throughout recovery $(P<0.05 ; \mathrm{Fig}$. 2). There was a marked increase in FVR in the first $3 \mathrm{~h}$ after release of occlusion, corresponding with the early increase in MAP. FVR then transiently fell for a few hours (although it remained above values in the sham group), rose to a second peak between 18 and $24 \mathrm{~h}$, then progressively fell, and was only mildly increased compared to sham control group levels in the final 24 h of the study.

\section{Endocrine data}

There were no significant baseline differences in ACTH or cortisol levels between the sham and asphyxia groups. After $20 \mathrm{~min}$ of cord occlusion there was a significant rise in plasma concentrations of both ACTH $(P<0.05$, ANOVA $)$ and cortisol $(P<0.05)$. Following reperfusion, plasma ACTH levels peaked between 2 and $4 \mathrm{~h}$ in the asphyxia group and returned to control values at $24 \mathrm{~h}$ (Fig. 3, top panel). Plasma cortisol levels remained significantly elevated after the end of occlusion compared to 
Flgure 2. Time sequence of changes in fetal heart rate (FHR), mean arterial blood pressure $[M A P]$, fernonal blood low (FBF) and femoral vascular resistance (FVR) in the shan control (o) and the asphyxia group (-) from 12 h before occlusion until 72 $\mathrm{h}$ after release of occlusion

The 25 min period of umbilical cord occlusion occurs at time 0 and is not shown (see Fig. 1). Data are means \pm S.E.M.; ${ }^{*} P<0.05 * P<0.05$, compered to sham controls.

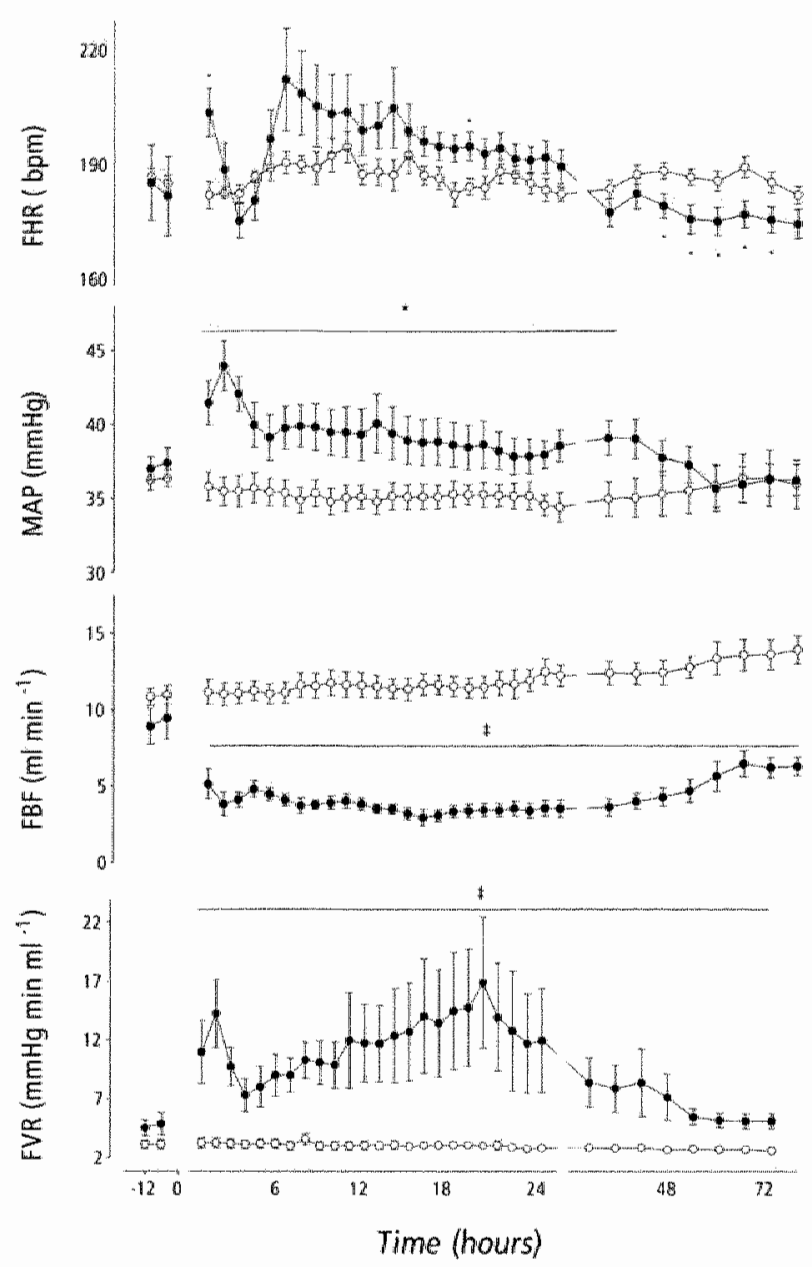

the sham control group until 72 h after occlusion $(P<0.05$; Fig. 3 , bottom panel). There was a modest correlation between fetal cortisol levels and fetal mean arterial blood pressure in the $72 \mathrm{~h}$ after umbilical cord occlusion $\left(r^{2}=0.15, P=0.05\right.$, within-subjects regression analysis).

\section{DISCUSSION}

The present study demonstrates for the first time that exposure to severe hypoxia induced by umbilical cord occlusion was associated with a rapid and marked rise in ACTH followed by increased cortisol levels, in unanaesthetized preterm fetal sheep. Cortisol levels rose substantially, to 31 -fold greater than in the sham control group after release of occlusion, compared with approximately 10 -fold after severe hypoxia near term (Jackson et al. 1989; Gardner et al. 2001). The absolute levels were similar to those attained with a pharmacological infusion of $2-3 \mathrm{mg} \mathrm{kg}^{-1}$ dayl of cortisol (Forhead \& Fowden, 2004). Furthermore, this rise was sustained for $48 \mathrm{~h}$ after the end of the asphyxial insult. Thus this study strongly refutes the hypothesis that the preterm fetus has an immature HPA response to hypoxic stress. 


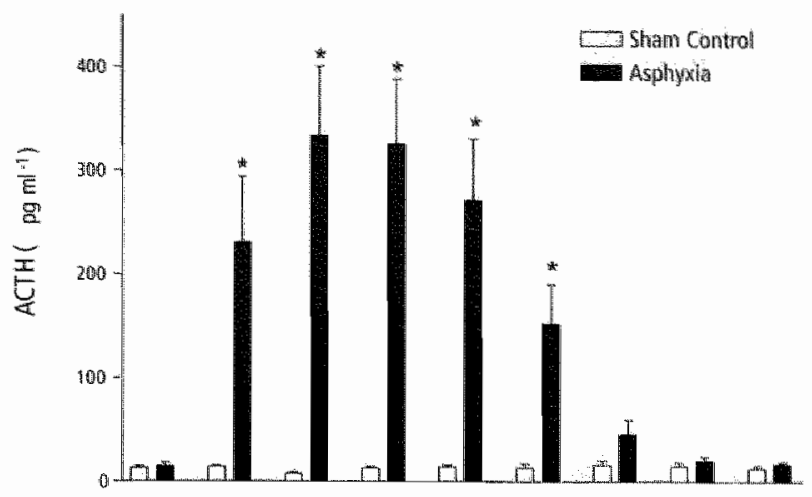

Figure 3. Fetal plasna ACTH and cortisol levels before, during and after sham occlusion or $25 \mathrm{~min}$ of asphyxia induced by occlusion of the umbilical cord.

Data are means $\&$ S.E.M. * $P<0.05$ compared to sham occlusion. Con, preocclusion values; Occl, values during occlusion.

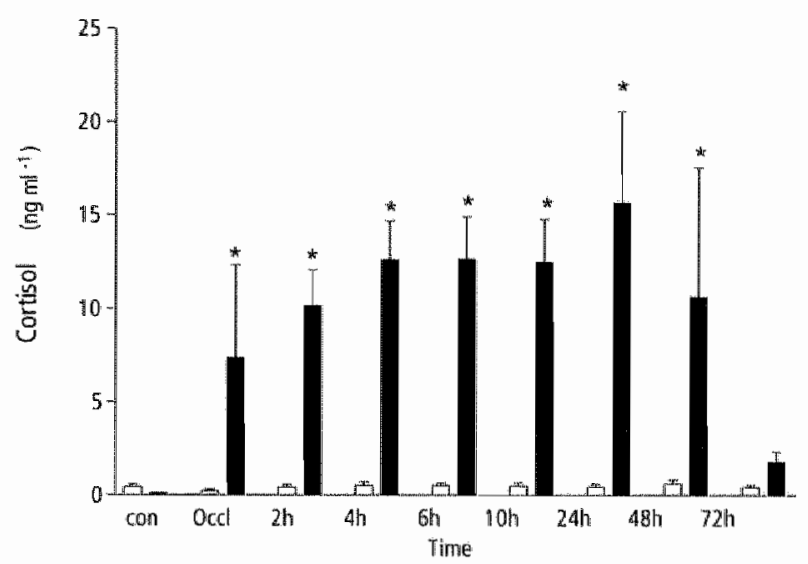

Activation of the HPA axis is a well-characterized response to stresses such as hypoxia (Jackson et al. 1989; Richardson et al. 1996; Carmichael et al. 1997; Unno et al. 1997; Fraser et al. 2001) and hypotension (Rose et al. 1978) in the near-term and term fetus and neonate. Comparison with studies in earlier gestation are complicated by the many-fold lower basal cortisol levels seen in the preterm fetus (Challis \& Brooks, 1989); however, with some caution, the relative rise in cortisol may be used as an index suggesting broadly equivalent physiological significance. On this basis, a four- to 10 -fold rise in cortisol levels during hypoxic stress has been observed in near-term fetal sheep Jackson et al. 1989; Unno et al. 1997; Gardner et al. 2001 j, whereas no rise in cortisol was found following brief cord occlusion ormoderate hypoxaemia or hypotension in preterm fetuses (Rose et al. 1981; Akagi \& Challis, 1990a; Green et al. 2000).

Results from other types of study, however, have raised contradictory evidence. For example, although basal cortisol levels are low in the preterm ovine fetus, the fetal pituitary is highly responsive both to endogenous stimuli such as infusion of corticotrophin releasing hormone and to exogenous stimuli such as exteriorization and haemorrhage (McFarlane et al. 1995). However, these studies did not examine the adrenal responses.

In the present study, when the preterm fetus was exposed to a more severe challenge, the ACTH and cortisol responses were far more pronounced than in previous studies of the preterm fetus that used inhalational hypoxia (Richardson et al. 1996) or intermittent short umbilical cord occlusion (Green et al. 2000). It is likely that the apparent discrepancy between the present findings and previous 
reports is related to the far greater anaerobic tolerance of the preterm fetus (Mott, 1961), with higher cardiac glycogen levels than at term (Shelley, 1964) This means that the preterm fetus can survive far more prolonged intervals of severe asphyxia than at term (George et al. 2004). Thus, one reason for the attenuated HPA response in previous studies of hypoxia or shorter periods of asphyzia might be simply that, in effect, the insults were only mild or even subthreshold stimuli for the preterm fetus. It is interesting that in a previous study of short ( $90 \mathrm{~s}$ ) umbilical cord occlusions in preterm fetuses, which were approximately 10 days older than in the present study and presumably correspondingly more mature, there was a significant rise in ACTH but not cortisol levels on the first day of occlusions (Green et al. 2000 j. After 4 days of continued occlusions in that study, however, a small (2.8-fold) postocclusion rise in cortisol levels was found. This suggests that a critical duration of stimulation is required to trigger the cortisol response of the preterm fetus. Consistent with this hypothesis, at 105-112 days gestation in the fetal sheep, an infusion of ACTH was associated with only a three fold rise in fetal cortisol levels after $3 \mathrm{~h}$, but 28 -fold after $24 \mathrm{~h}$ (Carter et al. 1998).

The acute cardiovascular responses in the present study also contrast with previous studies of moderate hypoxia. Such studies suggested that the preterm fetus does not reduce peripheral blood flow during hypoxia (Iwamoto et al. 1989) and during partial cord compression cannot increase arterial blood pressure (Iwamoto et al. 1991 ), i.e. that the ability to centralize circulation in response to a hypoxic challenge is immature. In contrast, and consistent with previous studies of the renal responses to asphyxia at this gestational age (Quaedackers et al. 2004b), we found marked initial hypertension during complete umbilical cord occlusion associated with an initial, actively mediated fall in FBF, as shown by the very rapid and large increase in vascular resistance in the first 6 min after the start of umbilical cord occlusion. In the nearterm fetus the initial vasoconstriction during asphyxia is primarily mediated by sympathetic neural activity (Jensen \& Lang, 1992) and possibly augmented by rellease of stress hormones such as arginine vasopressin and renin-angiotensin system (RAS) activation (Raff et al. 1991; Giussani et al. 19946, Rosnes et al. 1998); limited data suggest that this also occurs in preterm fetuses (Cheung, 1992; Lumbers et al. 2001). Finally, the rise in circulating cortisol demonstrated in the present study may also help to support initial hypertension, as discussed below.

The degree of peripheral vasoconstriction observed initially during occlusion in the present study is similar to that measured using the microsphere technique in the near-term fetus (Jensen et al. 1987). This response is believed to be an important adaptive mechanism acting to redistribute combined ventricular output from non-essential or 'peripheral' organs to essential organs such as the heart, brain and adrenals (Hanson, 1988). The present data provide further evidence that this initial cardiowascular defence response is 'mature' in the preterm fetus (Gunn et al. 2001). However, consistent with studies in the nearterm fetus, this initial adaptation was rapidly lost, leading to partial peripheral reperfusion, followed by a nearly pressure-passive fall in paralle] with the secondary fall in arterial blood pressure (Jensen et al. 1987; Jensen \& Lang, 1992). The failure of redistribution of combined ventricular output during asphyxia is not simply a function of maturation, since the response is seen at all ages examined thus far, but the mechanisms that mediate this loss of peripheral vascular tone are unknown. Furthermore, it is not unique to the femoral vascular bed, with similar responses being seen in the gut and kidney (Quaedackers et al. 2004a,b). Potentially, loss of vasoconstriction could reflect loss of sympathetic activity. However, this seems improbable given that circulating catecholamines increase markedly during prolonged asphyxia (Gu et al 1985). Similarly, it does not reflect loss of adrenal activity since, in the present study, cortisol levels were high at the end of the period of cord occlusion. Thus these data suggest that some additional factor, such as severe local tissue acidosis, actively inhibits femoral vascular tone during prolonged asphyxia.

The initial HPA axis response during hypoxia in our study suggests an ACTH-driven rise in cortisoll levels, with a rapid rise in both hormones. There is some evidence that the fetal lung can also secrete 
ACTH during stress, but since the lung clears ACTH at higher concentrations, it is unlikely to be a factor in the present study (Cudd \& Wood, 1995). Maternal cortisol can cross the placenta (Wood \& Rudolph, 1984). However, the major increase in fetal cortisol levels in the present study occurred during the interval of complete occlusion of the umbilical cord, suggesting that a maternal contribution is improbable.

Later in recovery there was a marked dissociation between fetal ACTH and cortisol levels, with significantly elevated cortisol values at 24 and $48 \mathrm{~h}$ in the asphyxia group, while ACTH concentrations were not different from sham control levels. This suggests the possibility of an ACTH-independent adrenal response in that phase, as previously proposed (Gagnon et al. 1997). Furthermore, there are data indicating that carotid sinus denervation delays the rise in cortisol levels but not ACTH concentrations [Giussani et al. 1994a), suggesting the possibility of partial neural control of cortisol release. However, it might potentially reflect slower clearance of cortisol, although there are few data on relative clearance rates in the preterm fetus. Alternatively, the delayed fall in cortisol levels may simply reflect local adrenal cortisol upregulation which is slower to resolve. Tangalakis et al. (1990), for example, have shown that in preterm fetal sheep at a very similar gestational age to the present study, an infusion of ACTH induced an increase in the width of the adrenal cortex and in the levels of $M R N A$ for key steroidogenic enzymes.

The physiological importance of the sustained elevation of fetal cortisol in the recovery period is unknown. As recently demonstrated, sympathetic nervous system activation is the major mediator of the peripheral vasoconstriction and mild increase in MAP after asphyxia in preterm fetal sheep (Quaedackers et al. 2004a). The correlation between fetal MAP during the 3 day recovery period with cortisol levels in the present study suggests that the adrenocortical response also has a role in sustaining blood pressure during recovery. This is consistent with the observation that exogenous infusions of cortisol increase fetal arterial blood pressure (Tangalakis et al. 1992; Forhead et al. 2000an Hegarty et al. 2000; Forhead \& Fowden, 2004). The sustained increase in femoral vascular resistance, which had not fully resolved after $72 \mathrm{~h}$, is similar to that which we have reported in other vascular beds at this age (Quaedackers et al. 2004a,b). It may be speculated that increased resistance across all peripheral vascular beds is necessary to help support blood pressure because of transiently impaired cardiac contractility secondary to reversible cardiac injury (Barberi et al. 1999; Gunn et al. 2000).

The mechanisms of the effect of cortisol on blood pressure remain unclear. Glucocorticoids have direct cardiac effects, mediated by augmented coupling of the $\beta$-adrenoreceptors to cellular postreceptor signal transduction (Bian et al. 1993) and, of particular interest, potentially by augmented sympathetic responses (Chan et al. 1991; Segar et al. 2001). Consistent with this suggestion, Padbury et al. (1995) have shown that neonatal lambs which had received antenatal betamethasone had significantly elevated blood pressure, cardiac output and cardiac contractility, despite similar preload las assessed by left ventricular end-diastolic pressure). In part this may be due to a significant increase in $\beta$ adrenergic receptor dependent myocardial cyclic adenosine monophosphate generation (Stein $e t$ al. 1993). Furthermore, synthetic glucocorticold administration is associated with increased vascular resistance (Derks et al. 1997; Fletcher et al. 2000; Schwab et al. 2000). Finally, there is evidence in late gestation that hypercortisolaemia leads to activation of the fetal RAS (Forhead et al. 2000b; Zimmermann et al. 2003). However, the initial rise in blood pressure was independent of the RAS (Forhead \& Fowden, 2004) and we have previously reported that, in the present model, renin levels are reduced during recovery from asphyxia (Quaedackers et al. 2004b). 


\section{CONCLUSIONS}

Profound asphyxia in the preterm fetus led to a very large relative increase in ACTH and cortisol levels during asphyxia, which was comparable with nearterm responses, followed by sustained elevation that gradually resolved between 24 and $72 \mathrm{~h}$. These data do not support the concept that there is a phase of adrenocortical underresponsiveness in the preterm fetus. Rather they suggest that the greater anaerobic tolerance of the preterm fetus, compared with the nearterm fetus, means that its full range of responses is only activated by more severe insults. The correlation between cortisol levels following severe asphyxia and fetal MAP suggests that, at least in part, the prolonged adrenocortical response may help to sustain fetal blood pressure during a critical period of recovery. 


\section{REFERENCES}

Akagi K \& Challis JR (1990a). Threshold of hormonal and biophysical responses to acite hypoxemia in fetal sheep at different gestational ages. Can I Physiol Phamacol 68, 549-555.

Akagi $K$ \& Challis IR (1990b). Hormonal and biophysical responses to acute hypoxemia in fetal sheep at $0.7-0.8$ gesiation. Can I Physiol Pharmacol 68, 1527-1532.

Barberi I, Calabro MP, Condaro S, Gitto E, Sotile A, Prudente D et al. (1990). Myocardial ischaemia in neonates with perimatal asphyxia. Electrocardiographic, echocardiographic and enzymatic correlations. European $]$ Pediatrics 158, 742-747.

Bernet L, Quaedackers IS, Gunn AJ, Rossenrode S\& Heineman E [2000]. The effect of asphyxia on superior mesenteric artery blood flow in the premature sheep letus. / Pediatric Surg 35, 34-40.

Bennet L, Rossenrode S, Gunning MI, Gluckman PD \& Gunn AI (1999). The cardiovascular and cerebrovascular responses of the immature fetal sheep to acute umbilical cord occlusion. I Physiol $517,2,47-257$.

Bian X, Seidler F, Olsen C, Raymond JR Slotkin TA (1993). Effects of fetal dexamethasone exposure on postnatal control of cardiac adenylate cyclase: beta-adrenergic receptor coupling to Gs regulatory protein. Teratology $48,169-177$.

Bland JM \& Altman DG (1995). Calculating correlation coeficients with repeated obserwations: part 1 correlation within subjects. BM/310, 446.

Bolt Rl, vanWeissenbruch MM, Laffeber HN \& Delemarre-wan deWaa HA (2002). Development of the hypothalamicpituitary- adrenal axis in the fetus and preterm infant. / Pediatric Endocrinol Metabolism 15 , $759-769$.

Carmichael L, Sadowsky D, Olson D, Challis I \& Richardson. B (1997). Activation of the fetal hypothalamicpituitaryadrenal axis with prolonged and graded hypoxemia. / Soc for Gmecologic Investigation 4, 8-14.

Carter AM, Challis JR \& Svendsen P (1998). Vasodilator response to exogenous adrenocorticotropic hormone in fetal adrenal cortex precedes increased steroidogenesis in sheep at 105-112 days gestation. European J Obstetrics, Gymecology, Reprod Biol 81, 87-94.

Challis JR \& Brooks AN [1989]. Maturation and activation of hypothalamic-pituitary adrenal function in fetal sheep. Endocrine Rev $10,182-204$.

Chan MY, Dai S, He JH \& Ogle CW(1991). In-vivo and in-vitro studies on the effects of chronic dexamethasone treatment on cardiovascular responses to sympathetic stimulation. Arch Intes Physiologie, Biochimie de Blophysique $90,323-329$.

Cheung CY (1092). Autonomic and arginine vasopressin modulaton of the hypoxiatinduced atrial natriuretic factor release in immature and mature ovine fetuses. Am / Obstetrics Gynecol 167, 1443-1453.

Cudd TA \& Wood CE (1995). Secretion and clearance of immunoreactive ACTH by letal lung. Am / Physiol 268, $\mathrm{E} 845 \mathrm{~EB} 8 \mathrm{~B}$.

Dawes GS, Mott JC \& Shelley HJ (1959). The importance of cardiac glycogen for the mantenance of lile in foetal lambs and newborn animals during anoxia. J Physiol $140,516-538$.

Derks JB, Giussani DA, Jenkins SL, Wentworth RA, Visser GH et al. (1997). A comparative study of cardiovascular, endocrine and behavioural effects of betamethasone and dexamethasone administration to fetal sheep. $/$ Physiol $499,217-220$.

Fletcher A, Goodfellow MR, Forhead A), Gardner DS, MCGarrigle HH et al. (2000). Jow doses of dexamethasone suppress pituitary-adrenal function but augment the glycemic response to acule hypoxemia in fetal sheep during late gestation. Pediatric Res $47,684-691$.

Forhead A), Broughton Pipkin F \& Fowden AL (2000a). Effect of cortsol on blood pressure and the renin-angiotensin system in fetal sheep during late gestation. J Physiol 526, 167-176. 
Forhed A \& Fowden AL (2004). Role of angotensin II in the pressor response to cortisol in fetal sheep during late gestation. Exp Physiol $89,323-329$.

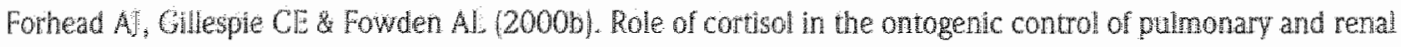
angiotensin-convering enzyme in fetal sheep near tem. J Physiol $526,409-416$.

Fraser $M$, Braems GA \& Challis JR (2001]. Developmental regulation of corticotrophin receptor gene expression in the adrenal gland of the ovine fetus and newbom lamb: effects of hyoxia during late pregnancy. I Endocrinol $169,1-10$.

Fraser M, Mathews $\mathrm{SG}$, Braems $\mathrm{G}$, Jeffiay T 8 Challis JR (1997). Developmental regulation of preproenkephalin (PENK) gene expression in the adrenal gland of the ovine fetus and newborn lamb: effects of hypoxemia and exogenous cortisol infusion. J Endocrinol $155,143-149$.

Gagnon R, Murotsuki, Chalis JR, Fraher L. \& Richardson BS (1997). Fetall sheep endocrine responses to sustained hypoxemic stress after chronic fetal placental embolization. Am / Physiol272, E817 E823.

Gardner DS, Fletcher $\mathrm{A}$; Fowden AL \& Giussani DA (2001). Plasma adrenocorticotropin and cortisol concentrations during acute hypoxemia after a reversible period of adverse intrauterine conditions in the ovine letus during late gestation. Endochinology 142,589-598.

George S, Gunn AJ, Westgate JA, Brabyn C; Guan I \& Bennet L (2004). Fetal heart rate variability and brainstem injury after asphyxia in preterm fetal sheep. American Journal of Physiology 287, R925-R933.

Giussani DA, McGarrigle HH, Moore P], Bennet L, Spencer IA \&Hanson MA (1994a). Carotid sinus nerve section and the increase in plasma cortisol during acute hypoxia in tetal sheep. J Physiol 477, 75-80.

Giussani DA, McGarrigle HH, Spencer IA, Moore P], Bennet L \& Hanson MA (1994b). Effect of carotid denervation on plasma vasopressin levels during acule hypoxta in the late-gestation sheep fetus. $f$ Physto $477,81-87$.

Giussani: DA, Spencer JAD \& Hanson MA (1994c). Fetal and cardiovascular reflex responses to hypoxaemia. Fetal Maternal Med Rev 0, 17-37.

Green LR, Kawagoe Y, Fraser M, Challis JR \& Richardson BS (2000). Activation of the hypothalamic-pituitary adrenal axis with repetitive umbilical cord occlusion in the preterm ovine retus. I Soc for Gynecologic investigation 7, 224-232.

Gu W, Jones CT \& Parer )T (1985). Metabolic and cardiowascular effects on fetal sheep of sustained reduction of uterine blood flow: / Physiol 308, 109-129.

Gunn Al, Maxwell L, de Haan HH, Bennel L, Williams CE et al. (2000). Delayed hypotension and subendocardial injury after repeated umbilical cord occlusion in neartem fetal lambs. Am J Obstetrics Gynecol 183 , $1504-1572$.

Gunn AJ, Quadackers JS, Guan J, Heineman E \& Bernet L (2001). The premature fetus: not as defenseless as we thought, but stil paradoxically vulnerable? Dev Neutoscience 23, 175-179.

Hanson MA (1988), The importance of baro-and chemoreflexes in the control of the fetal cardiovascular system. J Dev Physiol 10,491-511.

Hegarty BD, Burrell JH, Gilson KJ, McMullen JR \& Lumbers ER (2000). Effect of cortisol on fetal ovine vascullar angiotensin [1 receptors and contractility. European f Phamaco $406,439-448$.

Iwamoto HS, Kauman T, Keil LC \& Rudolph AM 1989). Responses to acute hypoxemia in fetal sheep at 0.6-0.7 gestation. Am I Physiol 250, H6\3-H620.

Iwamoto HS, Sucky E \& Roman CM (1991). Effect of graded unbilical cord compression in fetal sheep at 0.6-0.7 gestation. Am I Physiol 26l, H1268-H1274.

Jackson BT, Mortison SH, Cohn HE \& Piasecki G] (1989). Adrenal secretion of glucocorticoids during hypoxemia in fetal sheep. Endocrinology $125,2751-2757$.

Jensen $A_{*}$ Hohmann $M$ \&unzeW (1987). Dynamic changes in organ blood llow and oxygen consumption during acute asphyxia in fetal sheep. $/$ Dev Physiol $9,543-559$. 
Jensen A \& Lang U (1992). Foetal circulatory responses to arrest of uterine blood flow m sheep: effects of chemical sympathectomy. f Dev Physiol 17, 75-80.

Low JA (2004). Determining the contribution of asphyxia to brain damage in the reonate $/$ Obstetrics $G$ yrdecol Res $30,276-286$.

Low JA, Killen $\mathrm{H}$ \& Derrick $\mathrm{E}$ [2003]. Antepartum fetal asphyxia in the preterm pregnancy. Am / Obstetrics Gynecol 188, $461-465$.

Lumbers ER, Gunn AJ, Zhang DY, Wu J], Maxwell L\& Benned L (2001). Nonimmune hydrops fetalis and activation of the renin-angiotensin system after asphria in preterm tetal sheep. American Jownal of Phystology 280 , R1045-R1051.

McFarlane AC, Potocnik S, Towstoless M, Moritz K \& Wintour EM (1995). Pituitary-adrenal function in the immature ovine foetus. / Endocrinol 145, 455-460.

McIntosh GH, Baghurst KI, Potter B] \& Hetzel BS (1979). Foetal brain development in the sheep. Neuropathol Appl Neurobiol 5, 103-114.

Matsuda Y, Patrick J, Carmichael L, Challis I \& Richardson B [1992). Effects of sustaned hypoxemia on the sheep fetus at midgestation: endocrine, candiowascular, and biophysical responses. Am / Obstertics Gynecol 167. $531-540$.

Mott JC (1961). The ability of young mammals to withstand total oxvgen lack. Br Med Bull 17, 144-148.

$\mathrm{Ng}$ PC, Lee CH, Lam CW, Ma KC, Fok TF et al. (2004). Transient adrenocortical insufficiency of prematurity and systemic hypotension in very low birthweight infants. Anch Dis Chilhood Fotal Neonatal Edition $89, \mathrm{~F} 119-\mathrm{F} 120$.

Padbury JE, PolkDH, ErvinMG, Berry LM, Ikegami M \& Jobe AH [1995]. Postnatal cardiovascular and metabolic responses to a single intramuscular dose of betamethasone in fetal sheep born prenaturely by Cesarean section. Pediatric Res $38,709-715$.

Quaedackers JS, Roelfsema V, Heineman E, Gum Al \& Bennet L (2004a). The role of the sympathetic nervous system in post-asphyxial intestinal hypoperfusion in the preterm sheep fetus. J Physiol 557, 1.033-1044.

Quaedackers IS, Roelísema V, Hunter CI, Heineman E, Gunn Al \& Bennet L. (2004b). Polyuria and impaired renal blood flow after asphyxia in preterm fetal sheep. Anterican foumal of Physlology $280, \mathrm{R} 576-\mathrm{R} 583$.

Raff $\mathrm{H}$, Kane CW \&Wood CE (1991). Arginine vasopressin responses to hypoxia and hypercapnia in late-gestation fetal sheep. Am / Physiol 260, R1077-R1081.

Richardson B, Korkola S, Asano H, Challis J, Polk D \& Fraser M (1990). Regional blood flow and the endocrine response to sustained hypoxemia in the preterm ovine letus. Pediatric Res $40,337-343$.

Rose JC, MacDonald AA, Heymann MA \& Rudolph AM [1978). Developmental aspects of the pituitary actrenal axis response to hemorhagic stress in lamb fetuses in utero. / Chin invest $61,44-4232$.

Rose $]_{G}$, Meis PJ \& Morris M [19811. Ontogeny of endocrine (ACTH, vasopressin, cortisol) responses to hypotension in lamb fetuses. Am / Physiol 240, E656-E661.

Rose IC, Meis PJ, Urban RR \& Greiss FC Jr 119821 . In wivo evidence for increased adrenal sensitivity to adrenocorticotropin - (1-24) in the lamb fetus late in gestation. Endocinology $111,80-85$.

Rosnes 15 , Valego $N$, Wang J, Zehnder T \& Rose JC 1998 . Actve renin, prorenin, and renin gene expression after reduced renal perfusion pressure in tem ovine fetuses. Am I Physiol275, R141-R147.

Schwab M, Roedel M. Anwar MA, Muller T, Schubert H, Buchwalder LF et al (2000). Effects of betamethasone administration to the fetal sheep in late gestation on tetal cerebral blood flow. / Physio $528,619-632$.

Segar 1 L, Bedell KA \& Smith Of (2001). Glucocorticoid modulation of cardiovascular and atuonomic function in pretermlambs: role of ANG II. Am / Physiol 280, R640-R654.

Shelley HI (1964). Carbohydrate reserves in the newbon infant. Br Med/5378, 273-275.

Sten HM, Oyama K, Martinez A, Chappell BA, Buhl E ei al. (1993). Effects of corticosteroids in preterm sheep on adaptation and sympathoadrenal mechanisms at birth. Am f Physiol 264, E763-E769. 


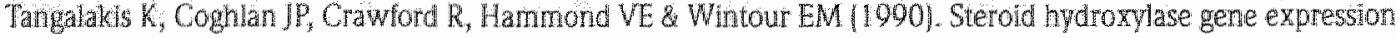
in the ovine fotal adrenal gland following ACTH infuston. Acka Endocrinologica $123,371-377$.

Tangalakis K, Lumbers ER, Moritz KM, Towstoless MK \& Wintour EM 11992). Effect of cortisol on blood pressure and wascular reactivity in the ovine fetus. Exp Physiol 77, 709-717.

Unno N, Giussan DA, Hing WK, Ding XY, Collins JH \& Nathanielsz PW (1997). Changes in adrenocoricotropin and cortisol responsiveness after repeated partial umbilical cord occlusions in the late gestation ovine fetus. Endocrinology $138,259-263$.

Whitule WL, Patel FA, Alfaidy N, Holloway AC. Fraser M, Gyomoney S et al. [2001]. Glucocorticoid regulation of human and ovine parturition: the relationship beween fetal hypothalamic-pituitary-adrenal axis activation and intraterine prostaglandin production. Biol Reprod 64, 1019-1032.

Wood CE Rudolph AM(1984). Can maternal stress alter fetal adtenoconticotropin secretion? Endocrinology $115,298-301$.

Zmmemann H, Gardner DS, Jellyman JK, Fowden AL, Giussanl DA \& Forhead Al (2003). Effect of dexamethasone on pulmonary and renal angiotensinconverting enzyme concentration in fetal sheep during late gestation. Am J Obstetrics Gynecol 189, 1467-1471.

\section{ACKNOWLEDGEMENTS}

This study was supported by the Health Research Conncil of New Zealand, Auckland Medical Research Foundation, and the Lottery Grants Board of New Zealand. 


\section{CHAPTER 3}

IMPROVED NEURAL OUTCOME WITH CEREBRAL HYPOTHERMIA AFTER ASPHYXIA

IN PRETERM FETAL SHEEP

IS ASSOCIATED WITH SUPPRESSION

OF EEG TRANSIENTS

DURING RECOVERY

Submitted

Roelfsema V, Bennet L, George S, Gunn TR, Quaedackers IS, Dean JM, Gunn AJ 


\section{ABSTRACT}

Prolonged, moderate cerebral hypothermia is consistently neuroprotective after experimental hypoxiaischemia; however, there is little information in the preterm brain. Using a model of complete umbilical. cord occlusion for 25 min in 0.7 gestation fetal sheep we examined the effects of cerebral hypothermia (fetal extradural temperature reduced from $39.4 \pm 0.1^{\circ} \mathrm{C}$ to $29.5 \pm 2.6^{\circ} \mathrm{C}$ ) from $90 \mathrm{~min}$ to $70 \mathrm{~h}$ after the end of occlusion. Asphyxia led to severe acidosis and profound hypotension. In the first $6 \mathrm{~h}$ after reperfusion fetal EEG activity was abnormal with a mixture of fast and slow epileptiform transients superimposed on a suppressed background; stereotypical evolving seizures developed from $9.1 \pm 5.3 \mathrm{~h}$. Hypothermia was associated with a marked reduction in numbers of epileptiform transients in the first $6 \mathrm{~h}$, and reduced amplitude of overt seizures. After 3 days recovery the EEG spectral frequency, but not total intensity, was increased in the cooled group compared with asphyxia alone. Hypothermia was associated with a significant overall reduction in neuronal loss in the hippocampus and basal ganglia $(P<0.001)$, with suppression of activated caspase-3 and microglia (isolectin B4 positive). In conclusion, neuroprotection with delayed, prolonged head cooling after a severe asphyxial insult in the premature fetus was assoclated with potent, specific suppression of epileptiform transients in the early recovery phase, but not of numbers of delayed seizures.

Keywords: Asphyxia - prematurity - hypothermia, induced - EEG - epileptiform transients

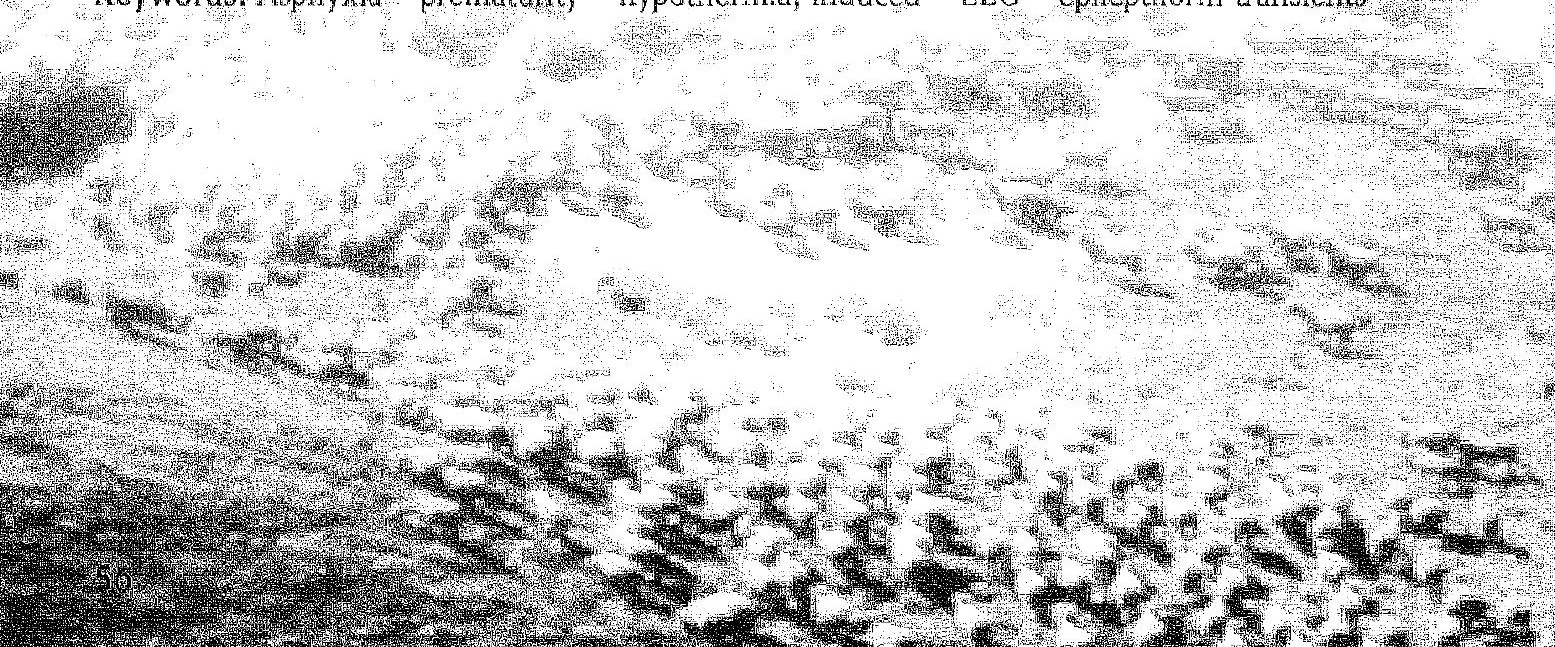




\section{INTRODUCTION}

There is now strong experimental evidence from a range of animal models that a reduction in brain temperature of 2 to $5^{\circ} \mathrm{C}$, applied following perinatal hypoxia-ischemia, can improve neuropathological (Bona et al. 1998; Edwards et al. 1995; Guan et al. 1997; Gunn et al. 1998; Roelfsema et al. 2004; Sirimanne et al. 1996; Tooley et al. 2003), cerebral energetic (Nedelcu et al. 2000; Thoresen et al. 1995), electrophysiological (Gunn et al. 1997; Gunn 2000) and functional outcomes (Bona et al. 1998; Wagner et al. 2002). However, these studies have focused on neuroprotection with hypothermia at term or later. Preterm infants have a very high burden of neurological injury (du Plessis and Volpe 2002). It is unknown whether hypothermia is protective in the very immature brain. Further, preterm infants may be particularly vulnerable to adverse systemic effects during mild hypothermia (Silverman et al. 1958).

Although the etiology of preterm brain injury is complex and multifactorial, exposure to perinatal asphyxia is highly associated with worse outcomes (Low et al. 1995), is more common in infants born prematurely than at term (Low 2004) and frequently occurs before the onset of labor (Low et al. 2003). The typical pattern of neural injury after exposure to severe perinatal hypoxia in preterm infants is distinctive, with severe damage in the basal ganglia and other subcortical regions, but sparing of the cerebral cortex (Barkovich and Truwit 1990; Barkovich and Sargent 1995; de Vries et al. 1998; Gilles et al. 1998). In the long-term, involvement of subcortical nuclei is a common feature in surviving preterm infants (Argyropoulou et al. 2003; Lin et al. 2001; Yokochi 1997).

We have recently reported that exposure to severe asphyxia in the preterm fetal sheep leads to a similar pattern of subcortical neural injury with cortical sparing (George et al. 2004). Strikingly, while overall EEG activity was profoundly suppressed for many hours after the asphyxial insult, regardless of whether injury later developed or not, epileptiform EEG transient activity during the early recovery phase was seen only in fetuses that went on to develop neural injury (George et al. 2004). These EEG transients were low to moderate amplitude events similar to the subtle, brief spikes and waveforms observed in preterm infants (Scher et al. 1994). The timing of these events corresponds with a secondary fall in carotid blood flow (Bennet et al. 1999; George et al. 2004) and a fall in cerebral oxygenation on near-inifrared spectroscopy (Bennet et al. 1999). These data suggest the hypothesis that these events may directly contribute to evolving injury, similar to adult models of ischemic injury (Golanov and Reis 1999; Hossmann 1996; Wolf et al. 1997). Although the effects of mild to moderate hypothermia on overt, stereotypical seizures remain controversial (Gunn et al. 1997; Thoresen et al. 1999; Tooley et al. 2003), local brain cooling can inhibit epileptiform activity (Baldwin and Frost 1956; Karkar et al. 2002).

The aim of this study was therefore to test the hypothesis that following hypoxic-ischemic injury induced by profound asphyxia in the 0.7 gestation fetal sheep treatment with cerebral hypothermia, induced $90 \mathrm{~min}$ after reperfusion and continued for 3 days, would improve neural outcome and suppress the development of post-asphyxial EEG transients on continuous EEG monitoring. In terms of cerebral maturity the 0.7 gestation fetal sheep is comparable to the human brain at term at 30-32 weeks of gestation (McIntosh et al. 1979), just prior to the onset of cortical myelination (Barlow 1969).

\section{Materials \& METHODS}

\section{Experimental preparation}

All procedures were approved by the Animal Ethics Committee of The University of Auckland. Twenty three singleton Romney/Suffolk fetal sheep were instrumented at 97.99 days of gestation (term $=147$ days) under general anesthesia ( $2 \%$ halothane in 02 ) using sterile techniques. Catheters were placed 
in the left femoral artery and vein, right brachial artery and vein, and the amniotic sac. Carotid artery blood flow (CaBF) was measured by a $3 S$ ultrasound blood flow probe (Transonic Systems Inc., Ithaca, NY, USA). Two pairs of electroencephalographic (EEG) electrodes (AS633-5SSF, Cooner wire Co., Chatsworth, CA, USA) were placed on the dura over the parasagittal parietal cortex ( $5 \mathrm{~mm}$ and $15 \mathrm{~mm}$ anterior to bregma and $10 \mathrm{~mm}$ laterall), with a reference electrode sewn over the occiput. A thermistor (Incu-temp-1, Mallinckrodt Medical Inc., St Louis, MO) was placed over the parasagittal dura $20 \mathrm{~mm}$ anterior to bregma, to measure extradural temperature, and the burr holes were sealed and the skin over the fetal skull was secured with cyanoacrylate glue. Electromyographic (EMG) electrodes were placed in the nuchal muscle and electrocardiogram (ECG) electrodes were sewn across the chest to record the fetal ECG. A second thermistor (to measure fetal core body temperature) was placed in the fetal esophagus at the level of the right atrium (Gunn et al. 1997). An inflatable silicone occluder was placed around the umbilical cord of all fetuses (In Vivo Metric, Healdsburg, CA, USA).

A cooling coil made from silicone tubing (external diameter $7.9 \mathrm{~mm}$, internal diameter $4.8 \mathrm{~mm}$; Silclear, Degania Silicone, Degania Bet, Israel) was attached over the dorsal surface of the scalp and extended over the lateral surface of the cranium down to the level of the external auditory meatus. The fetus was returned to the uterus and all fetal leads were exteriorized through the maternal flank. The maternal long saphenous vein was catheterized to provide access for maternal care and euthanasia. Antibiotics were given to the ewes $(5 \mathrm{mls}$ of Streptopen, $1 . \mathrm{m}$.) prior to the start of surgery, were administered into the amniotic sac prior to closure of the uterus ( $80 \mathrm{mg}$ Gentamicin), and after surgery (80 $\mathrm{mg}$ Gentamicin L.v. daily for the first 3 days, and $600 \mathrm{mg}$ Crystapen i.v. for 4 days).

After surgery sheep were housed together in separate metabolic cages with access to water and food ad libitum. They were kept in a temperature-controlled room $\left(16 \pm 1^{\circ} \mathrm{C}\right.$, humidity $\left.50 \pm 10 \%\right)$, in a $12 \mathrm{~h}$ light/dark cycle. A period of 4.6 days post-operative recovery was allowed. Fetal arterial blood was taken daily from the brachial artery for blood gas analysis for the assessment of fetal health. Catheters were maintained patent by continuous infusion of heparinized saline (20 $\mathrm{U} \mathrm{ml}^{-1}$ at $\left.0.15 \mathrm{~mJ} \mathrm{~h} \mathrm{~h}^{-1}\right)$.

\section{Experimental design and recordings}

Experiments were conducted at 103-104 days gestation. Fetal mean arterial pressure (MAP), corrected for maternal movement by subtraction of amniotic fluid pressure, heart rate (FHR), CaBF, EEG and nuchal EMG activity were recorded continuously from $12 \mathrm{~h}$ before the experiment until $72 \mathrm{~h}$ afterwards. Data were collected by computer and stored to disk for off-line analysis (Labview for Windows, National Instruments Ltd., Austin, Texas, USA).

Fetuses were randomly assigned to either the asphyxia-normothermia group $(n=8)$, asphyxiacooling group $(n=8)$ or sham control $(n=7)$. Fetal asphyxia was induced in both groups by rapid inflation of the umbilical cord occluder for 25 min with sterile saline of a defined volume known to completely inflate the occluder. Successful occlusion was confirmed by observation of a rapid flattening of the EEG. In all groups fetal arterial blood were taken at $15 \mathrm{~min}$ prior to asphyxia, 5 and $20 \mathrm{~min}$ during asphyxia, and $0.5,2,4,6,24,48$ and $72 \mathrm{~h}$ post-asphyxia for blood gas, acid-base balance (CibaCorning Dlagnostics 845 blood gas analyzer and co-oximeter, MA, USA) and for glucose and lactate determination (YSI model 2300, Yellow Springs, Ohio, USA). Intrauterine cooling was performed from $90 \mathrm{~min}$ to $70 \mathrm{~h}$ after the end of acclusion. Fetuses were then rewarmed for $2 \mathrm{~h}$. Cooling was induced by circulating cold water $\left(10^{\circ} \mathrm{C}\right)$ through a coil around the fetal head. Cooling was titrated in the first $2 \mathrm{~h}$ to reduce fetal extradural temperature from $39.4 \pm 0.1^{\circ} \mathrm{C}$ to between 29 and $33^{\circ} \mathrm{C}$.

Fetuses were studied for 3 days after the end of occlusion. On completion of the experiment the ewes and fetuses were killed by an overdose of sodium pentobarbitone $9 \mathrm{~g}$ i.v. to the ewe: Pentobarb 300, Chemstock International, Christchurch, New Zealand). 


\section{Histology Tissue Preparation}

Fetal brains were perfusion fixed in situ with hormal saline followed by $500 \mathrm{ml}$ of $10 \%$ phosphate buffered formalin. Following removal from the skull, tissue was fixed for a further 5-6 days before processing and embedding using a standard paraffin tissue preparation (Gunn et al. 1997). Neuronal loss was evaluated by light microscopy by an assessor masked to the treatment group on $8 \mathrm{\mu m}$ thick coronal sections stained with thionin and acid fuchsin (Gunn et al. 1997). The proportion of neurons showing ischemic cell change as shown by nuclear condensation and acid fuschin [pink] staining of the cytoplasm in multiple pre-assigned areas was scored on a 6 point scale as follows: $0=$ no dead neurons; $5=>0-10 \% ; 30=>10-50 \% ; 70=>50-90 \% ; 95=90-<100 \%$; and $100=100 \%$ dead neurons. Average scores were calculated for each region (Gunn et al. 1997). Activated microglial cells were labelled on parallel sections using the lectin, Bandeiraea simplicifolia I isolectin-B4 (Sigma, St. Louis, MO, U.S.A.) (Roelfsema et al. 2004).

\section{Caspase 3 expression}

Staining was performed on coronal sections $(6 \mu \mathrm{m})$ at the levell of the mid striatum cut and mounted on chrome alum coated slides. Prior to specific staining all the slides were deparaffinized in xylene twice for $15 \mathrm{~min}$, dehydrated in a series of ethanol $(100 \%, 100 \%, 95 \%, 95 \%, 70 \%$, for two min each), and incubated in $0.1 \mathrm{M}$ phosphate buffered saline (PBS) twice for $5 \mathrm{~min}$. The sections were boiled in $0.1 \mathrm{mM}$ citrate buffer for antigen unmasking. The sections were then pretreated with $1 \% \mathrm{H}_{2} \mathrm{O}_{2}$ in $50 \%$ methanol for $20 \mathrm{~min}$, washed in PBS ( $3 \times 5 \mathrm{~min})$ and incubated with the primaty antibody for 2 days at $4^{\circ} \mathrm{C}$.

Rabbit anti-Caspase-3 Asp 175 was used (cleaved Caspase-3 Antibody which detects endogenous levels of the large fragment of activated caspase-3 (17-20kDa), Cell Signaling Technology, Beverly, MA, USA). The antibody was diluted 1:1000 in PBS containing normal horse serum/goat serum. The primary antibody was washed off with PBS $(3 \times 10 \mathrm{~min})$ and then incubated with anti-rabbit biotinylated immunoglobulin $\mathrm{G}$ (Vector laboratories, Burlingame, CA, USA, diluted $1: 200$ ) overnight at $4^{\circ} \mathrm{C}$. The sections were washed, incubated in avidin-biotin complex (ABC, Vector Laboratories, Peterborough, England, diluted 1:100) in the ratio 1:500 for $3 \mathrm{~h}$ at room temperature, washed again in PBS, and then reacted in diaminobenzidine tetrahydrochloride (DAB, Sigma). Sections were then dehydrated in a series of alcohol to xylene washes and overslipped with mounting medium. Control sections were processed in the same way except that the primary antibody was omitted from the incubation solution.

Numbers of activated caspase 3 positive cells were counted by light microscopy at $\times 100$ magnification on coronal sections using a $1 \mathrm{~cm}^{2}$ grid in pre-selected areas of the dorsollateral aspect of the caudated nucleus and the putamen. Values from the left and right hemisphere were averaged. The cross-sectional area of each nucleus was measured.

\section{Data analysis and statistics}

Offline analysis of electronic data was performed using an analysis program written using Labview for Windows. The nuchal EMG signal was bandpass filtered between $100 \mathrm{~Hz}$ and $1 \mathrm{kHz}$ and the signal then integrated using a time constant of $1 \mathrm{sec}$. The EEG signal was low-pass filtered with a $6^{\text {th }}$ order low-pass Butterworth filter, with a cut-off frequency of $50 \mathrm{~Hz}$. A power spectrum was then calculated from this $256 \mathrm{~Hz}$ sampled signal. The EEG intensity and spectral edge were then calculated on the portion of the power spectrum between $1 \mathrm{~Hz}$ and $20 \mathrm{~Hz}$, and stored as $1 \mathrm{~min}$ averages for the analysis of average EEG changes over time. Data from left and right EEG electrodes were averaged to give mean total EEG activity. For clarity of data display the EEG intensity was log transformed I dB, $20 \mathrm{x}$ $\log ($ intensity)), as this transformation gives a better approximation of the normal distribution (Williams 
et al. 1990), and normalized. Additionally, the raw EEG signal was processed through a digital FIR low-pass filter with a cut-off frequency of $30 \mathrm{~Hz}$ and stored at a sampling rate of $64 \mathrm{~Hz}$ for analysis of seizures.

The raw EEG was assessed for epileptiform activity; specifically the presence of spikes and sharp waves (i.e. epileptiform transients (George et al. 2004)). A spike was defined as having a sharp outline and duration of less than $70 \mathrm{msec}$. Sharp waves were assessed as single or repeated mono- or diphasic transients lasting 100 to $250 \mathrm{msec}$, with an amplitude greater than $10 \mu \mathrm{V}$, typically superimposed on a flat EEG background (Scher 2003; Scher 2002). Overt electrographic seizures were identified visually and defined as the concurrenit appearance of sudden, repetitive, evolving stereotyped waveforms in the EEG signal lasting more than $10 \mathrm{sec}$ (Scher 2002).

Treatment effects were evaluated by analysis of variance (ANOVA, SPSS v10, SPSS Inc.), followed by the protected least-significant difference post-hoc test when a significant overall effect was found. For comparisons over time, baseline levels were used as a covariate (ANCOVA). The baseline period was taken as the mean of the 6 hours before occlusion. Cerebral region in the histology score and time series data were treated as repeated measures to allow for repeated sampling. Statistical significance was accepted when $P<0.05$. Data are mean \pm SD.

Table 1 Fetal arterial pH, blood gases, glucose and lactate values for sham control (C), normothermia asphyxia (N) and hypothermia asphyxia (H) groups $15 \mathrm{~min}$ before (baseline), at $20 \mathrm{~min}$ during (occl), and $30 \mathrm{~min}, 2 \mathrm{~h}, 4 \mathrm{~h}, 6 \mathrm{~h}, 24$ $\mathrm{h}, 48 \mathrm{~h}$ and $72 \mathrm{~h}$ after either sham occlusion or 25 min of umbilical cord occlusion. Data are mean $\pm \mathrm{SD}$. * $\mathrm{P}<0.05$ compared to sham control, 株 $P<0.05$ asphyxia normothermia vs hypothermia (ANOVA, followed by the Least Slgnilicant Difference post-hoc test for between group comparisons).

\begin{tabular}{|c|c|c|c|c|c|}
\hline 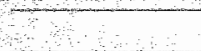 & 3 & Control & $20 \mathrm{~min} \mathrm{occl}$ & $30 \mathrm{~min}$ & $2 \mathrm{~h}$ \\
\hline \multirow[t]{3}{*}{$\mathrm{pH}$} & C & $7.39 \pm 0.0$ & $7.38 \pm 0.0$ & $7.38 \pm 0.0$ & $7.39 \pm 0.0$ \\
\hline & N & $7.37 \pm 0.0$ & $6.82 \pm 0.0^{*}$ & $7.25 \pm 0.0^{*}$ & $7.34 \pm 0.0^{*}$ \\
\hline & $H$ & $7.39 \pm 0.0$ & $6.85 \pm 0.0^{*}$ & $7,27 \pm 0: 0^{*}$ & $7.39 \pm 0.04$ \\
\hline \multirow[t]{3}{*}{$\mathrm{PeCO}_{2}(\mathrm{mmHg})$} & C & $48.8+4.5$ & $49.11 \pm 4.1$ & $47.8 \pm 4.1$ & $48.1 \pm 4.3$ \\
\hline & N & $48,2 \pm 2.6$ & $1422 \pm 6^{\prime \prime}$ & $45.8 \pm 2.2$ & $46.8 \pm 2.6$ \\
\hline & $H$ & $47.8 \pm 4.3$ & $138.4 \pm 24^{*}$ & $37.8 \pm 3.5^{*}$ & $37.9 \pm 2.9^{*}, \mathrm{H}$ \\
\hline \multirow[t]{3}{*}{$\mathrm{PaO}_{2}(\mathrm{~mm} / \mathrm{Hg})$} & c & $22.5 \pm 2.6$ & $22.7 \pm 2.3$ & $22.3 \pm 2.1$ & $22.1 \pm 2.6$ \\
\hline & N & $23.0 \pm 2.6$ & $8.7 \pm 2.2^{*}$ & $27.9 \pm 3.8^{*}$ & $26.2 \pm 3.8^{*}$ \\
\hline & H & $24.7+3.0$ & $9.1 \pm 43^{*}$ & $27.3 \pm 2.0^{*}$ & $24.7 \pm 3.7$ \\
\hline \multirow[t]{3}{*}{$\mathrm{O}_{2} \mathrm{Ct}$} & c & $3.6 \pm 0.5$ & $3.5+0.5$ & $3.6 \pm 0.5$ & $34 \pm 0.6$ \\
\hline & N & $3.5 \pm 0.5$ & $0.5 \pm 0.1^{*}$ & $3.9 \pm 0.5$ & $4.1 \pm 0.5$ \\
\hline & $H$ & $3.7 \pm 0.4$ & $0.5 \pm 0.2^{*}$ & $3.9 \pm 0.6$ & $4.2 \pm 0.8^{*}$ \\
\hline \multirow[t]{3}{*}{ Glucose (mM) } & C & $1.0 \pm 0.3$ & $1.0 \pm 0.3$ & $1.0 \pm 0.2$ & $1.0 \pm 0.3$ \\
\hline & N & $1.0 \pm 0.2$ & $0.7 \pm 0.3^{*}$ & $1.3 \pm 0.4$ & $1.2 \pm 0.2$ \\
\hline & $H$ & $0.9 \pm 0.2$ & $0.5 \pm 0.4^{*}$ & $1.4 \pm 0.5$ & $1.3 \pm 0.3$ \\
\hline \multirow[t]{3}{*}{ Lactate (mM) } & C & $0.8 \pm 0.2$ & $0.8 \pm 0.1$ & $0.8 \pm 0.2$ & $0.8 \pm 0.4$ \\
\hline & N & $0.6 \pm 0.2^{*}$ & $6.5 \pm 0.5^{*}$ & $4.8 \pm 0.5^{*}$ & $3.6 \pm 1.5^{*}$ \\
\hline & $H$ & $0.7 \pm 0.1^{*}$ & $5.8 \pm 1.4^{*}$ & $4.7 \pm 1.3^{*}$ & $2.9 \pm 1.6^{*}$ \\
\hline
\end{tabular}




\section{RESULTS}

\section{Baseline}

All fetuses had normal FHR, MAP, blood gases, acid base, glucose and lactate status, and EEG signals before each experiment, according to the standards of our laboratory. Values and statistical comparisons for arterial $\mathrm{pH}$, blood gases, and glucose and lactate levels for the sham control, asphyxia normothermia and asphyxia hypothermia groups are presented in Table 1.

\section{Effect of umbilical occlusion}

Umbilical cord occlusion was associated with marked fetal hypoxia and acidosis (table 1) and led to bradycardia, hypotension and cerebral hypoperfusion. Both EEG intensity and nuchal EMG activity were rapidly and profoundly depressed during the entire period of occlusion $(P<0.05$ for each variable; data not shown). There were no significant differences between the animais allocated to the normothermia and the hypothermia group during the occlusion period.

\section{Blood composition in the recovery period}

Following release of the umbilical occluder, there was rapid recovery of blood gases, $\mathrm{pH}$ and glucose and lactate levels by 4 to $6 \mathrm{~h}$ (Table 1). Compared to the sham control group, arterial $\mathrm{pO}_{2}$ and $\mathrm{O}_{2} \mathrm{ct}$ were significantly elevated in the two asphyxia groups for most of the recovery period. There was a small reduction in arterial $\mathrm{pCO}_{2}$ in the cooled group $(P<0.05)$ compared to both sham controls and the asphyxia normothermia group, with mildly elevated $\mathrm{pH}$ levels $(P<0.05)$.

\section{Effect of cooling on brain and body temperature}

Head cooling was initiated 90 min after the end of the umbilical cord occlusion and was associated with a significant fall in extradural temperature starting within an hour after the onset of cooling,

\begin{tabular}{|c|c|c|c|c|}
\hline $4 \mathrm{~h}$ & $6 \mathrm{~h}$ & $24 \mathrm{~h}$ & $48 \mathrm{~h}$ & $72 \mathrm{~h}$ \\
\hline $7.39 \pm 0.0$ & $7,38 \pm 0,0$ & $7.38 \pm 0.0$ & $7.37+0.0$ & $7.37 \pm 00$ \\
\hline $7.40 \pm 0.0$ & $7,41 \pm 0.0^{*}$ & $7.37 \pm 0.0$ & $7.38 \pm 0.0$ & $7.38 \pm 0.0$ \\
\hline $746 \pm 0,0^{\circ}, 4$ & $744 \pm 00^{*}$; & $7,43 \pm 000^{*}$, & $744 \pm 0.0 \%$ & $7.43 \pm 0.0^{*}$ \\
\hline $49.2+52$ & $49,4 \pm 5,0$ & $47.5 \pm 6.3$ & 49244. & $48.2 \pm 6.4$ \\
\hline $477 \pm 3.2$ & $45,6 \pm 4.0$ & $47.4 \pm 2.9$ & $47.1 \pm 2.5$ & $46.4 \pm 3.2$ \\
\hline $39.8 \pm 40^{*}$, \# & $39.5 \pm 3.0 \%$ & $38.8 \pm 7.3^{*}$, 非 & $41.5 \pm 2.9^{\circ}$ & 42951 \\
\hline $22.6 \pm 2.6$ & $22.3 \pm 2.5$ & $22.2 \pm 4.8$ & $23.4 \pm 4.0$ & $23.5 \pm 3.7$ \\
\hline $24.8 \pm 2.8$ & $24.8 \pm 2.5$ & $266 \pm 3.7^{*}$ & $28.0 \pm 3.2^{*}$ & $28.3 \pm 3.6$ \\
\hline $25.1 \pm 3.7$ & $24.4 \pm 3.2$ & $23.6 \pm 2,6$ & $24.5 \pm 43$ & 27047.1 \\
\hline $3.4 \pm 0.6$ & $3.4 \pm 0.6$ & $3.2 \pm 0.6$ & $3.4 \pm 0.7$ & $3.7 \pm 0.6$ \\
\hline $3.9 \pm 0.8$ & $4.0 \pm 0.7$ & $4.1 \pm 0.8$ & $4.1 \pm 0.7$ & $4.2 \pm 0.7$ \\
\hline $4.5 \pm 0.6^{*}$ & $4.5 \pm 0.8^{*}$ & $4.2 \pm 0.5$ & $3.9 \pm 0.6$ & $4.3 \pm 0.5$ \\
\hline $1.1 \pm 0.2$ & $1.1 \pm 0.2$ & $1.2 \pm 0.3$ & $1.2+0.2$ & $1.1 \pm 0.3$ \\
\hline $1.3 \pm 0.3$ & $1.4 \pm 0.3^{*}$ & $1.5 \pm 0.4$ & $1.3 \pm 0.2$ & $1.2 \pm 0.2$ \\
\hline $1.4 \pm 0.3^{*}$ & $1.5 \pm 0.3^{\circ}$ & $1.4 \pm 0.4$ & $1.3 \pm 0.4$ & $1.4 \pm 0.3$ \\
\hline $0.8 \pm 0.2$ & $0.9 \pm 0.3$ & $0.7 \pm 0.1$ & $0.8 \pm 0.3$ & $0.9 \pm 0.3$ \\
\hline $2.4 \pm 1.3^{*}$ & $1.9 \pm 0.7^{*}$ & $1.0 \pm 0.3^{*}$ & $0.8 \pm 0.3$ & $0.9 \pm 0.2$ \\
\hline $1.4 \pm 0.8 \#$ & $1.2+0.5^{*}$ & $0.9 \pm 03$ & $0.7 \pm 0.2$ & $0.8 \pm 0.2$ \\
\hline
\end{tabular}


Figure 1. Time sequence of changes in retal temperature, electroencephalogram (EEG) intensity (power) and spectral edge (frequency). The $25 \mathrm{~min}$ period of umbilical cord acclusion is shown by the solid vertical lines, while cooling is shown by the shaded bar. The top panel shows changes in extradural and core body (esophageal) temperatures in the hypothermia [closed symbols) and asphyxia normothermia (oper symbols) groups. The extradural and esophageal temperature were signilicandy diflerent from nomothermia fetuses throughout the cooling perlod $(P<0.001$, not shown). Bar plus * P<0.05 hypothermia vs noromothermia; bar plus \# P<0.05 aspiyxia normothermia vs shan control group. Data are mean $上$ SD.
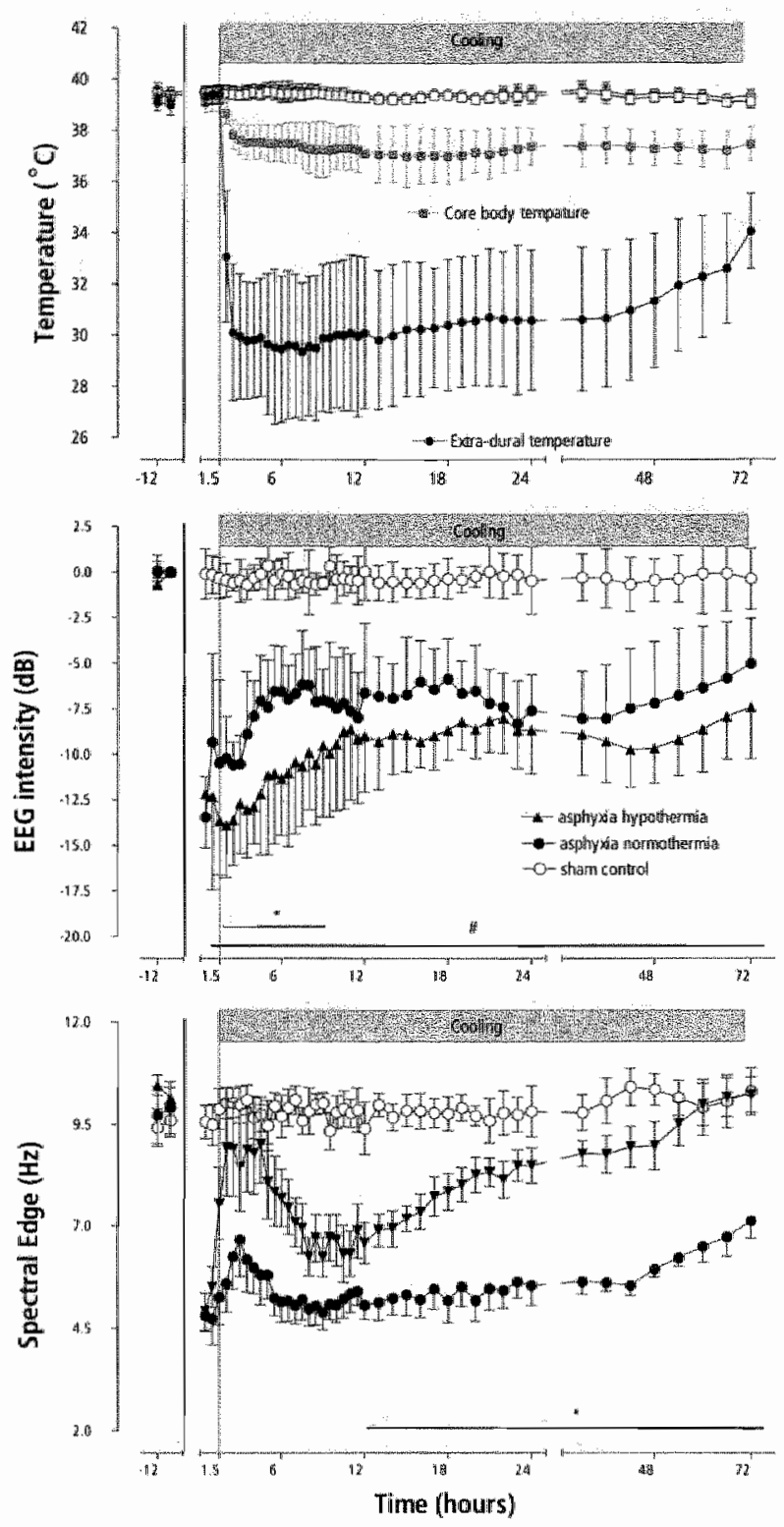

reaching a nadir of $29.5 \pm 2.6^{\circ} \mathrm{C}$ (vs $39.3 \pm 0.3^{\circ} \mathrm{C} ; P<0.05$, Fig 1). Extradural temperature gradually increased during the second and third day of cooling to a mean of $32.3 \pm 2.2^{\circ} \mathrm{C}$ in the last $6 \mathrm{~h}$. During cooling, core body temperature dropped mildly to a nadir of $37.2 \pm 0.8^{\circ} \mathrm{C}$ (vs $\left.39.0 \pm 0.4^{\circ} \mathrm{C} ; P<0.05\right)$, which was sustained over the whole cooling period.

\section{EEG intensity and spectral edge}

EEG intensity was rapidly suppressed at the onset of occlusion in both asphyxia groups, and remained significantly suppressed compared with sham controls following reperfusion for the remainder of the 


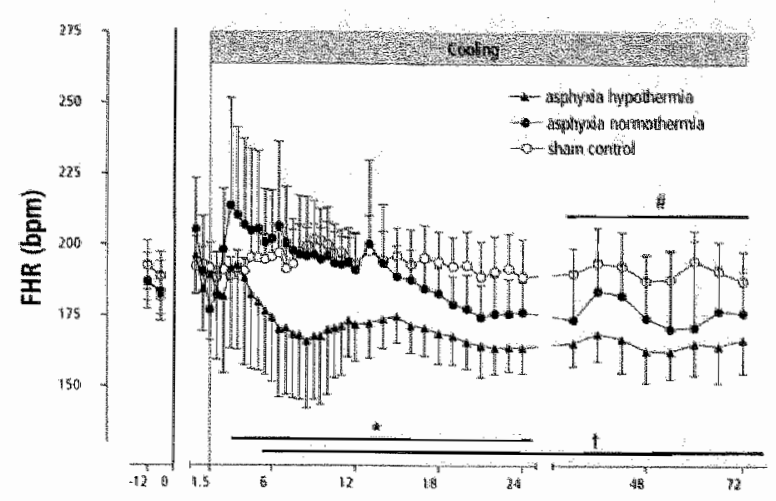

Figure 2. Time sequence of changes in fetal heart

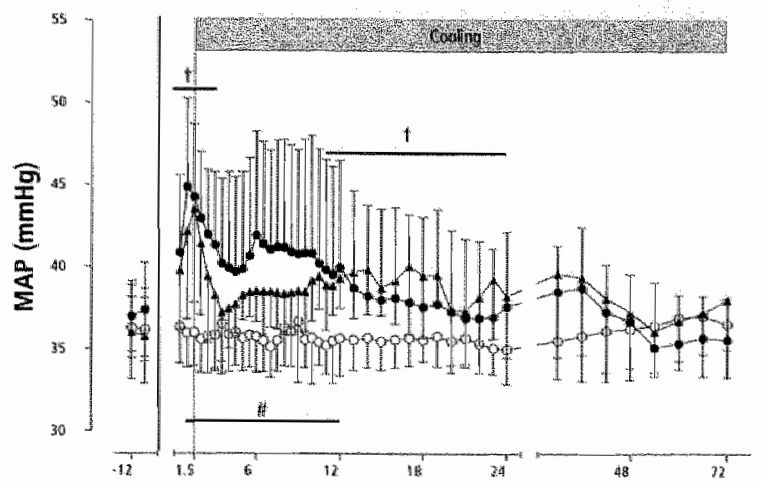
rate (bpm), mean arterial blood pressure (MAP, mmHg) and total carotid blood flow (CaBF), in the hypothermia $[\mathbf{A}]_{\text {. }}$ asphyxia normothemia $[\mathbf{O}]$ and sham control (a) groups. The $25 \mathrm{~min}$ pertod of umbilical cord occlusion is shown by the vertical ines, while cooting is shown by the shaded bat. Data are mean $\pm \mathrm{SD}$, * P<0.05 hypothermia vs asphyxia nomothermia. $+P<0.05$ cooling $w$ sham asphyxia. $\quad P<0.05$ asphyxia normothermia ws sham controls.

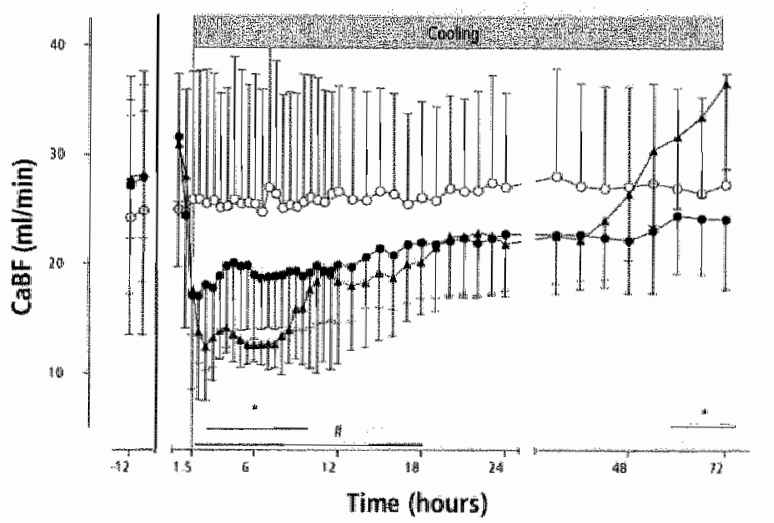

experiment $(P<0.01)$. Hypothermia was associated with an immediate fall in EEG intensity, which remained significantly less than in the normothermia asphyxia group until 9 h after occlusion $(P<0.05)$; thereafter there was no significant difference between the two groups.

EEG spectral edge (SE) was also markedly suppressed in both occlusion groups during and after reperfusion with a modest rise in the first $4 \mathrm{~h}$, followed by a fall reaching its nadir at approximately $7 \mathrm{~h}$. SE was not significantly increased in the hypothermia group compared to the normothermia group during the first $12 \mathrm{~h}$ of cooling (N.S.). From $12 \mathrm{~h}$ onward SE was significantly increased $(P<0.001$, repeated measures ANOVA) in the hypothermia group compared to the asphyxia normothermia group, attaining sham control values in the final $24 \mathrm{~h}$ of the study. 

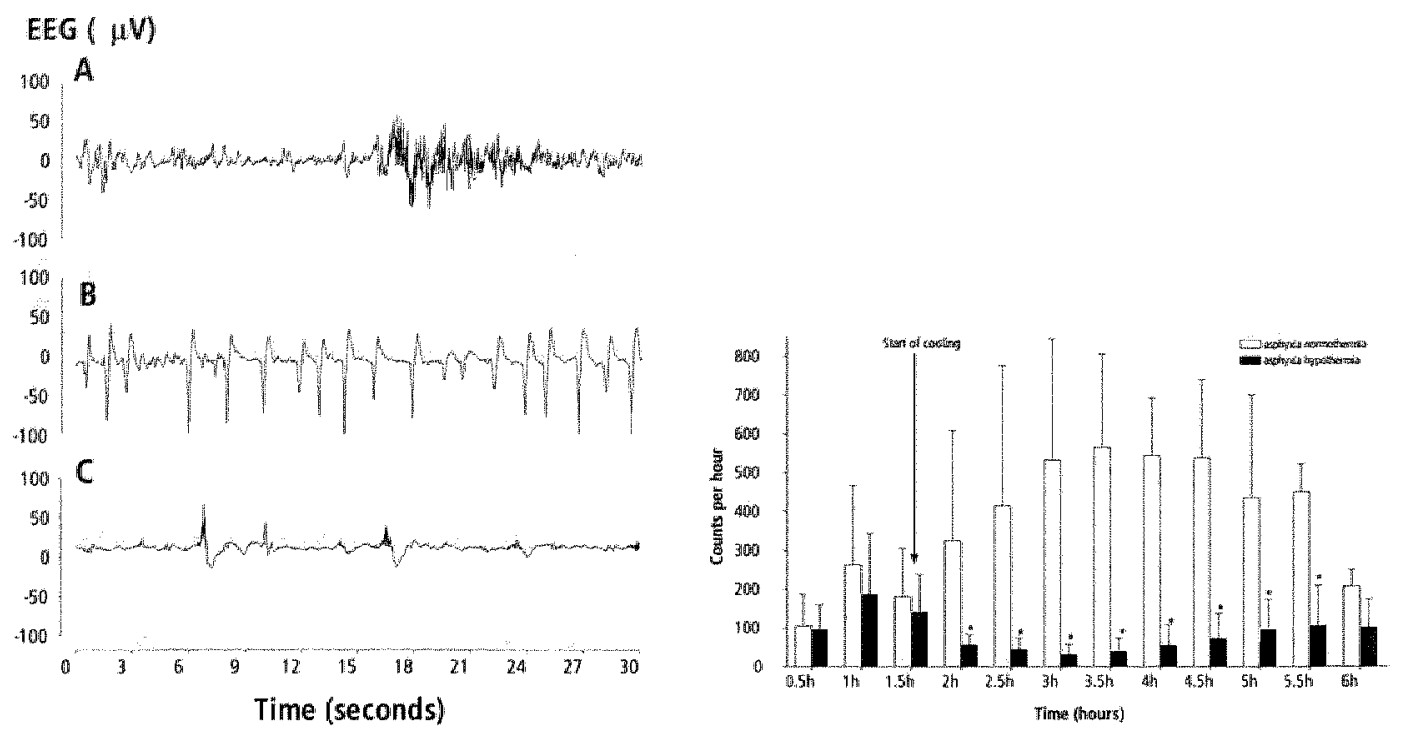

Figure 3. Examples of raw electroencephalographic (EEG) data showing normal discontinuous mixed frequency EEG activity Ipanel Al, epileptiform transients (fast spikes) superimposed on a suppressed $E E G$ background at 3 h post-occlusion (panel B) and marked suppression of EEG transients during hypothermia at $3 \mathrm{~h}$ (panel Cl. The bottom panel quantifies numbers of events per minute in the asphyxia normothermia and hypothermia groups. * $P<0,05$ hypothermia us asphyxia normothermia group.

Data are mean $\pm S D$.

\section{Epileptiform activity}

The raw EEG signal after reperfusion was highly abnormal showing marked loss of background activity, with frequent high voltage sharp and spike wave transients in the asphyxia group but not sham controls (Fig. 3). These EEG transients peaked between 3 and $5 \mathrm{~h}$ after the end of occlusion. No abnormal EEG wavelorms, or burst suppression activity was observed in the sham control group at any time. The start of cooling at $90 \mathrm{~min}$ was associated with an immediate reduction in numbers of EEG transients $(P<0.001$, Fig. 3). Although there was a trend for increasing numbers of transients in the hypothermia group after approximately $5 \mathrm{~h}$, the onset of overt EEG seizures at this time in some fetuses meant that EEG transients could no longer be reliably counted.

This interval of last and sharp wave splke activity was then followed by the onset of high amplitude, low trequency stereotypic evolving seizure activity from $9.1 \pm 5.3 \mathrm{~h}$ in the asphyxia group vs $10.1 \pm$ $4.7 \mathrm{~h}$ in the hypothermia group (N.S.). A total of $66.5 \pm 65.5$ ws $73.1 \pm 70.3$ seizure events occurred (N.S.). The amplitude of these events was reduced in the cooling group (130.4 \pm 62.8 vs $67.5 \pm 20.9$ $\mu \mathrm{V}, P=0.006$, Mann-Whitney $\mathrm{U}$ test $)$. No seizures were observed in sham control fetuses at any time.

The raw EEG recordings were examined in the final hour of recording (i.e. after rewarming the hypothermia group). Both asphyxia groups showed marked suppression of EEG amplitude at that time (see examples Fig. 4). In the asphyxia normothermia group the activity is predominantly low frequency and occasional epileptiform transients were seen. The asphyxia hypothermia group showed a mixture of high and Jower frequency activity, but no epileptiform transients. 
Figure 4. Examples of raw electroencephalographic $[E E G]$ data taken $72 \mathrm{~h}$ after either sinam acclusion (panel A) or umbilical cord occlusion followed by normothermia (panel B) or hypothermia. [panel C]. The sham control shows typical discontinuous mixed frequency EEG activity. EEG amplitude is markedly suppressed in both asphyxia groups. In the asphyxia normothermia group the activity is predominantly low frequency (panel $B$ ), whereas in the asphyxia bypothermia group a mixture of high and lower frequency activity is seen (panel C).
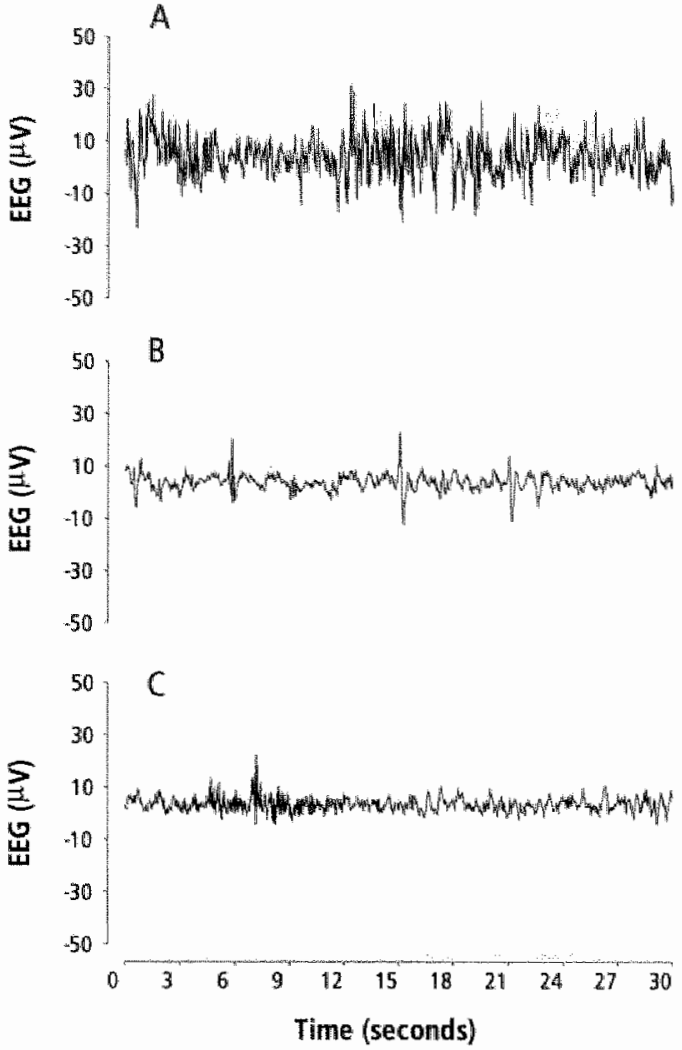

\section{CaBF, MAP and FHR}

Following reperfusion, there was an initial rapid recovery in MAP, FHR and CaBF. The asphyxia-normothermia group showed a transient tachycardia (maximal at $3 \mathrm{~h}$ after occlusion), followed by a gradual fall, and became significantly lower than in sham controls in the final $48 \mathrm{~h}$ of the study $[P<0.05$, ANOVA]. In contrast, cooling was associated with a significant reduction in FHR compared to both sham controls $(P<0.001$, from $5 \mathrm{~h}$ untill the end of cooling) and the asphyxia normothermia group ( $P<0.05$, from $3 \mathrm{~h}$ to $24 \mathrm{~h})$.

MAP was significantly elevated in the first $24 \mathrm{~h}$ after the end of occlusion in the normothermia and hypothermia asphyxia groups compared with sham controls $(P<0.005$, ANOVA). The elevation wàs maximal at $1 \mathrm{~h}$, and returned to sham control values in the final $48 \mathrm{~h}$. The hypothermia group was not significantly different from the asphyxia normothermia group overall (ANOVA); however, there was an apparently more rapid resolution of the initial elevation of MAP, such that the hypothermia group was not significantly different from sham controls from $3 \mathrm{~h}$ to $12 \mathrm{~h}$ after occlusion.

CaBF initially returned to sham control values after occlusion, followed by a secondary fall, which was significantly less than sham controls from $90 \mathrm{~min}$ to $18 \mathrm{~h}$ after occlusion. Thereafter CaBF was not significantly different from sham controls. Hypothermia was associated with a greater reduction in $\mathrm{CaBF}$ than in the asphyxia-normothermia group from 2.5 to $8 \mathrm{~h}(P<0.05)$. In the final $42 \mathrm{~h}$ of the experiment the hypothermia group showed a progressive increase in $\mathrm{CaBF}$, reaching values greater than the asphyxia normothermia group in the final $24 \mathrm{~h}(P<0.05$, ANOVA). 

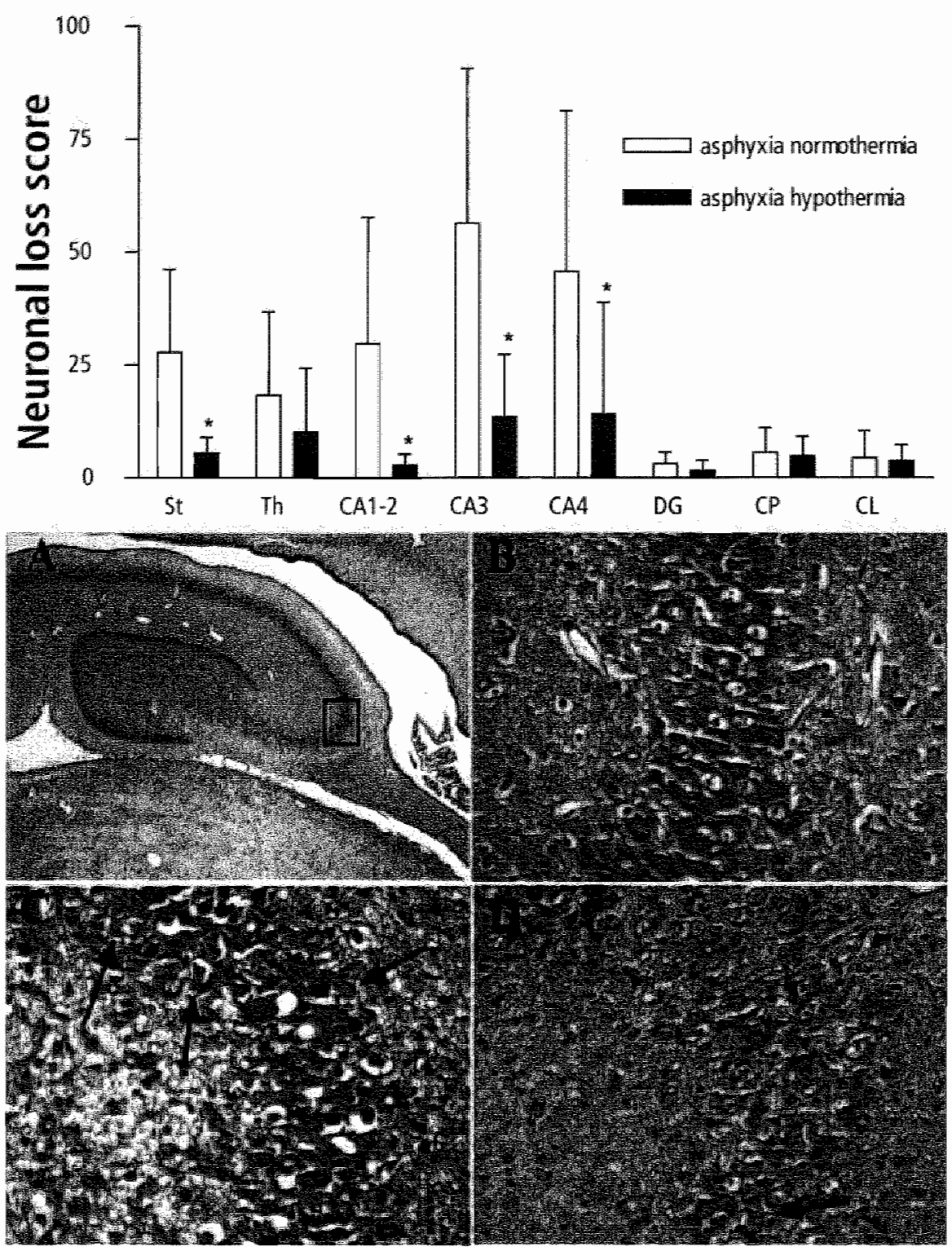

Figure 5. The top panel quantifies neuronal loss in hypothermia-treated and sham cooled fetuses. Mean $\pm S D,{ }^{*}=P<0.05$ hypothermia ws. sham cooled fetuses. CP (Parasagittal cortex), CL (Lateral or temporal cortex), DG identate gyrus), CA (cornu ammonis of the hippocampus), St (Striatum), Th (Thalamus).

The panel at the botton shows photomicrographs of the CA 3 region of the dorsal arm of the hippocampus stained with acid fuschin and thionin staining. Photomicrograph $A$, the box shows the selected $C A 3$ region. Photomicrograph $B$, an example of a sham control showing normal neuronal morphology. Photomicrograph $C$, example of a sham cooled (asphyxia) fetus showing severe neuronal loss. Photomicrograph $\mathrm{D}$, a fetus treated with hypothermia showing increased numbers of intact cells. The arrows indicate examples of ischemic cell change. 
Figure 6. Photomicrographs showing isolectin B.4 staining in the $C A$ region of the dorsal hippocampus. No isolectin $B-4$ positive cells were seen in sham controls (A). Umbilical cord acclusion was associated with intense induction of isolectin $B-4$ posituve cells $|B|$, which was almost completely suppressed by early initiation of cooling (hypothermia group, C). Scale bar $=50 \mu \mathrm{m}$.

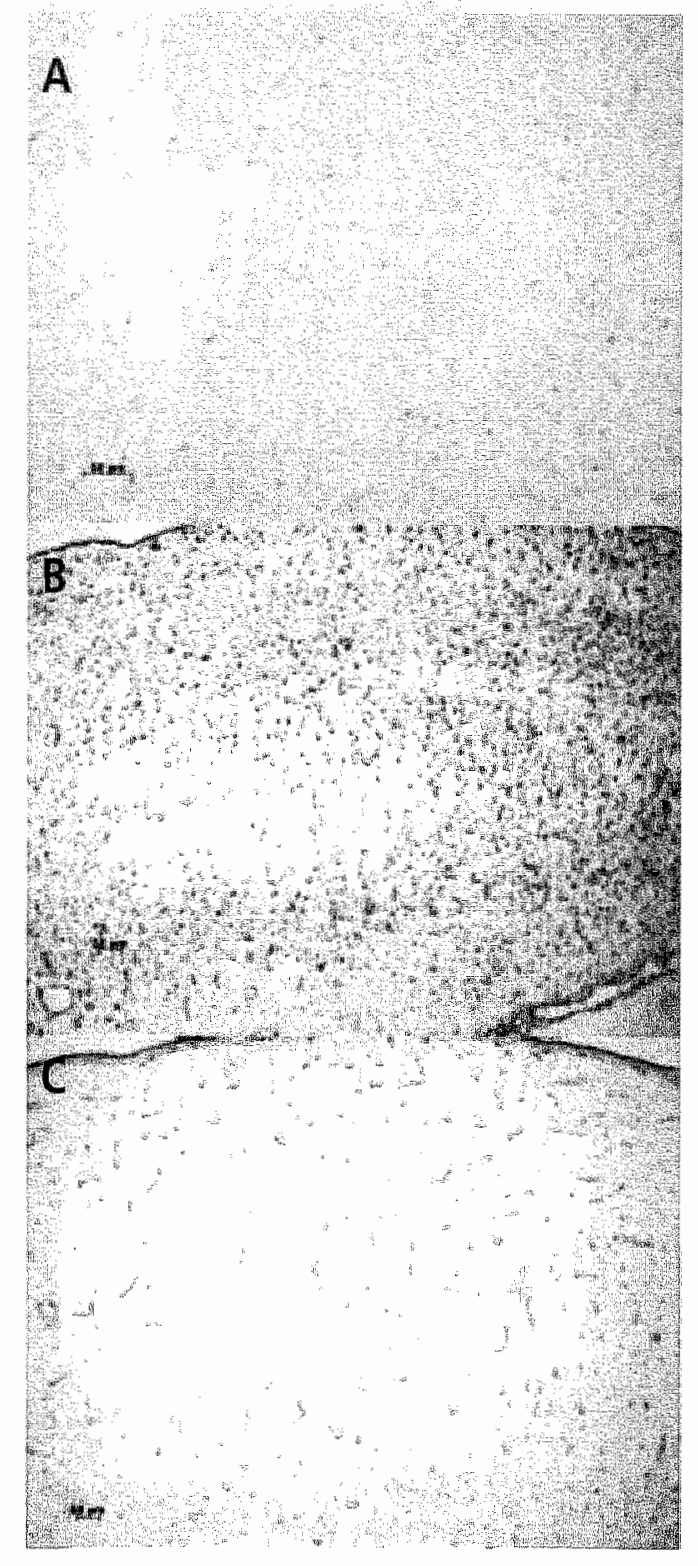

\section{Histology}

There was no histological injury or cell loss visible on acid fuschin and thionin staining in sham control animals. Asphyxia was associated with severe subcortical neuronal loss, particularly in the dorsolateral aspect of the basal ganglia and the connu ammonis (CA) regions of the dorsal horn of the hippocampus. There was only trivial neuronal loss in the cortical regions, typically only a few cells in the parasagittal gyrii. Hypothermia was associated with a significant overall reduction in neuronal loss $(\mathrm{P}<0.001)$, which was greatest in the striatum $(27.8 \pm 6.4$ vs $5.5 \pm 1.2 \%)$ and CA regions of the hippocampus 


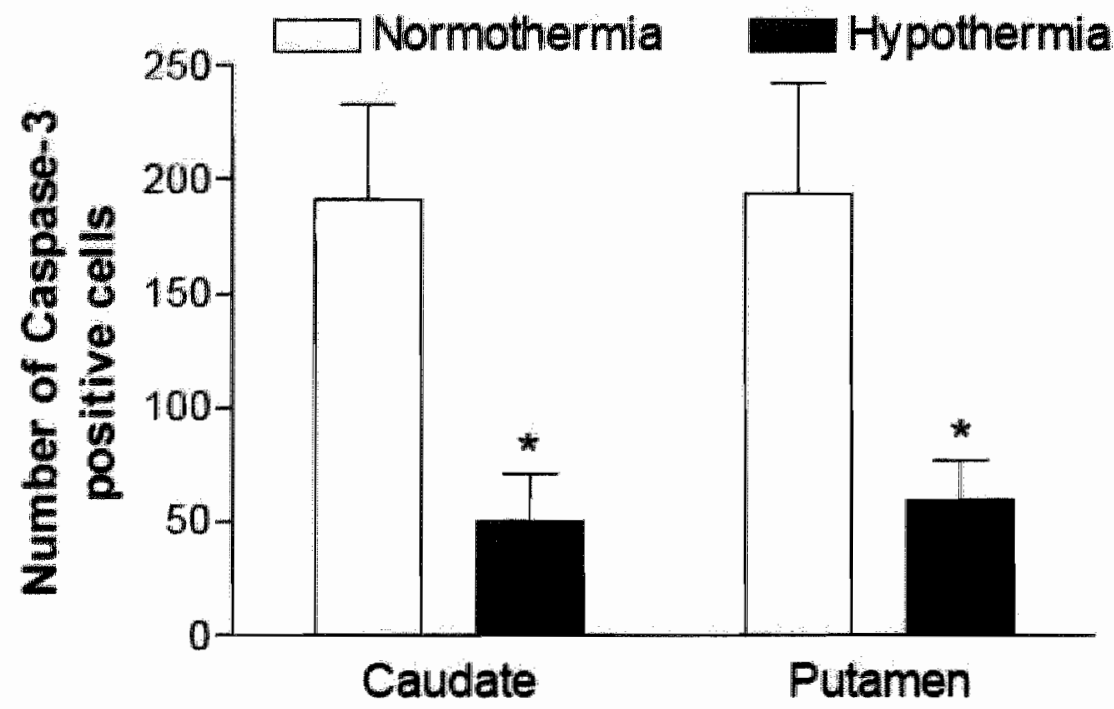

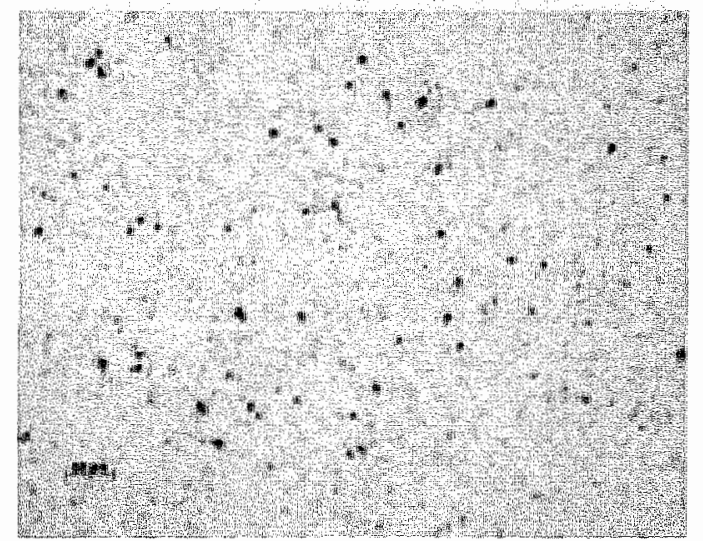

Asphyxia-Normothemia

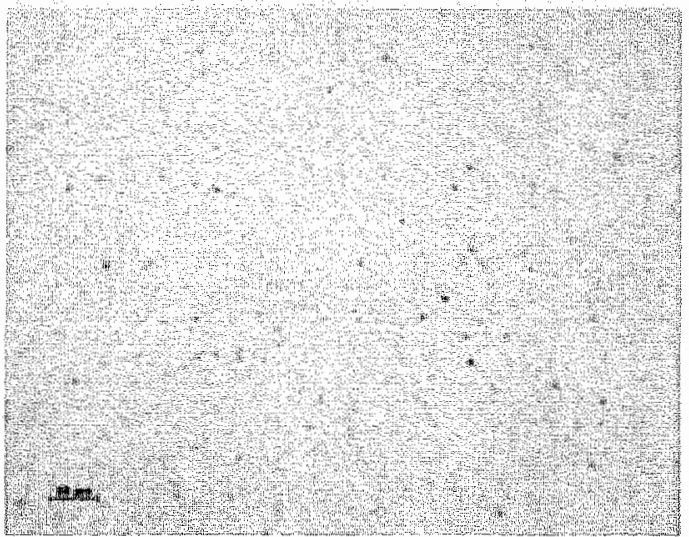

Asphyxia-Hypothermia

Figure 7 . Top panel: numbers of caspase-3 (Asp 175) positive cells counted in a $1 . \mathrm{cm}^{3}$ area in the catudate nucleus and putamen wete significantly increased after three days recowery from umbilical cord occlusion compared to the sham control group. The mpothermia group showed marked suppression of caspase-3 activation compared to the asphyxianomothermia group. *, PC0.001. Data are mean $\pm S D$.

Botom pane: Photomicrographs showing examples of caspase 3 positive staining (brown) In the caudate mucleus 3 days after umbilical cord accius ion in 0.7 gestation fetal sheep, with many positive cells in the asphyxia nomothemia letus (left), and suppression un the hypothemia fetus (right). In the asphyxia nomothermia fetus note the presence of coarse granular fragments of caspase positive material around some of the positive cells. Scale $\mathrm{bar}=50 \mu \mathrm{m}$. 
( $43.9 \pm 10.0$ vs $10.1 \pm 4.3 \%$, Fig. 5). Sham control animals showed virtually no isolectin B-4 staining in any region. Occlusion was associated with induction of isolectin B4 staining activated microglia, greatest in the CA regions of the hippocampus. This was nearly completely suppressed in the hypothermia group (Fig. 6).

\section{Activated caspase- 3 expression in the striatum}

Only occasional cleaved $17 \mathrm{kD}$ caspase-3 positive cells were seen, in a few sham control animals. Following umbilical cord occlusion in the asphyxia normothermia group, marked activated caspase- 3 expression was seen in the caudate mucleus and putamen (Fig. 7). The density of caspase-3 staining varied between cells due to the timing of cleavage of caspase-3. Cells were counted which had evidence of newly cleaved caspase-3, as shown by morphologically dense caspase-3 (Asp 175) staining evenly distributed within the ectoplasm (Fig. 7, bottom panel). Hypothermia was associated with significantly reduced numbers of cells expressing activated caspase- 3 compared to normothermia $(P<0.001$, ANOVA $)$.

\section{DisCUSSION}

The present study demonstrates that moderate, delayed cerebral hypothermia from 90 minutes and continued until 70 hours after a prolonged episode of umbilical cord occlusion is associated with improved electrophysiological and histological recovery in preterm fetal sheep. Cooling was associated with marked suppression of numbers of early onset epileptiform transients. Although cooling did not prevent the development of subsequent, delayed stereotypic EEG seizures, the amplitude of these events was significantly reduced. After three days recovery from asphyxia, carotid blood flow was significantly greater in the hypothermia group than in the asphyxia alone group, and EEG frequency, although not amplitude, had returned to sham control levels. These hemodymamic and electrophysiological improvements were reflected in greater histollogical neuronal survival in the striatum and the cornu ammonis regions of the hippocampus, with suppression of induction of activated caspase- 3 and of microglia.

It is now well established that hypoxic-ischemic injury is an evolving process in which final cell death may not occur until well after the initial insult (Kirino 1982). It is this delay that has raised the tantalizing possibility that asphyxial damage might be able to be prevented even well after reperfusion. For example, many term infants with hypoxic-ischemic encephalopathy show initial, transient recovery of cerebral oxidative metabolism after birth in a "latent" phase, followed by secondary deterioration with cerebral energy failure from 6 to 15 hours after birth (Azzopardi et al. 1989; Roth et al. 1992). Experimentally, at the term equivalent in the fetal sheep, this secondary deterioration is marked by the delayed onset of seizures, accumulation of excitotoxins and redox deterioration (Gunn et al. 1997; Marks et al. 1996; Tan et al. 1996). The severity of this secondary deterioration is closely correlated with neurodevelopmental outcome at 1 and 4 years of age (Roth et al. 1992). Critically, there are data that experimental hypothermia may be effective only if it is initiated in this latent phase (Gunn et al. 1997; Gunn et al. 1999; Thoresen et al. 1995).

The key mechanisms that mediate the effects of hypothermia in the latent phase are unclear, but likely include suppression of excitotoxic activity (Thoresen et al. 1997), apoptotic events (Edwards et al. 1995; Roelfsema et al. 2004), and local inflammation (Gunn and Bennet 2002; Roelfsema et al. 2004). In the present study, hypothermia potently inhibited the spikes and sharp and slow wave complexes observed in the normothermia group in the latent phase and caused a significant further 
suppression of EEG intensity compared with the normothermia group. The immature brain appears to be particularly susceptible to post-hypoxic hyperexcitability (Jensen and Wang 1996). The appearance of epileptiform transients after exposure to asphyxia and their apparent correlation with brain infury is consistent with other studies, which have reported the comrnon presence of fast epileptiform EEG transients in preterm newborns (Scher et al. 1994; Vecchierini-Blineau et al. 1996). Although these events can occur in asymptomatic newborns with a normal outcome (Scher et al. 1994; Vecchierini-Blineau et al. 1996), overall, the appearance of such activity in preterm infants is strongly associated with poor outcome (Biagioni et al. 2000; Hughes and Guerra 1994; Marret et al. 1997; Okumura et al. 2003; Rowe et al. 1985; Vecchierini-Blineau et al. 1996).

Many studies have suggested that excitotoxic activity is particularly important in preterm brain injury, as recently reviewed (du Plessis and Volpe 2002). Adult studies suggest that this may be mediated by an increase in glutamate receptor-mediated excitatory responses following ischemia rather than by high extracellular glutamate concentrations (Kalemenev et aL 2002; Mitani et al. 1998). The mechanism of suppression of the EEG transients by hypothermia is unknown. However, it is well established that in vitro hypothermia reduces the slope of excitatory postsynaptic potentials (Aihara et at. 2001) and of glutamate release after depolarisation (Nakashima and Todd 1996) in a temperature dependent manner. Further, focal cerebral cooling can reduce epileptiform activity in animals (Baldwin and Frost 1956) and in patients (Karkar et al. 2002) without changing the motor threshold. In our study, this effect seemed to be specific, since continued cooling did not reduce numbers of late onset stereotypic, evolving seizures that were seen from a mean of 9 hours. This is consistent with previous studies, which have reported that hypothermia is associated with either no significant effect on secondary seizures (Gunn et al. 1997; Gunn et al. 1998) or a modest reduction (Tooley et al. 2003).

A likely further potential mechanism is suppression of apoptosis by hypothermia. Apoptotic pathways are suggested to be relatively more important in hypoxic-ischemic brain damage in the neonate compared to adult (Hu et al. 2000), and several studies have suggested that hypothermia selectively suppresses morphological apoptotic cell loss in the neonatal brain (Edwards et al. 1995; Xu et al. 1998). Supporting this concept, mild hypothermia can reduce mitochondrial cytochrome $\mathrm{C}$ translocation, a critical step in the intrinsic pathway of apoptosis (Xu et al. 2002; Yenari et al. 2002). and has been shown to suppress expression of caspase-3 both following hypoxia-ischemia in vivo (Fukuda et al. 2001; Tomimatsu et al. 2001) and serum deprivation in vitro (Xu et al. 2002). Consistent with these results, the present study confirms a significant suppression by hypothermia of post-asphyxial activated caspase-3 in the striatum.

Alternatively, there is considerable evidence that inflammatory processes, including induction of activated microglia with subsequent release of pro-inflammatory cytokines, contribute to both evolving neuronal and white matter injury (Silverstein et al. 1997). Cytokines exacerbate brain injury through various pathways including direct neurotoxicity and induction of apoptosis or by promoting stimulation of capillary endothelial cell pro-inflammatory responses and leukocyte adhesion and infiltration into the ischemic brain (Mallard et al. 2003; Silverstein et al. 1997). Thus, the present finding that early post-occlusion cerebral hypothermia markedly reduced microglial induction in subcortical regions, suggests that this may contribute to reduced neuronal loss. In the present study, microglial induction was greatest in the hippocampus after exposure to umbilical cord occlusion, and milder in the striatum, likely reflecting the severity of injury in each region. Thus, the effect of hypothermia could be either primary, or secondary to reduced cell loss and local tissue damage leading to a reduced stimulus to further microglial induction (Roelfsema et al. 2004).

In order to provide adequate neuroprotection with minimal risk of systemic adverse effects in sick, unstable neonates, ideally only the brain would be cooled. Although this has been demonstrated 
experimentally using cardiac bypass procedures (Wass et al. 1998), it is clearly impractical in routine practice. Pragmatically, partially selective cerebral cooling can be obtained using a cooling cap applied to the scalp (Gluckman et al. 2004). Previous studies of head cooling in the term piglet have shown that a significant gradient between core brain temperature and rectal temperature can be maintained for at least 24 hours (Tooley et al. 2002). The current study confirms that a significant gradient is able to be established and maintained between the extradural space and core body temperature using this technique in the preterm fetal sheep

The present study can only partially address whether this approach can prevent deleterious systemic effects in the apparently uniquely vulnerable preterm infant (Silverman et al. 1958); further studies in large newborn species will be required to fully resolve this. Nevertheless, in the present study, FHR was mildly reduced by cooling compared to the normathermia group, consistent with its well established effects on cardiac conduction (Solomon et al. 1989), and clinical studies at term (Azzopardi et al. 2000; Gluckman et al. 2004). MAP was reduced in the first 10 hours in hypothermic compared with normothermic animals, however hypotension did not develop. Furthermore, there was no evidence of significant metabolic acidosis or other adverse changes, except for a mild alkalosis.

Hypothermia was associated with a transient exaggeration of the secondary fall in $\mathrm{CaBF}$, from 2 to 8 hours after asplyyxia, compared to normothermic controls, similar to its effect after reversible cerebral ischemia at term (Gunn et al. 1997). However, over the last two days of the present study, CaBF progressively increased despite continued cooling and became significantly greater than in the asphyxia normothermia group in the final $24 \mathrm{~h}$. This increase was accompanied by normalization of the frequency of EEG activity to sham control values, whereas frequency remained suppressed in the normothermia group. Together, these data suggest that cerebral function and activity significantly improved during continued cooling.

The results of the present study clearly cannot and should not be extrapolated to all preterm infants, since the etiology of preterm neural injury is extremely complex and has been associated with both antenatal and postnatal events including systemic inflammation, as well as hypoxia-ischemia (du Plessis and Volpe 2002). Nevertheless, data from serial EEG recordings and early MRI imaging suggest that many cases are related to events in the immediate peripartum period (de Vries et al. 1998; Hayakawa et al. 1999; Okumura et al. 2001). Overt perinatal insults are not uncommon, and are associated with 'ominous' fetal heart rate changes (de Vries et al. 1998). Pathologically, such asphyxial events are associated with a developmentally defined pattern of neural injury, with cortical sparing and severe damage in subcortical nuclei (Barkovich and Truwit 1990; Barkovich and Sargent 1.995; de Vries et al. 1998), consistent with that seen in the asphyxia normothermia group in the present study. Thus, although no one experimental model can possibly represent the full spectrum of preterm neural injury, the present findings suggest that at least some cases of preterm neural injury may benefit from hypothermia.

Finally, it is important to recognize that evolving neuronal injury may extend for longer than the 3 days recovery from asphyxia in the present study (Geddes et al. 2001). Previous studies using short periods of hypothermia have suggested that protection can be attenuated over time (Trescher et al. 1997]. However, this may relate to the duration of cooling, since 6 hours of mild cooling in the infant rat after hypoxia-ischemia was not associated with long-term improvement but 72 hours was (Sirimanne et al. 1996). Subsequent studies both in the 7 day rat and in adult species have confirmed that prolonged cooling for 24 to 72 hours initiated within 6 hours of injury is associated with persistent behavioral and histological protection (Bona et al. 1998; Colbourne et al. 1998; Colbourne et al. 1999; Nedelcu et al. 2000; Wagner et al. 2002). Further studies are in progress to evaluate the longer term impact of asphyxia and hypothermia on the preterm brain.

In summary, these data demonstrate that selective cerebral hypothermia after profound asphyxia 
can reduce short-term injury of subcortical neuronal structures in the preterm brain. These histological changes were associated with progressive normalization of EEG frequency and carotid blood flow, consistent with possible functional improvements. Hypothermia was not associated with hypotension or acid-base changes, suggesting it may be safe in the preterm infant if carefully controlled. The critical developmental events occurring in the preterm infant, and their potential vulnerability to the adverse systemic effects of hypothermia make it critical to systematically evaluate factors, such as the window of opportunity for starting cooling and the critical depth of hypothermia that determine its effectiveness before human studies can be contemplated.

\section{ACKNOWLEDGEMENTS}

The present study was supported by the Health Research Council of New Zealand, the Auckland Medical Research Foundation and the Lottery Grants Board of New Zealand. 


\section{REFERENCES}

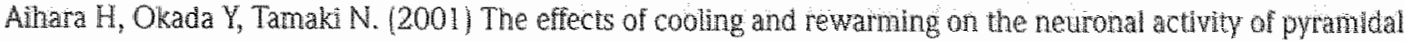
neurons in guinea pig hippocampal slices. Brain Res 893:36-45

Argyropoulou MI, Xydis V, Drougia A, Argyropoulou PI, Tzouf M, Bassounas A, Andronikou S, Efremidis $\$ \mathrm{C}$. 12003) MRI measurements of the pons and cerebellum in children born preterm; associations with the severity of periventricular leukomalacia and perinatal risk factors. Neuroradiology $45: 730-734$

Azzopardi D. Wyatt IS, Cady EB, Delpy DT, Baudin J, Stewart AL, Hope PL, Hamilton PA, Reynolds EO. (1089) Prognosis of newborn infants with hypoxic-ischemic brain iniury assessed by phosphorus magnetic resonance spectroscopy. Pediat Res 25:445-451

Azzopardi D, Robertson NJ, Cowan FM, Rutherford MA, Rampling M, Edwards AD. (2000) Pllot study of treatment with whole body hypotherma for neonatal encephalopathy. Pediatrics 100:684.694

Baldwin M, Frost LL. (1950) Effect of hypothermia on epileptiform activity in the primate temporal lobe. Sclence $124: 931.932$

Barkowich A], Truwit. CL. (1090) Brain damage from perinatal asphyxia: Correlation of MR fndings with gestational age. A/NR Am / Neuroradio 1 1:10871096

Barkovich AJ, Sargent SK. (1995) Profound asphyxia in the premature infant: imaging findings. ANR Am J Neuroradiol 16:1837-1846

Bariow RM. (1969) The foetal sheep: Morphogenesis of the nerwous system and histochemical aspects of myelination. / Comp Neurol 135:249-262

Bennet $\mathbb{L}$, Rossenrode S, Gunning MI, Gluckman PD, Gunn AJ. [1999) The cardiovascular and cerebrovascular responses of the immature fetal sheep to acute umbilical cord occitsion. f Physiol (Lond) 517:247-257

Biagioni E, Bartalena L, Boldrini A, Pieri R, Cioni G. (2000) Electroencephalography in infants with periventricular leukomalacia: Prognositic features at preterm and term age. J Child Newrol 15:1 6

Bona E, Hagberg H, Loberg EM, Bagenholm R, Thoresen M. (1998) Protective effects of moderate hypothermia after neonatal hypoxia- ischemia: Short- and longterm outcome. Pediatr Res 43:738-745

Colboume F, Auer RN, Sutherland GR. (1998) Characterization of postischemic behavioral deficits in gerbils with and without hypothermic neuroprotection. Brain Res 803:69-78.

Coiboume F, Li H, Buchan AM. (1999) Indefatigable cal sector neuroprotection with mild hypothermia induced 6 hours after severe forebrain ischemia in rats. I Cereb Blood Flow Metab 19:742.749

de Vries LS, Eken F, Groenendaal Hi: Rademaker KJ, Hoogervorst B, Bruinse HW. (1908) Antenatal onset of haemorhagic and/or ischaemic lesions in preterm infants: Prevalence and associated obstetric vartables. Arch Dis Child Fetal Neonatal Ed 78.F51.56

du Plessis Al, Volpe Jl. (2002) Perinatal brain injury in the preterm and term newborn. Curr Opin Neurol 15:151.157

Edwards AD, Yue X, Squier MV, Thoresen M, Cady EB, Penrice J, Cooper CE, Wyat IS, Revmolds EO, Mehmet H. (1995) Specific inhibition of apoptosis after cerebral hypoxiatschaemia by moderate postinsult hypothermia. Biochent Biophys Res Commun 217:1193-1199

Fukuda H, Tomimatsu T, Watanabe W, Wu MJ, Kohzuki M. Endo M, Fuji E, Kanzaki T, Murata Y. (2001) Postischemic hypothermia blocks caspase-3 activation in the newborn rat brain after hypoxiaxischemia. Brain Res 910:187-19!

Geddes R, Vannucci RC, Vannucci SJ. (2001) Delayed cerebral atrophy following moderate hypoxia-ischemia in the immature rat. Dev Neurosci 23:180 185

George S, Gunn Al, Westgate JA, Brabyn C, Guan J, Bennet L. (2004) Fetal heart rate variability and brainstem injury after asphyxia in preterm fetal sheep. Am I Physiol Regul Integr Comp Physiol 287:Ro25.R933

Giles FH, Leviton A, Golden JA, Paneth N, Rudelli RD. (1998) Groups of histopathologic abnormalities in brains of very low birthweight infants. I Neuropathol Exp Neurol 57:1020-1034 
Gluckrian PD, Wyat IS, Azzopardi D, Ballard D, Edwards AD, Femero DM, Polin RA, Robertson CM, Thoresen M, Whitelaw A, Gunn A., the CoolCap study group. (2004) Selective head cooling with mild systemic hypotherma to improve neurodevelopmental outcome following neonatal encephalopathy. Lancet $/ n$, press

Golanov EV, Reis DJ. (1999) Neuroprotective electrical stimulation of cerebellar fastigial nucleus attenuates expresston of perinfarction depolarizing waves (pids) and inhibits cortical spreading depression. Brain Res 818:304-315

Gunn A), Gun TR, de Haan HH, Willams CE, Gluckman PD. (1997) Dramatic neuronal rescue with prolonged selective head cooling atter ischemia in letal lambs. / Clin /mvest 99:248.256

Gunn Al, Gunn TR, Gunning MI, Willams CE, Guckman PD. 11998 / Neuroprotection with prolonged head cooling started before postischemic seizures in fetal sheep. Pediatrics 102:1098-1106

Guni Al, Bennet L, Gunning MI, Gluckman PD, Gurn TR. (1999) Cerebral hypothermia is not neuroprotective when started after postischemic selzures in letal sheep. Pediatr Res 46:274.280

Gunn A. (2000) Cerebral hypothermia for prevention of brain injury following perinatal asphyxia. Curr Opin Pediat 12:11:115

Gunn Al, Bennet L. (2002) Hypothermia in the management of hypoxic-ischemic encephalopathy. NeoReviews 3:e $116-e ! 22$

Hayakawa 1 , Okumura A, Kato T, Kuno K, Watanabe K. 11 g99) Determination of timing of brain injury in preterm infants with periventricular Jeukomalacia with serial neonatal electroencephalography. Pediatrics $104: 1077 \% 1081$

Hossmann KA. (1996) Peninfarct depolarizations. Cerebrovasc Brain Metab Rev 8: 195-208

Hu BR, Liu CL, Ouyang Y, Blomgren K, Siesjo BK. 2000 I Involvement of caspase-3 in cell death after hypoxiaischemia declines during brain maturation. J Cereb Blood Flow Metab 20:1294-1300

Hughes JR, Guerra R. (1994) The use of the EEG to predict outcome in premature infants with positive sharp waves. Clin Electroencephalogr 25:127-135

Jensen FE, Wang C. (1996) Hypoxia-induced hyperexcitability in vivo and in vitro in the immature hippocampus. Epilepsy Res 20:131-140

Kalemenev SV, Savin AV, Levin SG, Godukhin OV. (2002) Longterm potentiation of glutamatergic transmission and epileptiform activity induced by transient episodes of anoxia in slices of rats hippocampus field cal. Neurosicl Behav Physiol 32:43》*434

Karkar KM, Garcia PA, Bateman LM, Smyth MD, Barbaro NM, Berger M. 2002] Focal cooling suppresses spontaneous epileptiform activity without changing the cortical motor threshold. Epilepsia 43:932-935

Kitno T. (1982) Delayed neuronal death in the gerbil hippocampus following ischemia. Brain Res, 239.57 .69

Lin Y, Okumura A, Hayakawa F, Kato K, Kuno T, Watanabe K. (2001) Quantitative evaluation of thalami and basal ganglia in infants with periventricular leukomalacla. Dev Med Child Neuro 43:481-485

Low IA, Panagotopoulos C, Derrick $\mathrm{E}$. (1095) Newbon complications after intrapartum asphyxia with metabolic acidosis in the preterm fetus. Am J Oostet Gynecol 172:805-810

Low JA, Killen H, Dertick EI. (2003) Antepartum fetal asphyxia in the preterm pregnancy. Am J Obster Cynecol $188: 401.405$

Low $)$ A. (2004) Determining the contribution of asphywia to brain damage in the neonate. J Obstet Gynaecol Res 30.276286

Mallard C, Welin AK, Peebles D, Hagberg $H$, Kjellmer 1. (2003) White matter injury following systemic endotoxemia or asphyxia in the fetal sheep. Neurochem Res $28: 215.223$

Marks KA, Mallard EC, Roberts I, Williams CE, Sirimanne ES, Johnston B, Gluckman PD, Edwards AD. (1996) Delayed vasodilation and altered oxygenation after cerebral ischemia in fetal sheep. Pedratr Res 39:48.54

Marret S, Parain D, Menard JF, Blanc T, Devaux AM, Ensel P, Fessard C, Samson Dollus D. 11997) Prognostic value of neonatal electroencephalography in premature newborns less than 33 weeks of gestational age. Electroencephalogr Cin Neurophysiol 102:178-185 
Mchnosh GH, Baghurs KI, Potter B., Hetzel BS. (1979) Foetal brain development in the sheep. Newopatho? Appl Nevrobiol 5:103-114

Mitani A, Namba S, Jkemune K, Yanase $H$, Arai T, Kataoka K. (1998) Postischemic enhancements of n-methyldaspartic acid (NMDA) and non NMDA receptor-mediated responses in hippocampal cal pyramidal neutons. JCereb Blood Flow Metab 18:1088-1098

Nakashima K, Todd MM. (1996) Effects of hypothermia on the rate of excitatory amino acid release after ischemic depolarization. Stroke 27:913-918

Nedelcu I, Klein MA, Aguzzi A, Martin E. (2000) Resuscitative hypothermia protects the neonatal rat brain from hypoxic-ischemic injury. Brain Pathol 10:01-71

Okumura A, Watanabe K, Hayakawa F, Kato T. (2001) The timing of brain insults in preterm infants who later developed west syndrome. Neuropediatrics $32: 245-249$

Okumura A, Hayakawa E, Kato T, Maruyama K, Kubota T, Suzuki M, Kidokoro H, Kuno K, Watanabe K. (2003) Abnormal sharp transients on electroencephalograms in preterm infants with periwentricular leukomalacia. J Pediatr 143:26-30

Roelfsema V, Bennet L, George S, Wu D, Guan J, Veerman M, Gunn AJ. (2004) The window of opportunlty fol: cerebral hypothermia and white macter injury after cerebral ischemia in nearterm fetal sheep. $/$ Cereb Blood Flow Metab 24:877.886

Roth SC, Edwards AD, Gady EB, Delpy DT, Wyatt IS, Azzopardi D, Baudin J, Townsend I, Stewart Al, Reynolds EO. (1992) Relation between cerebral oxidative metabolism following birth asphyxia, and neurodevelopmental outcome and brain growth at one year. Dev Med Child Neural 34:285-295

Rowe JC, Holmes GL, Hafford J, Babowal D, Robinson S, Philipps A, Rosenkrantz T, Raye J. (1985) Prognostic walue of the electroencephalogram in term and preterm inlants following neonatal selzures. Electroencephalogr Clin Neurophysiol $60: 183.196$

Scher M. (2003) Neonatal seizures: An expression of fetal or neonatal brain disorders. In: Fetal and neonatal brain injury Mechanisns, management and the risks of practice (Stevenson DKB, W.E. Sunstine, P., ed), Cambridge: Cambridge University Press, pp 735-784

Scher MS, Bova JM, Dokjanakis SG, Steppe DA. (1994) Physiological significance of sharp wave transients on EEG recordings of healthy pre-term and full-term neonates. Electroencephalogr Chin Neurophysiol $90: 179$ 185

Scher MS. 2002$)$ Controversies regarding neonatall seizure recognition. Epileptic Disord 4:130.158

Silverman WA, Fertg JW, Berger AP. (1958) The influence of the themal environment upon the surviva of newly born premature infants. Pedatrics 22:876-880

Siverstein FS, Barks JD, Hagan P, Liu XH, Ivacko J. Szaftarsk $\ .1997$. Cytokines and perinatal brain injury. Neurochem Int $30: 375 \cdot 383$

Sirimanne ES, Blumberg RM, Bossano D, Gunning M, Edwards AD, Gluckman PD, Willams CE. (1900) The effect of prolonged modification of cerebral temperature on outcome after hypoxic-ischemic brain injury in the infant rat. Pediatr Res 39.591 .597

Solomon A, Barish RA, Browne B, Tso E. (1989) The electrocardiographic features of hypothermia. fEmerg. Med 7.169.173

Tan WK, Willams CE, During M, Mallard CE, Gunning MI, Gunn Al, Gluckman PD. (1990) Accumulation of cytotoxins during the development of seizures and edema after hypoxicischemic injury in late gestation fetal sheep. Pediatr Res 39:791-797

Thoresen M, Pentice I, Lorek A, Cady EB, Wylezinska M, Kirkbride V, Cooper CE, Brown CC, Edwards AD, Wyat JS. (1995) Mild hypothemia after severe transient hypoxia-lschemia ameliorates delayed cerebrat energy failure in the newbon piglet. Pediatr Res 37:667-670 
Thoresen M, Satas S, Puka sundvall M, Whitelaw A. Halstrom A, Loberg EM, Ungerstedt U, Steen PA, Hagberg H. (1997) Posthpoxic hypothemia reduces cerebrocontical release of no and excitotoxins. Neuroreport 8.3350 .3362

Thoresen M, Satas S, Loberg E, Lindgren C, Steen P, Haug E, Whitelaw A. (1999) Posthypoxic hypothermia for 24 hrs in unsedated newbon pigs gives no neuroprotection. [abstract. Pediatr Res 45:46A

Tomimaisu T, Fukuda H, Endo M, Watanabe N, Mu ), Kohzuki M, Fuiti E, Kanzaki T, Murata Y. (2001) Effects of hypothermia on neonatal hypoxic-ischemic brain injury in the rat: Phosphorylation of akt, activation of caspase-3 like protease. Neurosch Let $312: 21 \cdot 24$

Tooley J, Satas S, Eagle R, Silver IA, Thoresen M. (2002) Significant selective head cooling can be maintained longterm after global hyporta ischeria in newborm piglets. Pediatrics 109:643-649

Tooley IR, Satas S, Porter H, Siver IA, Thonesen M. (2003) Head cooling with mild systemic hypothermia in anesthetized piglets is neuroprotective. Ann Neurol 53:65.72

Trescher WH, Ishiwa S, Johnston MV. (1997) Brief post-hypoxic-ischemic bypothermia markedly delays neonatal brain injury. Brain Dev 19:326-338

Vechlerini-Blineau MF; Nogues B, Louvet $\$$, Destontaines O. (1996) Positive temporal sharp waves in electroencephalograms of the premature newborn. Neurophysiol Cin $26: 350.362$

Wagner BP, Nedelcu J, Martin E. (2002) Delayed postischemic hypothermia improves long-term behavioral autcome after cerebral hypoxia-ischemia in neonatal rats. Pediatr Res 51:354-360

Wass CI, Waggoner JR, Cable DO, Schaff HV, Schroeder DR, Lanier WL. (1998) Selective convective brain cooling during nomothermic cardiopulmonary bypass in dogs. J ThoracCardiovascSurg 115:1350-1357

Willams CE, Gumn Al, Synek B, Gluckman PD. (1990) Delayed seizures occurring with hypoxic-ischemic encephalopathy in the fetal sheep. Pediatr Res 27:561-565

Wolf T, Lindauer U, Reuter U, Back T, Villringer A, Einhaupl K, Dirnagl U. (1997) Noninvasive near infrared spectroscopy monitoring of regional cerebral blood oxygenation changes during peri-infarct depolarizations in focal cerebral ischemia in the rat. J Cereb Blood Flow Metab 17:950-954

XU L, Yenari MA, Steinberg CK, Giffard RG. (2002) Mild hypothermia reduces apoptosis of mouse neurons in vitro early in the cascade. $/$ Cereb Blood Flow Metab 22:21-28

Xu RX, Nakamura T, Nagao S, Miyamoto O, Jin L, Toyoshima T, Itano T. (19981 Specific inhibition of apoptosis after cold-induced brain injury by moderate postinfury hypothermia. Neurosurgery 43:107-114

Yenari MA, Iwayama S, Cheng D, Sun GH, Fuimura M, Morita Fulimura Y, Chan PH, Steinberg GK. (2002) Mld hypothermia attenuates cytochrome c release but does not alter" bcl 2 expression or caspase activation after experimental stroke. J Cereb Blood Flow Metab 22:29-38

Yokochi K. (1997) Thatamic lesions revealed by MR associated with periventricular levkomalacia and clinical prolles of subjects. Acta Paediatr 80.493 .496 


\section{CHAPTER 4}

THE EFFECT OF MILD

HYPOTHERMIA ON INSULIN-LIKE

GROWTH FACTORS

AFTER SEVERE ASPHYXIA

IN THE PRETERM FETAL SHEEP

Journal of the Society for Gynecologic Investigation. 2005;12(4):232:237.

Roelfsema V, Gunn AJ, Breier BH, Quaedackers IS, Bennet J. 


\section{ABSTRACT}

Objectives: Persistent reductions in insulin-like growth factor I (IGF-I) levels in the preterm infant are strongly associated with increased risk of retinopathy and other complications, and may result from exposure to severe hypoxia. The effects of a potential new treatment for hypoxic-ischemic encephalopathy, cerebral hypothermia, on the responses of the IGF axis to hypoxia are unknown. The aim of this study was to examine the effects of prenatal asphyxia and cerebral hypothermia on changes in IGF-I and. II, IGF-binding protein 1 (IGFBP-1), and insulin levels.

Methods: Fetal sheep at 0.7 of gestation underwent either sham asphyxia and sham cooling $(n=7)$, asphyxia induced by 25 minutes of complete umbilical cord occlusion alone $(\mathrm{n}=8)$, or asphyxia and head cooling ( $n=8$, extradural temperature $29.5 \pm 2.6 \mathrm{C}$ [vs $39.4 \pm 0.3 \mathrm{C} ; \mathrm{P} .05]$ ]. Fetuses were studied for 3 days post-insult, during which time fetal blood samples were taken for endocrine measurements.

Results: There were no IGF axis changes during occlusion. Plasma IGF-I levels significantly decreased between 6 hours and 48 hours after asphyxia and IGF-II levels by 10 hours, in both asphyxia groups.

IGFBP-1 rose from 4 hours, reaching a peak at 10 hours and teturning to control values by 48 hours in the normothermia group, and by 24 hours in the hypothermia group. Insulin levels decreased between 2 hours and 10 hours aftel asphyxia in both asphyxia groups, and subsequently normalized. Conclusions: This study demonstrates for the first time that transient asphyxia in the preterm sheep fetus is associated with a significant decrease in IGF-II as well as IGF-I during recovery, and that these W. responses are not altered by mild systemic hypothermia.

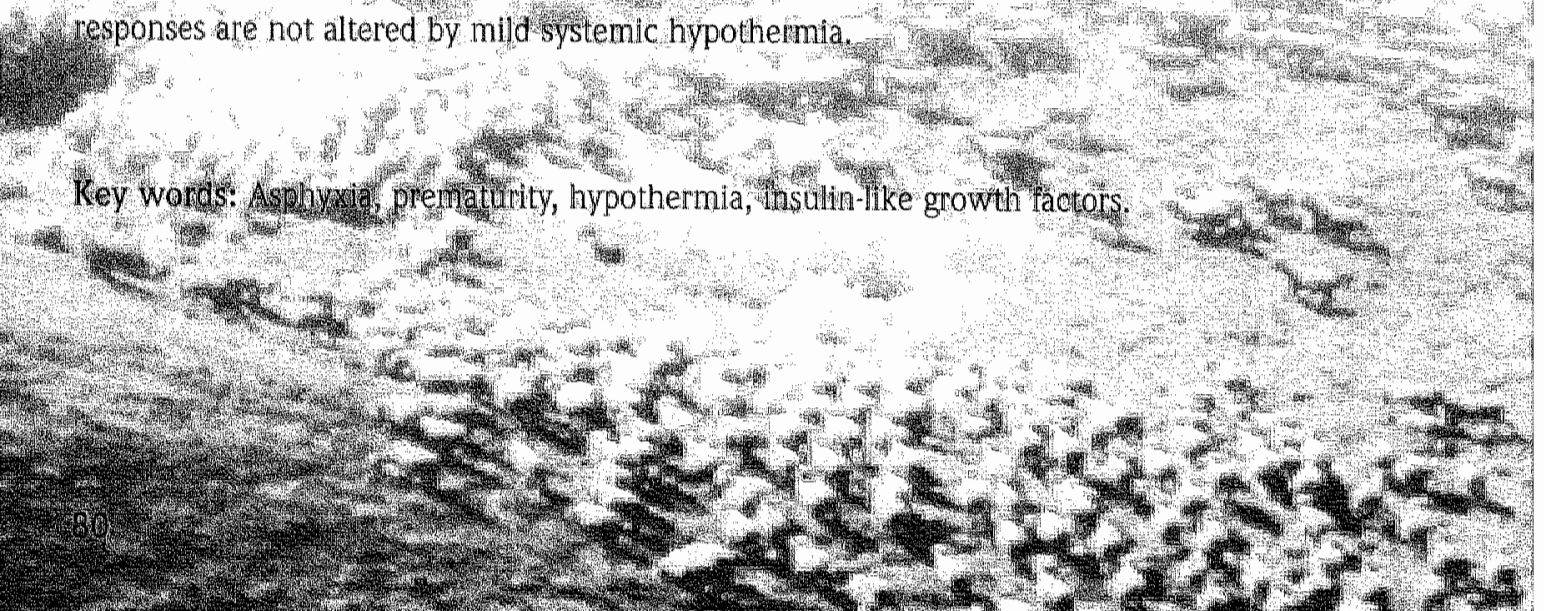




\section{INTRODUCTION}

There is now strong experimental evidence that cerebral hypothermia initiated during the early hours after perinatal hypoxia-ischemia can prevent delayed cell death and iniprove neural recovery. ${ }^{1}$ While clinical trials are currently underway in the term infant, ${ }^{2}$ hypothermia has not been evaluated in the preterm infant, despite their much higher burden of neurologic impairment and systemic complications. ${ }^{3}$ It has been suggested from studies at term that hypothermia can cause adverse endocrine and metabolic effects that may reduce its neuroprotective effects and impair recovery 4 ; however, there are no data from preterm paradigms. In recent years, there has been increasing interest in the key role insulin-like growth factors (IGFs) may play in metabolic regulation, growth, and organ function and development in preterm infants. ${ }^{5-8}$ Preterm birth is associated with a rapid fall in serum IGF-I levels. 9,10 Persistent reductions in IGFI levels are associated with an increased risk for later retinopathy, and other complications of prematurity, particularly in infants born around the critical organ development period of $30-33$ weeks. ${ }^{11,12}$ Although the etiology of preterm injury is highly complex and multifactorial, ${ }^{13}$ hypoxia-ischemia is one of the many factors that may complicate the courses of preterm infants, ${ }^{13}$ and it may contribute to adverse outcomes. Hypoxia-ischemia can occur before, during, or after birth ${ }^{14,15}$ and it may exacerbate the low levels of IGF.I in premature infants. 16 It was the purpose of the current study, therefore, to determine the IGF, insulin, and IGF-binding protein 1 (IGFBP-1) responses of the preterm fetal sheep to severe acute hypoxia in utero and to evaluate whether these responses are modified by cerebral hypothermia at an age corresponding to human neuronal maturation of 30-32 weeks. ${ }^{17}$

\section{Materials and Methods}

\section{Experimentall Preparation}

All procedures were approved by the Animal Ethics Committee of The University of Auckland. Twenty three time-mated singleton Romney/Suffolk fetal sheep were operated on at $98-99$ days of gestation (term 147 days). Food, but not water, was withdrawn 18 hours before surgery. Ewes were given $5 \mathrm{~mL}$ of Streptopen (Procaine Penicillin 1250,000 IU] and Dihydrostreptomycin $1250 \mathrm{mg} \cdot \mathrm{mL} \cdot{ }^{-1}$; Stockguard Labs Ltd, Hamilton, New Zealand|] intramuscularly for prophylaxis 30 minutes prior to the start of surgery. Anesthesia was induced by intravenous (IV) injection of Alfaxan $\left(3 \mathrm{mg} \cdot \mathrm{kg}{ }^{1}\right.$; Alphaxalone, Jurox, Rutherford, NSW, Australia), and general anesthesia maintained using $2-3 \%$ halothane in $\mathrm{O}_{2}$. Ewes were not ventilated and the depth of anesthesia, maternal heart rate, and respiration were constantly monitored by trained anesthetic staff.

All surgical procedures were performed using sterile techniques. ${ }^{18}$ Polyvinyl catheters were placed in the left fetal femoral artery and vein, right brachial artery, and the amniotic sac. A stainless steel electrode (Cooner Wire, Chatsworth, CA) was placed across the fetal chest to measure the fetal electrocardiogram (ECG). A thermistor (Incu-Temp-1, Mallinckrodt Medical Inc, St Louis, MO) was placed over the parasagittal dura $20 \mathrm{~mm}$ anterior to the bregma; the burr holes were sealed, and the skin over the fetal skuli was closed using cyanoacrylate glue. A cooling cap made from a coll of silicone tubing lexternal diameter, $7.9 \mathrm{~mm}$; internal diameter, $4.8 \mathrm{~mm}$; Degania Silicone, Degania, Bet, Emek Hayarden, Israel) was attached over the dorsal surface of the scalp and extended over the lateral surface of the cranium down to the level of the external auditory meatus. An inflatable silicone occluder was placed around the umbilical cord of all fetuses (In Vivo Metric, Healdsburg, CA). A second thermistor (to measure fetal core body temperature) was placed in the fetal esophagus at the level of the right 
atrum. All fetal leads were exterionized through the maternal flank and a maternall long saphenous vein was catheterized to provide access for postoperative care and euthanasia. Antibiotics ( $80 \mathrm{mg}$ Gentamicin; Pharmacia and Upjohn, Rydalmere, NSW, Australia) were administered into the amniotic sac prior to closure of the uterus.

Postoperatively, all sheep were housed together in separate metabolic cages with access to water and food ad libitum. They were kept in a temperature-controlled room $(16 \pm 1 \mathrm{C}$, humidity $50 \% 10 \%)$, on a 12-hour light/dark cycle. A period of 4-6 days postoperative recovery was allowed before experiments commenced, during which time antibiotics were administered IV to the ewe daily for 4 days $1600 \mathrm{mg}$ Benzylpenícillin Sodium; Novartis Ltd, Auckland, New Zealand, and $80 \mathrm{mg}$ Gentamicin). Fetal catheters were maintained patent by continuous infusion of heparinized saline (20 $\mathrm{U} / \mathrm{mL}$ at $0.15 \mathrm{~mL} / \mathrm{h}$ ) and the maternal catheter maintained by daily flushing.

\section{Experimental Design}

Experiments were conducted at 103-104 days gestation (0.7 of gestation). Mean arterial pressure [MAP], corrected for maternal movement by subtraction of amniotic fluid pressure, and the fetal ECG were recorded continuously from 12 hours before occlusion to 72 hours after occlusion. Data were stored to disk by custom software for off-line analysis (Labview for Windows; National Instruments Ltd, Austin, TX). Fetuses were randomly assigned to one of three groups: sham controls (sham asphyxia and sham cooling, $n=7$ ), asphyxia group (asphyxia with sham cooling, $n=8$ ), and hypothermia group (asphyxia with induced hypothermia, $n=8$ ). In the asphyxia groups, fetal asphyxia was induced by rapid inflation of the umbilical cord occluder for 25 minutes with sterile saline of a defined volume known to completely inflate the occluder as determined in pilot experiments with a Transonic flow probe placed around an umbilical vein. ${ }^{19}$ The duration of occlusion was chosen as one that we have previously reported to represent an acute, severe, near-terminal insult but which could be survived without post-asphyxial cardiac support. 18,20 Successful occlusion was confirmed by observation of a rapid onset of bradycardia with a rise in MAP, and by $\mathrm{pH}$ and blood gas measurements.

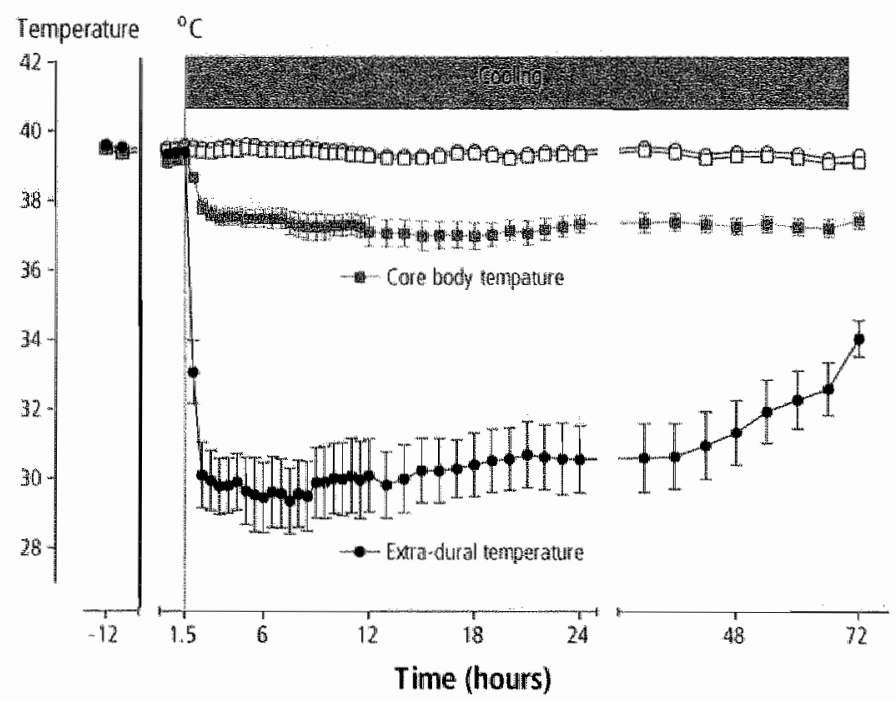

Figure 1. Time course of changes in fetal core body temperature (squares) and extradural temperature (circles) in the normothermic (open symbols) and hypothermic asphyxia (closed symbols) groups. Data are mean \pm SEM. 
In the hypothermia group, intrauterine cooling was initiated 90 minutes after the end of asphyxia and continued until 2 hours before the end of the study ( 72 hours after asphyxia or sham asphyxia). Cooling was induced by circulating cold water $(10 \mathrm{C})$ through the silicone coil around the fetal head. Cooling was titrated in the first 2 hours to reduce fetal extradural temperature from $39.4 \pm 0.1 \mathrm{C}$ to between 29 and $33 \mathrm{C}$ (Figure 1).

Fetal arterial blood samples were taken 15 minutes prior to asphyxia or sham asphyxia, 5 and 20 minutes during asphyxia or sham asphyxia, and $2,4,6,10,24,48$, and 72 hours post-asphyxia or sham asphyxia for blood gas, acid-base balance (Ciba-Corning Diagnostics 845 blood gas analyzer and cooximeter; Boston, MA) and for glucose and lactate determination (YSI model 2300; Yellow Springs, $\mathrm{OH}$ ). In the hypothermia group, the 72 hour blood sample was taken after rewarming for 2 hours. Blood was transferred immediately upon collection to chilled test tubes and centrifuged at $4 \mathrm{C}(3000 \mathrm{rpm})$ for 15 minutes. Plasma was stored at $20 \mathrm{C}$ for subsequent hormone analysis (IGF-I, IGF-II, IGFBP-1, insulin). After the last blood sample ewes and fetuses were killed by an IV overdose of pentobarbitone sodium $(9 \mathrm{~g})$ to the ewe (Pentobarb 300; Chemstock International, Christchurch, New Zealand).

\section{Data Analysis and Statistics}

Fetal plasma IGF-1, IGF-II, IGFBP-1, and insulin levels were measured using specific ovine radioimmunoassays (RIA) established and validated in this laboratory. ${ }^{10}$ Statistical analyses were performed using SPSS version 10 (SPSS Inc, Chicago, IL). Differences between groups were determined by analysis of variance, adjusted using baseline levels as a covariate (ANCOVA); the endocrine time series data were treated as repeated measures to allow for repeated sampling. Where a significant effect of treatment group or an interaction with group was found, post hoc comparisons were undertaken using the least significant difference test. Statistical significance was accepted at $P<.05$.

Figure 2. Fetal plasma concentration changes in IGF-I and $1 \mathrm{GF}$ II before, during (sample taken at 20 minutes of a 25 -minute occlusion insult and after $[2,4,6,10,24,48 \text {, and } 72 \text { hours }]_{\text {, }}$ in sham-controls (open bars), asphyxia. with normothermia (dark bars) or asphyxia with hypothermia started 90 minutes after the insult and continued until 2 hours before the 72 hour sample (hatched bars\}. Data are mean \pm SEM. * P.05 compared to sham controls.
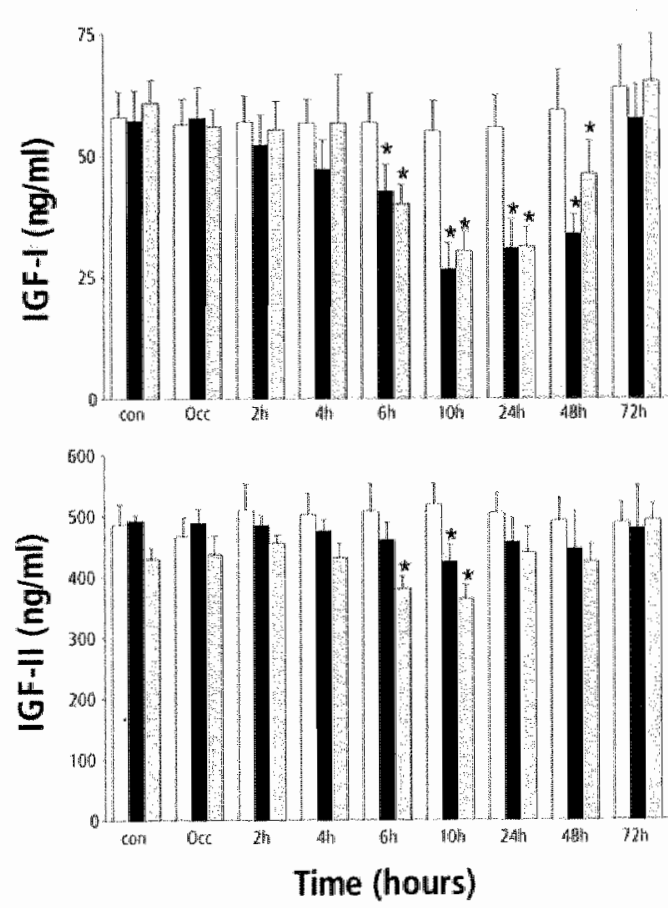


\section{RESULTS}

\section{Blood Composition Measurements}

Data for letal arterial pH, blood gas, and glucose levels are presented in Table 1.

\section{Effect of Cooling on Brain and Body Temperature}

Head cooling caused a significant fall in extradural temperature starting within 1 hour after the onset of cooling, reaching a nadir of $29.5 \pm 2.6 \mathrm{C}$ (vs $39.4 \pm 0.3 \mathrm{C} ; \mathrm{P}<.0001$, ANOVA). Extradural temperature gradually increased during the second and third day of cooling to a mean of $32.3 \pm 2.2 \mathrm{C}$ by 72 hours. During cooling, core body temperature dropped to a nadir of $37.2 \pm 0.8 \mathrm{C}$ (vs $39.3 \pm$ $0.1 \mathrm{C} ; P<.05$ ) and averaged $37.5 \pm 0.7 \mathrm{C}$ over the whole cooling period (Figure 1 ).

\section{Endocrine Data}

There was no significant difference between groups for any endocrine measure during the baseline period. There were no significant changes during asphyxia. IGF-1. levels showed a significant effect of treatment group $(P=.006$, repeated measures $A N O V A)$, with a significant interaction between time and group $(P=.001)$. There was a significant reduction in circulating plasma concentrations of IGF-I after asphyxia from 6 to 48 hours in the asphyxia and hypothermia groups $(P<.05$ for both groups compared to sham controls, Figure 2), with no significant difference between the asphyxia and hypothermia groups. There was no overall effect of group on [GF-]I levels, but an interaction between asphyxia and time $(P<.05)$, with a fall in IGF-II levels at 10 hours in the asphyxia-normothermia group and at 6 and 10 hours in the hypothermia group ( $P<.05$ compared to sham control, Figure 2 ). However, there was no significant difference between the normothermia and hypothermia groups.

Table 1. Feral anterial pH, blood gas, glucose, and lactate values for Sham Control, Asphyxia plus normothermia, and Asplwxia plus hypothermia groups before umbilical cond occlusion (baselinel, after 20 minutes of acclusion or Sham acclusion (asphyxial, and $2,4,6,24,48$, and 72 hours after release of occlusion.

\begin{tabular}{|c|c|c|c|c|}
\hline 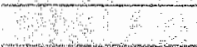 & & Baseline & Asphyxia & 2 hours \\
\hline \multirow{3}{*}{$p H$} & $S$ & $739 \pm 0,00$ & $738+0.00$ & $7.39 \pm 0.00$ \\
\hline & $A$ & $7.37 \pm 0,00$ & $6.82 \pm 0.03^{\text {省 }}$ & $7.34 \pm 0.01$ \\
\hline & H & $739 \pm 000$ & $6.85 \pm 0.02^{\circ}$ & $7.39 \pm 0.00$ \\
\hline \multirow[t]{3}{*}{$\mathrm{PaCO}_{2}$ (mmi $\left.\mathrm{Hg}\right)$} & 5 & 48.813 & $48.3 \pm 1.5$ & $46.8 \pm 1.0$ \\
\hline & A & 48221.0 & $142.2 \pm 6.0^{*}$ & $46.8+1.0$ \\
\hline & $H$ & $485+16$ & $1390 \pm 9.0^{\circ}$ & $38.0 \pm 1.06$ \\
\hline \multirow[t]{3}{*}{$\mathrm{PaO}_{2}(\mathrm{~mm} \mathrm{Hg})$} & S & $22.5+0.9$ & $22.7 \pm 0.9$ & $22.1 \pm 1.0$ \\
\hline & $A_{2}$ & $23.0 \pm 0.9$ & $8.7 \pm 0.8^{\circ}$ & $26.2+13^{\circ}$ \\
\hline & H & $247 \pm 1$. & $9.1 \pm 16^{*}$ & $24.7+1.3$ \\
\hline \multirow[t]{3}{*}{ Glucose (mM) } & $s$ & 1.031010 & $1,03 \pm 0, \| 1$ & $1.01 \pm 0.12$ \\
\hline & A. & $1.02 \pm 0.10$ & $0.67 \neq 0.10^{*}$ & $124 \pm 0.10$ \\
\hline & $H$ & 0.9540 .10 & $0.53+0.14^{*}$ & $130+0,10$ \\
\hline \multirow[t]{3}{*}{ Lactate (mM) } & S: & $0.73 \pm 0.10$ & $0.73 \pm 0.11$ & $0.66+0.12$ \\
\hline & A & $0.72 \pm 0.03$ & $6.46 \pm 0.17^{*}$ & $3.6 \pm 0.52^{\circ}$ \\
\hline & $\mathrm{H}$ & $0.70 \pm 0.03$ & $6.11 \pm 0.52^{*}$ & $2.90 \pm 6.0^{*}$ \\
\hline
\end{tabular}

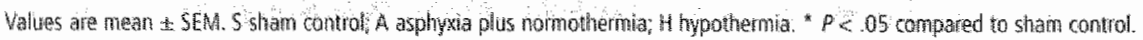


Changes in IGFBP- 1 concentrations showed a significant effect of treatment group $(P=.001)$ with a significant interaction between time and treatment group $(P=.003)$, such that concentrations of IGFBP-1 increased dramatically from 4 hours in both asphyxia groups, and remained significantly elevated until 24 hours in the asphyxia group and until 10 hours in the hypothermia group $(P<.05$, Figure 3]. Plasma insulin levels showed a significant overall effect of treatment group $(P<.05)$ but no interaction between treatment and time $(P=3)$. There was a significant fall in plasma concentrations of insulin between 2 and 10 hours after asphyxia in both asphyxia groups $(p<.05$, Figure 3$)$, with no significant difference between the normothermic and hypothermic asphyxia groups.

\section{DISCUSSION}

The present study demonstrated that prenatal exposure to asphyxia is associated with a rapid fall in circulating levels of insulin, IGF-I and IGF-II in unanesthetized preterm fetal sheep. These changes were associated with a dramatic rise in IGFBP-1 levels, which would help to further reduce bioavailable circulating IGF- The data demonstrate that cerebral cooling with mild systemic hypothermia did not significantly alter the pattern of changes in circulating IGF-I and IGF-II, IGFBP-I, and insulin after an acute severe asphyxia. Further, the current study demonstrates for the first time, in contrast with previous data, ${ }^{10}$ that exposure to asphyxia can be associated with a transient reduction in IGF-II levels. The present study suggests that following acute severe hypoxia, IGFs and binding proteins play a key role in metabolic regulation in the preterm sheep fetus. Previous studies in the fetal sheep have shown that an infusion of IGF-I with insulin is highly anabolic. ${ }^{21}$ Thus, the reductions of both circulating IGF-I and insulin levels in the present study may facilitate peripheral protein catabolism. The present study suggests that IGF-II may also contribute to acute metabolic regulation, with circulating IGF-II levels falling at 6 hours and significantly suppressed by 10 hours after occlusion, albeit more modestly than IGF-I. In the fetus, IGF-II has been classically seen as constitutive, and IGF-I more labile. Large environmental changes, such as severe starvation or very prolonged hypoxia, were

\begin{tabular}{|ccccc}
\hline 4 hours & 6 hours & 24 hours & 48 hours & 72 hours \\
\hline $7.39 \pm 0.00$ & $7.38 \pm 0.00$ & $7.38 \pm 0.00$ & $73.7 \pm 0.00$ & $7.37 \pm 0.01$ \\
$7.40 \pm 0.00$ & $7.41 \pm 0.00$ & $7.37 \pm 0.00$ & $7.38 \pm 0.00$ & $7.38 \pm 0.00$ \\
$7.46 \pm 0.01^{*}$ & $7.44 \pm 0.00^{*}$ & $7.43 \pm 0.01^{*}$ & $7.41 \pm 0.00^{*}$ & $7.43 \pm 0.00^{*}$ \\
\hline $473 \pm 0.8$ & $47.8 \pm 1.2$ & $45.0 \pm 1.7$ & $48.0 \pm 1.1$ & $46.3 \pm 1.6$ \\
$47.8 \pm 1.2$ & $45.6 \pm 1.4$ & $47.4 \pm 1.1$ & $47.2 \pm 0.9$ & $46.5 \pm 1.2$ \\
$40.0 \pm 1.0^{*}$ & $40.0 \pm 1.1^{*}$ & $39.0 \pm 3.0^{*}$ & $42.5 \pm 1.0^{*}$ & $42.9 \pm 2.0$ \\
\hline $22.6 \pm 1.0$ & $22.3 \pm 1.0$ & $22.2 \pm 2.1$ & $23.4 \pm 1.5$ & $23.5 \pm 1.4$ \\
$24.8 \pm 1.0$ & $24.8 \pm 0.9$ & $26.6 \pm 1.3$ & $28.0 \pm 1.3$ & $28.3 \pm 3.6^{*}$ \\
$25.1 \pm 1.4$ & $24.4 \pm 1.1$ & $23.6 \pm 0.9$ & $24.5 \pm 1.5$ & $27.0 \pm 2.7$ \\
\hline $1.10 \pm 0.06$ & $1.11 \pm 0.10$ & $1.20 \pm 0.12$ & $1.20 \pm 0.10$ & $1.20 \pm 0.10$ \\
$1.30 \pm 0.10^{*}$ & $1.40 \pm 0.10^{*}$ & $1.50 \pm 0.14^{*}$ & $1.30 \pm 0.10$ & $1.23 \pm 0.10$ \\
$1.40 \pm 0.12^{*}$ & $1.52 \pm 0.10^{*}$ & $1.43 \pm 0.13$ & $130 \pm 0.13$ & $1.42 \pm 0.10$ \\
\hline $0.75 \pm 0.04$ & $0.75 \pm 0.15$ & $0.64 \pm 0.10$ & $0.83 \pm 0.11$ & $0.90 \pm 0.12$ \\
$2.48 \pm 0.44^{*}$ & $1.86 \pm 0.24^{*}$ & $1.00 \pm 0.12^{*}$ & $0.78 \pm 0.10$ & $0.88 \pm 0.10$ \\
$1.40 \pm 0.32^{*}$ & $1.21 \pm 0.16^{*}$ & $0.92 \pm 0.12$ & $0.73 \pm 0.10$ & $0.80 \pm 0.10$ \\
\hline
\end{tabular}


Figure 3. Fetal plasma concentration changes in IGFBP. 1 and unsulin levels before, duning Isample taken at 20 minutes of a 25 minute occlusion Insilt) and after $(2,4,6,10,24,48$, and 72 hours), in sham controls (open bars), asphyxla with normothermia (dark bars), or asphyxia with hiypothermia started 90 minutes after the insult and continued until 2 hours before the 72.hour sample (hatched bars). Data are mean * SEM. * $P<.05$ compared to sham controls.
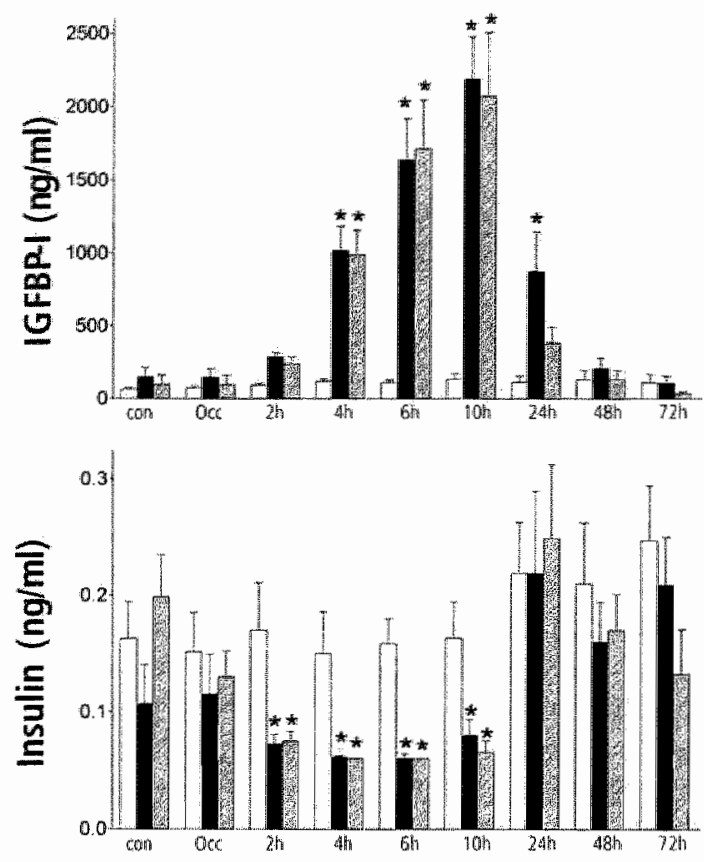

Time (hours)

required before circulating concentrations of IGF-II changed significantly. ${ }^{22,23}$ Recent studies, however, suggest an important role for IGF-II in modulating both the placental supply and fetal demand for nutrition. ${ }^{24,25}$ Thus, the present finding of relatively acute changes in IGF-ll levels may reflect the dynamic metabolic adaptations required after severe asphyxia.

The bioavailability and activity of the IGFs is further regulated by changes in the IGFBPs and the IGF receptors. For example, although there are limited data, hypoxia can modulate IGF-I receptor

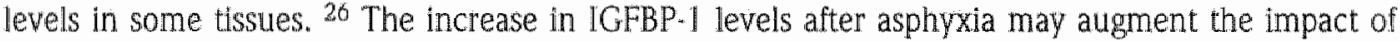
reduced circulating IGF-1 levels by reducing its bioavailability. Several mechanisms are likely to have contributed to the increase in IGFBP-1. In vitro, expression of IGFBP-1 in the liver has been shown to be stimulated by hypoxia. ${ }^{27}$ The intron 1 region of the IGFBP. 1 gene contains an hypoxia response element (HRE), which can be induced either directly by hypoxia or indirectly through release of hypoxia-inducible factor-1 (HIF-1). ${ }^{28}$ In the present study, IGFBP-1 started to rise from 4 hours after umbilical cord occlusion, at a time when the hypoxia was resolved completely, consistent with the observed delay in vitro between the onset of hypoxia and the subsequent rise in IGFBP-1. ${ }^{28}$

In addition, insulin is an important modulator of IGFBP-1 levels, ${ }^{29}$ such that fetal IGFBP-1 levels are inversely related to insulin concentrations. ${ }^{30}$ Consistent with this, our current findings show that reduced insulin levels after asphyxia preceded the rise in IGFBP-1 levels. We have recently demonstrated in the 0.7 gestation fetus that sympathetic tone is significantly elevated after asphyxia. 20 This increase in sympathetic activity may also be important because the hypoxic inhibition of insulin secretion is mediated by an $\alpha_{2}$-adrenergic mechanism, ${ }^{31}$ which in turn stimulates IGFBP-I production. 32 In adults, IGFBP-1 is cleared from the circulation by the kidney and impaired renal function results in high circulating IGFBP-1 levels ${ }^{33}$; however, this is unlikely to be important in the fetus as at this 
gestation there is only a small, transient reduction in glomerular filtration rate following asphyxia. ${ }^{18}$ The present study demonstrates for the first time that induced head cooling with mild systemic hypothermia did not affect the changes in plasma IGF-I levels or IGF-II after asphyxia. IGFBP-1 levels resolved by 24 hours in the hypothermic asphyxia group but remained elevated in the normothermic asphyxia group, even though insulin levels had returned to normal in both groups. This was associated with higher blood glucose levels in the normothermia asphyxia group, and may reflect the hyperglycemic effects of IGFBP1. ${ }^{34}$ We did observe a mild metabolic alkalosis during cooling, which may be related to stimulation of maternal breathing by cooling. 35

Compared with a previous report in younger fetuses (0.6 of gestation) the present study demonstrated a less pronounced fall in IGF-I (50\% vs $80 \%$ ) and an acute fall in IGF-II levels in contrast with a small secondary rise in the days following asphyxia in the younger fetuses. ${ }^{18}$ The insults at each gestation are comparable and near terminal. The extent to which these differences reflect differences in metabolic demand and degree of injury between the two ages, maturational differences in sympathetic tone, ${ }^{20}$ or renin-angiotensin system activity ${ }^{36}$ remains to be determined.

In conclusion, this study demonstrates that therapeutic head-cooling in the preterm fetus is not associated with major changes in the responses of circulating concentrations of IGFs after asphyxia. The overall profile of the changes in IGFs and insulin is consistent with facilitation of catabolism. Intriguingly, this study suggests for the first time that by 0.7 of gestation changes in IGF-II may also contribute, in addition to IGF-I, to regulation of fetal metabolism during the acute phase of postasphyxial recovery in utero. 


\section{REFERENCES}

1. Gun AJ. Cerebral hypotherma for prevention of brain injury following perinatal asphyxia. Curr Opin Pedatr $2000 ; 12: 111-5$.

2. Guckman PD, Wyatt IS, Azzopardi D, et al. Selective head cooling with mild systemic hypothermia to improxe neurodevelopmental outcome following neonatal encephalopathy. Pediarr Res $2004 ; 55: 582 \mathrm{~A}$.

3. Sweet MP. Hodgman JE, Pena I, Barton L, Pavlova Z, Ramanahan R. Two-year outcome of infants weighing 600 grams or less at birth and bom 1994 through 1998. Obstet Gynecol 2003; 101:18-23.

4. Thoresen M, Salas S, Loberg EM, et al. Twenty-four hours of mild hypothermia in unsedated newborn pigs starting after a severe global hypoxic -ischemic insult is not netroprotective. Pediatr Res 2001:50:405-11.

5. Fant ME, Weisoly D. Insulin and insulin like growth factors in human development: Implications for the perinatal period. Semin Perinatol $2001 ; 25: 426-35$.

6. Ogilvy Stuart AL, Hands SI, Adcock Cl, et al. Insulin, insulinilke growth factor I (IGFI), loF binding protein. 1, growth hormone, and feeding in the newborn. / Cln Endocrinol Metab 1998;83:3550 7 .

7. Smith WJ, Underwood LE, Keyes L, Clemmons DR. Use of insulin-like growth factor I IGF I] and IGFbinding protein measurements to monitor feeding of premalure infants. / Clin Endocrino/ Metab 1997,82:3982 8.

8. Kormhauser C, Dubey LA, Garay ME, Perez-Luque EL, Malacara JM, Vargas-Origel A Serum and urinary insulin-like growth factor- 1 and tumor necrosis factor in neonates with and without acute renal. fallure. Pediatr Nephrol 2002;17:332-6.

9. Lineham JD, Smith RM, Dahlenburg GW, et al. Circulating insulin-like growth factor I levels in newbom. premature and full-term infants followed longitudinally. Early Hum Dev 1986;13:37-46.

10. Hikino $S$, Ihara $\mathbb{K}$, Yamamoto I, et al. Physical growth and retinopathy in pretem infants: Involvement of IGF-I and GH. Pediatr Res 2001;50:732-6.

11. Hellstrom A, Engstrom E, Hard AL, et al. Postnatal serum insulin-ike growth factor I deficiency is associated with retinopathy of prematurity and other complications of premature birth. Pediatrics $2003 ; 112: 1016-20$.

12. Smith LE. Pathogernesis of retinopathy of prematurity. Semin Neonatol $2003 ; 8: 469-73$.

13. Volpe II. Neurobiology of periventricular leukomalacia in the premature infant. Peduatr Res 2001;50:553-62.

14. Low JA. Determining the contribution of asphyxia to brain damage in the neonate / Obstet Gynaecol Res $2004 ; 30: 276 m 86$

15. Perlman M. White matter injury in the preterm infant: An important determination of abnorinal neurodevelopment outcome. Eary Hum Dev 1998;53;99-120.

10. Benmet L, Olver MH, Gunn AJ, Hennies M, Breter B. Differentia changes in insulin-like growth factors and their binding proteins following asphyxia in the preterm fetal sheep. / Physiol /Lond 2001;531:835-41.

17. McIntosh CH, Baghurst KI, Potter B], HeLel BS. Foetal brain development in the sheep. Nevropathol Appl Neurobiol 1979;5:103-14.

18. Quaedackers JS, Roelisema V, Hunter CJ, Heineman E, Gunn A, Bennet L. Polyuria and impaired renal blood fow after asphyxia in preterm fetal sheep. Am I Physiol Regut Integr Comp Physiol 2004;280:R570-33.

19. Bennet L, Rossenrode S, Gunning MI, Gluckman PD, Gunn A. The cardiovascular and cerebrovascuar responses of the immature fetal sheep to acute umbilical cord occlusion. J Physiof /Lond 1990,517:247-57.

20. Quaedackers JS, Roelfsema V, Heineman E, Gunn AJ, Bennet L.. The role of the sympathetic nerwous system in postasphyxial intestinal hpoperfusion in the preterm sheep letus. I Physiol (Lond) 2004,557(Pt $3: 1033-4.4$.

21. Shen W, Wisniowski P, Anmed L, Boyle DW, Denne SC, Liechty EA. Protein anabolic effects of insulin and IGF- in the ovine fotus. Am / Physiol Endocrinol Metab 2003;284:E748-50.

22. Bassett NS, Onwer MH, Breier BH, Gluckman PD. The effect of matemal starvation on plasma insulin-like growth factor I concentrations in the late gestation ovine fetus. Pediatr Res 1990:27:401-4. 
23. Owens $I A$, Kind KL, Carbone F, Robinson JS, Owens PC. Circulating insulin-lke growth factors-I and II and substrates in fetal sheep following restrtiction of placental growth. IEndocrinol 1994:140;5-13.

24. Rekk $W$, Constancia $M$, Fowden $A$, et al. Regulation of supply and demand for maternal muirients in mammals by imprinted genes. / Physiol Lond 2003;547:35-44.

25. Constancia $M$, Hemberger M, Hughes $J$, et al Placental-specilic $1 G F-l l$ is a major modulator of placental and fetal growth. Nattire 2002,417,945-8.

26. Moromisato DY, Moromisato MY, Zanconato S, Roberts CT Jr. Effect of hypoxia on lung, heart, and liver tnsulinike growth factorl gene and receptor expression in the newborn rat. Crit Care Med $1996,24: 919-24$.

27. Sugawara J, Tazuke SI, Suer LF, et al. Regulation of insulin-like growth factorbinding protein I by hypoxia and $3=, 5=$ cyclic adenosine monophosphate is additive in HepG2 cells. / Clin Endocrinol Metab $2000 ; 85: 382 I-7$

28. Tazuke S1, Mazure $\mathbb{N M}$, Sugawara I, et al. Hypoxia stimulates insulin-like growth factor binding protein I (IGFBP.1) gene expression in HepG2 cells: A possible model for IGFBP-1 expression in fetal hypoxia. Proc Natl Acad ScillSA 1998; 95:10188-93.

29. Unteman TG, Oehler DT, Murphy L], Lacson RG. Mutihormonal regulation of insulindike growth factorbinding protein-1 in rat H4IE hepaloma cells: The dominant role of insulin. Endocrinology $1991 ; 128: 2693-701$.

30. Oliver MH, Harding JE, Breier BH, Guckman PD. Fetal insulin-like growth factor (IGF) I and IGFII are regulated differently by glucose or insulin in the sheep fetus. Reprod Fertil Dev 1996;8:167-72.

31. Jackson BT, Plasecki GJ, Cohn HE, Cohen WR. Control of fetal insulin secretion. Am I Physiol Regul Integr Comp Physiol 2000:279:R2179-88.

32. Fowden AL. The insulin like growth factors and feto-placental growth. Placenta 2003;24:803-12.

33. Roelsema V, Clark RG. The growth hormone and insulinlike growth factor axis: Its manipulation for the benefit of growth disorders in renal failure. J Am Soc Nephrol 2001;12:1297-1306.

34. Lewitt MS, Denyer CS, Cooney GJ, Baxter RC. Insulin-like growth factorbinding protein 1 modulates blood glucose levels. Endocrinology 1991; 129:2254-6.

35. Gluckman PD, Gunn TR, Johnston BM. The effect of cooling on breathing and shivering in unanaesthetized fetal lambs in utero. J Physiol (Lond) 1983;343:495-506.

36. Brink $M_{\mathrm{s}}$ Price $S R_{\mathrm{g}}$ Chrast $\mathrm{I}$, et al. Angiotensin 11 induces skeletal muscle wasting through enhanced protein degradation and downregulates autocrine insulin-lke growth factor /. Endocrinology $2001 ; 142: 1489-96$. 



\section{ABSTRACT}

Summary: Postresuscitation cerebral hypothermia is consistently neuroprotective in experimental preparations; however, its effects on white matter injury are poorly understood. Using a model of reversible cerebral ischemia in unanesthetized nearterm fetal sheep, we examined the effects of cerebral hypothermia (fetal extradural temperature reduced from $39.4 \pm 0.1^{\circ} \mathrm{C}$ to between 30 and $33^{\circ} \mathrm{C}$, induced at different times after reperfusion and continued for 72 hours after ischemia, on injury in the parasagittal white matter 5 days after ischemia. Cooling started within 90 minutes of reperfusion was associated with a significant increase in bioactive oligodendrocytes in the intragyral white matter compared with sham cooling ( $41 \pm 20$ vs $18 \pm 11$ per field, $P<0.05$ ), increased myelin basic protein density and reduced expression of activated caspase- $3[14 \pm 12$ vs $91 \pm 51, P<0.05]$. Reactive microglia were profoundly suppressed compared with sham cooling ( $4 \pm 6$ vs $38 \pm 18$ per field, $P<0.05$ ) with no effect on numbers of astrocytes. When cooling was delayed until 5.5 hours after reperfusion there was no significant effect on loss of oligodendrocytes ( $24 \pm 12$ per field). In conclusion, hypothermia can effectively protect white matter after ischemia, but only if initiated early after the insult. Protection was closely associated with reduced expression of both activated caspase- 3 and of reactive microglia:

Key Words: Hypotherma - White matter-Brain injury.

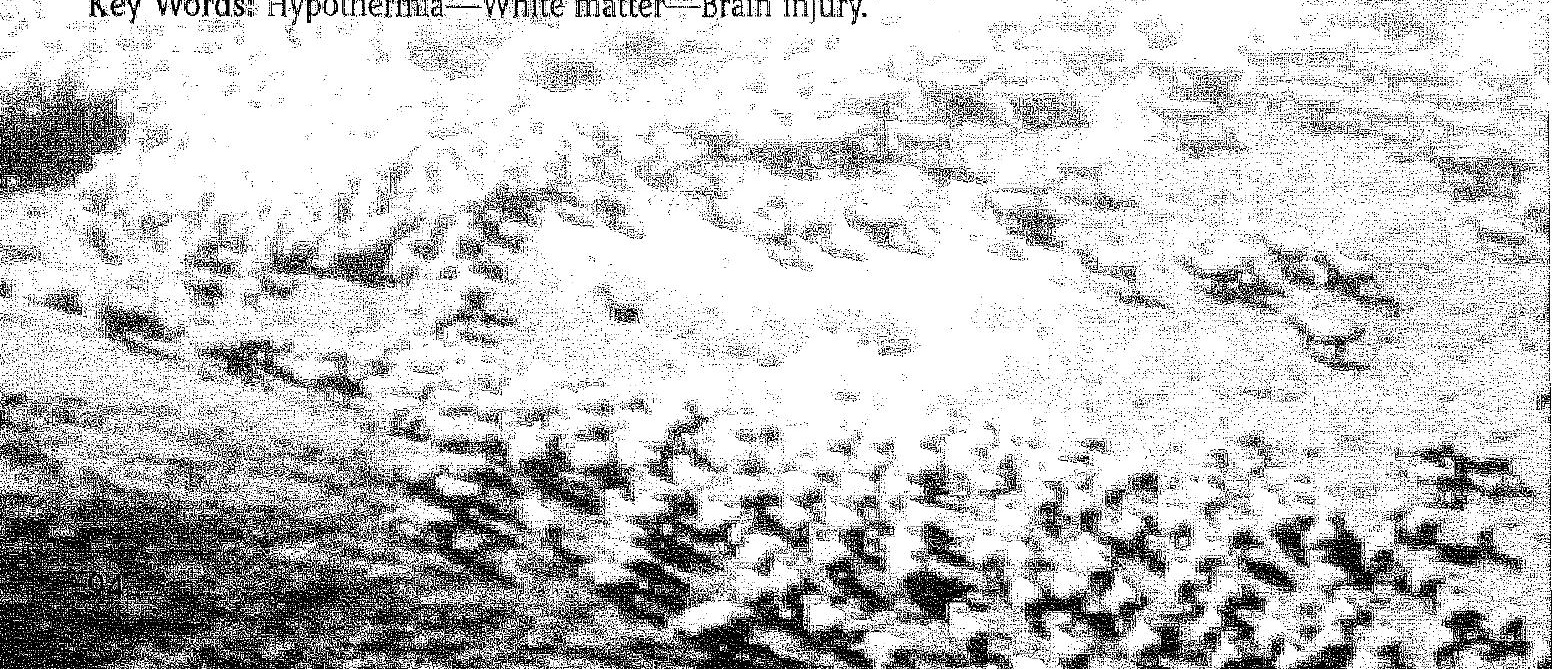




\section{INTRODUCTION}

Although white matter injury is well known to be the dominant cause of neural handicap in premature infants (Inder et al., 1999), there is increasing evidence from magnetic resonance imaging studies that it is also a significant contributon to neurodevelopmental problems at term (Barkovich et al., 1995; Mercuri et al., 1999; Okumura et al., 1997). Experimentally, mature, myelinating oligodendrocytes are at least as vulnerable to ischemic injury as neurons (Cao et al., 2003; Guan et al., 2000; Ikeda et al., 1998; Loeliger et al., 2003; Pantoni et al, 1996; Petersson et al., 20021. Indeed, after aspliyxia in the near-term fetal sheep, the mildest pathologic findings were vacuolation and loss of myelin in white matter, rather than neuronal death (Ikeda et al., 1998).

There is now strong clinical and experimental evidence that prolonged period of moderate cerebral hypothermia initiated within a few hours after severe hypoxia-ischemia can markedly reduce subsequent neuronal loss and improve behavioral recovery (Bernard et al., 2002; Colboume and Corbett, 1995; Gunn et al, 1997, 1998b; The Hypothermia after Cardiac Arrest Study Group, 2002; Tooley et al., 2003). Although there are few data on perinatal white matter damage, early initiation of hypothermia can ameliorate posttraumatic spinal cord injury (Inamasu et al., 2003), and there is increasing evidence that many of the effects of cooling are relevant to the proposed mechanisms of hypoxic-ischemic oligodendrocyte loss.

Recent studies have shown that the pathogenesis of postischemic demyelination includes a substantial element of delayed or secondary loss (Cao et al, 2003), likely mediated by apoptosis and microglia activation (Hagberg et al., 2002; Shibata et al., 2000). Apoptosis is a significant component of postasphyxial cell death in the developing brain (Edwards et al., 1997; Scott and Hegyi, 1997). Although multiple pathways are likely to be involved in such postischemic apoptosis, caspase-3, one of the family of cysteine proteases, is reported to play a crucial role in the immature brain (Hu et al., 2000; Johnson et al., 1999; Zhu et al., 2003), and specifically in loss of oligodendrocytes (Cao et al., 2003; Shibata et a1., 2000). Several reports suggest that hypothermia can specifically suppress the development of apoptotic injury (Edwards et al., 1995; Xu et al., 1998).

In addition, there is increasing evidence that cytokine induction and the assaciated inflammatory reaction ane major contributors to perinatail brain injury (Hagberg et al., 2002). In particular, microglia activated by interferon-gamma induce contact-dependent oligodendroglial death (Nicholas et al., 2003). Hypothermia potently reduces cytokine release and microglial activalion both in wivo and in vitro (Gibbons et al., 2003; Inamasu et al., 2000; Wang et al., 2002).

The effects of cooling on neuronal loss are known to be highly dependent on the timing of inituation of cooling, with rapid loss of effect as delay is increased (Gunn and Bennet, 2002). This relationship has not been established for perinatal white matter injury. Therefore, in the present study we examined the effect of time of initiation of moderate cerebral hypothermia fo: 3 days after ischemia on white matter damage after transient cerebral ischemia in nearterm (0.85 gestation) fetal sheep. In terms of cerebral maturity and myelination, this stage is comparable to the human brain at term (McIntosh et al., 1979). The effects of hypothermia on postischemic white matter apoptosis and the Inflammatory reaction after 5 days recovery from ischemia were assessed using proteolipid protein (PLP) mRNA to identify bioactive oligodendrocytes and immunohistochemistry to identify other glial cell types. 


\section{Materials and Methods}

\section{Experimental preparation}

All procedures were approved by the Animal Ethics Committee of the University of Auckland. Singleton Romney/Suffolk fetal sheep, while under general anesthesia $\left(2 \%\right.$ halothane in $\left.\mathrm{O}_{2}\right)$, were instrumented at 117 to 124 days of gestation (term $=147$ days) using sterile techniques. Ewes were given $5 \mathrm{~mL}$ of Streptopen (Stockguard Labs Lid., Hamilton, New Zealand) intramuscularly before the start of surgery. Polyvinyl catheters were placed in the brachial arteries, a brachial vein, and the amniotic sac. Electrocardiogram (ECG) electrodes were sewn across the chest to record the fetal electrocardiogram. A thermistor was placed in the fetal esophagus at the level of the right atrium to measure fetal core body temperature (Gunn et al., 1997). The vertebral-occipital anastomoses were ligated bilaterally to restrict vertebral blood supply to the carotid arteries. A double-ballooned inflatable occluder was placed around each carotid artery (Gunn et al., 1997). Two pairs of electroencephalographic electrodes (AS633-5SSF, Cooner Wire Co., Chatsworth, CA, U.S.A.) were placed on the dura over the parasagittal parietal cortex $(5 \mathrm{~mm}$ and $15 \mathrm{~mm}$ anterior to bregma and $10 \mathrm{~mm}$ lateral), with a reference electrode sewn over the occiput. Cortical impedance was measured using a third pair of electrodes (AS633-3SSF, Cooner Wire Co.) placed over the dura, $5 \mathrm{~mm}$ lateral to the electroencephalographic electrodes. A second thermistor Incu-temp-1; Mallinckrodi Medical, St. Louis, MO, U.S.A.) was placed over the parasagittal dura $20 \mathrm{~mm}$ anterior to bregma and the burr holes were sealed and the skin over the fetal skull was secured with cyanoacrylate glue.

A. cooling coil made from silicone tubing (external diameter, $7.9 \mathrm{~mm}$; internal diameter, $4.8 \mathrm{~mm}$; Silclear, Degania Silicone, Degania Bet, Israel) was attached over the dorsal surface of the scalp and extended over the lateral surface of the cranium down to the level of the external auditory meatus. The fetus was returned to the uterus and $80 \mathrm{mg}$ of gentamicin was administered into the amniotic sac before closure of the uterus. All fetal leads were exteriorized through the maternal flank. The maternal long saphenous vein was catheterized for administration of antibiotics and for euthanasia. A thermistor was inserted with the catheter to permit measurement of maternal temperature.

After surgery, sheep were housed together in separate metabolic cages with access to water and food ad libitum. They were kept in a temperature-controlled room $\left(16 \pm 1^{\circ} \mathrm{C}\right.$, humidity $\left.50 \% \pm 10 \%\right)$, in a 12-hour light/dark cycle. A period of 3 to 5 days' postoperative recovery was allowed, during which the ewe was injected with daily intravenous (i.v.) gentamicin ( $80 \mathrm{mg}$ gentamicin, Pharmacia \& Uplohn, Perth, Australiaj. Fetal arterial blood was taken daily from the brachial artery, for blood gas analysis. Catheters were maintained patent by continuous infusion of heparinized saline $140 \mathrm{U} . \mathrm{mL}^{\text {: }}$ at $0.2 \mathrm{~mL}_{\mathrm{L}} \mathrm{h}^{-1}$.

\section{Experimental design and recordings}

Fetuses were randomly assigned to one of four groups: sham control, ischemia plus sham cooling, or ischemia plus cooling, starting either 2 hours (2-hour cooling groupl or 6 hours (6 hour cooling group) after the start of ischemia. Fetal mean arterial pressure, corrected for maternal movement by subtraction of amniotic fluid pressure, fetal heart rate, carotid artery blood flow, fetal electroencephalogram, spectral edge, and impedance were recorded continuously from 12 hours before the experiment until 5 days afterwards. Data were stored at 1 -minute intervals to disk by custom software for off-line analysis (Labview for Windows, National Instruments Ltd, Austin, TX, U.S.A.).

Cerebral ischemia was induced by rapid inflation of the carotid artery occluders bilaterally for 30 minutes with sterile saline. Successfui occlusion was confirmed by observation of a rapid, sustained flattening of the electroencephalogram. Cooling was started either 2 or 6 hours after the onset of the 
ischemic period (i.e., 90 minutes vs. 5.5 hours after the initiation of reperfusion) and was continued until 72 hours after occlusion. Fetal arterial blood was taken 60 minutes before carotid occlusion, and then at 35 minutes after the start of occlusion [i.e., 5 minutes aiter the end of occlusion), and 2, 4, $6,12,24,48,72,96$, and 120 hours and analyzed for $\mathrm{pH}$ and blood gas determination (Ciba-Corning Diagnostics 845 blood gas analyzer and co-oximeter, East Walpole, MA, U.S.A.l and for glucose and lactate measurements (YSI model 2300, Yellow Springs, OH, U.S.A.).

On completion of the experiment at 120 hours, the ewe and fetus were killed by an overdose of pentobarbitone sodium given IV to the ewe. The fetal brain was perfusion fixed with saline followed by $10 \%$ neutral buffered formalin, stored overnight for fixation in $10 \%$ neutral buffered formalin, then embedded in paraffin using a standard paraffin tissue preparation.

The $\mathrm{pH}$, blood gas data, and glucose and lactate measurements, carotid blood flow and electrophysiologic changes, and neuronal loss scores have been published in a subset of these animals [Gunn et al, 1997, 1998b].

\section{Immunohistochemistry}

Immunohistochemical staining was performed on coronal sections $(6 \mu \mathrm{m})$, at the level of the parietal cortex, cut and mounted on chrome alum-coated slides. Before specific staining, all the slides were deparaffinized in xylene, twice for 15 minutes, dehydrated in a series of ethanol $100 \%, 100 \%, 95 \%$, $95 \%, 70 \%$, for 2 minutes each), and incubated in $0.1 \mathrm{~mol} / \mathrm{L}$ phosphate buffered saline (PBS) twice for 5 minutes. The sections were pretreated with $1 \% \mathrm{H}_{2} \mathrm{O}_{2}$ in $50 \%$ methanol for 20 minutes, washed in PBS ( $3 \times 5$ minutes) and incubated with the primary antibody for 2 days at $4^{\circ} \mathrm{C}$. The following primary antibodies and dilutions were used: mouse anti-myelin basic protein (MBP, Roche, Mannheim, Germany; 1:200); isolectin B-4 (Sigma, St. Louis, MO, U.S.A.; 1:100); mouse anti-glial fibrillary acidic protein (Sigma; 1:200); mouse-proliferating cell nuclear antigen PC10 (PCNA; DAKO, Denmark, diluted 1:100); rabbit anti-Caspase-3 Asp 175 (cleaved Caspase-3 Antibody, detects endogenous levels of the large fragment of activated caspase-3 (17-20kDa), Cell Signaling Technology, Beverly, MA, U.S.A., diluted $1: 1,000)$. The antibodies were diluted in PBS containing normal horse serum/goat serum. The primary antibodies were washed off with PBS ( $3 \times 10$ minutes) and then incubated with anti-mouse/anti-goat biotinylated immunoglobulin G (Vector Laboratories, Burlingame, CA, U.S.A., diluted 1:200) overnight at $4^{\circ} \mathrm{C}$. The sections were washed, incubated in avidin-biotin complex $(A B C$, Vector Laboratories, Peterborough, England, diluted $1: 100$ ) in the ratio

1:500 for 3 hours at room temperature, washed again in PBS, and then reacted in diaminobenzidine tetrahydrochloride (DAB, Sigma). Sections were then dehydrated in a series of alcohol to xylene: washes and coverslipped with mounting medium. Control sections were processed in the same way except that the primary antibody was omitted from the incubation solution.

\section{In situ hybridization}

In situ hybridization, using a sheep PLP RNA probe, was used to identify bioactive oligodendrocytes, as previously described (Guan et al., 2001).

\section{Analysis and statistics}

Scoring of oligodendrocytes, astrocytes, microglia, and density of myelin was performed on coronal sections by light microscopy at $\times 200$ magnification. Within these sections, cells were counted using a fixed grid $(0.42 \times 0.21 \mathrm{~mm})$, in three areas in the intragyrai white matter of the parasagittal cortex, and one in the corona radiata, of both hemispheres (Fig. 1). The density of MBP from the same areas and their background was measured using image analysis (Sigmascan, SPSS, Chicago, IL, U.S.A.). The difference between the 
Figure 1. Photomicrograph whowing the regions used to count different cell inpers anid to assess the ayerage density of myelin in the intragral white matter and the corona radiata. Three regions in the intragyral white matter (squares 1,2 , and 3 and one area in the corona radiata (sciuare 4), in both hemispheres, were used for assersment.

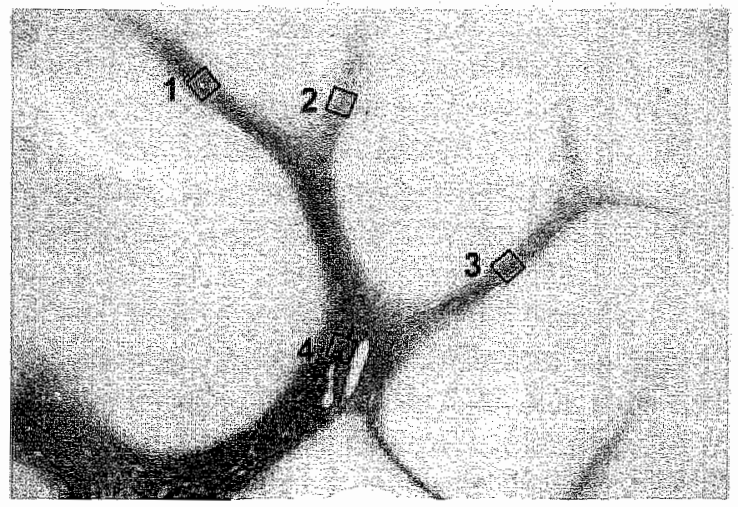

MBP density and the background reading from adjacent gray matter was calculated and used for data analysis. The number of cells positive for glial fibrillary acidic protein, IB-4, PLP, and PCNA and the MBP density were averaged from the three selected intragyral areas. Because of the relatively low density of caspase-3 (Asp 175) positively stained cells, the measurement represents the total number of caspase-3 (Asp 175)-positive cells present in the white matter tract of the first parasagittal gyrus.

The sham cooling (ischemia) group showed marked tissue swelling in the intragyral regions, with a significant increase in intragyral white matter areas compared with sham controls. To correct for decreased cell and staining density because of tissue swelling, cell counts and MBP staining density measurements in the sham cooling group were adjusted by the relative increase in white matter area (the ratio of intragyral white matter area in sham cooled fetuses to the sham control group) before statistical analysis. There was no significant tissue swelling in the two hypothermia groups; therefore the counts and staining density were not adjusted. Treatment effects were evaluated by analysis of variance (SPSS v10, SPSS Inc.), followed by the protected least-significant difference post-hoc test when a significant overall effect was found. Significance was accepted at $P<0.05$. Data are mean $\pm S D$.

\section{RESULTS}

\section{Myelin Basic Protein}

Myelin basic protein immunohistochemistry showed specific staining of myelin sheaths in the intragyral and corona radiata without obvious staining of cell bodies (Figs. 2a and 2e). Cerebral ischemia was associated with a severe loss of MBP density compared with sham controls (Figs. $2 \mathrm{~b}$ and $2 \mathrm{f}$, and Fig. $3, P<0.05)$, which was greatest in the parasagittal intragyral white matter $(P<0.05)$. Morphologically, the normally parallel microstructure of MBP was disorganized and fragmented. The intragyral white matter tracts were markedly swollen (Figs. $2 \mathrm{~b}$ and $2 \mathrm{f}$ ), with a significant increase of the intragyral white matter area compared with sham controls ( $12.70 \pm 2.25$ vs $7.11 \pm 1.63 \mathrm{~mm}^{2}, P$ $<0.05\}$.

Both cooling groups showed reduced loss of MBP staining density in the intragyral white matter and corona radiata after 5 days recovery compared with the shamcooled ischemia group, which was greatest in the 2 -hour group (Figs. $2 c, 2 \mathrm{~d}, 2 \mathrm{~g}, 2 \mathrm{~h}$, and Fig. 3, $P<0.05$ ). On visual assessment, MBP staining was denser, more compact and less fragmented than in the sham-cooled (ischemia) group (Figs. $2 \mathrm{~g}$ and $2 \mathrm{~h}$ ). Consistent with this, the area of the intragyral white matter area was significantly 
Figure 2. Photomicrographs showing the distribution (a, $b, c, d, s c a l e ~ b a r=1 \mathrm{~mm}$ ) and the morphologic appearance of myelin basic protein (MBP) $(e, \hat{i}$, $\mathrm{g}, \mathrm{h}$, scalle bar $=50 \mathrm{um}$ ) in sham controls (a and $e)$, ischemia with sham cooling ( $b$ and $i)$, and ischemia followed by cooling commenced at either 2 hours (2hour cooling group, $c$ and g) or 6 hours ( 6 -hour cooling group, $d \&$ h) after the start of ischemia. In sham control fetal sheep, the white matter tracts were densely labeled with MBP, which was greatest in the corona radiata (a). Morphologically, the MBP staining fibers are compact and parallel the white matter tracts (e). After ischemia, the density of $\mathrm{MBP}$ staining was significantly reduced in the sham cooled group, with severe loss in the intragyral regions of the white matter tracts accompanied by marked tissue swelling (b). MBP inmunopositive staining associated with the white matter fibers was reduced, fragmented, and less compact compared with the sham controls (f). Eally initiation of cooling (2-hour group) was associated with nearly complete normalization of average MBP density (c). Morphologically, cooling also partially restored both the distribution and compactness of MBPpositive nerve fibers (g). Late initiation of cooling (6-hour cooling group) was associated with an intermediate degree of loss of MBP staining (d). Morphologically, this group showed some continuing edema and fragmentation of the MBP.positive nerwe fibers, but to a lesser extent than in the sham cooled fetuses (h).

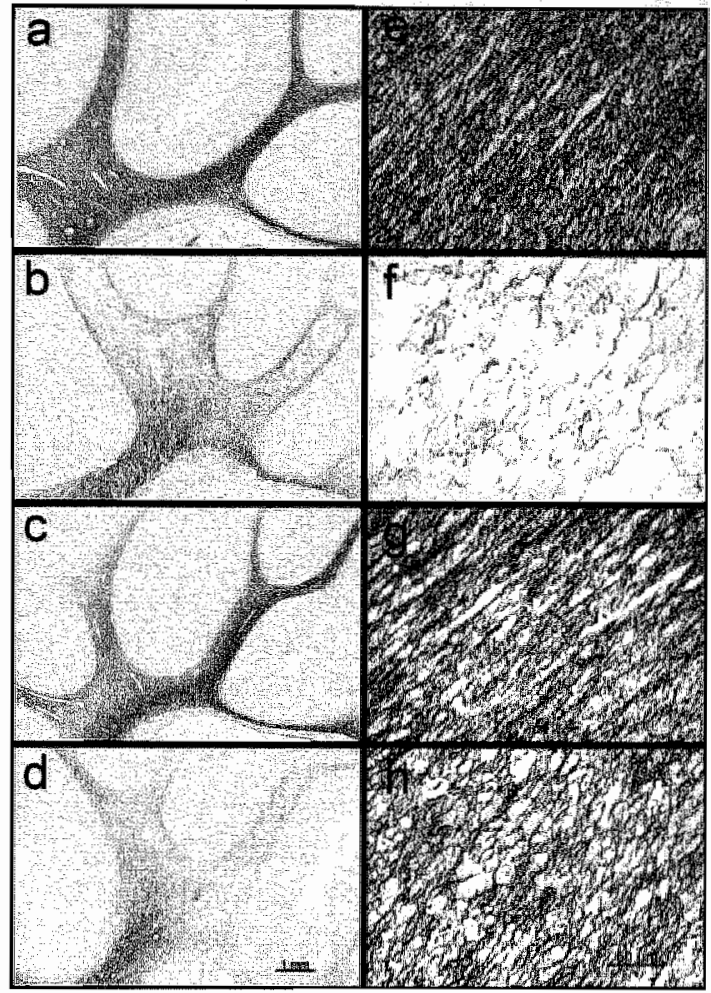

reduced in both the 2 -and 6 -hour cooling groups compared to ischemia alone $(P<0.05,8.30 \pm 243$ and $9.02 \pm 3.29 \mathrm{~mm}^{2}$, respectively) and not significantly different from sham controls.

\section{Proteolipid protein mRNA expression}

In the sham control group, PLP mRNA staining was densely distributed from the corona radiata area toward the intragyral regions of the parasagittal white matter tracts. Proteolipid protein staining was localized in the periphery of the cytoplasm of oligodendrocytes in a bipolar distribution, as previously described (Guan et al., 2001). Ischemia was associated with a significant reduction in the number of the PLP staining oligodendrocytes compared to sham controls $(P<0.05$; bottom panel, Fig. 3); the loss was greater in intragyral white matter tracts compared with the corona radiata $(P<0.05)$. The 2 
Figure 3. Density of myetin basic protein [MBP, top\} immumostaining and numbers of proteolipid proteir (PLP, botom) MRMApositive cells in parasagital white mater. Ischenia resulted in a severe loss of MBP density (topl after 5 days recovery compared to the sham concrol group. Both the 2hour and the 6hour cooling groups showed a significant increase in awerage MBP density after ischemia compared to sham cooled (Ischemial fetuses, both in the intragyral white matter and the corona radiata. There was a significant los of PLP mRNA.containing cells (bottom) in the sham cooling (ischemia) group compared to sham controls both in the lintragrral white matter and the corona radiata. The 2hout but not the 6hour caoling group showed a significant increase in PLP MRNA. positive cells compared to the sham cooling (Ischemia) group. $P<0.05$ ws sham controls, ${ }^{\star} P<0.05$ vs ischemia with sham cooling. Data are mean \pm SD.
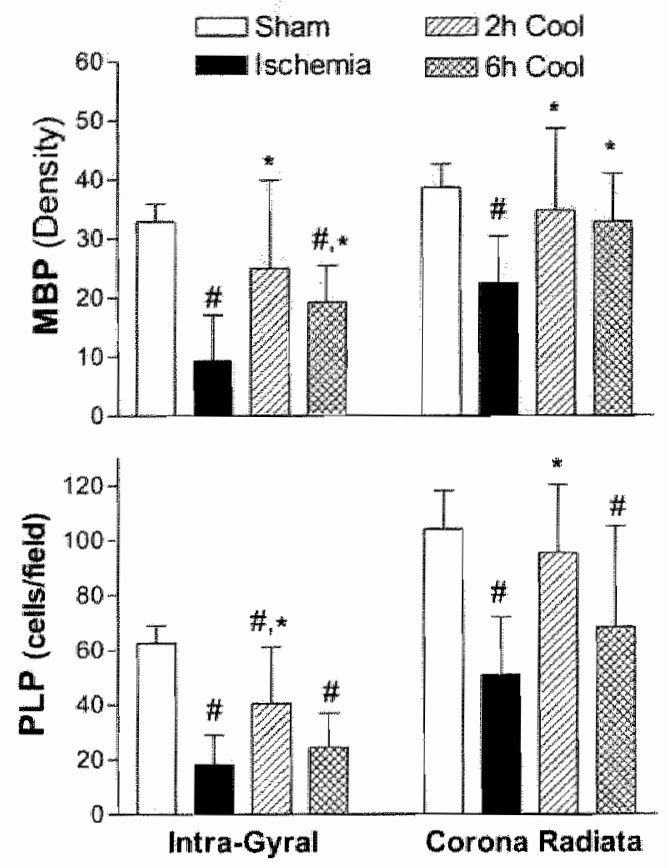

hour, but not the 6-hour, cooling group showed a sigrificantly greater number of PLP mRNA-positive cells than in the sham cooling (ischemia) group in both white matter regions $(P<0.05)$. Numbers of PLP mRNA cells in the 2-hour cooling group were still less than in sham controls in the intragyral white matter $(P<0.05)$ but similar to sham controls in the corona radiata.

\section{Astrocytes and microglia}

Glial. librillary acidic protein-positive astrocytes were localized throughout the fetal white matter tracts of sham control animals (Fig. 4a). Double labeling of glial fibrillary acidic protein with PLP mRNA showed a close association between astrocytes and oligodendrocytes in the white matter (data not shown). Ischemia was associated with an apparent reduction in numbers of astrocytes in the intragyral white matter (Fig. 4b) but not the corona radiata (Fig. 5). However, this was not statistically significant after correction for tissue swelling in this group (Fig. 5). There was no significant effect of cooling (Figs. 4c, 4d, and Fig. 5).

Sham control animals showed virtually no isolectin B-4 staining in the intragyral regions or corona radiata (Fig. 4e). Ischemia was associated with a significant increase of isolectin B-4 staining activated microglia in the intragyral and the corona radiata regions. (Fig. $4 \mathrm{f}$ and Fig. 5). Both the 2 -hour and 6hour cooling groups showed a significant reduction in numbers of microglia compared with the sham cooled (ischemia) group (Figs. $4 \mathrm{~g}$ and $4 \mathrm{~h}$, respectively, $P<0.05$ ) in both white matter regions, which was relatively greater in the 2 -hour cooling group (Fig. 5).

\section{Activated caspase- 3 expression}

Only occasional cleaved $17 \mathrm{kD}$ caspase-3 positive cells were seen in a few sham control animals. After ischemia in the sham-cooled (ischemia) and both cooling groups, there was a significant increase in activated caspase- 3 expression in the parasagittal cerebral white matter (Fig. 6). The density of caspase- 
Figure 4. Photomicrographs showing glial fibrillary acidic protein immunostaining $(\mathrm{a}-\mathrm{d})$ and isolectin $\mathrm{B}-4$ staining ( $\mathrm{e}-\mathrm{h})$ in the intragyral white matter. The sham control group showed abundant glial fibrillary acidic protein glial fibrillary acidic protein staining (a). There was an apparent reduction in numbers of gilial fibrillary acidic protein-positive cells after ischemia (b). because of severe tissue swelling. Both the 2 . hour and ohour cooling groups showed numbers of glial fibrillary acidic protein-positive cells that were similar to the sham controls (c and d). No isolectin B-4 positive cells were seen in sham controls (e). Ischernia was associated with intense induction of isolectin B-4 positive cells (f), which was almosti completely suppressed by early initiation of cooling (2-hour cooling group] (g). The 6 hour cooling group. showed intermediate expression of isolectin $B$ 4 positive cells (h). Scale bar $=50 \mu \mathrm{m}$.

Figure 5. Numbers of isolectin B-4 (Iso-B4, top) and glial fibrillary acidic protein (GFAP, bottom. immunopositive cells in predefined areas of the intragyal cerebral white matter and parasagital. corona radiata. The number of Iso-B4 positive cells was significantly increased after ischemic injury compared to the sham controls. Treatment with either early (2 hour group) or late (6-hour group) initiation of hypotherma significantly suppressed isolectin B-4 positive cells compared to the sham cooled group, although the degree of suppression was less with late cooling. Corrected for the area of the intragyral white matter tracts, there was no effect of ischemia on numbers of GFMP cels (bottom), and no effect of hypothermia. 郝 $P<$ 0.05 ws sham controls, ${ }^{*} P<0.05$ vs ischemia with sham cooling. Data are mean $\pm \mathrm{SD}$.
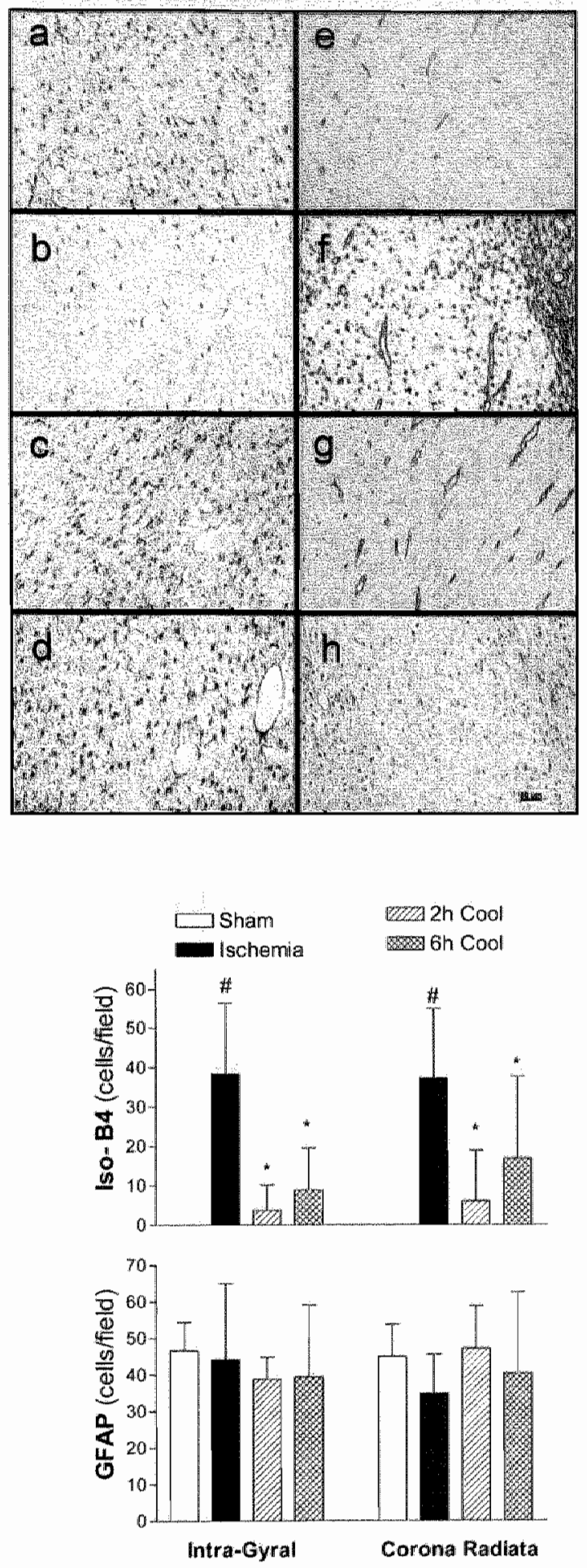
Figure 6. The total number of caspase.3 (Asp175)posiluve cells in the parasagittal cerebral white matter tract (top) was significantly increased after 5 days" recovery from cerebral ischemia compared to the sham control group. The 2 hour cooling group showed near-compllete suppression of caspase-3 activation cornpared to the sham cooled group, with a much smallerr effect in the bthour cooling group. Ischemia reduced the number of prollferating cell nuclear antigen PCNA, bottomi-positive cells in the intragyral white matter tract. There was no stgnificant additional effect of hypothermia. HP $<0.05$ vs sham controls, ${ }^{*} P<0.05$ vs uschemia with sham cooling, Data are mean $\pm S D$.

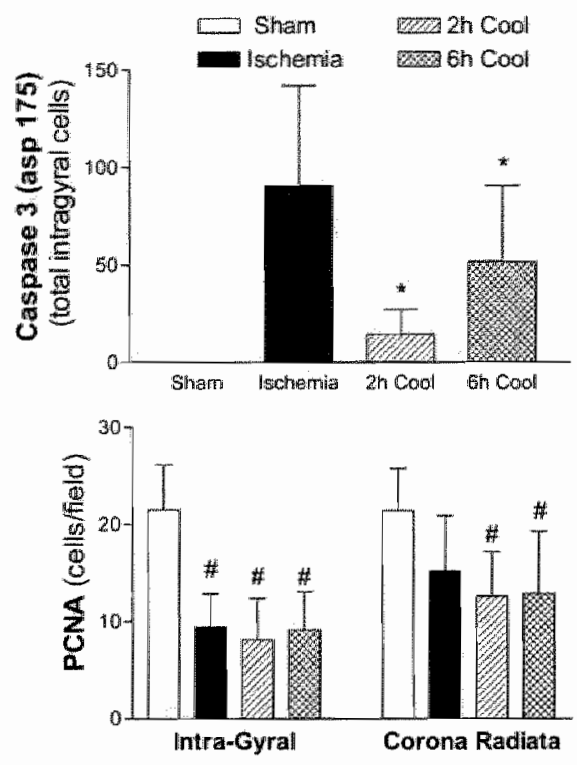

3 staining varied between cells because of the timing of cleavage of caspase-3. Cells were counted that had evidence of newly cleaved caspase-3, as shown by morphologically dense caspase-3 (Asp 175) staining evenly distributed within the ectoplasm, with coarse granular fragments around the cells (Fig. 7). Thionine counterstaining showed condensed chromatin fragments within the caspase-3 (Asp 175)positive cells. Both cooling groups showed significantly reduced numbers of cells expressing activated caspase-3 compared to sham cooling; the reduction in the 2-hour cooling group was greater than in the 6-hour cooling group (Fig. $6, P<0.05$ ).

\section{Proliferating cell nuclear antigen expression}

Figure 6 shows changes in cell proliferation in the white matter tracts assessed by PCNA immunohistochemistry. There were abundant PCNA labeling cells in sham control animals. Ischemia was associated with a significant reduction in the number of PCNA labeling cells compared to sham control $(P<0.05)$. The number of PCNA labeled cells was not significantly different between sham cooling (ischemia) and the two cooling groups.

\section{Discussion}

The present study demonstrates that moderate, delayed cerebral hypothermia is associated with potent, delaydependent suppression of postischemic cerebral demyelination in the near-term fetal sheep. Moderate hypothermia was begun 90 minutes after reperfusion (2-hour cooling group) and continued until 3 days after insult, and was associated with greater oligodendrocyte survival and myelin density and with reduced tissue edema in the parasagittal white matter tracts when evaluated 5 days after the ischemic insult. Oligodendrocyte protection was lost when initiation of cooling was delayed until 5.5 hours after reperfusion. The effects of hypothermia were strongly associated with suppression of both activated caspase-3 expression and the microglial reaction. 
Figure 7. Photomicrograph showing an example of caspase-3positiwe staining (brown) in the intragyral white matter tracts after cerebral ischemia in the near-term fetal sheep. Note the nuclear condensation within the caspase-3 (Asp 175).positiwe cells and coarse granular fragments of caspase-positive material around the cells.

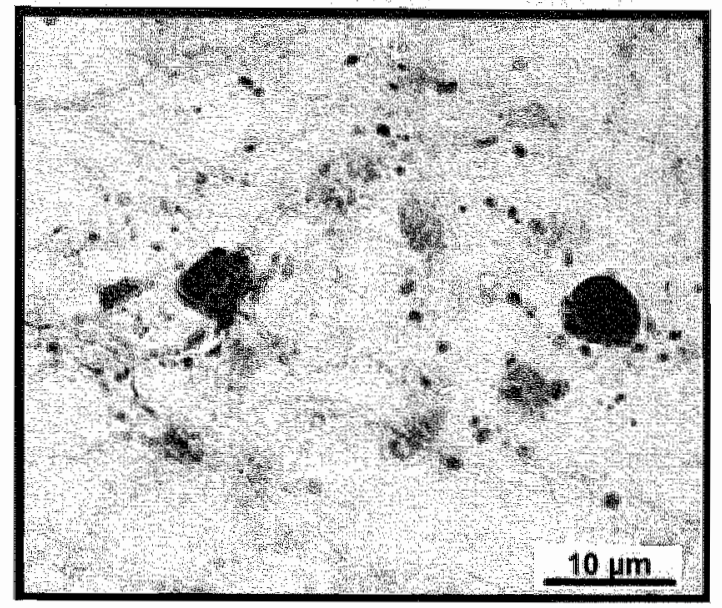

Proteolipid protein (PLP) gene expression has been used as a sensitive marker to detect bioactive oligodendrocytes at the translation stage of myelination (Guan et al., 2001; Mandai et al., 1997). Expression of PLP in the central nervous system is classically reported only in differentiated, myelinating oligodendrocytes, although trace amounts may be found earlier in development (Schindler et al., 1990). in vitro and in vivo evidence now clearly demonstrate that both mature and immature oligodendrocytes are exquisitely vulnerable to hypoxicischemic injury (Back et al., 2001; Pantoni et al., 1996; Skoff et al., 2001). Although in vitro myelinating oligodendrocytes are reported to be relatively resistant to excitotoxicity compared to immature oligodendrocytes (Rosenberg et al., 2003), there is increasing evidence that white matter injury is also a significant contributor to neurodevelopmental disability after hypoxic-ischemic encephalopathy at term (Mercuri et al., 1999; Okumura et al., 1997; Rutherford et al., 1998). Because cooling is already being tested clinically as a potential neuroprotective treatment for newborn infants exposed to perinatal asphyxia (Gunn et al., 1998a; Shankaran et al., 2002), it is important to ascertain whether cooling is effective in reducing white matter loss at term.

We have previously reported, in the same experimental model as the present study, that improved neuronal loss and electrophysiologic recovery with cerebral hypothermia are dependent on the timing of initiation of cooling after reperfusion. There is dramatic improvement if moderate cooling is initiated within a few hours of severe ischemia (Gunn et al., 1997), but only partial protection if cooling is delayed until 6 hours from the start of ischemia ( 5.5 hours after reperfusion) (Gunn et al., 1998b). Clinically, the development of seizures in the recovery period after asphyxia is one of the major prognostic factors associated with an adverse outcome (Caravale et al., 2003), and most clinicians would prefer to treat only infants who demonstrate seizures. However, experimentally, when cooling was delayed until after seizures were established ( 8.5 hours after reperfusion), there was no electrophysiologic or overall histologic improvement (Gunn et al., 1999).

These studies demonstrated the importance of starting cooling during the latent phase of recovery (approximately the first $\sigma$ hours in this paradigm), before the phase of secondary deterioration with seizures and cytotoxic edema (Gunn et al., 1999). This finding supports the hypothesis that there are events during early recovery, well after resolution of the insult itself, which contribute significantly to the final severity of injury. The present data show that hypothermia is associated with an even more acute time dependence for improvement in oligodendrocyte loss than for neuronal loss, such that 
cooling delayed by 5.5 hours after reperfusion did not improve numbers of oligodendrocytes after 5 days recovery. Thus, the current study further highlights the considerable importance of early initiation of cooling for cerebral protection.

The mechanisms of this rapid loss of protection of both oligodendrocytes and neurons with hypothermia with increasing delay are unclear. One potential mechanism is the timing of induction of caspase-mediated cell death. in vitro, cytoplasmic activation of caspases occurs in the latent phase, before the active or "execution" phase of programmed cell death involving intranuclear mechanisms (Samejima et al., 1998). Apoptotic pathways are suggested to have a relatively more important role in ischemic brain damage in the neonate compared to the adult (Hu et al., 2000), particularly in mediating posthypoxic loss of oligodendrocytes (Shibata et al., 2000). Similarly, we have reported that ischemia in the near-term fetal sheep leads to a marked increase in cells expressing activated caspase3 , and that this colocalized exclusively with PLP mRNA expression (Cao et al., 2003).

Several studies have suggested that hypothermia acts to reduce morphologic apoptotic cell loss in the neonatal brain (Edwards et al., 1995; Xu et al., 1998). Supporting this concept, mild hypothermia can reduce mitochondrial cytochrome $\mathrm{C}$ translocation, a critical step in the intrinsic pathway of apoptosis (Xu et al., 2002; Yenari et al., 2002), and has been shown to suppress expression of caspase3 both after hypoxia-ischemia in vivo (Fukuda et al., 2001; Tomimatsu et al., 2001) and serum deprivation in vitro (Xu et al., 2002). Consistent with these results, the present study confirms a significant time of initiation-dependent suppression by hypothermia of postischemic activated caspase3 in the cerebral white matter.

However, quantitatively, caspase-3 expression after 5 days' recovery can only account for a minority of oligodendrocyte cell loss, with a relatively low density of caspase-positive cells observed relative to the extent of loss of PLP-labeled cells. Speculatively, this discrepancy is likely related to the timing of histologic evaluation, with the preponderance of activation of caspases occurring much earlier after ischemia (Northington et al., 2001). A recent study has demonstrated that in the early stages of the development of cerebral necrosis, neurons display a number of features of early apoptosis, including cytoplasmic and nuclear condensation and specific caspase activation (Benchoua et al., 2001). Furthermore, in addition to caspase-mediated mechanisms, caspase independent apoptotic pathways, such as apoptosis inducing factor, contribute to delayed cell death and to necrotic processes (Leist and Jaattela, 2001; SanchezGomez et al., 2003). Often, more than one of these pathways seem to be activated simultaneously, and cell fate is then determined by the relative speed of each process (Leist and Jaattela, 2001).

Alternatively, suppression of secondary inflammatory processes after hypoxic-ischemic insults may be an important mechanism of protection with hypothermia. There is considerable evidence that such processes, including induction of activated microglia with subsequent release of proinflammatory cytokines, contribute to both evolving neuronal and white matter injury (Silverstein et al., 1997). Cytokines exacerbate brain injury through various pathways including direct neurotoxicity and induction of apoptosis or by promoting stimulation of capillary endothelial cell proinflammatory responses and leukocyte adhesion and infiltration into the ischemic brain (Mallard et al., 2003; Silverstein et al., 1997].

However, the role of microglia in the brain is complex. Under physiologic conditions, microglia may actually help promote oligodendrocyte survival (Nicholas et al., 2003; Rabchevsky and Streit, 1997), but once activated, microglia induce contact-dependent oligodendroglial death in vitro (Nicholas et al., 2003!. Thus, the present finding that early postischemic hypothermia profoundly reduced microglial induction suggests that this may be a significant contributor to improved oligodendrocyte survival. The effect on microglia was specific, because there was no effect of hypothermia on numbers of astrocytes. Clearly this effect could be either primary, or secondary to reduced cell. loss and local. 
tissue damage, leading to a reduced stimulus to further microglial induction. The markedly reduced effect of late cooling on microglia closely paralleled the loss of effect on oligodendrocyte numbers, despite an identical period of recovery after rewarming to the early cooling group. This time dependence strongly suggests a significant secondary element.

Nevertheless, there is good evidence that postischemic cooling directly suppresses the inflammatory reaction. in vitro, hypothermia potently inhibits proliferation and superoxide and nitric oxide (NO) production by cultured microglia (Si et al., 1997), with a greater effect on inducible NO production than on other sources (Gibbons et al., 2003). Similarly, to the present study, postischemic hypothermia delays microglial activation after transient focal ischemia in the adult rat (Inamasu et al., 2000). Thus, a direct effect of early cooling on microglia cannot be ruled out. It is striking that in the present study, late cooling in the 6-hour group was associated with reduced tissue swelling and with substantial preservation of myelin, despite no significant effect on numbers of oligodendrocytes. This raises the possibility that a major effect of suppression of microglial induction by hypothermia may not have been on cell survival per se, but rather to reduce local effects of microglia on the extracellular matrix and degradation of myelin.

The present findings that early initiation of cerebral cooling improved oligodendrocyte survival with reduced microglial activation and reduced total proliferation provide an interesting contrast with our previous report that early IGF-1 treatment also improves oligodendrocyte survival, but with significantly increased glial. induction and overall proliferation [Cao et al., 2003]. This difference is consistent with in vitro data showing that hypothermia acts to broadly suppress the cell death program (Bossenmeyer-Pourie et al., 2000), whereas IGF-1mediated receptor activity actively initiates cellular programs including anti-apoptotic pathways and proliferation (Mason et al., 2000; McMorris et al., 1986). The changes in proliferation, as measured by PCNA immunohistochemistry, are consistent with this interpretation. In the control group there was abundant PCNA expression in the white matter tracts, which was markedly reduced after ischemia. Given the severity of cell death, it is likely that the residual proliferation in the sham cooling (ischemia) group reflected almost entirely microglia. In contrast, the persistent reduction in PCNA expression after hypothermia despite increased oligodendrocyte survival must reflect general suppression of glial proliferation (Lee et al, 2002), not just microglia (Si et al., 1997).

Finally, evolving neuronal and white matter injury may extend for longer than the 5-day recovery from ischemia in the present study (Geddes et al., 2001). The continued presence of activated caspase-3 at this time also suggests ongoing injury, and thus it is possible that the observed white matter protection will reduce over time. Nevertheless, there was markedly reduced caspase- 3 expression as well as greater oligodendrocyte survival in the 2 -hour group 48 hours after rewarming, suggesting a reduction in ongoing damage. Consistent with this, in adult rodents persistent neuronal protection with hypothermia has been found 2 to 6 months after ischemia (Colboume and Corbett, 1995; Corbett et al., 2000), although clearly further longer term outcome studies are necessary to confirm the present findings.

\section{CONCLUSION}

Prolonged moderate cerebral hypothermia can prevent postischemic white matter damage in the nealterm fetal sheep, but there is rapid attenuation of this effect with increasing delay in the initiation of cooling. Furthermore, hypothermic white matter protection was closely associated with reduced activation of both caspase-3 and microglia. These data strongly support the critical importance of early initiation of cooling in clinical trials. 
chapter 5 


\section{REFERENCES}

Back SA, Luo NL, Borenstein NS, Lewine JM, Volpe J], Kinney HC (2001I Late oligodendrocyte progenitors concide with the developmental window of vunerability for human perinatal white matter ingury. Neurosct $21: 1302-1312$

Barkovich A), Westmark $\mathrm{R}$, Partridge C, Sola A, Ferriero DM(1995) Perinatal asphyxia: MR findings in the first 10 days. ANR Am/Neuroradiol 16:427-438

Benchoua A, Guegan C, Couriaud C, Hosseini H, Sampaio N, Morin D, Onteniente B (2001) Specific caspase pathways are activated in the two stages of cerebral infarction. J Newrosct $21: 7127-7134$

Bernard SA, Gray TW, Buist MD, Jones BM, Silvester W, Gutteridge G, Smith K (2002) Treatment of comatose survivors of out-ohospital cardiac arrest with induced hypothermia. $N$ Engl / Med $346.557-503$

Bossenmeyer-Fourie C, Koziel V, Daval JL (2000) Effects of hypothermia on hypoxia-induced apoptosis in cultured neurons from developing rat forebrain: Comparison with preconditioning. Pediatr Res 47:385-391

Cao Y, Gunn AJ, Bennet L, Wu D, George S, Gluckman PD, Shao XM, Guan I (2003) Insulin-like growtl factor [IGF]-1 suppresses oligodendrocyte caspase-3 activation and increases glial proliferation after ischemia in nearterm fetal sheep. J Cereb Blood Fow Metab 23:739-747

Caravale B, Allemand F, Libenson MH (2003) Factors predictive of seizures and neurologic outcome in perinatal depression. Pediatr Neurol 29:18-25

Colbourne F, Corbett D (1995) Delayed postischemic hypothermia: A six month survival study using behavional and histological assessments of neuroprotection. / Neurosci 15:7250-7260

Corbett D, Hamiliton M, Colboume F (2000) Persistent neuroprotection with prolonged postischemic hypothermia in adult rats subjected to transient middle cerebral artery occlusion. Exp Neurol 163:200-200

Edwards AD, Yue X, Squier MV, Thoresen M, Cady EB, Penrice I, Cooper CE, Wyati JS, Reynolds EO, Mehmet H (1995) Specific inhibition of apoptosis after cerebral hypoxia-ischaemia by moderate post-insult hypothemia. Biochem Biophys Res Commun 217: 1193-1199

Edwards AD, Yue X, Cox P, Hope PL, Azzopardi DV, Squier MV, Mehmet H [1997) Apoptosis in the brains of infants suffering intrauterine cerebral injury. Pediatr Res 42:684-689

Fukuda H, Tomimatsu T, Watanabe N, Wu M, Konzuki M, Endo M, Fuli E, Kanzaki T, Murata Y (2001) Postischemic hypothermia blocks caspase-3 activation in the newborn rat brain after hypoxiaischemia. Brain Res 910:187 -191

Geddes R, Vannucci RC, Vannucci S) (2001) Delayed cerebral atrophy following moderate hypoxiatischemia in the immature rat. Dev Neurosci $23: 180-185$

Gibbons H, Sato TA, Dragunow M (2003) Hypothemia suppresses inducible nitric oxlde synthase and silmulates cyclooxygenase-2 in lipopolysaccharide stimulated bw-2 cells. Mol Bain Res 110:63-75

Guan J, Gunn AI, Sirmame ES, Tuffin I, Gunning M1, Clark R, Gluckman PD (2000) The window of opportunty for neuronal rescue with insulin-like growth factor-I after hypoxia-ischemia in rats is critically modulated by cerebral temperature during recovery. I Cereb Blood How Metab 20:513-519

Guan I, Bennet L, George S, Wu D, Waldvogel HJ, Guckman PD, Faull RL, Crosier PS, Gurn AJ (2001) Insulinlike growh factor-l reduces postischemic whie matter injury in fetal sheep. / Cereb Blood Flow Metab 21:493-502

Gunn A, Gunn TR, de Haan HH, Willams CE, Giuckman PD (1997) Dramatic neuronal rescue with prolonged selecture head cooling after ischemia in fetal lambs. J Clin /nvest 99.248-256

Gunn A), Gluckman PD, Gunn TR (1998a Selective head cooling in newbom infants after perinatal asphyxia: A safety study. Pediatrics $102: 885892$

Gunn A., Gunn TR, Gunning M1, Williams CE, Gluckman PD (1998b) Neuroprotection with prolonged head cooling started before postischemic seizures in fetal sheep. Pediatics 102:1098-1106 
Gumn Al, Bennet L, Gumning MI, Gluckman PD, Gunn TR ( 1990 ) Cerebral hypothermia is not neuroprotective When started after postischemic seizures in fetal sheep. Pediatr Res 46:274-280

Gunn AJ, Bennet L. (2002) Hypothemia in the management of hypoxic-ischemic encephalopathy. NeoReviews $3: e 116-e 122$

Hagberg H, Peebles D, Mailard C (2002) Models of white matter injury: Comparison of infectious, hypoxicischemic, and excitotoxic insults. Ment Retard Dev Disabil Res Rev 8:30-38

Hu BR, Liu CL, Ouyang Y, Blomgren K, Siesjo BK (2000) Involyement of caspase-3 in cell death after hypoziaischemia declines during brain maturation. J Cereb Blood Flow Metab 20:1294-1300

Ikeda T, Murata Y, Quilligan EJ, Choi BH, Parer JT, Doi S, Park SD (1998) Physiologic and histologic changes in nearterm fetal lambs exposed to asphyxia by partial umbilical cord occlusion. Am / Obstet Gynecol $178: 24-32$

Inamasu J, Suga S, Sato S, Horiguchi T, Akaji K, Mayanagi K, Kawase T (2000) Post-jschemic hypothermia delayed neutrophil accumulation and microglial activation following transient focal ischemia in rats. J Neurommunol $109: 66-74$

Inamasu ], Nakamura Y, Ichikizaki K (2003) Induced hypothermia in experimental traumatic spinal cord injury: An update. INeurol Sci 209:55-60

Inder TE, Huppi PS, Warfield S, Kikinis R, Zientara GP, Barnes PD, Jolesz F, Volpe JJ (1999) Periventricular white matter injury in the premature infant is followed by reduced cerebral cortical gray matter volume at term. Ann Neurol 46:755-760

Johnson MD, Kinoshita Y, Xiang H, Ghatan S, Morrison RS (1999) Contribution of p53-dependent caspase activation to neuronal cell death deciines with neuronal maturation. I Neurosci 19:2996-3006

Lee KS, Lim BV, Jang MH, Shin MC, Lee TH, Kim YP, Shin HS, Cho SY, Kim H, Shin MS, Kim EH, Kim Cl (2002) Hypothermia inhibits cell proliferation and nitric oxide synthase expression in rats. Neurosci Lett 329:53-56

Leist $M$, Jaattela M (2001) Four deaths and a funeral: From caspases to alternative mechanisms. Nat Rev Mol Cell Biol $2.589-598$

Loeliger M, Watson CS, Reynolds JD, Penning DH, Harding R, Bocking AD, Rees SM (2003) Extracellular glutamate levels and neuropathology in cerebral white matter following repeated umbilical cord occlusion in the near term fetal sheep. Neuroscience 116:705-

Mallard $\mathrm{C}$, Welin AK, Peebles D, Hagberg $\mathrm{H}$, Kjellmer I (2003) White matter injury following systemic endotoxemia or asphyxia in the fetal sheep. Neurochem Res 28:215-223

Mandai K, Matsumoto $M_{3}$ Kitagawa K, Matsushita K, Ohtsuki T, Mabuchi T, Colman DR, Kamada T, Yanagihara T (1907) Ischemic dariage and subsequent proliferation of oligodendrocytes in focal cerebral ischemia. Neuroscience 77:849-861

Mason JL, Ye P, Suzuki K, D'Ercole A], Matsushima GK (2000) Insulin-like growth factor 1 inlibits mature oligodendrocyte apoptosis during primary demyelination. / Neurosci 20:5703-5708

Mclntosh GH, Baghurst KI, Potter BJ, Hetzel BS (1979) Fetal brain development in the sheep. Neuropathol Appl Neurobiol $5: 103-114$

McMorris FA, Smith TM, DeSalvo S, Furlanetto RW (1986) insulinlike growth factor $1 /$ somatomedin C: A potent inducer of oligodendrocyte development. Proc Natl Acad SCi USA 83:822-826

Mercuri E, Guzzetta A, Haataja L, Cowan F, Rutherford M, Counsel S, Papadimitriou M, Cioni G, Dubowitz L (1999) Neonatal neurological examination in infants with hypoxic ischemic encephalopathy: Correlation with MRI findings. Neuropediatrics 30:83-89

Nicholas R, Stevens $\$$, Wing M, Compston A (2003) Oligodendroglialderived stress signals recruit microglia in vitro. Neuroreport ] 4: 1001-1005

Northington F, Ferriero DM, Flock DL, Martin U (2001) Delayed neurodegeneration in neonatal rat thalamus after hypoxia-ischemia is apoptosis. INeurosci 21:1931-1938. 
Okumura A, Hayakawa F, Kato T, Kuno K, Watanabe K (1907] MRI findings in patients with spastic cerebal palsy. 1: Correlation with gesiational age at bith. Dev Med Chlo Neurol 39:363-368

Pantoni L, Garcia JH, Gutierrez JA (1996) Cerebral white matter is highty vulnerable to ischemua. Stroke $27: 1641-1046$

Petersson KH, Pinar H, Stopa EG, Faris RA, Sadowska CB, Hanumara RC, Stonestreet BS (2002) White matter injury after cerebral ischemía in ovine fetuses. Pediatr Res 51:768-776

Rabchevsky AG, Streit WJ (1997) Grafting of cultured microglial cells into the lesioned spinal cord of adult rats enhances neurite outgrowth. I Neurosci Res 47:34-48

Rosenberg PA, Dai W, Gan XD, Ali S, Fu J, Back SA, Sanchez RM, Segal MM, Follet PL, Jensen FE, Volpe IJ (2003) Mature myelin basic protein-expressing oligodendrocytes are insensitive to kainate toxicity. / Neurosc: Res 71:237-245

Rutherfond MA, Pennock IM, Counsel SJ, Mercuri E, Cowan FM, Dubowitz LMS, Edwards AD 119981 Abnomal magnetic resonance signal in the internal capsule predicts poor neurodevelopmental outcome in infants with iypoxic-ischemic encephalopathy. Pediatrics 102:323-328

Samejima $K$, Tone S, Kotke TH, Enari M, Sakahira H, Cooke CA, Durrieu F, Martins LM, Nagata S, Kaufmann SH, Earnshaw WC (1998) Transition from caspase-dependent to caspase-independent mechamisms at the onset of apoptotic execution. / Cell Biol 1 $43: 225-239$

Sanchez-Gomez MV, Alberdi $\mathbb{E}$, lbarretxe C, Torre I, Matute C 12003$\}$ Caspasedependent and caspase independent oligodendrocyte death mediated by AMPA and kainate receptors. / Neurosci 23: 9519-9528

Schindler P, Luu B, Sorokine O, Trifilieff E, Van Dorsselaer A 11900 ] Developnental study of proteolipids in bovine brain: A novel proteolipid and DM-20 appear before proteolipid protein (PLP) during myelination. I Neurochem 55:2079-2085

Scott R], Hegyi L [1997] Cell death in perinatal hypoxic-1schemic brain injury. Neuropathol Appl Neurobio 23:307-314.

Shankaran S, Laptook A, Wrighl LL, Ehrenkranz RA, Donowan EE, Fanarolf AA, Stark AR, Tyson JE, Poote R, Carlo WA, Lemons JA, On W, Stoll BI, Papile LA, Bauer CR, Stevenson DK, Korones SB, McDonald S (2002) Wholebody hypothermia for neonatal encephalopathy: Animal observations as a basis for a randomized, controlled. pilot study in tem infants. Pediatrics 110:377-385

Shibata M, Hisahara S, Hara H, Yamawaki T, Fukuuchi Y, Yuan J, Okano H, Mura M (2000) Caspases determine the vulnerability of oligodendrocytes in the ischemic brain. / Chin Invest 106:643-653

Si QS, Nakamura Y, Kataoka K (1997) Hypothermic suppression of microglial activation in culture: Inhibition of cell proliferation and production of nitric oxide and superoxide. Neuroscience $31: 223-229$

Siverstein FS, Barks ID. Hagan P, Liu XH, Ivacko J, Szaflarsk I (1997) Cyrokines and perinatal brain injury. Newochem Int $30: 375-383$

Skoff RP, Bessert DA, Barks JD, Song D, Cerghet M, Siverstein FS (200 1 j Hypoxic-ischemic trjury results in acute disuption of myelin gene expression and death of oligodendroglial precursors in neonatal mice. Int f Dev Newrosci 19:197-208

The Hypothermia after Cardiac Arrest Sudy Group (2002) Mild therapeutic hypothemia lo improve the neurologic outcome after cardiac arrest. N Engl/ Med 346.549-550

Tomimatsu T, Fukuda H, Endo M, Watanabe N, Mu J, Konzuki M, Fuji E, Kanzaki T, Murata Y (2001) Effects of hypothermia on neonatal hypoxic-ischemic brain injury in the rat: Phosphorylation of Akt, activation of caspase-3-like protease. Neurosct Lett $312: 21-24$

Tooley JR, Satas S, Porter H, Silver LA, Thoresen M (2003) Head cooling with mild systemic hypothermia in anesthetized pigles is neuroprotective. Ann Neurol $53: 65-72$

Wang G), Deng HY, Maier CM, Sun GH, Yenari MA (2002) Mild rypothermia reduces ICAM-I expression, netrophil inflitration and microglia/monocyte accumulation following experimental stroke. Neuroscience $114: 1081-1090$ 


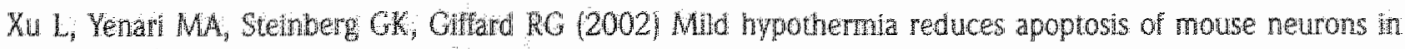
vitro early in the cascade. I Cereb Blood Flow Metab 22:21-28

Xu RX, Nakamura T, Naga S, Myanoto O, Jin L, Toyoshina T, Itano T (1098) Specific inhibition of apoptosis after coldinduced brain injury by moderate posinjury hypothemia. Neurosurgery 43:107-114

Yenar MA, lwayama S, Cheng D, Sun GH, Fujmura M, Morita-Fuinura Y, Chan PH, Steinberg GK (2002) Mild hypothemia attenuates cytochrone crelease but does not alter $\mathrm{BCl}-2$ expression or caspase activation after experimental stroke. J Cereb Blood Flow Metab 22:29-38

Zhu C, Oiu L, Wang $\mathrm{X}$, Hallin U, Cande $\mathrm{C}$, Kroemer $\mathrm{G}$, Hagberg H, Blomgren K (2003) Inwolvement of apoptosisInducing factor in neuronal death after hypoxia-ischenia in the neonatal rat brain. I Neurochem $86: 300-317$ 
Window of opportunity of cerebral hypothermia for postischaemic white matter injury 


\section{CHAPTER 6}

THE GROWTH HORMONE

AND INSULIN-LIKE

GROWTH FACTOR AXIS:

ITS MANIPULATION

FOR THE BENEFIT

OF GROWTH DISORDERS

IN RENAL FAILURE.

Joumal of the American Society of Nephrology 2001: 12 101 1297-1300.

Roelfsema V, Clark RG.

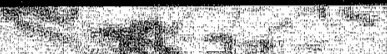


ABSTRACT.

Renal fallure is associated with dramatic changes in the growth hormone/insulin-like growth factor (GH/IGF) axis. In children, this results in growth retardation, which is treated with injections of recombinant human $\mathrm{GH}(\mathrm{rhGH})$. Given the many recent advances in the knowledge of the components of the GH/IGF axis, it is timely to review the role of GH in renal failure and to discuss likely new treatments for growth failure. Renal failure is not a state of $\mathrm{GH}$ deficiency but a state of $\mathrm{GH}$ and IGF resistance, making other approaches to manipulating the GH axis more logical than treatment with rhGH alone. Although in children rhGH is safe, in critically ill adults it can be lethal. As the mechanisms of these lethal actions of rhGH are unknown, caution is advised when using rhGH outside approved indications. In renal failure, an optimal balance between safety and efficacy for growth may be achieved with the use of the combination of rhGH and rhiGF-I, as animal studies have shown synergistic growth responses. However, inhibition of the GH axis, with the use of $\mathrm{GH}$ antagonists, is likely to be tested clinically given the beneficial effects of $\mathrm{GH}$ antagonists on renal function in animal models of renal disease. Manipulating IGF-I by either administering rhIGF-1 or its binding proteins or Increasing IGFI bioavallability with the use of IGF displacers could prove to be a safer and more effective iltematwe to the use of rhGH in renal sailure. In the future, both rhGH and rhIGF-1 likely will be included in growth-promoting hormone cocktails tailored to correct specific growth disorders:

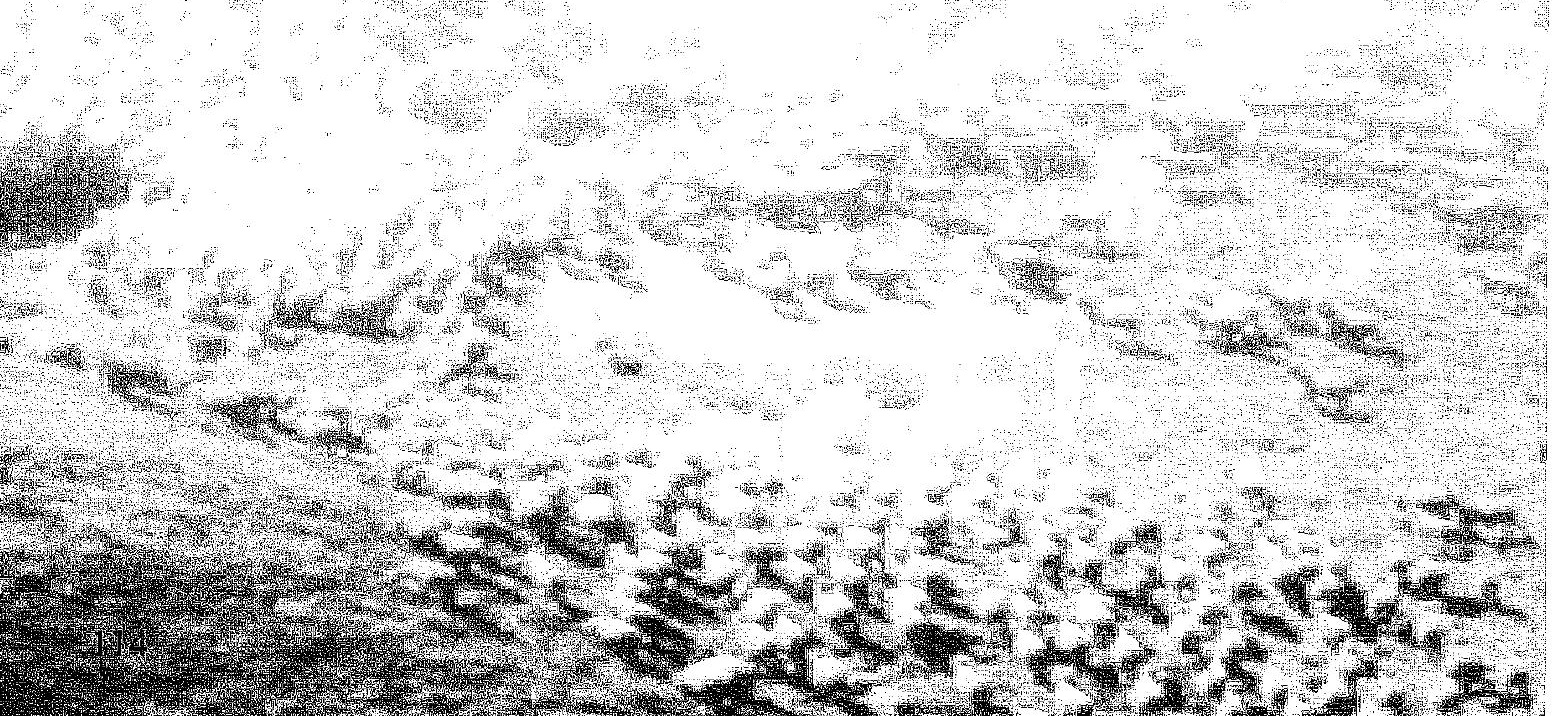




\section{INTRODUCTION}

Chronic renal failure (CRF) is associated with many severe metabolic and homonal derangements, inciuding alterations in the growth hormone/insulin-like growth factor. [GH/IGFI] axis, which is an important contributor to the growth disorders of renal failure. This review focuses on recent discoveries and insights into the GH/IGF axis and examines potential novel treatment modalities for renal-related growth disorders.

\section{Normal Regulation of the GH Axis}

The GH/IGF axis is a key endocrine modulator of postnatal growth and metabolism (Figure 1). The normal regulation of the axis is well understood as are some of the disruptions induced by renal failure. The axis involves the peripheral effector peptide hormones GH, IGF-I, and IGF-II and a regu-latory feedback loop (reviewed in references 1-3).

$\mathrm{GH}$ is secreted by the anterior pituitary gland in a pulsatile manner under the acute stimulatory effects of the hypothalamic peptide GH-releasing hormone [GHRH] and the inhibitory effects of somatostatin. The recent discovery of ghrelin, a naturally occurring GH-releasing peptide (GHRP) that is expressed in both the stomach and the hypothalamus and is present in the blood of rats and humans, suggests that this molecule is involved in the hormonal regulation of GH release (4). The presence of ghrelin in the stomach suggests that it may play a role in the nutritional regulation of the $\mathrm{GH} / \mathrm{GF}$ axis. However, many hormones affect $\mathrm{GH}$ release, including insulin, so the true functions of gut ghrelin remain to be determined.

Once GH is released from the pitultary gland, it circulates in the blood to increase IGF-I production in many tissues, leading to a rise in blood IGF-I, which provides a long-term inhibition of further pituitary GH secretion (2). Similarly, the adminis-tration of IGF-1 reduces GH secretion; conversely, genetically engineered IGF-I null mutant mice show markedly increased GH secretion (5).

\section{GH and IGF-I Physiology}

In the 1970s and 1980s, the somatomedin hypothesis proposed that IGF-I (formerly termed somatomedin C) mediated all of the effects of GH (1). Liver.generated IGF-I, the major contributor to IGF-I levels in the blood, was proposed to be crucial to the growth-promoting actions of GH. However, IGF-I is produced by many tissues of both epithelial and mesenchymal origin during both fetal and adult life [6]. Because $\mathrm{GH}$ receptors occur in many tissues and some of the effects of $\mathrm{GH}$ do not involve the generation of IGF-I, it was necessary to modify the somatomedin hypothesis. It was proposed, therefore, that GH could act directly on many tissues, including cartilage and kidney, and produce IGF-I Jocally (7).

Recent studies in knockout mice have supported this modified hypothesis. As predicted by the somatomedin hypothesis, IGF-I $-/-$ knockout mice are dramatically growth retarded (8). Depending an their genetic background, up to $95 \%$ of IGF-I - - dwarl mice die shortly after birth. Knockout mice that do survive show a markedly reduced growth rate compared with wild-type mice and have an adult weight of approximately $30 \%$ of normal (8). In contrast, liver-specific (Cre/loxP) JGF-l knockout mice, in which only liver-generated [GF.] is reduced, have low blood levels of IGF-] but are viable and show normal growth (9).

This result was surprising given the belief that liver-generated endocrine IGF-l is important for body growth. GH supplementation in mice in which IGF-I is knocked out in all tissues does not increase growth (5). These studies suggest that although IGF-I is essential for normal postnatal body growth, liver-generated circulating IGF-I is not crucial for normal growth. In contrast, these experiments show 
the importance of local $\mathrm{GH}$ actions and/or IGF-I production, for example on bone growth (Figure 1). It is possible that liver-specific IGF-I knockout mice grow normally because the bioactivity of IGF-I in the blood is unchanged, despite that total levels of circulating IGF-I are decreased markedly. Conversely, the high GH levels in these mice argues for a reduced bioactivity of blood IGF-I.

In blood, approximately 97\% of the IGF are bound to six IGF-binding proteins (IGFBP-1 to IGFBP-6), with the remaining IGF-I either in a bioactive-free fraction (approximately $1 \%$ ) or in an easily dissociable form (10). Most IGF-I in the circulation is bound in a 150-kD complex of IGF-I, IGFBP-3 and a third protein, the acid-labile subunit. This ternary IGF complex is a storage form of IGF in blood and has a half-life of several hours (1). The binding of IGF-II to IGFBP limits the bioactivity of IGF-1, as bound IGFI probably cannot activate the IGF-I receptor.

Figure 1. The somatotropic axis. The synthesis and release of growth homnone (GH) from the pituitary are controlled by the hypothalamic hoirnones GH.releasing hormone (GHRH) and somatostatin (SRIV), which in turn are regulated by leedback (dashed ines) from blood GH and insulin-like growti lactor-\| (KF-l) concentations. The recently discovered endogenous GH-releasing peptide, called ghrelin, also stimulates $\mathrm{GH}$ release. Circulating GH acts drecty on many organs to stimulate IGF-I production, with IGF-I production in the liver providing the main sounce of blood IGF-I. Most of the IGF In the circulation is bound to IGF-binding protein-3 (IGFBP-3) in a ternary complex with acid-lablle subunit (ALS): a smaller flaction is bound to the five other

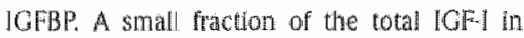
blood is in bioactive free fraction. Iti the kidney, IG increases remal plasma flow and GFF, wheteas on bone It acts on the eplphysial phate, which leads to longitudinal bone growti. As illustrated. Gitt also has direct effects on many organs, including kiney and cartilage, which can be independent of IGF-I action.

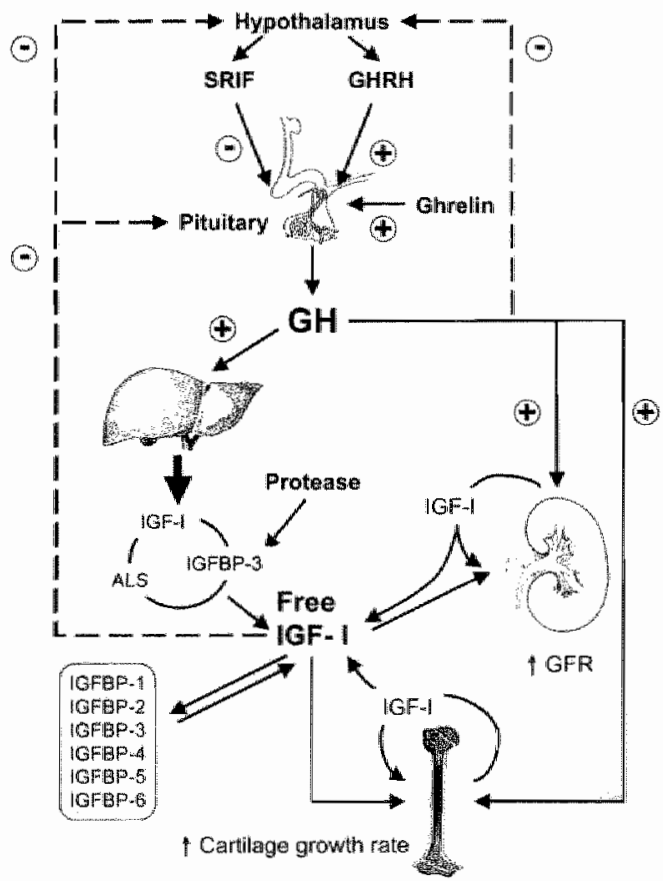

"This inlibition of bioactivity, especially that by IGFBP-1 and -2 , has been shown in several experiments; for example, the administration of IGFBP-I blocks the effects of both GH and IGF-I on body growth 111 , and IGFBP-1 and IGFBP-2 transgenic mice are growth retarded yet have nomal total IGF-I concentrations in blood (12). Therefore, in renal fallure, IGF I bioactivity in blood is probably low as citculating concentrations of IGFBP-1 and -2 are elevated (13,14). 


\section{GH/IGF Axis and the Kidney}

The GH/IGF/IGFBP system is present in the kidney and is important to kidney structure and function. GH receptors are expressed in proximal tubules and thick ascending limb, whereas IGF.I receptors are found predominantly in the glomerulus and proximal and distal tubules (15). Both GH and IGF. increase renal plasma flow and GFR. These effects of GH are likely to be mediated by IGF-I, as IGF-I increases these parameters within minutes to hours, whereas the effects of $\mathrm{GH}$ are delayed until IGF-I levels rise (15).

The role of IGF.I in renal development is thought to be minor as general kidney morphology of complete IGF-I $-/-$ mice is normal (16). It is of interest to produce a kidney-specific IGF-I deletion, as it would show the relative importance of local IGF.I to kidney growth and function. Targeted gene deletion in the kidney now is feasible (17). Furthermore, in such an IGF-deleted mouse, recovery from renal injury would be of particular interest.

Although most actions of GH are mediated by IGF-I, and GH and IGF-I share several activities, there are actions of GH and IGF-I that are very different. For example, mice that are transgenic for IGF-I develop glomerular hypertrophy, whereas mice that are transgenic for $\mathrm{GH}$ develop glomerular sclerosis (18). Therefore, on the kidney, GH and IGF-I can have quite different actions.

\section{Cancer Risk}

Epidemiologic studies have associated the IGF axis as a risk factor for several common cancers. Multiple prospective case-control studies have found that elevated serum IGF-1 levels and low IGFBP-3 levels are associated with an increased risk of prostate, colorectal, breast, and lung cancers $(19,20)$. It is important to note that a causal role of IGF-I in the pathogenesis of cancer has not been established and that the interpretation of these new data are the subject of much debate.

\section{Fetal Programming, GH/IGF, and the Kidney}

Large epidemiologic studies have found a strong correlation between low birth weight and the subsequent incidence of obesity, diabetes, hypertension, and renal disease during aduit life (the so-called Barker hypothesis) (21). There also is evidence that intrauterine growth restriction (IUGR) results in aitered programming of the GH/IGF system, altered programming of the renin-angiotensin system, and/or altered gene expression, causing abnormal renal and cardiovascular physiology $(22,23)$. Renal abnormalities include structural changes such as a low nephron count, which eventually may underlie the development of adult hypertension $(23,24)$.

Abnormalities in the GH/IGF axis have been associated with growth failure after IUGR and also could lead to the above-described long-term health sequelae. It remains to be established whether therapeutic interventions after IUGR aimed at deprogramming the GH/IGF axis or other regulatory systems early in life will affect the long-term outcomes of metabolic, cardiovascular, and renal disease.

\section{Changes in GH, IGF, and IGFBP during Renal Failure}

CRF is associated with several derangements in the GH/IGF/ IGFBP axis (Figure 2), including in children an increased pulsatile release of $\mathrm{GH}$ and reduced metabolic clearance rate of $\mathrm{GH}$, resulting in a rise in circulating GH concentrations $(25,26)$. This should result in high IGF-I concentrations, but in uremia IGF-I synthesis in the liver is reduced, which results in normal concentrations of circulating 
Figure 2. Deranged somatotroplc axis in chronic renal pallure. The GH/IGFI axis in chronic renal Ballure (CRF) is changed markedly compared with the nomal axis, shown in figure 1 . In CRE, the fotal concentrations of the hormones in the GH/GFI axis are not reduced, but thete is reduced effectiveness of endogenous $\mathrm{CH}$ and ICF-1, which probably plays a mafor role in reducing linear bone growh. The reduced effectiveness of endogenous IGF likely is due to decreased levels of free, bloactive IGF as levels of circulaing inhibitory IGFBP are increased. In addition, less 1Gf-I is circulating in the corplex whth ALS and IGFBP-3 as a result of increased proteolysis of IGFBP-3. Togethen, these lead to decreased IGFI receptor activation and a decreased feedback to the hypothalamus and pituitary. Low free IGF.I and high IGEBP.I and 2 levels probably contribute to a reduced renal function and lead to a reduced stature. The direct effects of $\mathrm{GH}$ on bone, which are poorly understood, also are blunted.

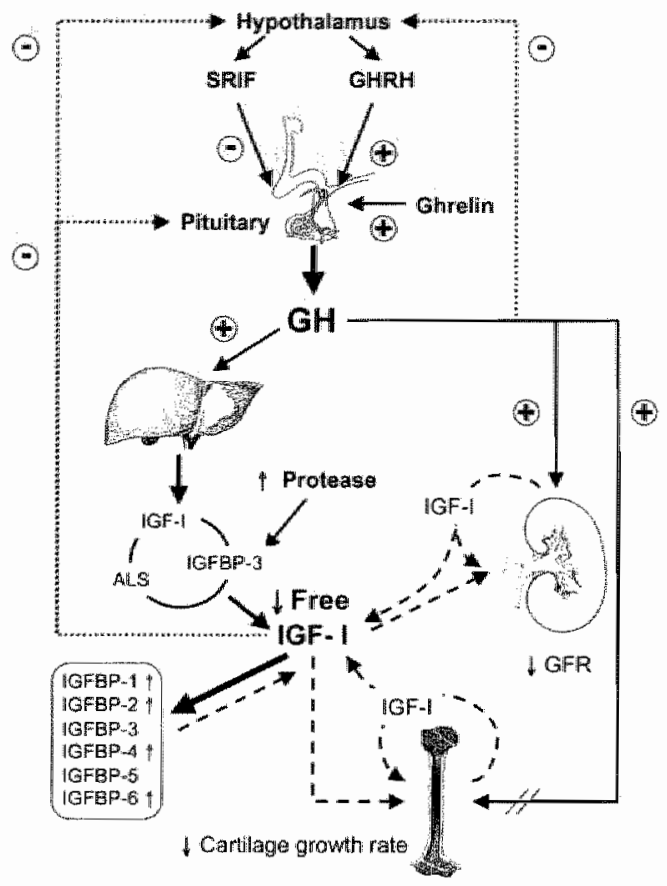

IGF-I (27). However, IGF-I bioavailability probably is reduced in renal failure as a result of increased plasma levels of IGFBP-1,-2,-4, and $-6(15,28)$. In CRF, there are increased amounts of low molecular weight IGFBP-3 fragments, which have a reduced affinity for IGF-I and which accumulate because of reduced renal clearance (13).

The increased levels of IGFBP- 1 and -2 in CRF are correlated inversely with residual GFR and with height (13). Free IGF I levels, however, are correlated positively with renal function (14). Therefore, the high IGFBP.1 and IGFBP.2 levels probably contribute to the resistance to the metabolic and growth-promoting properties of GH and IGF-I in renal failure.

There is some evidence for receptol-mediated GH and IGF resistance in CRF In experimental CRF; there is evidence of a decreased GH receptor abundance in tibial growth plates (29) and liver (30) and a defect in IGF signaling in muscle [31]. However, the weight of evidence favors a key involvement of the IGFBP in the GH and IGF resistance that can occur in renal failure. Thus, renal failure is not a state of GH of IGF-I deficiency but a state in which the regulation and bioavailability of components of the GH/IGF system are altered.

\section{Therapeutic Manipulation of the GH/IGF Axis in Renal Failure}

\section{Growth Hormone}

Growth. Recombinant human $\mathrm{GH}(\mathrm{rhGH})$ is approved for the treatment of growth failure in children with CRF. A daily dosage of $0.05 \mathrm{mg} / \mathrm{kg}$ body wt given by subcutaneous injection is recommended (32). 


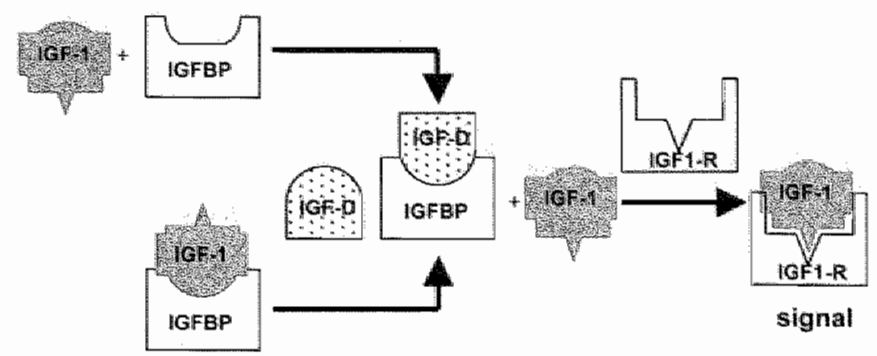

Figure 3. Mechanism of action of an IGF displacer compound. A novel concept for manipulating the IGF axis is shown. The

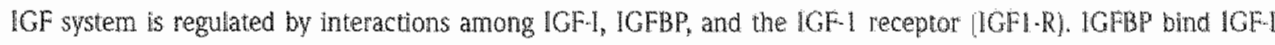
with high affinity, so very litule IGF-I is available normally to bind to and activate lGF receptoss. The intoduction of an IGF displacer (TGF-D) will both prevent IGFI binding to an IGFBP and displace ICFI that is bound to an IGFBP. The IGF displacer therefore will act as an indirect IGF agonist by increasing the amount of IGFil that is available for binding to IGF receptors. This strategy could be particulatly useful in renal fallure, in which there are excess IGFBP.

Using this dose, two large multicenter clinical trials in CRF patients showed that rhGH treatment can improve statural growth $(33,34)$. Recent studies showed that rhGH treatment is most effective when it is started at an early age and that the growth response is affected by the degree of renal impairment (35).

Although treatment with rhGH clearly stimulates body growth in children with renal failure, it is possible that rhGH may adversely affect renal function in some situations. For example, $\mathrm{GH}$ has been suggested to play a role in the development of glomerulosclerosis in mice (18), but there is no proof in children that rhGH has deleterious effects on renal function or, when given before renal transplantation, on graft function (36). However, rhGH treatment is not an ideal treatment for the growth disorders assaciated with CRF in children because a state of GH excess already exists in CRF.

RhGH therapy also has been proposed for the treatment of growth failure after renal transplantation, as catch-up growth does not occur in up to $75 \%$ of these patients (37). Guest et al. (38) showed in a prospective randomized study that rhGH therapy after renal transplantation tended to increase the number of acute biopsy-proven rejections ( 9 rejections in 44 rhGH-created patients versus 4 of 46 control patients l, although this was related to a previous history of rejection. RhGH treatment after renal transplantation still must be considered experimental (39).

Anabolic and Cardiovascular Effects. Studies have suggested a beneficial effect of rhGH treatment on left ventricular mass in patients with dilated cardiomyopathy, but this has not always been associated with an improved clinical outcome $(40,41)$. In nine adult hemodialysis patients (median age, $48.6 \mathrm{yr})$, rhGH treatment ( $4 \mathrm{IU} / \mathrm{m}^{2}$ per d for $6 \mathrm{mo}$ ) significantly increased lean body mass, reduced fat mass (42), and significantly increased left ventricular muscle mass but had no effect on ejection fraction, BP, or maximum exercise capacity (43). One rhGH-treated patient died as a result of severe pneumonia. Johannsson et al. (44) showed that rhGH administration $166 \mathrm{\mu g} / \mathrm{kg}$ given three times a week for $6 \mathrm{mo}$ ) in 10 elderly patients (mean age, $73 \mathrm{yr}$ ) who were on maincenance dialysis increased serum albumin and increased muscle strength. Two patients in the rhGH group died, whereas no placebo-treated patients died during the treatment period.

The use of rhGH to treat catabolism in dialysis patients also is of doubtful value given the lack of effect on clinical outcome and the adverse side effects of rhGH in intensive care patients (45). 


\section{Sustained-Release GH}

New formulations of rhGH, to allow more convenient administration regimens, have been tested in animals $(40,47)$.

One form, an injectable sustained-release formulation of rh $\mathrm{GH}$ in erodable polylactate polyglycolate microspheres, was approved recently by the FDA for use in pediatric GH-deficient patients. Two multicenter, open-label clinical studies in prepu-bertal GH-deficient children showed that this formulation of rhGH caused significant catch-up growth (48). Patients who were maintained on rhGH depot for 12 mo showed a mean growth rate of $7.8 \pm 1.9 \mathrm{~cm} / \mathrm{yr}$, which was lower compared with the firstyear growth rate of $10.0 \pm 3.1 \mathrm{~cm} / \mathrm{yr}$ that could be expected if the patients were given daily injections of rhGH (32).

Sustained-release thGH has not yet been studied in patients with renal insufficiency. A potential issue in these patients is that the clearance of $\mathrm{GH}$ is slowed, which could lead to $\mathrm{GH}$ accumulation. In addition, different effects of $\mathrm{GH}$ can be produced by intermittent or continuous $\mathrm{GH}$ administration (46). For example, compared with daily $\mathrm{GH}$ injections, continuous $\mathrm{GH}$ administration in rodents produces an initial rapid response in body growth, which wanes rapidly. Long.term studies in humans comparing intermittent exposure using daily $\mathrm{GH}$ injections with continual exposure using the depot formulation may be needed to allay such efficacy concerns. In our opinion, the efficacy of this new formulation of rhGH needs to be established in long-term controlled studies, especially for use in pediatric CRF patients.

\section{Adverse Effects of $\mathrm{GH}$}

RhGH treatment has been proposed as an anabolic therapy for catabolic critically ill patients (49). However, two large multicenter, double-blind, placebo-controlled Phase III clinical trials showed very clearly $(\mathrm{P}<0.001)$ that $\mathrm{rhGH}(0.10 \mathrm{mg} / \mathrm{kg}$ body wt) doubled the overall mortality of critically ill patients from approximately 20 to $40 \%$ (45). The dosage of rhGH in the critically ill patients was double the recommended dosage for growth disorders in pediatric CRF.

It now is recommended that rhGH treatment not be initiated in patients with an acute critical illness. The cause of the increase in mortality is unknown; therefore, great caution needs to be exercised in the use of rhGH in adults outside the currently approved use in $\mathrm{GH}$ deficiency. There is no clear recommendation on the course of action to take when a patient who is already receiving rhGH treatment develops an acute illness. However, it seems reasonable to cease rhGH treatment in both children and adults if an acute illness occurs, as there are no parameters available to gauge the risk of an adverse outcome if treatment is continued. This is partly because the adverse effects of rhGH may be via either the direct or the indirect effects of $\mathrm{GH}$. Initial experimental studies in animals suggest that metabolic or cytokine responses may be involved in these adverse effects (50). There has been much recent debate on the safety of manipulating the GH/IGF axis in acute critical illness (51).

Other adverse reactions to GH treatment in CRF include an increased risk of benign intracranial hypertension (52). The recent suggestion of an increased incidence of type II diabetes mellitus in children who are treated with $\mathrm{GH}$ also indicates that rhGH-treated patients deserve close monitoring (53). It seems prudent in pediatric CRF to start GH treatment with a half-dose, which should be ramped up to the therapeutic dose within 1 to 2 mo.

The use of rhIGF-I or rhIGF-I plus rhGH in catabolic states such as end-stage renal disease (ESRD), critical illness, and AIDS has not been associated with an increased mortality $(54,55)$. These data reinforce our theme of differences between the physiology and the pharmacology of rhGH and rhIGF. I treatment. 


\section{Insulin-Like Growth Factor-I}

Although rhIGF-I seems to be a logical treatment for growth failure in pediatric CRF, because of the increased IGFBP in this condition, clinical studies with rhIGF-I have not been performed in children outside of patients with GH insensitivity syndrome (GHIS). Studies in animal models of CRF 15/6 nephrectomy) show that the growth response after rhIGFI treatment is almost comparable to that after GH treatment (56). Besides effects on stature, rhlGF-I has direct anabolic effects and improves renal function. In normal subjects, rhIGF-I rapidly increases GFR and renal plasma flow by approximately $30 \%$ (57).

Acute Renal Failure. No drug has been approved as a stimulator of renal function in acute renal failure (ARF) (58). However, there is an obvious need for new treatments, as morbidity and mortality remain high after ARF. In animal models, rhIGF-l can improve both functional and histologic recovery after renal ischemia and reperfusion damage (59). These beneficial effects may be due to a variety of actions, such as increasing anabolism and hemodynamic effects in the glomerulus and the preglomerular vessels. RhIGF-I decreases both afferent and efferent arteriolar resistance in the glomeru-lus and increases renal blood flow by dilation of preglomerular vessels. These effects most likely are mediated by nitric oxide and vasodilatory prostaglandins (15). Recent studies also have shown that whlGF-I can reduce the inflammatory process after renal ischemia and reperfusion by inhibiting apoptosis (60). Early timing of treatment may be crucial for these effects, although other studies have shown that rhlGF-1 treatment can enhance renal repair when administered up to $24 \mathrm{~h}$ after injury (59).

These advantageous effects of rhIGF-I administration in animals have led to two randomized, doubleblind, placebo-controlled trials (61]. Franklin et al. [62) examined the effects of thiGF-l on recovery of renal function in 58 patients who underwent vascular surgery of the renal artery or the aorta, and Hirschberg et al. (63) tested rhIGF-I in 72 intensive care unit patients with confirmed ARF from different causes. Overall, both studies failed to show clinically significant effects on renal function or outcome.

The disappointing results of these clinical studies in ARF are in contrast to the very positive results in equivalent animai models. These differences are difficult to explain. It seems unlikely that there will be additional studies to test rhIGF-I in human ARF, although the lack of other candidate drugs sug. gests that IGF-I does deserve additional testing in humans.

Chronic Renal Failure. No drug has been approved for use in patients with CRF and ESRD to stimulate renal function or to delay the need for dialysis (64). The positive effects of rhlGF-I on renal function in healthy subjects led to several studies in CRF patients. Initial studies with high doses of rhIGF-I (100 $\mathrm{\mu g} / \mathrm{kg}$ twice a day) increased renal function for several days but caused serious side effects $(65,66)$. Recently, studies by Vijayan et al. (67) showed in patients with ESRD that efficacy could be maintained and side effects could be reduced with the use of an intermittent treatment regimen $(4 \mathrm{~d}$ on treatment, $3 \mathrm{~d}$ off treatment) for rhIGF-I (50 $\mathrm{\mu g} / \mathrm{kg}$ per d). This approach was well tolerated and resulted in a sustained improvement in renal function, which may be related to the IGFBP's being relatively unaffected by this mode of delivery. In other human studies, large rises in IGFBP-2 seem to be related to overdosing and the occurrence of side effects (68).

Additional rh[GF-J treatment studies, particularly in CRF in children, seem justified. However, the current limited interest by pharmaceutical companies and the lack of availability of clinical grade thlGF-I make this unlikely.

\section{Combination Treatment with GH Plus IGF-I or IGF-I Plus IGFBP-3}

Studies of combinations of hormones, in animals with the use of GH plus rhlGFI $(29,56)$ or in humans with rhIGF-I plus IGFBP-3 (69), suggest that there may be advantages in terms of efficacy and safety for combination therapy. The combination of rhGH plus rhlGF-I has been tested in catabolic states in 
adults (55) but has not been tested as a growth-promoting agent in pediatric patients. Animal studies suggest that combined treatment is more effective as a growth-promoting agent in experimental uremia (29,56). In catabolic humans, an initial study of the combination of rhGH plus rhlGF-I (both given once daily] suggested a beneficial anabolic effect (55). However, a second study, in which the rhGH was given twice daily (and at half the dose), failed to show a beneficial effect in patients with AIDSassociated wasting (54). The combination of rhlGF-I plus IGFBP-3 is being tested in humans (69), but as yet no growth studies in pediatric patients have been reported, perhaps because only an intravenous formulation has been available. The combination of rhGH plus rhIGF-I remains the most attractive untested therapeutic option for treating pediatric growth disorders. In the near term, human studies with rhGH plus rhlGF-I seem unlikely, as pharmaceutical companies do not seem to be interested in exploiting this combination.

\section{IGF Displacers}

The concept of activating the IGF axis, or increasing endogenous IGF-I bioactivity, has been proposed as a potential treatment modality. The idea is that by displacing bound IGF-l from IGF-binding proteins, the levels of "free" IGF-I should increase and thereby activate IGF receptors (Figure 3). Two independent studies $(70,71)$ have confirmed this hypothesis with the use of two different IGF-I analogs $\left(\right.$ Leu $24,59,60, \mathrm{Ala}^{3} \mathrm{~h} \mathrm{hlGF}-\mathrm{I}$ and Leu $\left.{ }^{24}, \mathrm{Ala} \mathrm{a}^{31} \mathrm{hlGF}-\mathrm{I}\right)$, which bind with high affinity to the IGFBP but do not activate directly the IGF receptor. One study showed that the administration of a "receptor inactive" IGF displacer in the rat increased body weight, increased kidney weight, and decreased creatinine and blood urea nitrogen, despite that total rat IGF-I levels fell dramatically (71). In extensions of this work, phage display has been used to discover synthetic peptides that bind to IGFBP (71).

In renai failure, in which free JGF bioactivity is low as a result of elevated IGFBP levels, the administration of IGF displacer peptides seems to be a logical way of increasing the bioavailability of IGF-I (72). This is a more physiologic approach to manipulating the GH/IGF axis in renal failure and should have fewer side effects than the administration of GH or IGF-I. Unfortunately, these peptides do not bind to rodent IGFBP, so their efficacy in animals is difficult to establish. However, because renal failure is characterized by excess IGFBP and not a deficiency of IGF, the concept of IGF displacement as a treatment option in renal failure seems promising. The concept of IGF displacement has been proved in animals, so a drug candidate with the desired characteristics now is needed so that efficacy can be tested in humans with renal disease.

\section{GH-Releasing Hormone}

It has been shown that GHRH can induce a growth response in rats (73) and in humans. Thorner et al. (74) studied the efficacy and safety of GHRH (GHRH-(1-29), $30 \mu \mathrm{g} / \mathrm{kg}$ per d) therapy in 110 previously untreated prepubertal GH-deficient children. Treatment for up to 1 yr in this multicenter, open-label study increased height velocity from approximately $4 \mathrm{~cm} / \mathrm{yr}$ to $8 \mathrm{~cm} / \mathrm{yr}$ for the first $6 \mathrm{mo}$ and $7 \mathrm{~cm} / y \mathrm{r}$ thereafter, although not all children were responsive. It seems unlikely that GHRH will replace GH as the treatment of choice for pediatric growth disorders. This is partly because GHRH must be given by injection, whereas a newer class of compounds, the GH secretagogues (GHS), which also release $\mathrm{GH}$, can be given orally (75).

\section{GH-Releasing Peptides}

GHRP or GHS are small synthetic molecules that can stimulate the release of GH from the pituitary (75). GHRP are highly specific for GH release and can be more effective at releasing GH than GHRH. However, compared with GHRH, the GHRP have little effect on GH synthesis and storage, which may 
limit their efficacy. The GHS receptor (GHS-R) has been cloned (76), and an endogenous ligand was discovered recently and named ghrelin (4). Ghrelin is expressed predominanty in the stomach and other tissues, including the kidney (77).

Therapeutic applications for GHRP have been studied, but no clear efficacy end point has been established. Potentially, GHRP could be used in situations in which rhGH is currently approved. A requirement for the use of GHRP is that the hypothalamo-pituitary function be intact (78). It has been proposed that GHRP may be preferential to rhGH treaiment in some conditions, as GHRP can induce a more physiologic pulsatile GH secretion that is self-regulating via $\mathrm{GH}$ and IGF. feedback.

Small-molecule GHRP can be given orally, would be less expensive than rhGH treatment, and therefore seem attractive for treating some forms of growth failure. After the discovery of ghrelin and its receptor, it is possible that new indications for GHRP will be discovered. In renal failure, in which GH secretion is already increased, it seems unlikely that GHRP would be a preferred form of therapy.

\section{GH-Receptor Antagonists and Somatostatin Analogues}

Several studies that used amimal models of diabetes mellitus found a relationship between elements of the GH/IGF axis and both early and late renal deterioration (79). Diabetes-associated kidney damage is reduced in genetically modified animals that either have a disrupted $\mathrm{GH}$ receptor gene or overexpress a $\mathrm{GH}$ antagonist $(80,81)$. $\mathrm{GH}$ antagonists, which are $\mathrm{GH}$ mutant molecules that bind only to one $\mathrm{GH}$ receptor, prevent $\mathrm{GH}$ receptor dimerization and receptor activation. The administration of $\mathrm{GH}$ antagonists has been shown to prevent renal disease in animal models of diabetic nephropathy (82). Similar effects were seen when endogenous GH was suppressed with the use of long-acting somatostatin analogues $(79)$.

\section{CONCLUSIONS}

The success of recombinant DNA technology has made GH widely available for the treatment of growth disorders. Advances in our understanding of the endocrinology of growth have produced new ways of manipulating the GH/TGF axis in renal failure. This has led to new potential treatment modalities that could affect body growth, anabolism, renal function, and even renal disease.

One reason that new treatment regimens are needed is that renal failure is not a disorder of $\mathrm{GH}$ deficiency but a derangement of the GH/LF/LGFBP system, resulting in decreased effects of endogenous GH and IGF. The need for new treatments has been highlighted recently by the questioning of the safety of rhGH treatment in critically ill adults. Two placebo-controlied, double-blind clinical trials showed that rhGH treatment in adults had lethal, acute side effects (45). The causes of the lethal effects of rhGH or the organs involved are as yet ill-defined, making it very difficult to proceed with some indications for rhGH treatment, such as congestive heart failure.

In pediatric patients, rhGH is a safe treatment. However, because we do not yet understand why rhGH treatment had lethal effects in critically ill patients, there is no way to identify patients who are at risk or markers that can be used to predict when adverse consequences will ensue from rhGH treatment.

Most of the effects of $\mathrm{GH}$ depend on its pattern of administration. Therefore, the lethal side effects of rhGH also may depend on its pattern of administration. Research is needed to establish the relative safety of different means of manipulating GH levels, such as depot rhGH preparation or GHS. It is possible that stimulating endogenous pulses of $\mathrm{GH}$, with the use of a $\mathrm{GH}$ releaser, is safer than giving injections of a $\mathrm{GH}$ preparation. 
Molecules that act as antagonists at the $\mathrm{GH}$ receptor show efficacy in preventing renal damage in animal models of diabetic nephropathy and are likely to be tested in humans.

$\mathrm{An}$ obvious alternative to the use of $\mathrm{GH}$ or compounds that release $\mathrm{GH}$ for growth promotion is the manipulation of the IGFI axis. Unfortunately, rhIGFI treatment has not been tested for growth promotion in pediatric CRF patients, in whom it may increase renal function and delay the need for dialysis or transplantation. Safety has been a concern for rhIGF-I treatment. An intermittent pattern of rhlGF-I administration seems to produce a sustained renal response with reduced side effects in adult CRF patients. It is likely that an optimal balance between safety and efficacy on body growth can be achieved with the use of the combination treatment of rhGH and rhIGF-I, particularly in renal failure, as animal studies have shown that in combination they cause at least additive growth responses. However, the future use of rhlGF-I in clinical studies is uncertain, given the current limited interest by pharmaceutical companies.

Binding proteins for IGF-I are targets for drug development. The administration of IGFBP-3 plus rhlGFI is being tested in humans, but it seems unlikely that this combination will be used widely to promote growth in children. New strategies aimed at increasing endogenous levels of free, bioactive IGF-I show promise as high IGFBP levels probably mediate most of the relative IGF resistance in renal failure. A mutated form of IGF.I that binds to IGFBP but not to IGF receptors (Figure 3) caused growth promotion and affected renal structure and function in animals. Novel peptides, termed IGF displacers, which bind to IGFBP and displace IGF-I, also have been developed. It is hoped that a molecule of this type eventually will be tested in humans.

The success of rhGH as a drug has led to a large research effort and has produced a long list of new approaches to manipulating the GH/IGF axis in the laboratory and the clinic. In the future, it is likely that combinations of hormones will be used to adjust or correct the endocrine abnormalities that cause disordered growth. Children with CRF and children with isolated $\mathrm{GH}$ deficiency both show reduced stature. However, their GH/IGF axes are disordered in very different ways. At present, rhGH treatment is used in both cases. It seems logical that a child with CRF and a child with isolated GH deficiency should receive different and tailor-made treatments to correct their GH/IGF system. For the foreseeable future, $\mathrm{GH}$ will remain the cornerstone of treatment, but in the future, treatment will be tailored with other compounds, such as IGF-1, being added in a cocktail to produce an optimal growth response.

\section{ACKNOWLEDGMENTS}

Professor Erik Heineman and Dr. Greg Thomas are acknowledged for reading and commenting on this manuscript. 


\section{REFERENCES}

1. Jones 1, Clemmons DR: Insulin-like growth factors and their binding proteins: Brological actons. Ehdoct Rev 10:3-34, 1095

2. Clark RG, Robinson IC: Up and down the growth hormone cascade. Cytokne Grow hactor Rev 7: 65-80, 1906

3. Muller EE, Locatell V, Cocchi D: Neuroendocrine control of growth homone secretion. Physiol Rev 79 : $511-607,1990$

4. Kojima M, Hosoda $H$, Date $Y$, Nakazato M, Matsuo H, Kangawa K: Ghrelin is a growth homone releasing acylated peptide from stomach. Nature 402: 656-660, 1999

5. Liu J, LeRoith D: Insulin-like growth factor I is essential for postnatal growth in response to grow th homone. Endocrinology 140:5178-5184, 1999

6. Daughaday WH, Rotwein P: Insulin-like growth factors I and II. Peptide, messenger ribonucleic acid and gene structures, serum, and tissue concentrations. Endocr Rev 10:68-91, 1989

7. Isaksson $O G$, Lindahl A, Nilsson A, Isgaard J: Mechanism of the stimulatory effect of growth homone on longitudinal bone growth. Endocr Rev 8: 426-438, 1987

8. Liu JP, Baker J, Perkins AS, Robertson EJ, Efstratiadis A: Mice canrying null mutations of the genes encoding insulin-like growth factor I (Ig:-1) and type I IGF receptor (Igtir). Cell 75: 59-72, 1993

9. Siogren K, Liu JL, Blad K, Skrtic S, Vidal O, Wallenius $V$, LeRoith D, Tomell J, Isaksson OG, Jansson JO, Ohtsson C: Liverderived insulin-like growth factor I (IGF-l) is the principal source of IGF-I in blood but is not required for postnatal body growth in mice. Proc Nat Acad SCi USA 96: 7088-7092, 1909

10. Juul A, Fywbjerg A, Frystyk I, Muller I, Skakkebaek NE: Serum concentrations of free and total insulin-ike growth factor 1 , IGF binding proteins 1 and 3 and IGFBP-3 protease activity in boys with normal or precocious puberty. Clin Endocrinol 44: $515-523,1996$

11. Cox GN, McDermott MJ, Merkel E, Stroh CA, Ko SC, Squires CH, Gleason TM, Russell D: Recombinamt human insulin-like growth factor (ICF)-binding protein-1 inhibits somatic growth sumulated by IGFI and growth hormone in hypophysectomized rats. Endocrinology 135: 1913-1920, 1994

12. Hoeflich A, Wu M, Mohan S, Foll J, Wanke R, Froehlich T, Arnold Gl, Lahm H, Kolb HJ, Wolf E: Overexpression of insulin like growth factor-binding protein-2 in transgenic mice reduces postnatal body weight gain. Endocrinology 140: $5488-5496,1999$

13. Tonshoff B, Blum WF, Wingen AM, Melns O: Serum insulinlike growth factors IGGS and IGF binding proteins 1,2 , and 3 in children with chronic renal falure: Relationship to height and glomerular filtration rate. The European Study Group tor Nutritonal Treatment of Chronic Renal Failure in Childhood. J Chn Endocrinol Metab 80: 2084-2691, 1995

14. Frystyk J, Ivarsen P, Skjaerbaek C, Flyvbjerg A, Pedersen EB, Orskow H: Serum-free insulin-like grow th facior I correlates with clearance in patients with chonjc renal fallure. Kidney /nt $50: 2070-2084,1009$

15. Hirchberg $\mathbb{R}$, Adler S: Insuin-like growth factor system and the kidney: Physiology, pathophysiology, and therapeutic implications. Am / Kidney Dis 31: $901-919,1908$

16. Rogers SA, Powell BL, Hammerman MR: Insulin-like growth factor I regulates renal development in rodents. Dev Genet 24: 293-298, 1999

17. Strickett PK, Nelson RD, Kohan DE: The Cre/lox Pystem and gene targeting in the kidney. Am / Physiol 270: $\mathbb{0} 051-F 057,1999$

18. Doi T, Striker LI, Quaife C, Conti FG, Palmiter R, Behringer R, Brinste: R, Striker GE: Progressive glomerulosclerosis develops in transgenic mice chronically expressing growth homone and grow th homone releasing factor but not in those expressing insulin-like growh factor- 1 . Am / Pahol 131: 398-403, 1988

19. Chan IM, Stampfer MJ, Giovannucci E, Gann PH, Ma J, Wikinson P, Hernekens CH, Pollak M: Plasma insulin-like growth factor-I and prostate cancer risk: A prospective study. Science 270:503-560, 1998 
20. Pollak M: Insuin llke growth factor physiology and cancer risk. Eur / Cancer 36: 1224-1228, 2000

21. Barker DJ, Hales CN, Fall CH, Osmond C, Phips K, Clark PM: Type 2 Inon-insulindependent diabetes mellitus, hypertension and hypenipidaemia (sndrome X): Relation to reduced fetal growth. Daberologia 30 : 6267,1993

22. Fall CH, Pandi AN, Law CM, Vanik CS, Cark PM, Breler B, Osmond C, Shiell AW, Guckman PD, Barker D) Size at birth and plasma insulinilike growth factor 1 concentrations. Arch Dis Child 73: 287-293, 1095

23. Ingelfinger $J R$, Woods $\mathrm{LL}$ : Cardiorenal destny: The role of genes and envirommental factors. Semin Nephrol $19: 201-210,1999$

24. Lellevre-Pegoner $M$, Merlet-Bentchou $C$ : The number of nephrons in the mammalian kidney: Environmental influences play a detemiming role. Exp Nephrol 8: 63-65,2000

25. Haffner D, Schaefer F, Girard J, Ritz $:$, Mehis O Metabolic clearance of recombinant human growth hormone in healh and chronic renal Galure. J Chin Invest 93 : 1163-1171, 1994

26. Tonshoff $B$, Veldhus JD, Heintich $U$, Mehs $O$. Deconvolution analysis of spontaneous nochurral growth homone secretion in prepubental chidden. with preterminal chronic renal failure and with end-stage renal disease. Pedhatr Res 37:80-93,1095

27. Tonshoff B, Powell DR, Zhao D, Dumam SK, Coleman ME, Domene HM, Blum WF, Baxter RC, Moore LC, Kaskel F]: Decreased hepatic insulin-like growth factor IIGFI and increased IGF binding protein-1 and -2 gene expression in experimental uremia. Endocrinology 138: 938-940, 1907

28. Powell DR, Dutham SK, Brewer ED, Frane JW, Watkins SL, Hogg RI, Mohan S: Effects of chronic renal failure and growth homone on serum levels of insulindike growth factorbinding protein 4 (IGFBP-4) and IGFBP. Sin children: A report of the Southwest Pediatric Nephrology Study Group. / Cin Endocrinol Metab 84: $596-601,1999$

29. Edmondson $\mathrm{SR}$, Baker $\mathrm{NL}, \mathrm{OH} J$, Kovacs $\mathrm{C}$, Werther $\mathrm{GA}$, Mehls $\mathrm{O}$ : Growth hormone receptor abundance in tibial growth plates of uremic rats: GH/GF-I treatment. Kidney Int 58: 62-70, 2000

30. Tonsholf B, Eden $S$, Weiser $E$, Carsson B, Robinson IC, Blum WF, Mehls O: Reduced hepatic growth hormone (GH) receptor gene expression and increased plasma GH binding protein in experimental uremia. Kidney Int 45: 1085-1092, 1994

31. Ding H, Gao XL, Hirschberg R, Vadgama JV, Kopple JD: Impaired actions of insulin-like growth factor 1 on protein symthesis and degradation in skeletal muscle of rats with chonic renal failure. Evidence for a postreceptor defect. J C/n hivest 97: 1064-1.075, 1996

32. Vance ML, Mauras N: Growh hormone therapy in adults and children. NEngl Med 341: 1206-1210, 1990

33. Hokken Koeleg AC, Stinen T, de Munck K, Wit JM, Wolf ED, de Jorg MC, Donckerwolcke RA, Abbad NC, Bot A, Blum WF: Placebocontrolled, doubleblind, cross-over tral of growth homone treatment in prepubertal children with chronic renal fallure. Lancet $338: 585-590,1991$

34. Fine $\mathrm{RN}$, Kohat EC, Brown D, Petman $\mathrm{A}$ : Growth after recombinant human growh hormone treatment in children with chronic renal fallure: Report of a multicenter randomized doubleblind placebo-controlled study. Genentech Cooperative Sudy Group. / Pediatr 124: 374-382, 1994

35. Hafner D, Schaefer F, Nissel R, Whh E, Tonshoff B, Mehls $O$ : Effect of growth hormone treatment on the adultheight of children with chronic renal failure. German Study Group for Growh Hormone Treatment in Chonic Renal Fallure. N Engl J Med 343: 923-930, 2000

30. Fine RN, Sulliwan EK, Kuntze J, Btethen S, Kohaut E: The impact of recombinant human growth homone treatment during chronic renal insufficiency on renal transplant recipients. / Pedatr $136: 376-382,2000$

37. Fine RN: Growth post renal-transplantation in children: Lessons from the North American Pediatric Renal Transplant Cooperative Study (NAPRTCS). Pediatr Transplant 1: 85-89, 1907

38. Guest $\mathrm{G}$, Berard E, Crosnier $\mathrm{H}$, Chevaller T, Rappaport $\mathrm{R}$, Broyer M. Effects of growth homone in short chidten after renal transplantation. Fench Sociey of Pediatric Nephrology. Pediatr Nephrol 12: 437-446, 1998 
39. Tonsholf $B$, Mehis $O$ : Factors affecting growh and strategies for treatment in children after renal transplantation. Pediatr Transplant 1: 176-182, 1907

40. Osterziel KI, Strohm O, Schuler J, Friedrich M, Hanein D, Whenbrock R, Anker SD, Poole Wilson PA, Ranke $\mathrm{MB}$, Dietz R: Randomised, double-bind, placebo-controlled trial of human recombinan growth homone in patients with chronic heart falure due to dilated cardiomyopathy. Lancet $351: 1233-1237,1098$

41. Fazio S, Sabatini D, Capaldo B, Vigorito C, Giordano A, Guida R, Pardo F. Biondi B, Sacca L: A preliminary study of growth hormone in the treatment of dilated cardiomyopatmy. N Engl/ Med 334: 800-81.4, 1996

42. Hansen TB, Gram I, Jensen PB, Kristiansen JH, Ekelund B, Chistiansen IS, Pedersen FB: Influence of growth hormone on whole body and regional soft tissue composition in aduit patients on hemodialysis. A double: blind, randomized, placebo-controlled study. Cin Nephrol 53: 99-107, 2000

43. Jensen PB, Ekelund B, Nielsen FT, Baumbach L, Pedersen FB, Oxhol H: Changes in cardiac muscle mass and function in hemodialysis paients during growth hormone treatment. Chin Nephrol $53: 25-32,2000$

44. Johannsson G, Bengtsson BA, AhImen J: Double-blind, placebocontrolled study of growth hormone treatment. in elderly patients undergoing chronic hemodialysis: Anabolic effect and Tunctional improvement. Am I Kidney Dis 33: 709-717, 1999

45. Takala J, Ruokonen E, Webster NR, Nielsen MS, Zandstra DF, Vundelinckx, Hinds CI: Increased mortality associated with growth homone treatment in critically ill adults. NErgl / Med 341: 785-792, 1999

46. Clark R, Olson K, Fuh G, Marian M, Mortensen D, Teshima G, Chang S, Chu H, Mukku V, Canova-Davis $E$. Somers $T$, Gronin $M$, Winkler $M$ : Long-acting growth hormones produced by conjugaton with polyethylene glycol. J Biol Chem 271:21969-21977, 1996

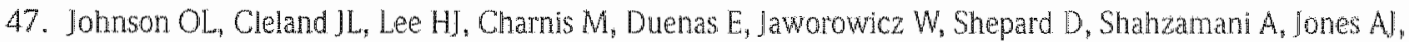
Putney SD: A month-long effect from a single injection of microencapsulated human growth hormone. Nat Med 2: 795-799, 1996

48. Reiter EO, Attie KM, Neuwirth R, Ford KM: Efficacy and safety of sustained release growth hormone (GH) given once or twice monthly in children with GH deficiency. Presented at the Endocrine Society Annual Meeting, San Diego, June 1909

49. Jenkins RC, Ross RJ: Growth hormone herapy for proten catabolism. Q/M 89: 813-819, 1906

50. Lila W, Rudling M, Angelin B: Contrasting effects of growth hormone and insulin-1ike growth factor $\|$ on the biological activities of endotoxin in the rat. Endocrimology 138:289-295, 1997

51. Bengtsson BA: Rethink about growth-hormone therapy for critically ill patients. Lancet 354: 1403-1404, 1999

52. Malozowski S, Tanner LA, Wysowsk D, Feming GA: Growth hormone, insulin -ike growth tactor ], and benign intracranial hypertension. N Engl/ Med 329:065-606, 1993

53. Cutfield WS, Wilton P, Bennmarker $H$, Abertsson-Wiktand $K$, Chatelain P, Ranke MB, Price DA: Incidence of diabetes mellitus and impaired glucose tolerance in children and adolescents receiving growth-homone treatment. Lancet 355: 610-613,2000

54. Lee PD, Piwarnik JM, Bukar JG, Murahainen N, Berry PS, Skolnik PR, Nerad JL, Kudsk KA, Jackson L, Ells KJ, Gesundheit N: A randomized, placebo-controlled irial of combined insulin-like growtl factor I and low dose growth hormone therapy for wasting associated with human immunodeliciency virus infection. / Chn Endocinol Metab 81:2968-2975, 1990

55. Waters D, Danska I, Hardy K, Koster F, Ouals C, Nickell D, Nightingale S, Gesundheit N, Watson D, Schade D: Recombinant human growth homone, insulin-like growth factor 1 , and combination therapy in AIDS. associated wasting. A randomized, doubleblind, placeboncontrolled tral. Ann Mntern Med $125: 805-872$, 1996

56. Hazel SI, Gillesple CM, Moore RI, Clark RG, Jureidini KF, Martin AA: Enhanced body growth in uremic rats treated with IGF-l and growth homone in combination. Kdney /nt 46: 58-68, 1094 
57. Guer HP, Schmid C, Zapl I, Foesch R: Effects of recombinant insulin like growth factor I on insulin secretion and renal function in momal humar subjects. Proc Nat Acad Sci USA 80: 2868-2872, 1989

58. Star RA: Treatment of acute renal fallure. Kidney Int 54:1817-1831, 1998

59. Mile SB, Martin DR, Kissane J, Hammeman MR: Rat modeis for clinical use of insulin Jke growth factor In acute renal halure. Am J Phystol 260: F949-F956, 1994

60. Daemen $M A$, van 1 Veer $C$, Denecker $G$, Heemskerk $V H$, Wols TG. Clausee $M$, Vandenabeele $P$, Bumman WA: Inhibition of apoptosis induced by ischemia-reperfusion prevents inflammation. I Clin Invest 104 : $541-549,1909$

61. Hammeman MR: Potential tole of growth factors in the prophylaxis and treatment of acute renal failure. Kidrey lnt Supp 64: $\$ 19-522,1998$

62. Franklin SC, Moulton M, Sicard GA, Hammerman MR, MHler SB: Insulin-like growth factor I preserves renal function postoperatively. Am I Physiol 272: F257-F259, 1997

63. Hirschberg R, Kopple J, Lipsett P, Benjamin E, Minei J, Aibertson T, Munger M, Metzler M, Zaloga G, Murray

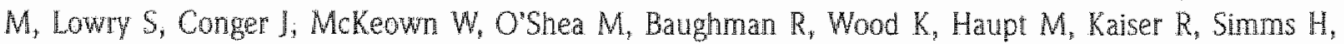
Wamock D, Summer W, Hintz R, Myers B, Haentiling K, Capra W: Multicenter clinical trial of recombinant human insulin-like growth factor I in patients with acute renal fallure. Kidney Int 55:2423-2432, 1999

64. Hammerman MR: The growth homone-insulin-like growth factor axis in kidney re- revisited. Nephrol Dial Transplant 14: 1853-1860, 1999

65. O'Shea $\mathrm{MH}$, Miller $\mathrm{SB}$, Hammerman MR: Effects of IGF- on renal function in patients with chronic renal failure. Am I Physiol 204: F917- 1922,1903

60. Miller SB, Moulton M, OShea M, Hammerman MR: Effects of IGF-I on renal function in end stage chronic renal faillure. Kidney /nt 40:201-207, 1994

67. Vijayan A, Franklin SC, Behrend T, Hammerman MR, Miller SB: Insulin-like growth factor I improves rena! function in patients with end-stage chronic renal fallure. Am I Physiol 270: R929-R934, 1999

68. Thrailkill K, Quattrin T, Baker L, Litton J, Dwigun K, Rearson M, Poppenheimer M, Kotlowker D, Giltinan D, Gesundheit $N$, Martha PJ: Dual hormonal replacement therapy with insulin and recombinant human insulin-like growth factor [ICF.I in insulindependent diabetes mellitus: Effects on the growth hommone/ IGF/GF-binding protein system. / Chin Endocrinol Metab 82: 1181-1187, 1997

69. Clemmons DR, Moses AC, Mckay MI, Sommer A, Rosen DM, Ruckle J: The combination of insulin.like growth factor I and insulin-like growth factorbinding protein-3 reduces insulin requirements in insulindejendent type I diabetes: Evidence for in vivo biological activity. / Chin Endocrinot Metab 85: 1518-1524, 2000

70. Loddick SA, Liu X, Lu ZX, Liu C, Behan DP, Chalmers DC, Foster AG, Vale WW, Ling $N$, De Souza EB: Displacement of insulin-like growth factors from their binding proteins as a potential meatment for stroke. Proc Natl Acad Sci USA 95: 1894-1898, 1998

71. Lowman HB, Chen YM, Sketon NJ, Mortensen DL., Tomlinson EE, Sadick MD, Robinson IC, Clark RG: Malecular mimics of insulin like growth factof I (IGF-1) for inhibiting IGF-1: IGFbinding protein interactions. Biochemistry $37: 8870 \sim 8878,1998$

72. Roelfsema $V$, Lane MH, Clark RG: Insulin-like growth factor binding proteñ (IGFBP) displacers: Relewance to the treatment of renal disease. Pediatr Nephrol 14:584-588, 2000

73. Clark RG, Robinson IC: Growth induced by pulsatile infusion of an amiclated fragment of human growth homone releasing factor in nomal and CHRF-deficient rats. Nature 314:281-283, 1985

74. Thoner M, Rochicclol P, Colle M, Lanes R, Grunt J, Galazka A, Landy H. Eengrand P. Shah S: Once daily subcutameous growth hormone-releasing hormone therapy accelerates growth in growth hormone-deficient children during the irst year of therapy. Geref Intemational Study Group. JClin Endocrinol Metab81:11891196.1996 
75. Clark RG: Growth hormone secretagogues: A pill for growth? Growh hom IGF Res ofSuppl Af: 85-88, 1999

76. Howard AD, Feighner SD, Cully DF, Arena JP, Lberator PA, Rosenblum Cl, Hamelin M, Hreniuk DL, Palyha OC, Anderson J, Paress PS, Diaz C, Ghou M, Lu KK, McKee KK, Pong SS, Chaung LW, Eibrecht A, Dashkewcz M, Heavens R, Rigby M, Sirinathsinghji DJS, Dean DG, Melilo DG, van der Ploeg LH: A receptor in pituitary and hypothalamus that functions in growth hormone release. Science 273: 974-977, 1996

77. Mori K, Yoshimoto A, Takaya K, Hosoda K, Ariyasu H, Yahata K, Mukoyama M, Sugawara A, Hosoda H, Kojima M, Kangawa K, Nakao K: Kidney produces a novel acylated peptide, ghrelin. FEBS Lett 480 : $213-216,2000$

78. Micic D, Casabiell X, Gualilo O, Pombo M, Dieguez C, Casanueva FF: Growth hormone secretagogues: the clinical future. Horm Res $51 /$ Suppl 3\%:29-33, 1999

79. Fyvbjerg $A$ : Role of growth homone, insulin-like growth factors (IGFs) and IGF- binding proteins in the renal complications of diabetes. Kidney Int Suppl 52: S12-S19, 1997

80. Chen NY, Chen WY, Bellush L, Yang CW, Striker LI, Striker GE, Kopchick Jj: Eflects of streptozotocin treatment in growth hormone (GH) and GH antagonist transgenic mice. Endocrinology 130:660-607, 1905

81. Bellush LL, Doublier S, Holland AN, Striker LJ, Striker GE, Kopchick IJ: Protection against diabetes Induced nephropathy in growth hormone receptor/binding protein gene-disrupted mice. Endocrinology 14:1: $163-168,2000$

82. Segev $Y$, Landau $D$, Rasch $R_{*}$ Fyrvierg $A$, Philip M: Growth hormone receptor antagonism prevents early renal changes in nonobese diabetic mice. I Am Soc Nephrol 10: 2374-2381, 1990 


\section{SUMMARY}

The aim of this thesis was to better understand the endocrine and cardiovascular responses of the fetus to severe hypoxia (asphyxia) and to examine the effects of rescue therapy with head cooling on neural and systemic recovery from such severe hypoxia.

Chapter 1 discusses the clinical and experimental background to this thesis. Ischaemia-reperfusion injury remains a significant chalienge for perinatal medicine today for both term and preterm infants Volpe 2001; Shalak and Perlman 2004; Salhab and Perlman 2005). Severe asphyxia can initiate a cascade of events in the brain and other organs, leading to organ and brain injury, which can result in life-long neurodevelopmental handicaps for the child. During hypoxia-ischaemia there is cellular energy failure, accumulation of excitotoxins due to increased neurotransmitter release and inhibition of re-uptake, an efflux of $\mathrm{K}^{+}$but a corresponding influx of $\mathrm{Na}^{+}$and water, increased free intracellular $\mathrm{Ca}^{2+}$, severe oxidatiwe stress, which lead to cell swelling and induction of cell death pathways.

Recovery from asphyxia can be divided into several phases of evolving injury. After the initial petiod of reperfusion, there is a latent phase, in which there is nearly complete normalisation of oxidalive cerebral energy metabolism, but electroencephalogram (EEG) activity is depressed and there is a secondary fall in cerebral blood flow (Williams et al. 1991; Lorek et al. 1994; Abi Raad et al. 1999). "The latent phase may last for many hours, up to $15 \mathrm{~h}$ in some studies, before being followed by a phase of secondary deterioration (Gunn 2000). This phase is marked clinically and experimentally by the onset of seizures, delayed cytotoxic edema (cell swelling), extracellular accumulation of excitotoxins, failure of oxidative metabolism, and induction of inflammatory responses, and ultimately delayed apoptotic and necrotic cell death.

Treatment strategies to prevent the (long-term) consequences of ischaemia-reperfusion are highly necessary for both term and preterm infants. Although there is no precise way of determining the exact "window of opportunity" for neuroprotective treatment, broadly the events occurring in the latent phase after hypoxia-ischaemia appear to be potentially amenable to neuroprotective strategies, whereas generally treatments begun after the onset of the secondary deterioration seem to have very little or no benefit (Gunn 2000). Therapeutic hypothermia is currently the most promising candidate for neonatal hypoxic-ischaemic encephalopathy (Gunn 2000).

Before new treatment strategies are studied in human infants it is vital to understand systemic effects both of the underlying hypoxic ischaemic insult and of the treatment, and not just the effects on the brain. Thus one goal of my thesis was to better understand the systemic effects of cooling to ensure that there are no adverse systemic effects that might compromise its neuroprotective benefits, especially for preterm neonates.

The chronically instrumented fetal sheep model of both global asphyxia and cerebral ischaemia. reperfusion has several great advantages above other experimental paradigms such as rodent models. In fetal sheep it is possible to continuously monitor cerebral and systemic physiologic parameters such as temperature, blood flow, blood pressure and electro-encephalography in utero, with the mother serving as a ideal stable incubator (Gunn et al. 1997). Furthermore it allows repeated blood sampling for example to study endocrine changes and post-mortem histological examination. The sheep brain, like the human brain is gyrencephalic (in contrast to the lisencephalic rat brain) and shares many developmental features with the human infant.

This is clearly a compromise as fetal and neonatal metabolism differ in several aspects. However, this approach provides a primary insult, which occurs under fetal conditions, and avoids hypothermia and anaesthesia, which can interact with drug treatment. In terms of cerebral maturity the 0.7 gestation fetal sheep is comparable to the human brain at $30-32$ weeks of gestation, whereas the nearterm, 0.8-0.85 gestation fetus is equivalent to the term infant (Mclntosh et al. 1979). 


\section{Chapter 2}

It is widely believed that one reason for the increased rate of neural injury after preterm birth is that the ability of the preterm fetus to defend itself from ischaemia-reperfusion is not as well developed as at term. In particular, it has been hypothesized that the hypothalamus-pituitary-adrenal (HPA) responses to stresses such as asphyxia are inmature in the preterm fetus and that this contributes to the frequent development of subsequent hypotension in the perinatal period. These experimental studies were undertaken using relatively mild insults. However, we now know that compared to the nearterm fetus, survival of the premature fetus is much more prolonged during a severe asphyxial insult (Gunn et al. 2001). We therefore examined the effects of prolonged, severe asphyxia induced by complete umbilical cord occlusion on. HPA responses in chronically instrumented preterm fetal sheep (at 0.7 of gestation) for 3 days.

Profound asphyxia in the preterm fetus led to a very large relative increase in ACTH and cortisol levels during asphyxia. Although the absolute levels of cortisol were much lower than at term, the pattern and magnitude of the relative changes were consistent with nearterm responses. In the recovery phase there was a sustained elevation that gradually resolved between 24 and $72 \mathrm{~h}$. There was a modest correlation between cortisol levels in the recovery phase and fetal mean arterial pressure suggesting that the adrenocortical response helps to sustain fetal blood pressure during a critical period of recovery.

Our conclusion is that the adrenocortical response of the preterm fetus is not immature. Rather our data suggest that the greater anerobic tolerance of the preterm fetus, compared with near-term, means that its full range of responses is only activated by more severe insults.

\section{Chapter 3}

Prolonged, moderate cerebral hypothermia has been shown to be able to reduce neural injury in a wide range of experimental ischaemia reperfusion paradigms, but not yet in a model of premature brain injury. Using a chronically instrumented preterm (0.7 gestation) fetal sheep model, we examined the effects of cerebral hypothermia starting in the early recovery phase (90 min after asphyxia) and continued for 3 days, on neuronal loss and epileptiform activity.

We found that delayed, prolonged head cooling after a severe asphyxial insult in the premature fetus was neuroprotective in the hippocampus and basal ganglia, and suppressed activated caspase-3 (apoptosis) and microglia (inflammation). Neuroprotection was associated with potent, specific suppression of epileptilorm transients in the early recovery phase, but not with number of delayed seizures. The histological improvement was associated with progressive normalisation of EEG frequency and carotid blood flow after reperfusion, consistent with possible functional improvements. Hypothermia was not associated with significant side-effects such as hypotension or acid-base changes, suggesting it may be safe in the preterm infant if carefully controlled.

Thus, our data demonstrate that selective cerebral hypothermia after profound asphyxia can reduce short-term injury of subcortical neuronal structures in the preterm brain. In view of the critical developmental events occurring in the preterm infant, and their potential vulnerability to the adverse systemic effects of hypothermia it will be critical to systematically evaluate the factors, such as delay before initiated cooling and the depth of hypothermia, that determine its effectiveness before human. studies can be contemplated.

\section{Chapter 4 and 6}

Insulin-like growth factor:- (I.GF-I) is a potent endogenous neuroprotective and metabolic and growth factor. The IGF-I axis involves the peripheral effector peptide hormones GH, IGF-I, and IGF-II and a regulatory feedback loop. In blood, approximately $97 \%$ of the IGF are bound to six IGF-binding proteins 
[GFBP. I to IGFBP-6), with the remaining IGF-I either in a bioactive-free fraction (approximately 1\%] or in an easily dissociable form. The binding of IGFI to IGFBP (especially IGFBP. I) limits the bioactivity of IGF-I, as bound IGF-I probably cannot activate the IGFI receptor. Manipulating IGF-I by either administering IGF-I or its binding proteins or increasing IGF-I bioavailability with the use of IGF displacers could prove to be a safer and more effective alternative to growth homone or IGF-I treatment, for example in paediatric renal failure or ischaemia-reperfusion injury.

The effects of asphyxia and hypothermia on circulating IGF-I are currently poorly understood, and may affect infants recovery from asphyxia. Our results show that the overall profile of changes in IGFs (and insulin) after asphyxia are highly consistent with facilitation of catabolic metabolism. While the primary IGF involved is clearly IGF-I, intriguingly, our study also suggests for the first time that by 0.7 of gestation IGF-II may also contribute to regulation of fetal metabolism during the acute recovery phase following asphyxia.

This study also demonstrates that therapeutic head-cooling in the preterm fetus is not associated with major changes in the responses of circulating concentrations of IGFs after asphyxia, suggesting reassuringly that hypothermia does not affect the metabolic adaptation mediated by circulating IGFs.

\section{Chapter 5}

Post-resuscitation cerebral hypothermia is consistently neuroprotective in experimental preparations. Less is understood about the effects of hypothermia on white matter injury loligodendrocytes and myelin]. This is of some importance since one proposed reason for the consistent clinical failure of putative neuroprotective drugs has been their failure to protect white matter as well as neurons. Using a model of reversible cerebral ischaemia in unanesthetised nearterm fetal sheep, we examined the effects of cerebral hypothermia (fetal extradural temperature reduced from $39.4 \pm 0.1^{\circ} \mathrm{C}$ to between 30 and $33^{\circ} \mathrm{Cj}$, induced at different times after reperfusion and continued for three days after ischaemia, on injury in the parasagittal white matter 5 days after ischaemia.

Cooling started within 90 minutes of reperfusion was associated with a significant increase in bioactive oligodendrocytes in the intragyral white matter compared with sham cooling, increased myelin. basic protein density and reduced expression of activated caspase-3. Reactive microglia were profoundly suppressed compared with sham cooling with no effect on numbers of astrocytes. When cooling was delayed until 5.5 hours after reperfusion there was no significant effect on loss of oligodendrocytes.

We conclude that prolonged moderate cerebral hypothermia can prevent post-ischaemic white matter damage in the near-term fetal sheep, but there is rapid attenuation of this effect with increasing delay in the initiation of cooling. Protection of the white matter was closely associated with reduced expression of both activated caspase- 3 and of reactive microglia. These data strongly support the critical importance of early initiation of coolling in clinical trials.

\section{FUTURE PERSPECTIVE}

\section{Prevention}

Obviously, prevention of injury of course is better than treatment. On one hand, improvements in routine obstetric care, to minimise the risk of hypoxia-ischaemia in both term and preterm infants, are possible. There is now some evidence that innovations in monitoring and early intervention can further improve detection of intrapartum asphyxia and thus reduce the rate of neonatal encephalopathy (AmerWahlir et al. 2001; Noren et al. 2003j. However, it is improbable that complete prevention of neonatal hypoxic-ischaemic encephalopathy could ever be achieved, and thus there will always be a need for 
rescue treatment. As many agents have been shown to be only effective when treatment is started during hypowia-ischaemia, an elegant approach would be to start treatment in at risk pregnancies before labour, for example by administrating neuroprotective agents to the mother. For example, there is some evidence that magnesium sulphate, which is a partial NMDA receptor antagonist, given to women immediately before very preterm birth may improve some neurodevelopmental outcomes in the children, although in this trial there was no overall statistically significant effect (Crowther et al. 2003).

\section{Therapeutic hypothermia}

As discussed in this thesis, hypothermia is currently one of the most promising interventions for neonatal hypoxic-ischaemic encephalopathy. In many different animal models it has consistently been shown to improve structural and functional outcome, and the pharmacological parameters for effective use have been reasonably well defined. Based on these experimental data randomised controlled clinical trials using either selective cerebral hypothermia ( $\mathrm{CoolCap}$ trial") or whole-body hypothermia have just been completed or are in progress Uacobs et al. 2004; Shankaran et al. 2004; Gluckman et al. 2005). Results from the CoolCap trial suggested that the combination of head coolling with mild systemic hypothermia reduced death or disability in the infants with less severe electroencephalographic changes at entry of the trial. However, cooling using this protocol was not significantly beneficial in infants with the most severe electroencephalographic changes before the onset of cooling. These data strongly suggest that further research is important to find better ways of selecting newborn infants who may benefit most from treatment. Currently (amplitude integrated)EEG appears to have the best potential selection capacities [Groenendaal and de Vries 2000], but further studies are needed to validate the CoolCap trial experience and to define the most robust, generally applicable criteria.

Many more questions remain about the best ways of optimizing clinicall neuroprotection with hypothermia. For example, it is unclear whether head cooling is better than whole body. It is likely that this will be a balance between risks and benefits, and we may speculate that there may prove to be better therapeutic effects of whole body cooling on subcortical structures at the expense of an increased risk of complications from the deeper systemic hypothermia used in whole body cooling. Further, the real width of the so called "window of opportunity" after birth, the, optimal depth and duration of cooling and of the speed of warming babies up after cooling are all highly unclear, and likely depend on factors such as the severity of injury, its precise timing before birth, the type of insult (e.g. single profound episode of anoxia vs. repeated shorter episodes), the age and maturity of the infant, the presence of preexisting growth retardation and so forth. Our results summarised above suggest that hypothermia may be potentially an effective intervention to reduce neurological morbidity in preterm infants. Given the well established finding of increased mortality in infants less than 1500 $\mathrm{g}$ who were allowed to get mildly hypothermic, much more basic research is needed before hypothermia could be considered for this uniquely vuinerable group.

\section{Combination therapy}

Although hypothermia reduces the massive cell death the first week after ischaemiareperfusion injury, protection is only partial, and there will often still be permanent structural and functional injury to the neonatal brain. One way of further improving protection would be to combine hypothermia with other neuroprotective agents. For example, the combination of hypothermia and NMDA-receptor antagonist xenon has recently been shown to have additive neuroprotective effects (Ma et al. 2005). Alternatively, mild early hypothermia can be used to prolong the window of opportunity for treatment with neuroprotective peptides such as insulin-like growth factor (IGF)-I (Guan et al. 2000). IGF-I has to be 
given directly into the cerebral ventricles; thus combination treatment of hypothermia with an IGFI displacer may be a more clinically acceptable approach (Loddick et al. 1998; Mackay et al. 2003).

\section{Plasticity}

Finally, it may also be fruitful to combine therapeutic hypothermia with factors that improve brain recovery. The neonatal brain has very high levels of endogenous growth factors, such as nerve growth factor (NGF), brain-derived neurotrophic factor (BDNF), and IGFI that are further upregulated in the recovery from injury (Beilharz et al. 1998; Lee et al. 2000). These growth factors are potently antiapoptotic, but can also stimulate the generation of new cells (both neurons and oligodendrocytes) and promote axon sprouting within and surrounding damaged areas (Zaidi et al. 2004). The endogenous adaptive responses following brain injury are termed plasticity. They include elimination of neurons through apoptosis and pruning of synapses. It is proposed that ischaemia-induced neurogenesis and plasticity contributes to the long-term recovery of function (Sharp et al. 2002). There must be some potential risk that excessive regeneration and plasticity may lead to maladaptive brain circuits. Nevertheless, the magnitude of this response in the brain compares poorly with the degree of regeneration and functional repair seen in other organs, for example the liver, and there is now intriguing evidence from adult and infant rats that environmental stimulation can enhance neurogenesis and improve recovery from various insults. Thus it seems likely that there is real potential for behavioural or drug treatments to augment neural regeneration and plasticity and thus improve long-term functional recovery from perinatal hypoxic-ischemic encephalopathy (Young et al. 1999; Faverjon et al. 2002]. 


\section{REFERENCES}

Abi Rad R, Tan WK, Bennet L, Gunn Ai, Davis SL, Gluckman PD, Johnston BM, Willams CE, 11009 . Role of the cerebrovascular and metabolic responses in the delayed phases of injury after transient cerebral ischemia in letal sheep. Stroke $30.2735 \cdot 2741$

Amer Wahlin I, Hellsten C, Noren H, Hagberg H, Herbst A, Kjellmer I, Lilia H, Lindoft C, Mansson M, Martensson L, Olofsson P, Sundstrom A, Marsal K. (2001) Cardiotocography only versus cardiotocography plus ST analysis of fetal electrocardiogram for intrapartum fetal monitoring: a Swedish randomised controlled ural. Lancet 358.534 .538

Bellharz EJ, Russo VC, Butler G, Baker NL, Connor B, Sirimanne ES, Dragunow M, Werther GA, Gluckman PD, Williams CE, Scheepens A. 11998$)$ Co-ordinated and cellular specilic induction of the components of the IGF/IGFBP axis in the rat brain following hypoxicischemic injury. Brain Res Mol Bram Res 594119-134

Crowther CA, Hiller JE, Doyle LW, Haslam RR. (2003) Effect of magnesium sulfate given for neuroprotection before preterm birth: a randomized controlled trial. JAMA 290:2669-2676

Faverion S, Siveira DC, Fu DD, Cha BH, Akman C, Hu Y, Holmes GL. (2002) Beneficial effects of enriched environment following status epilepticus in immature rats. Neurology 50:1356-1364

Gluckman PD, Wyatt IS, AZZopardi D, Ballard R, Edwards AD, Fermero DM, Polin RA, Robertson CM, Thoresen M, Whitelaw A, Gunn AJ. (2005) Selective head cooling with mild systemic hypothermia after neonatal encephalopathy: multicentre randomised trial. Lancet 365;663-670

Groenendaal F, de Vries LS. (2000) Selection of babies for intervention after birth asphyxia. Semin Neonatol 5:17. 32

Guan J, Gunn AI, Sirimanne ES, Tufin ), Gunning MI, Clark R, Gluckman PD. (2000) The window of opportunity for neuronal rescue with insulin-like growth factor-I after hypoxia-ischemia in rats is critically modulated by cerebral temperature during recovery. / Cereb Blood Flow Metab 20:513-519

Gunn AI. (2000) Cerebral hypothermia for prevention of brain injury following perinatal asphyxia. Curr Opin Pediatr 12:1111-115

Gunn Af, De Haan HH, Gluckman PD. (1997) Experimental models of perinatal brain injury. In: Fetal B Neonatal Brain Injury Mechanisms, management and the risks of practice(Stevenson DK, Sunshine P, eds), Oxford: Oxford Medical Publications, pp 59-70

Gunn AJ, Quaedackers JS, Guan J, Heineman E, Bennet L. (2001) The premature fetus: not as delenseless as we thought, but still paradoxically vulnerable? Dew Neurosci $23: 175 \cdot 179$

Jacobs S, Hunt R, Tamow-Mordi W, Inder T, Davis P. (2004) Cooling for newborns with hypoxic ischaemic encephalopathy (Cochrane Review). The Cochrane Library

Lee IM, Grabb MC, Ziplel G], Choi DW. (2000) Brain Ussue responses to ischenia. / Chin Invest 100:723.731.

Loddick SA, Liu XI, Lu ZX, Lu C, Behan DP, Chamers DC, Foster AC, Vale WW, Ling N, De Souza EB. 19081 Displacement of insulin-like growth factors from theil binding proteins as a patental treatment for stroke. Proc Nall Acad SciU 5 A 95:1894 1898

Lorek A, TakeI Y, Cady EB, Wyatt JS, Penrice J, Edwards AD, Peebles D, Wylezinske M, Owen Reece H, Kinbride V. (1094) Delayed ("secondary") cerebral energy fallure after acute hypoxia-ischemia in the newborn piglet: continuous 48-hour sudies by phosphorus magnetic resonance spectroscopy. Pediat Res 36:609.706

Ma D, Hossain M, Chow A, Arshad M, Batson RM, Sanders RD, Mehmet H, Edwards AD, Franks NP, Maze M. (2005) Xenon and hypothermia combine to provide neuroprotection from neonatal asphyxia. Amm Neurol $58: 182 \cdot 193$

Mackay KB, Loddick SA, Naeve GS, Vana AM, Verge GM, Foster AC. (2003) Neuroprolective effects of insulinlike growth factorbinding protein ligand inhibitors in vitro and in vivo. J Cereb Blood Fow Metab 23:1 160 . 1.167 
Mchow GH, Baghurt KI, Potter B], Hetzel BS. 1979$)$ Foetal brain development in the sheep. Newropathol Appl Newobiol $5103-114$

Noren H, Amer-Wahn I, Hagberg H, Herbst A, Kelmer L, Marsal K, Olofsson P, Rosen KG. (2003) Fetal electrocardiogitaphy in labor and neonatal outcome: data from the Swedish randomized controled trial on intrapartum fetal nonitoring. Am J Oostet Gyecol 188:183-192

Salhab WA, Perman JM. (2005) Severe fetal acidemia and subsequent neonatal encephalopathy in the larger prentature infanit. Pediatr Neurol $32: 25.29$

Shalak L, Perman IM. (2004) Hypoxic-1schemic brain injury in the term infant-current concepts. Early Hum Dev $80: 125-141$

Shankaran S, Laptook AR, Ehrenkanz RA, Donovan EA, Fanaroff AA, Tyson IE, McDonald SA, Poole K, Wright LL, Goldberg R. (2004) Safety of whole body hypothermia for hypowic-ischemic encephalopathy(HE). Pedatric Research 55:5824582a

Sharp FR, Lu J, Bernabeu R. (2002) Neurogenesis Following brain ischemia. Brain Res Dev Brain Res 134:23-30

Volpe J). (2001) Newrology of the Newborn. Boston, Massachusetts: W.B. Saunders Company

Willams CE, Gunn $A_{1}$ Gluckman PD. (1991) Time course of intraceliluar edema and epileptiform activity following prenatal cerebral ischemia in sheep. Stroke 22:516-521.

Young D, Lawlor PA, Leone 3 , Dragunow M, During MI. (1099) Environmental enrichment inhibits spontaneous apoptosis, prevents seizures and is neuroprotective. Nat Med 5:448-453

Zaidi AU, Bessent DA, Ong JE, Xw H, Barks JD, Silwerstein FS, Skoff RP. (2004) New oligodendrocytes are generated after neonatal hypoxic-ischemic brain injury in rodents. Gia $46.380-390$ 


\section{SAMENVATTING}

Het doel van dit proefschrift was om de hormonale en cardiovasculaire effecten van asfyxie lernstig zuurstof tekort leidend tot acidose en verminderde weefsel doorbloeding) te bestuderen en on de therapeutische effecten van koeling van het hoofd te bestuderen in premature en à terme foetale schapen.

In hoofdstuk 1 wordt de klinische en experimentele achtergrond van dit proefschift besproken. Hersenschade ten gevolge van asfyxie is nog steeds een veel voorkomend probleem bij zowel a terme als prematuur geboren zuigelingen. Neuronen in de grijze stof van de hersenen zijn zeer kwetsbare cellen. Voor hun functie zijn ze afhankelijk van cellen in hun omgeving (o.a. glia cellen). Het lichaam is er alles aan gelegen tijdens een periode van zuurstoftekort zo lang mogelijk de doorbloeding van de hersenen in stand te houden, zelfs ten koste van de doorbloeding van andere organen zoals de nieren. Indien er tijdens langdurige asfyxie toch een cerebraal cellulair energietekort optreedt, zullen cellen in de grijze en witte stof dood gaan. Voor een deel zal deze celdood acuut optreden (necrose). Een ander deel raakt beschadigd of verliest contacten met de omgeving door de schade in de witte stof. Beschadigde cellen zullen uren tot dagen na het insult alsnog sterven, meestal middels activatie van een cascade van zelfvernietigingseiwitten. Dit proces wordt ook wel geprogrammeerde celdood of apotose genoemd.

Klinisch kan de herstelperiode na asfyxie in verschillende fases verdeeld worden. In de eerste fase, ook wel de latente fase genoemd, treedt herstel op van oxidatief metabolisme. Het electroencefalografie signaal (EEG) is onderdrukt. Na 6-15 uur treedt er een fase op van verslechtering, de secundaire fase. Het begin van deze fase wordt meestal gemarkeerd door het ontstaan van epileptiforme activiteit op het EEG, het ontstaan van hersenzweling, de intrede van ontstekingscellen en celdood. Na enkele dagen komt de tertiaire fase van stabilisatie. Het is waarschinnlijk dat in deze fase nog meer celdood plaatsvindt.

Het is de laatste jaren duidelijk geworden dat niet alleen schade aan de grijze stof belangrijk is voor de klinische prognose, maar dat ook schade aan de witte stof een belangrijke rol speeit.

Inmiddels hebben vele studies aangetoond dat in de latente fase interventies mogelijk zijn om de mate van grijze stof schade te beperken. Momenteel is er nog geen klinisch bewezen effectieve behandeling om de lange termijn effecten van asfyxie te beperken. Voor zowel premature als à terme pasgeborenen is een effectieve behandeling om handicaps te voorkomen zeer gewenst. Therapeutisch koelen van de hersenen (hypothermie) is een van de meest veelbelovende behandelingsstrategleën ter voorkoming van permanente hersenschade bij pasgeborenen. Het is echter nog onduidelijk of deze therapie ook effectief is voor de witte stof en bij prematuren.

Alvorens nieuwe behandelingen kunnen worden getest op pasgeboren kinderen is het belangrijk om niet alleen naar de effecten op de hersenen te kijken maar tevens naar de systemische effecteri. Een van de doelstellingen van dit proefschrift was derhalve om de systemische effecten (0.a. bloeddruk, hersendoorbloeding en hormonale effectenj van koelen in de premature foetus te bestuderen.

Het chronisch geïnstrumenteerde foetale schapen model is een model dat al vele jaren wordt gebruikt voor studies van foetale fysiologie. Op vele relevante aspecten komt het foetale schaap overeen met de mens, ook qua ontwikkeling en structuur van de hersenen. De hersenen van een foetaal schaap op $70 \%$ van de totale zwangerschapsduur komen qua ontwikkeling overeen met humane hersenen van 30-32 weken zwangerschapsduur, terwijl schapen hersenen op $85 \%$ van de zwangerschapsduur overeenkomen met de à terme humane pasgeborene.

Het is in het schapenmodel mogelijk om continue metingen te doen van hersenfunctie (EEG) en fysiologische parameters zoals temperatuur, bloeddruk en weefsel doorbloeding. Aangezien de foetus 
in utero blift, kan de ool gezien worden als een ideale, stabiele couveuze. Tevens is het mogelik op verschillende momenten bloedmonsters af te nemen, en na afloop van de experimenten de weefsels nader te analyseren. In het chronisch geinstrumenteerde foetale schapenmodel is het magelik om selectief de doorbloeding vari de hersenen tijdelilk still te leggen (ischemie) door occlusie van de bloedvaten naar de hersenen, maar ook om de navelstreng tijdelik af te sluiten, waardoor er een algeheel zuurstof tekort optreedt. Beide methoden leiden tot patronen van hersenschade die relevant zijn voor humane perinatale hersenschade.

\section{Hoofdstuk 2}

Het prematuur geboren kind heeft een verhoogd risico op hersenschade. Een van de verondersteide potentielle mechanismen hiervan is dat de prematuur minder goede beschermingsmechanismen heeft tegen episoden van zuurstofgebrek (asfyxie).

Met name de hypothalamus hypofyse-bijnier as reactie op stress zoals asfyxie is potentieel immatuur, wat zou kunnen bijdragen tot het ontstaan van hypotensieve episoden. Echter, de studies die suggereerden dat de contisol stress respons verminderd is in prematuren hebber relatief milde insulten gebruikt. Premature foetale schapen hebben een grotere tolerantie voor asfyxie en zijn in staat $2 \times 20$ lange insulten te overleven vergeleken met à terme foetusen, derhalve is het mogelijk dat voorgaande studies de foetale stressreactie niet maximaal gestimuleerd hebben. Om de effecten van ernstige asfyxie op de ACTH-cortisol as te bestuderen hebben wij het chronisch geinstrumenteerde premature foetale schapen model gebruikt.

Onze studie liet zien dat de premature foetus geen immature hypothalamus hypofyse-bijnier functie heeft. Echter, door de grote anaërobe tolerantie van de premature foetus vergeleken met een à terme foetus, hoeft de premature foetus pas in een veel latere fase de stressrespons maximaal te activeren. Er was een verband tussen cortisolwaarden en bloeddruk hetgeen suggereert dat cortisol helpt om de bloeddruk stabiel te houden tijdens de kritische herstelperiode na ernstige asfyxie.

\section{Hoofdstuk 3}

Verschillende experimentele modellen wan hersenschade hebben aangetoond dat koelen van de hersenen een effectieve manier is om de grijze stof te beschermen. Er zijn echter nog geen studies verricht naar de gevolgen wan hypothermie voor hersenschade bij prematuren. Dit is relevant omdat prematuren mogelijk gevoeliger zlin voor de nadelige effecten van hypothermie en omdat het patroon van hersenschade verschilt tussen prematuren en à terme zuigelingen.

In het chronisch geinstrumenteende premature schapenmodel $170 \%$ van de zwangerschap, overeenkomend met 30-32 weken humaan! hebben we het effect bestudeerd van het koelen van de hersenen na een ernstig asfyctisch insult. Koelen was geassocieerd met een daling van epileptiforme activiteit. Koelen beschermt tegen het verlies van neuronen in de hippocampus en basale ganglia, en was geassocieerd met minder apoptose en microglia activatie.

We concluderen dat koelen na ernstige asfyxie in de premature foetus beschermt tegen hersenschade, zonder dat potentieel schadelijke effecten worden gezien, zoals hypotensie of verstoring van het zuurbase evenwicht.

\section{Hoofdstuk 4 en 6}

Insulin-like growth factor-I (IGF-I) is een krachtige endogene groeifactor met neuroprotectieve en metabole functies. De rol van groeifactor IGF-II is minder bekend. De aanmaak van IGF-I wordt gestimuleerd door groeihormoon (GH) wit de hypofyse. In het bioed is ongeveer $97 \%$ vam het IGF gebonden aan speciale bindingseiwitten (IGFBP $1-6$ ). Het overige kleine deel is in de actieve vrije vorm 
of los gebonden. Met name IGFBP-1 voorkomt dat IGFI zich kan binden aan de IGF receptor.

Er is nog weinig bekend over de effecten van asfyxie op circulerend IGF en bindingseiwitten. We hebben daarom de effecten van asfyxie en therapeutische hypothermie onderzocht op veranderingen in IGF en IGFBP-1. Onze resultaten laten na asfyxie een daling varn IGF-I en stijging van IGFBP.1 zien, waarschijnlijk om een catabole staat te faciliteren.

In hoofdstuk 6 wordt een nieuwe methode beschreven om de wrije fractie van IGF te verhogen. Behalve het direct toedienen van IGF-I lijkt het mogelijk een stof toe te dienen die IGF los maakt van het bindingseiwit om $z 0$ de biologische beschikbaarheid te verhogen. Zo'n stof is mogelijk eenvoudiger toe te dienen en mogelijk veiliger dan directe toediening van IGF.I.

Potentiële therapeutische opties van IGF displacers zijn groeistoornissen bij kinderen waarbij er een verhoogde hoeveelheid IGFBP-1 is, zoals bif nierfalen voorkomt. Daarnaast zìn IGF displacers mogelijk werkzaam bij hersenschade op basis van ischemie en reperfusie. De studie uit hoofdstuk 4 suggereert dat de werking van therapeutische hypothermie niet het gevolg is van door effecten op circulerend IGF 1 en dat milde systemische hypothermie de metabole aanpassingen na asfxie niet verstoort.

\section{Hoofdstuk 5}

Vele experimentele studies hebben aangetoond dat koelen van de hersenen de grijze stof (neuronen) beschermt na ischemie-reperfusie. Er is echter minder bekend over de effecten van hersenkoeling op de overige hersencellen, zoals de witte stof (myeline en oligodendrocyten) en de steuncellen (glia).

Aangezien het ter voorkoming van neurologische schade niet alleen belangrijk is om de grijze stof te beschermen, dient een potentieel succesvolle behandeling ook de witte stof te beschermen. Voor deze studie hebben we gebruik gemaakt van à terme chronisch geïnstrumenteerde schapen. Hersenschade werd aangebracht door het tijdelijk afsluiten van de arteria carotis beiderzijds. De hersenen werden gekoeld tot tussen 30 en 33 graden Celcius. Koelen werd op verschillende tijden na ischemie gestart en gecontinueerd voor 3 dagen.

Wanneer het koelen 90 minuten na herstel van de circulatie werd gestart bleek er een significant grotere dichtheid van myeline en betere overleving van oligodendrocyten te zijn in vergelijking met de controle groep zonder koeling. Tevens was er minder apoptose in de witte stof. Koelen zorgde voor een forse onderdrukking van microglia cellen, terwijl er geen significant effect was op astrocyten. Wanneer koelen pas 5,5 uur na ischemie werd gestart bleek er geen significant beschermend effect te zijn op de witte stof oligodendrocyten.

We concluderen dat het koelen van de hersenen niet alleen beschermend werkt voor de grijze stof maar ook voor de witte stof. Echter, des te later de aanvang van het koelen, hoe minde: effectief de bescherming. Bescherming van de witte stof was geassocieerd met een verminderde expresste van geactiveerd caspase-3 (apoptose) en van microglia cellen (inflammatie). De data onderstrepen het belang van het vroeg beginnen met koelen in de klinische studies.

\section{TOEKOMST PERSPECTIEF}

Koelen van de hersenen is een veel belovende therapie ter voorkoming van hersenschade voor à terme zuigelingen, maar mogelijk ook voor premature zuigelingen. Gerandomiseerde klinische studies zoals de "CoolCap trial" hebben nu ook aangetoond dat hypothermie effectief mogelijk is, maar met nane in zuigelingen met matig ernstige hersenschade. Naast het vaststellen van selectiecriteria voor kinderen die mogelijk baat zullen hebben bij behandeling met hypothermie zullen nog verschillende vragen beantwoord moeten worden voordat koelen een standaard therapie zal worden op de afdeling 
neonatologie. De maximale tijd waama koelen nog gestart kan worden na de geboorte, de mate van koelen en de optimale duur wan koelen vergen verder onderzoek. Alvorens koelen ook voor premature zuigelingen getest kan worden zin meer studies naar veiligheid en effectiviteit gewenst. Behalve interventie door middel van koelen alleen, zullen er ook studies gedaan moeten worden naar combinatie therapieên, zoals koelen en behandeling met groeifactoren zoals IGF-I. 


\section{Publications}

\section{First author}

Roelfsema V, Gunn AJ, Breier BH, Quaedackers IS, Bennet L. The elfect of mild hypothemia on insulin-like growth factors after severe asphyxia in the preterm fetal sheep. Joumal of the Socievy for Gynecologic Investigation. 2005; $12(4): 232 ; 237$.

Roelfsema V, Gunn AJ, Fraser M, Quaedackers SS, Bennet L. Cortisol and ACTH responses to severe asphyxia in preterm fetal sheep. Experimental Physiology. 2005; 90(4): 545-555.

Roelfsema V, Bennet L, George S, Wu D, Guan J, Veerman M, Gunn Al. Window of opportunity of cerebral hypothermia for postischaemic white matter injury in the near-term fetal sheep. Journal of Cerebral Blood Flow \& Metabolism 2004; 24: 877-886.

Roelfsema V, Thomas GB, Lin H, Breier B, Maxwell L, Heineman E, Clark RG, Gluckman PD. The metabolic effects of endotoxin are differentially affected by the pattern of $\mathrm{GH}$ administration in the rat. Joumal of Endocrinology 2001; 171 (1): 173-181.

Roelfsema V, Clark RG. The growth hormone and insulin-like growth factor axis: its manipulation for the benefit of growth disorders in renal failure. Journal of the American Society of Nephrology $2001 ; 12(0): 1297-1306$.

Roelfsema V, Clark RG. Insulin-like growth factor binding protein (igfbp) displacers: Relevance to the treatment of renal disease. Pediatr Nephrol 2000; 14 (7): 584-588.

\section{Co-author papers}

Bennet L, Roelfsema V, Pathipati P, Quaedackers JS, Gunn AJ. Relationship between evolving epileptiform activity and delayed loss of mitochondrial activity after asphyxia measured by near-infrared spectroscopy in preterm fetal sheep. Journal of Physiology 2006. In press.

Wibbens B, Westgate IA, Bennet L, Roelfsema V, De Haan HH, Hunter CI and Gunn AJ. Profound hypotension and associated electrocardiographic changes during prolonged cord occlusion in the near term fetal sheep. American Journal of Obstetrics and Gynecology. 2005; 193: 803-10

Quaedackers JS, Roelfsema V, Fraser M, Gunn AJ, Bennet L. Cardiovascular and endocrine effects of a single course of maternal dexamethasone treatment in preterm fetal sheep. British Journal of Obstetrics and Gynaecology (BJOG). 2005; $112(2$ ): 182-91.

Quaedackers $I S$, Roelfsema V, Heineman E, Gunn AJ, Bennet L. The role of the sympathetic nervous system in post-asphyxial intestinal hypoperfusion in the pretem sheep fetus. Joumal of physiology. 2004; 557 (3); $1033-1044$

Quaedackers IS, Roelfsema V, Hunter Cl, Heineman E, Gunn AJ, Bennet L. Polyuria and impailed renal blood flow after asphyxia in preterm fetal sheep. American Joumal of Physiology Regulatory Integrative and comparative Physiology. 2004; 286 (3): R576-83.

Hunter CI, Bennet L, Power GG, Roelfsema V, Blood AB, Quaedackers IS, George S, Guan J, Gunn AJ. Key neuroprotective role for endogenous adenosine A1 receptor activation during asphyxia in the fetal sheep. Stroke $2003 ; 34(9): 2240 \cdot 5$.

\section{Participation}

Todd MM et al., for the Intraoperative Hypothermia for Aneurysm Surgery Trial (IHAST) Investigators (including V. Roelfsema). Mild intraoperative hypothermia during sungery for intracranlal aneurysm. New England Journal of Medicine. 2005; 352: 135.45. 


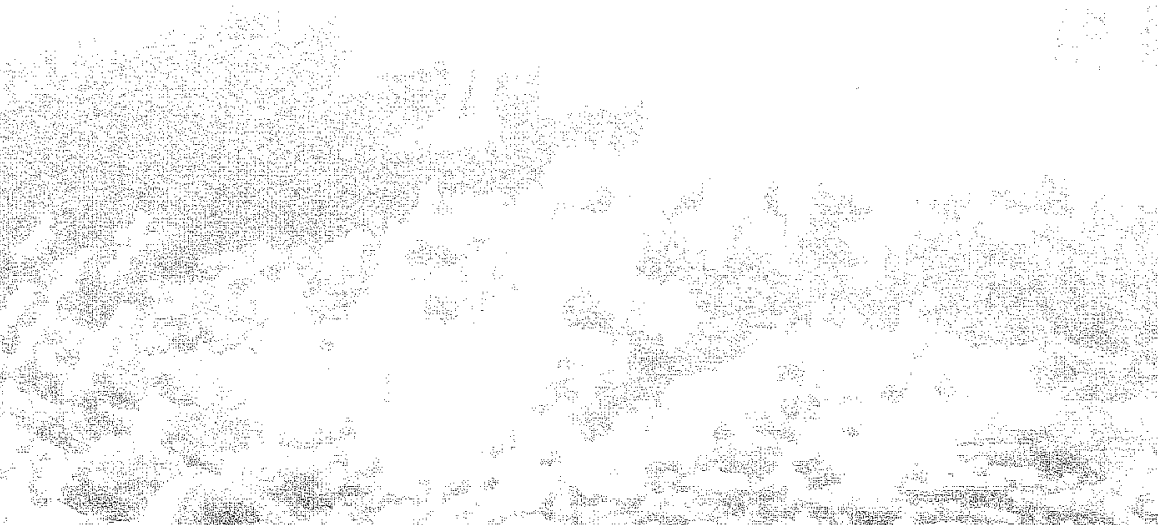

(1)

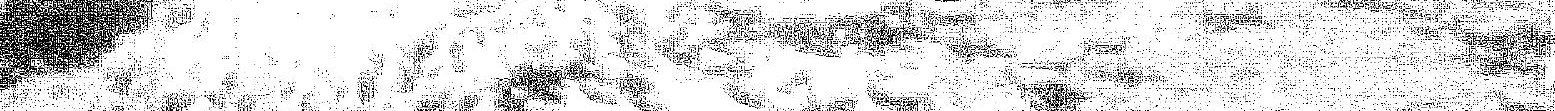
3
3

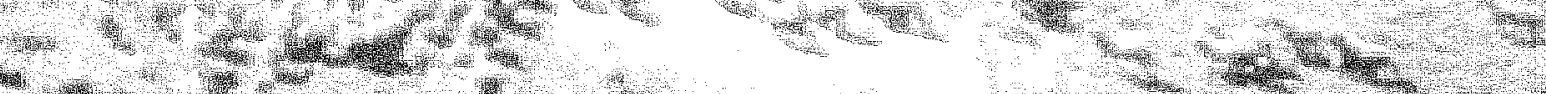

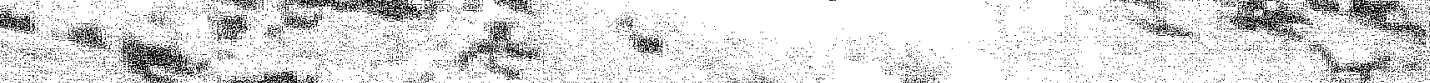

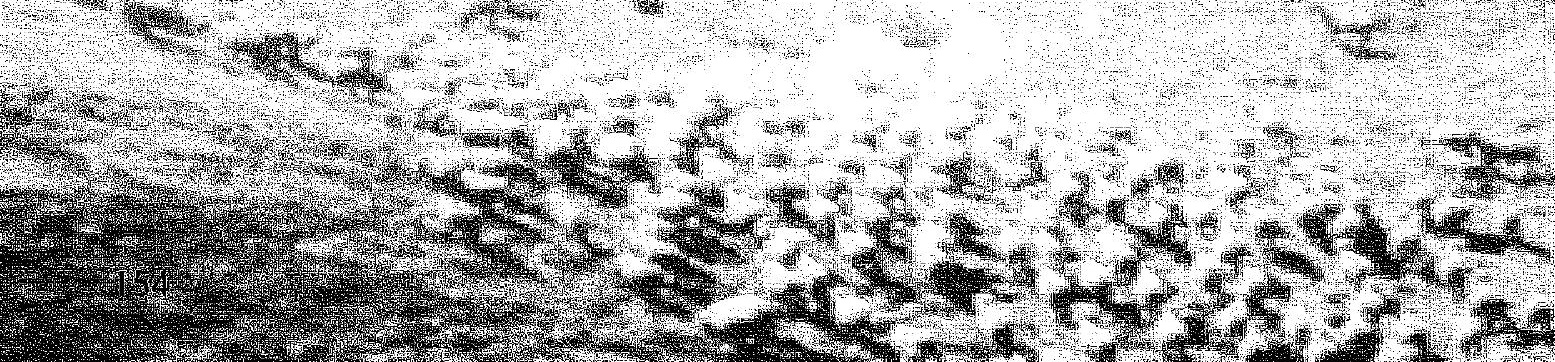

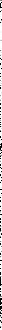




\section{ABBREVIATIONS}

$\begin{array}{ll}\text { ACTH } & \text { Adrenocorticotropic hormone } \\ \text { aEEG } & \text { amplitude-integrated electro-encephalogram } \\ \text { AGA } & \text { Appropriate for gestational age } \\ \text { AMPA } & \text { alpa-amino-3-hydroxy-5-methyl-4-isoxazole-propionic acid } \\ \text { ARF } & \text { Acute renal failure } \\ \text { BE } & \text { Base excess } \\ \text { BDNF } & \text { Brain-derived neurotrophic factor } \\ \text { CA } & \text { Cornu Ammonis, part of the hippocampus } \\ \text { CaBF } & \text { Carotid artery blood flow } \\ \text { CBF } & \text { Cerebral blood flow } \\ \text { CFM } & \text { Cerebral function monitor } \\ \text { CNS } & \text { Central nervous system } \\ \text { CRF } & \text { Chronic renal failure } \\ \text { DAB } & \text { Diaminobenzidine tetrahydrochloride } \\ \text { DWI } & \text { Diffusion-weighted imaging (MRI technique) } \\ \text { EEG } & \text { Electro-encephalogram } \\ \text { ELBW } & \text { Extremely low birth weight (<10oogram) } \\ \text { EMG } & \text { Electro-myograph } \\ \text { FHR } & \text { Fetal heart rate } \\ \text { GFAP } & \text { Glial Fibrillairy Acidic Protein (marker of astrocytes) } \\ \text { GH } & \text { Growth hormone } \\ \text { HI } & \text { Hypoxia-ischaemia } \\ \text { HIE } & \text { Hypoxic Ischaemic Encephalopathy } \\ \text { HPA } & \text { Hypothalamic-Pituitary-Adrenal axis } \\ \text { IB-4 } & \text { Isolectin B4 (marker of microglia) } \\ \text { ICA } & \text { Internal carotid artery } \\ \text { IGF } & \text { Insulin-like growth factor } \\ \text { IGFBP } & \text { Insulin-like growth factor binding protein } \\ \text { IL } & \text { Interleukin } \\ \text { IV } & \text { intravenous } \\ \text { IVH } & \text { Intraventricular haemorrhage } \\ \text { K+ } & \text { Potassium } \\ \text { LBW } & \text { Low birth weight ( }<2500 \text { gram) } \\ \text { MAP } & \text { Mean arterial pressure } \\ \text { MBP } & \text { Myelin Basic Protein (marker of myelin) } \\ \text { MCA } & \text { Middle cerebral artery } \\ \text { MgSO4 } & \text { Magnesium sulphate } \\ \text { mmHg } & \text { Millimeters of mercury } \\ \text { MRI } & \text { magnetic resonance imaging } \\ \text { mRNA } & \text { messenger RNA } \\ \text { MRS } & \text { Magnetic resonance spectroscopy } \\ \text { Na+ } & \text { Sodium } \\ \text { NGF } & \text { Nerve growth factor } \\ \text { NICU } & \text { Newborn intensive care unit } \\ \end{array}$




$\begin{array}{ll}\text { NIRS } & \text { Near infrared spectroscopy } \\ \text { NMDA } & \text { N-methyl-D-aspartate } \\ \text { NO } & \text { Nitric oxide } \\ \text { NOS } & \text { Nitric oxide synthase } \\ \text { nNOS } & \text { Neuronal nitric oxide synthase } \\ \text { O2 } & \text { Oxygen } \\ \text { PBS } & \text { Phosphate Buffered Saline } \\ \text { PaO2 } & \text { Partial pressure of oxygen } \\ \text { PCNA } & \text { Proliferating nuclear antigen } \\ \text { PLP } & \text { Proteolipid protein } \\ \text { PVH } & \text { Periventricular hemorrhage } \\ \text { PVL } & \text { Periventricular leukomalacia } \\ \text { RCT } & \text { Randomised controlled trial } \\ \text { Rh } & \text { Recombinant human } \\ \text { RNA } & \text { Ribo-Nucleic Acid } \\ \text { ROS } & \text { Reactive oxygen species } \\ \text { SGA } & \text { Small for gestational age } \\ \text { TGF } & \text { Transforming growth factor } \\ \text { TNF } & \text { Tumor necrosis factor } \\ \text { TUNEL } & \text { Terminal deoxynucleotidyl transferase end labelling } \\ \text { VEGF } & \text { Vascular endothelial growth factor } \\ \text { VLBW } & \text { Very low birth weight }<<1500 g r a m)\end{array}$




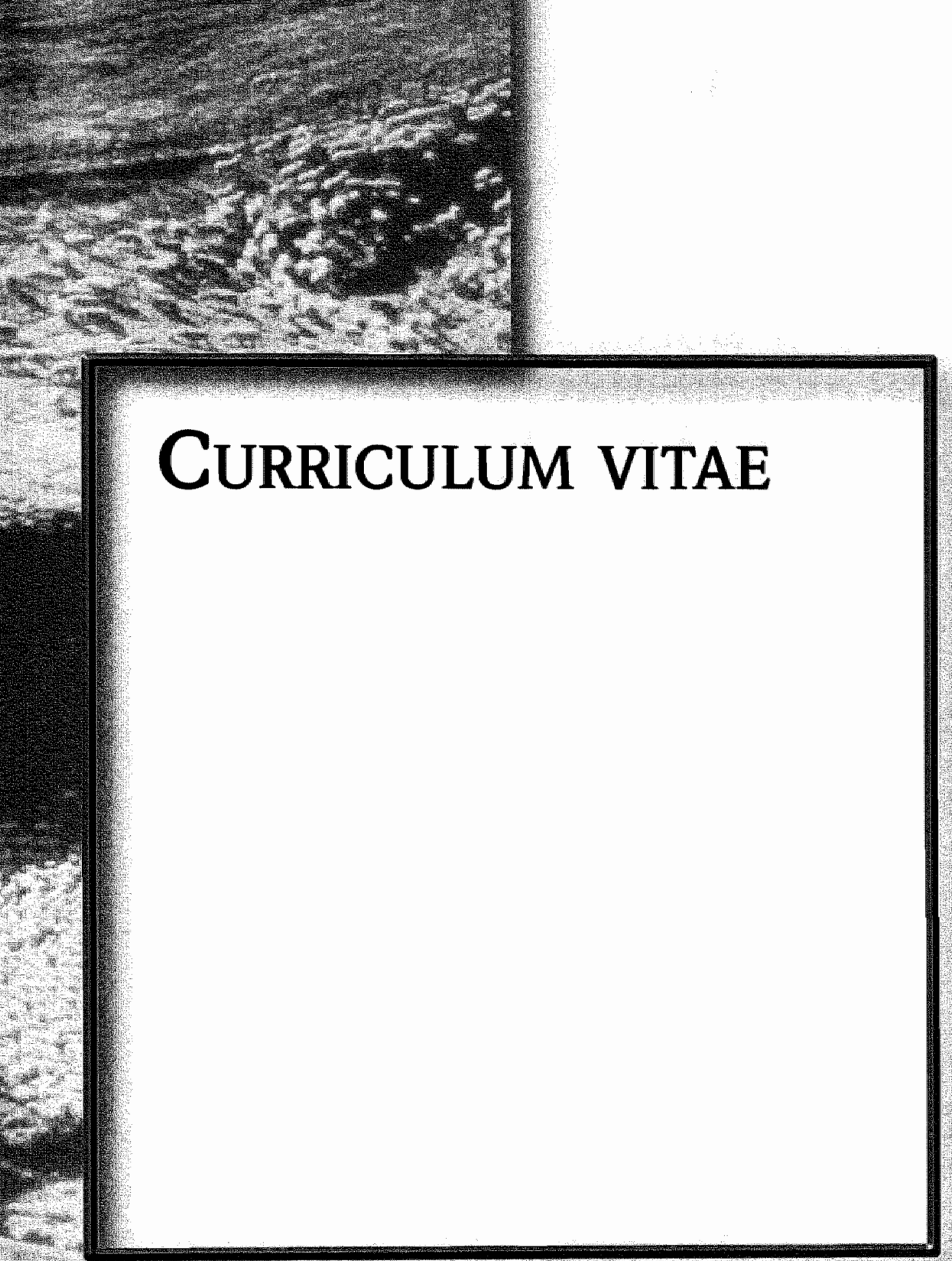




\section{CURRICULUM VITAE}

Vincent Roelfsema werd op 9 september 1976 geboren te Eindhoven. In 1994 behaalde hil zlin middelbare school diploma Atheneum aan het Bisschop Bekkers College in Eindhoven om vervolgens te beginnen aan de opleiding Geneeskunde aan de Universiteit Maastricht.

Tijdens zijn studie was hij actief lid van studentenvereniging Koko en in het bestuur van het Maastricht Medical Student Reseach Conference (MMSRC). In 1998 deed hij zijn wetenschapsstage en keuze coschap in het Starship Childrens Hospital bij Prof. Erik Heineman. Na het behalen van het doctoraal examen onderbrak Vincent zijn studie Geneeskunde om samen met Josine terug naar Nieuw Zeeland te gaan om verder onderzoek te doen aan de University of Auckland en het Liggins Institute. Dit onderzoek was in samenwerking met Professor J. de Haan wan het onderzoeksinstituut Groei en Ontwikkeling (GROW), Universiteit van Maastricht.

Na een verblijf van bijna 4 jaar in Auckland, Nieuw Zeeland, Keerden ze terug naar Maastricht om de co-schappen af te ronden. In september 2004 werd het artsexamen afgelegd met het predikaat "Cum Laude". Sinds oktober 2004 werkt Vincent als AGNIO kindergeneeskunde in het VieCuri Ziekenhuis te Venlo. In juli 2005 is hij begonnen aan de opleiding tot kinderarts.

$1988-1994$ 1994-1999 $1999-2002$

$2002 \cdot 2004$ 2004-2005 2005 present
Atheneum, Bisschop Bekkers College, Eindhoven, The Netherlands Master degree Medicine, Maastricht University. "Clear pass". Research Centre for Developmental Medicine and Biology, University of Auckland, New Zealand, Liggins Institute, University of Auckland, New Zealand in collaboration with the research institute Growth and Development (GROW), Maastricht University, The Netherlands.

Internships and Medical degree. "Cum Laude".

Department of paediatrics, VieCuri ziekenhuis, Venlo

Residency in Paediatrics

\section{Awards}

2000 Paykel travel grant 
$\begin{array}{r}2 \quad 0 \quad+2 \\ \hline\end{array}$ 


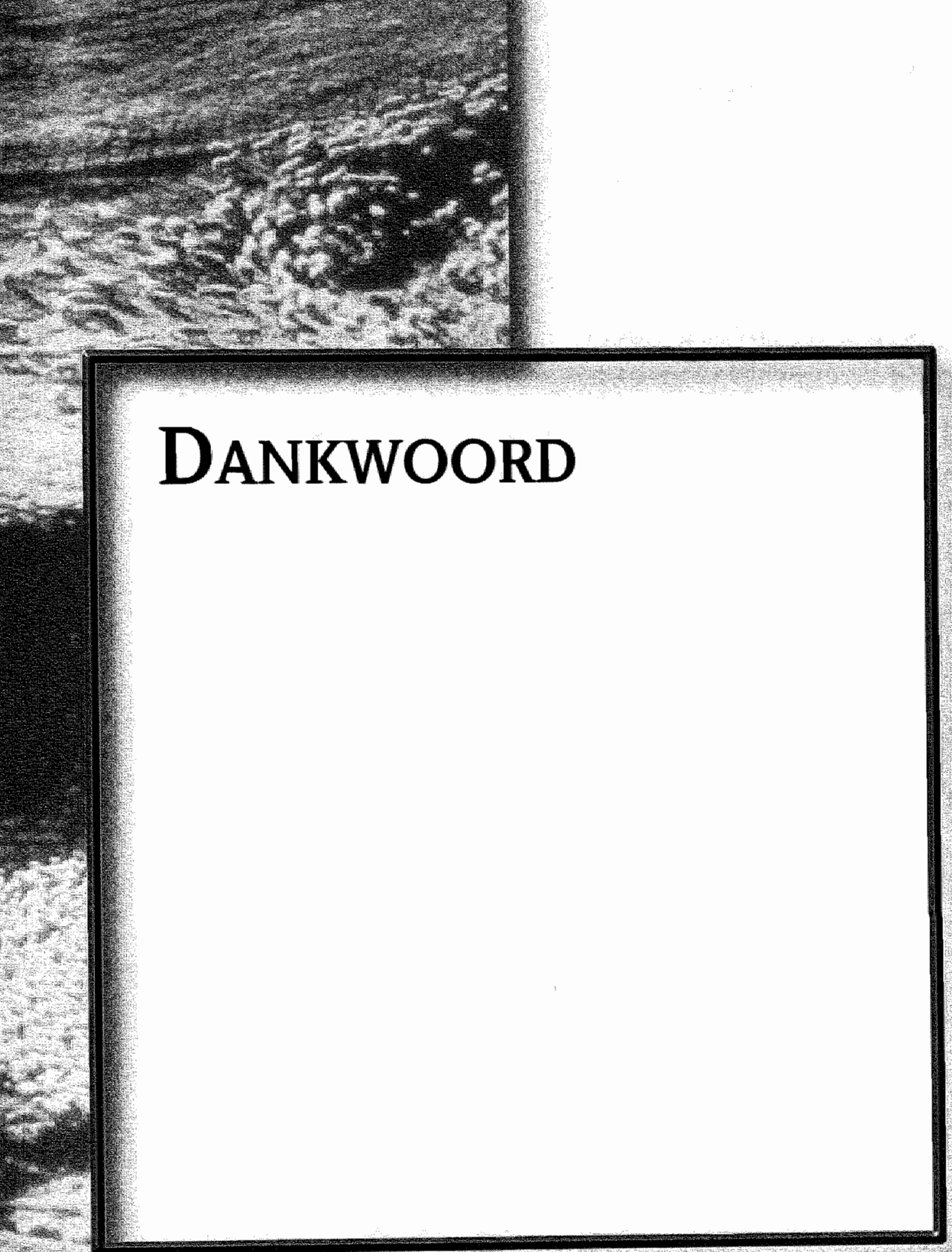

W.

2.

127.

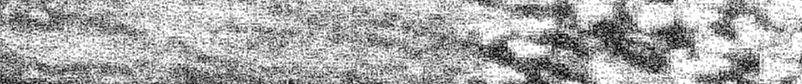
W. 10.

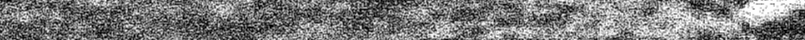
Prt

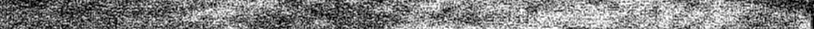




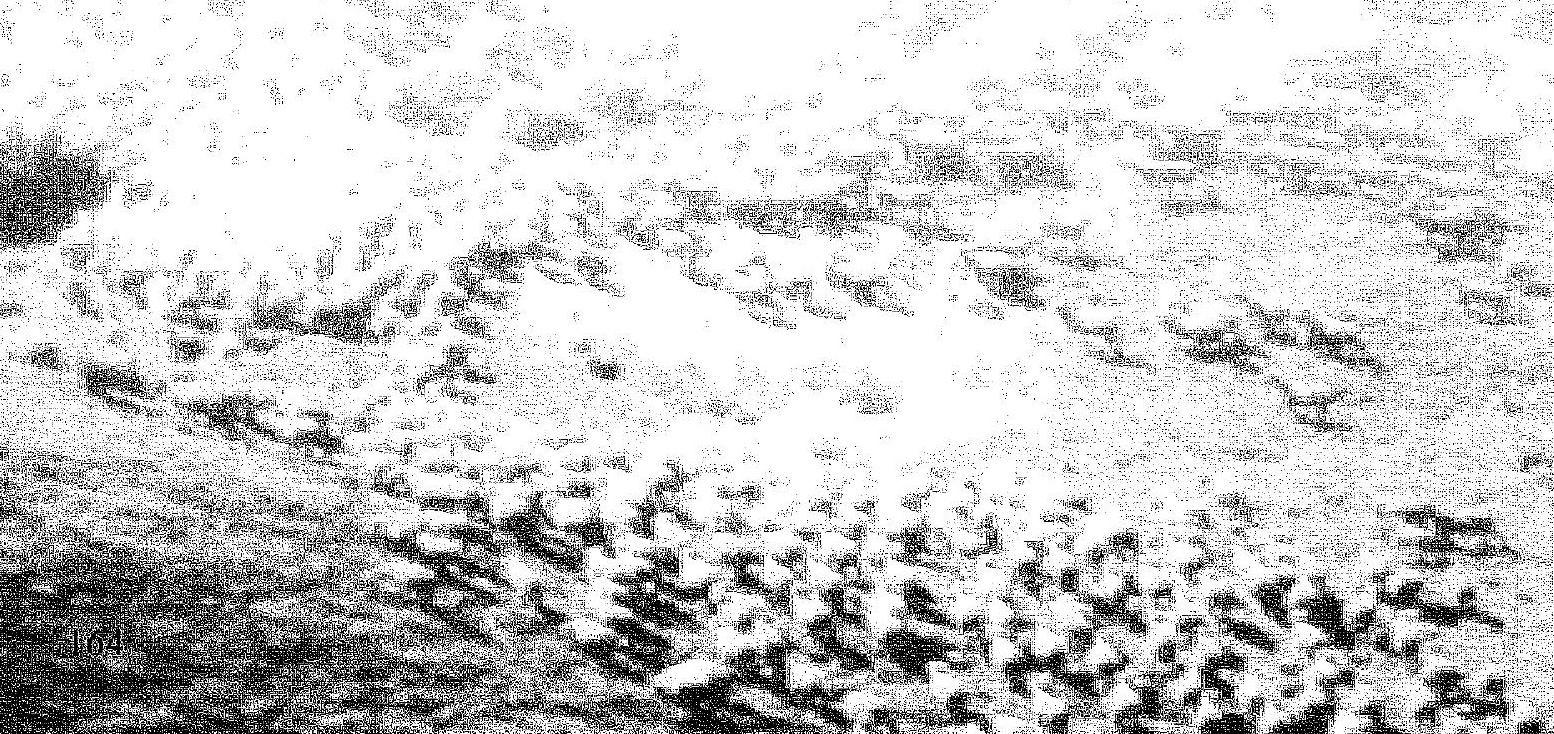


In 1998, het 4e jaar van de studie geneeskunde klopten Josine en ik aan bij Erik Heineman voor een wetenschapsstage 'down under' in Nieuw Zeeland, niet wetende dat dit het begin van een 4-jarig project zou worden. Bij deze wii ik iedereen die op enige wijze heeft bijgedragen aan de tot standkoming van dit proefschrift hartelijk danken.

Prof. Dr. E. Heineman, promotor. Beste Erik, inmiddels hebben vele studenten via jou de weg naar Nieuw Zeeland gevonden (en de laatste jaren de omgekeerde weg van Nieuw Zeeland naar Maastricht). Als AIO-eerste-lichting is mijn onderzoek ooit begonnen met de nier en geëindigd in het brein. Voor jou iets meer left-field, maar zonder jouw positieve instelling en peptalks was dit proefschrift er nooit gekomen. Bedankt voor je persoonlijke en professionele guidance. De hele familie Heinebots iSimone, Heike, Jikke en Hidde) bedankt voor de gezelligheid. Wonen in in Devonport vlak bij het strand was onvergetelijk.

Prof. Dr. J. de Haan, als promotor-op-afstand bent u altijd zeer betrokken en stimulerend geweest. $U$ hield de vorderingen nauwlettend in de gaten en was altijd bereikbaar voor discussie en commentaar op de manuscripten. Bedankt voor uw essentiële rol, met name in de afsluitende fase.

Assaciate professor A.J. Gunn, copromotor. Dear Alistair, it was an honour to work with you as a pioneer and world expert on hypothermia. I've learned a lot from you, including statistics and scientific writing. Our discussions over the odd glass of single malt were very enjoyable.

Associate professor L. Bennet, copromotor. Dear Laura, I would like to thank you for taking me aboard your team and for teaching me all about fetal sheep experiments. Aside from our foint labour in the basement lab at the university you've also shown us the true Kiwi lifestyle, such as enjoying the spectacular views and excellent New Zealand food and wine on your deck.

Dr: Sherly George, we've spend many late hours in the immunohistochemistry lab and behind the microscope. I enjoyed working with you. Your hard working and positive attitude has been inspiring. Thank you for the fantastic Indian food.

Michelle McAnulty-Smith, thanks for your help with processing tissues for histology.

Professor Ross Clark and Dr. Greg Thomas. Thank you for the time we worked together and for introducing me to cricket and horse racing. Ross, hope that one day l can prescribe an IGF-displacer or other Tercica product.

Professor Peter Gluckman, for enabling me to work in the Liggins institute.

I would also like to thank the fellow students at RCDMB and Liggins Institute. Andrew Baker (and Sasha), Tanja Moderscheim (and Paul], Justin Dean, Bettina, Simon, Tim. Sato, Suzanna, Praneeti Pathipati, David Wu, Elicia Berry, Susan Ravelich, Mark Vickers, Frank Bloomfield, Ross Drake, Nina, Femke Piersma and others for the fun times in the "student hole", the lab and in town. Dr. Christian Hunter and Bert Wibbens, thanks for the collaboration, discussions and fun.

Martijn Kwaijtaal, Niek en Ebtisam van Til, Marije Veerman. We hebben samen een erg leuke tijd gehad "down under". Golfen, de Tongariro crossing, zeilen en natuurlijk de top van Mt. Taranaki! Succes met jullie eigen promotie onderzoek! 
Collega arts-assistenten en kinderartsen uit het Viecuri ziekenhuis in Venlo, bedankt voor jullee ondersteuning.

Nick Guldemond en Menno Janssen (en wederhelften). Bedankt voor jullie vriendschap. Nick, wanneer gaan we weer mountain biken?

Jörgen ten Berge en Dr. Bart Rutten [en wederhelften], beste paranimfen. We begonnen samen aan de studie geneeskunde en inmiddels zijn we allemaal als arts werkzaam. leder in een andere richting, maar ook leder samenwonend met een studiegenote! Jörgen, ik vond het ontzettend leuk dat je ons bent komen opzoeken! Kayaken en zeilen bij Abel Tasman. Bart, jij bent me reeds voorgegaan op deze plek. Bedankt voor de steun en de awonden stappen woor de ontspanning.

Oma en familie Meijer bedankt voor jullie steun de afgelopen jaren.

Papa, mama, Edwin, Stefan en Marisol, jullie steun is ontzettend belangrijk geweest bij het tot stand komen van dit proefschrift. Al was het niet altijd goed te begrijpen wat we daar allemaal deden, waren julle altijd geïnteresseerd. Jullie hebben ons heel wat keren naar Schiphol gebracht en weer gehaald, maar we hebben jullie gelukkig ook een keer in Auckland van het vliegveld kunnen halen. Ik vind het erg leuk dat jullie met eigen ogen hebben kunnen zien waar we woonden en wat we deden.

Lieve Josine, ondanks dat onze projecten dicht bij elkaar lagen is het ons toch redelijk goed gelukt werk en privé gescheiden te houden. We hebben een fantastische tijd gehad in Nieuw Zeeland! Samen hebben we nu ook de horde van het proefschrift genomen. Zonder jouw liefde en steun was dat niet gelukt. Dikke puun. 